New Approaches to Conflict Analysis

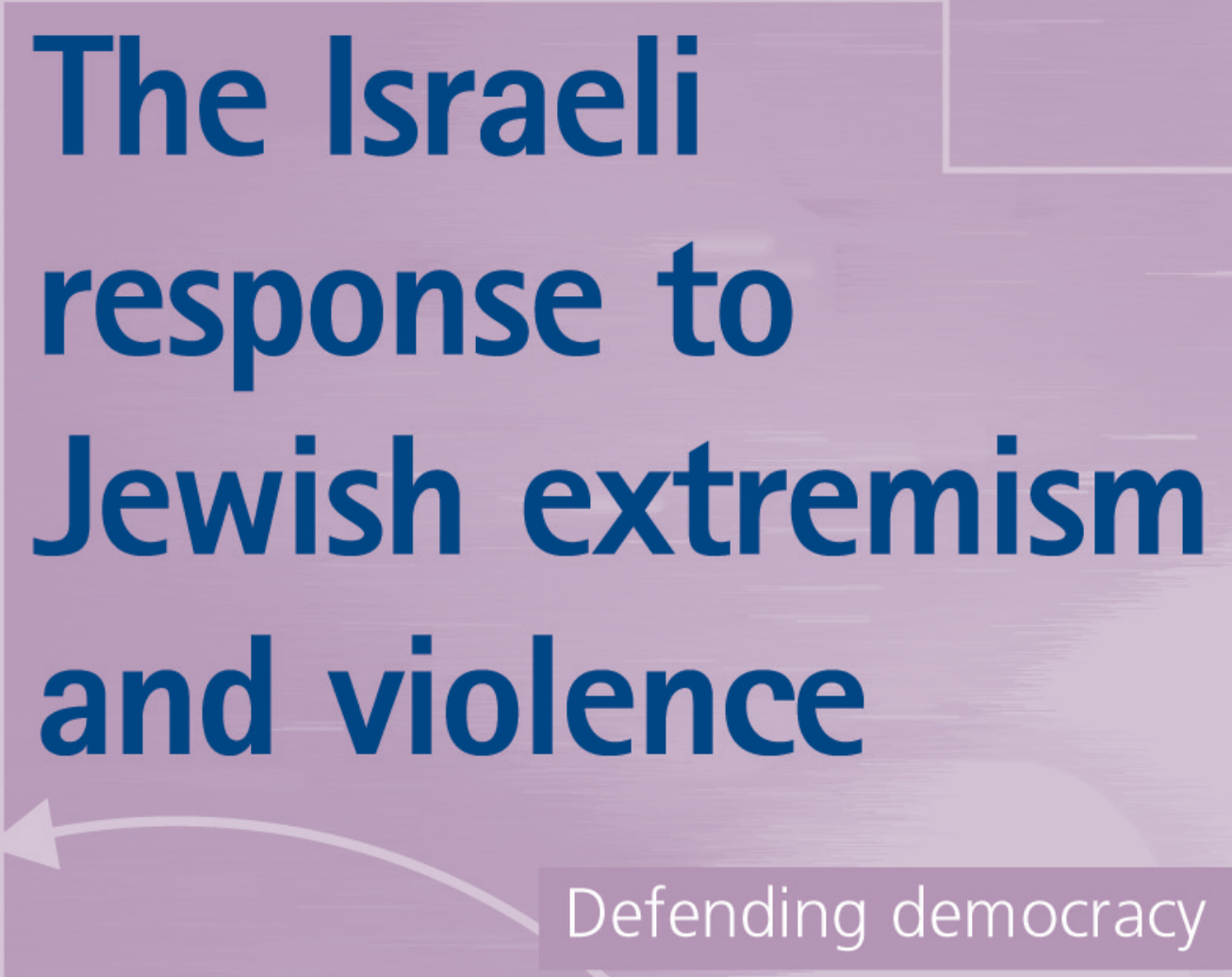

Defending democracy

\title{
Ami Pedahzur
}


THE ISR AELI RESPONSE TO JEWISH EXTREMISM AND VIOLENCE

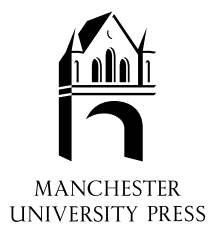




\title{
New Approaches to Conflict Analysis
}

\author{
Series editor: Peter Lawler \\ Senior Lecturer in International Relations, \\ Department of Government, University of Manchester
}

\begin{abstract}
Until recently, the study of conflict and conflict resolution remained comparatively immune to broad developments in social and political theory. When the changing nature and locus of large-scale conflict in the post-Cold War era is also taken into account, the case for a reconsideration of the fundamentals of conflict analysis and conflict resolution becomes all the more stark.
\end{abstract}

New Approaches to Conflict Analysis promotes the development of new theoretical insights and their application to concrete cases of large-scale conflict, broadly defined. The series intends not to ignore established approaches to conflict analysis and conflict resolution, but to contribute to the reconstruction of the field through a dialogue between orthodoxy and its contemporary critics. Equally, the series reflects the contemporary porosity of intellectual borderlines rather than simply perpetuating rigid boundaries around the study of conflict and peace. New Approaches to Conflict Analysis seeks to uphold the normative commitment of the field's founders yet also recognises that the moral impulse to research is properly part of its subject matter. To these ends, the series is comprised of the highest quality work of scholars drawn from throughout the international academic community, and from a wide range of disciplines within the social sciences.

PUBLISHED

M. Anne Brown

Human rights and the borders of suffering: the promotion of human rights in international politics

Karin Fierke

Changing games, changing strategies: critical investigations in security

Tami Amanda Jacoby and Brent Sasley (eds)

Redefining security in the Middle East

Deiniol Jones

Cosmopolitan mediation? Conflict resolution and the Oslo Accords

Helena Lindholm Schulz

Reconstruction of Palestinian nationalism:

between revolution and statehood

Jennifer Milliken

The social construction of the Korean War

Tarja Väyrynen

Culture and international conflict resolution:

a critical analysis of the work of John Burton 


\section{The Israeli response to Jewish extremism and violence}

Defending democracy

AMI PEDAHZUR

Manchester University Press MANCHESTER AND NEW YORK

distributed exclusively in the USA by Palgrave 
Copyright (C) Ami Pedahzur 2002

The right of Ami Pedahzur to be identified as the author of this work has been asserted by him in accordance with the Copyright, Designs and Patents Act 1988.

Published by Manchester University Press

Oxford Road, Manchester M13 9NR, UK

and Room 400, 175 Fifth Avenue, New York, NY 10010, USA

www.manchesteruniversitypress.co.uk

Distributed exclusively in the USA by

Palgrave, 175 Fifth Avenue, New York,

NY 10010, USA

Distributed exclusively in Canada by

UBC Press, University of British Columbia, 2029 West Mall,

Vancouver, BC, Canada V6T $1 \mathrm{Z2}$

British Library Cataloguing-in-Publication Data

A catalogue record for this book is available from the British Library

Library of Congress Cataloging-in-Publication Data applied for

ISBN 0719063728 hardback

First published 2002

$\begin{array}{lllllllllllllllllll}10 & 09 & 08 & 07 & 06 & 05 & 04 & 03 & 02 & 10 & 9 & 8 & 7 & 6 & 5 & 4 & 3 & 2 & 1\end{array}$

Typeset in Photina

by SNP Best-set Typesetter Ltd., Hong Kong

Printed in Great Britain

by Biddles Ltd, Guildford and King's Lynn 


\title{
CONTENTS
}

\author{
List of tables and figures — vii \\ Preface - viii
}

Introduction: the 'defending democracy' in Israel - a framework of analysis

The defending democracy: the search for a definition

The defending democracy: a framework of analysis

The defending democracy: in between the 'militant' and the 'immunised' route

The Israeli political context

$\begin{array}{ll}\text { Outline of book contents } & 21\end{array}$

Data sources and methodology $\quad 24$

1 The Israeli response to extremism: the parliamentary arena 30

The socio-political underpinnings of the response to extremism in Israel

Attitudes to far-right parties: between the 'militant' and the 'immunised' route

Conclusions

2 The State's response to extremism: attitudes towards subversive movements and violent organisations

Israel's early days: the predominance of the 'militant route'

The State of Israel from the 1950s to the 1970s: the institutionalising of the 'extended criminal justice model'

The State of Israel from the 1970s until the new millennium: towards a model of criminal justice

Issues accompanying the contraction of the 'criminal justice model'

Conclusions

3 The Israeli response to extremism: the social sphere

Civics education in Israel: the predominance of nationalist ideas in the first decades

Quandaries accompanying the efforts to reform civic studies

Educational reform in civics education in the new millennium: a quantitative assessment 
4 The role of 'civil society' in the 'defending democracy' 139 'Civil society' in Israel

The 'pro-democratic civil society' in Israel: targets and prominent organisations

The emergence of the 'pro-democratic civil society' in Israel Conclusions

5 The 'defending democracy': from the 'militant' to an 'immunised' route?

The 'defending democracy' in Israel: developments and challenges 171 The 'defending democracy' in comparative perspective

Index -194 


\section{LIST OF TABLES AND FIGURES}

\section{Tables}

2.1 Commitment to democratic values and attitudes

page 98

3.1 Effects of an education in democratic principles

3.2 Assessment of the effects of civic studies in relation to dependent variables (comparison between civics learners and non-civics learners)

3.3 Different levels of political knowledge acquired in civic studies courses (comparison between civic studies learners and non-civic studies learners)

\section{Figures}

I.1 The defending democracy and its different routes

3.1 A quantitative content analysis of the contents of Israeli civics education books

4.1 Pro-democratic civil society and the targets of its activities

4.2 The emergence of a 'pro-democratic civil society' in Israel 1950-2000 


\section{PREFACE}

I started working on this book in the spring of 2000. At that time, the political atmosphere in Israel seemed calm. My biggest concern was about the possible results of an evacuation of Jewish settlements from Judea, Samaria and the Gaza Strip as part of a possible progress in the peace process between Israel and the Palestinians. I was worried that the ideological rift between the different segments of Israeli society would manifest itself again in a violent way and that the events of 1994-95, which led to the assassination of Prime Minister Rabin could repeat themselves. Furthermore, I hoped that this time the Israeli State would use in its response to the growing wave of extremism measures that would not only be effective but would comply with the democratic nature of the State.

During the months in which I was doing the research for this book, two things happened simultaneously. First, the political reality in Israel, and later in other parts of the world, shifted dramatically and the question of how democracies should respond to challenges of extremism and violence became less of a theoretical issue and much more of an acute problem for policy-makers. Second, the more I studied the 'defending democracy' concept the better I understood that this term is much broader and more diversified than I first imagined. In light of the issues involved, I sincerely hope that this book will contribute not only to the theoretical understanding of the means by which democracies can respond to extremist and violent challenges and still adhere to democratic principles. I hope that it will also encourage policy-makers to take into consideration the different aspects and possible consequences of their policies and help them choose the 'immunised' route. Though this route requires more time and effort than the 'militant' one, it holds the potential for finding the 'golden path' in the defence of democracy from its challengers as well as from itself.

The completion of this book would not have been possible without the generous support of the Yitzhak Rabin Centre for Israel Studies as well as the Centre for the Study of National Security at the University of Haifa. I would like to thank both institutions for their generosity and for believing in the importance of this study. I owe a big debt of gratitude to three wonderful friends and colleagues. Professor Yael Yishai, my mentor, who not only shared her 'civil society' data with me but read large parts of the manuscript and gave me some wonderfully helpful words of advice. I will always cherish her guidance and friendship. Professor Gabi Ben-dor, my teacher and friend, who is always there for me with his endless wisdom. I thank him for doing everything he could to help me at every step of the way. Last, but not least, my dear and beloved friend Profes- 
sor Avraham Brichta, who spent so many precious hours talking to me, lifting my spirits and supporting my research. Thank you.

I also thank those colleagues who offered me a shoulder to lean on over the last few years, and who helped me put my ideas together: Dr Bruce Hoffman, Dr Magnus Ranstorp, Dr Cas Mudde, Dr Giovanni Capoccia, Dr Raphael CohenAlmagor and Professor Michael Minkenberg. A special word of gratitude to my friends in the Department of Political Science, at the University of Nevada, Professor Leonard Weinberg and Professor William Eubank, who made me feel at home during my stay in Reno and supported me through the last stages of completing the manuscript. I wish to express my appreciation to my friends at the University of Haifa: Dr Yair Zalmanovitch, Professor Aaron Cohen, Dr Andre Eshet, Ms Daphna Canetti, Mr Badi Hasisi and the dean of the Faculty of Social Sciences, Professor Arye Rattner. A special word of gratitude to two young friends and promising scholars: Mr Arie Perliger, my current research student, and Mr Eran Zaidise, a friend and former student, whose devotion to this project helped the book become a reality. I also thank Dani Shlossberg and Olga Sagi, who edited the manuscript.

Special gratitude goes to Tony Mason, Richard Delahunty and Marilyn Cresswell at Manchester University Press for the helpful way in which they treated both the manuscript and me.

Finally, a loving word of gratitude to my family. My parents, Ruth and Max Pedahzur, who taught me so much but left me before I could give something in return, and my own family: Galit, Rotem, Shahar and Doron. You are my world. Everything I do is thanks to your endless love and support. I love you.

Ami Pedahzur

Reno, Nevada 
For Galit 


\section{Introduction: the 'defending democracy' in Israel - a framework of analysis}

$\mathrm{T}$ HE TRIP TO Jerusalem on Monday morning, 6 November 1995, was uncomfortable, to put it mildly. The bus, provided by the Egged public transportation system, for citizens who wanted to take part in the funeral of Prime Minister Yitzhak Rabin was more than filled to capacity. Many of the travellers, mostly the younger ones, were teary-eyed. Others simply did not hold back, and their sobbing could be heard throughout the bus. I looked out of the window at the arid landscape of the hot Israeli autumn and tried to collect my thoughts. From within the deep sorrow that engulfed me something else was preying on my mind, yet, at that consequential moment, I found it hard to pin down. It was only a few days later that the picture began to become clear in my mind.

For a period of forty-seven years, from the day of its establishment to the day of the Prime Minister's assassination, the State of Israel has been fighting on many fronts - including the 'home front' - in order to stabilise its governmental system and try to fashion it after the exemplar of the democratic tradition. I, and many like me, often had strong misgivings over the malleable interpretation of the concept of a defending democracy held by the people of this country. I had grave doubts especially over the restrictions imposed upon those citizens, whether Arabs or Jews, secular or religious, left-wing or right-wing, who aspired to realise their basic rights within a democratic governmental system and who struggled to organise their cause into political action. The leaders of this country are accustomed to explain that the high price paid by a democracy which more than occasionally limits the freedom of expression of its citizens is ultimately justified. As they see it, enforcing the powers at the government's disposal against radicals and antagonists is the inevitable price which the democratic polity has to pay in order to maintain stability.

All through the days of mourning the prime minister the sense of frustration was unrelenting. The political murder itself, and the ominous process of delegitimation the Government of Israel had gone through prior to the murder, 
only proved that the forceful approach assumed by the country toward internal threats - and which exacted such a high price in terms of the quality of Israeli democracy - had helped little in terms of its stabilisation.

The key question that continued to perplex me in face of this reality was why had Israel become so entrapped in the snares along the way? The plural is used because I am speaking of more than one simple failing. On the one hand, the State was incapable of eradicating the political extremism and violence threatening it and, on the other, in trying to defeat these phenomena, it had caused grave harm to the democratic foundations on which it was based.

The near undoing of the State of Israel in this regard leads us to the essential theoretical discussion of one of the paradoxes which has been debated in democratic thought for many years. It focuses on the question: to what extent is it conceivable for a democratic polity to grant all its citizens - including those intent on undermining it - full liberty of action and thus, in effect, expedite their efforts in bringing about the possible demise of that same democracy? This quandary, otherwise christened the 'paradox of tolerance' by Karl Popper, embodies a further and inverse paradox which can be called the "paradox of the defending democracy'. This paradox raises the question: to what degree does a democratic polity have the mandate to suppress or overpower extremist elements germinating from within its borders - elements which often seek to challenge its stability and core values? For a heavy-handed response might lead to an erosion of those very same principles upon which the democracy is structured. Erosion of these foundations might well lead to a predicament where the boundaries between the methods used by the struggling democracy and those extremist threats aspiring to undermine it are rendered indistinct. An operative perspective deriving from this paradox focuses on the effectiveness of counteraction policy and especially on the question of whether a severe response initiated by the democracy - which evidently carries a high ethical price - does in fact eradicate extremism and violence and consequently uphold the polity's stability.

These convoluted problems and their derivatives have occupied philosophers and scholars for many years. Among them were John Stuart Mill, who lengthily contemplated the notion of freedom of expression, ${ }^{1}$ Karl Popper, who explored the question of tolerance toward the intolerant, ${ }^{2}$ and John Rawls, who studied the scope and limitations of the individual's action in a democratic state. ${ }^{3}$ In effect, the core of the argument addressing the tension between the defence of the democracy and the guaranteed protection of its basic liberties has for a long time been restricted to the philosophical playing field or the 'theoretical-normative level', to use a term made popular by Ignazi. ${ }^{4}$

As time passed, and particularly in the 1950s-1960s, this discourse was supplemented with another level of analysis - the political-institutional level. Close scrutiny of the argument involving this term indicates two principal lines 
of research. The first type, i.e. the legal-judicial, which finds its roots in works penned by Loewenstein in the late 1930s, focuses on the judicial statutes and verdicts handed down against extremist parties and violent organisations. ${ }^{5}$ The second course, the military-operative, places its emphasis on militaryintelligence-policing strategies and tactics in the battle against subversion, political violence and terror in democratic systems.

Although discussions couched in the terminology of theoretical-normative level were generally distinct from those on a political-constitutional scale, mention should be made of theorists such as Raphael Cohen-Almagor, Peter Chalk, Ronald Crelinsten, Alex Schmid and, more recently, Giovanni Capoccia, ${ }^{6}$ who were successful in bridging between these two levels of analysis. Works by these scholars were helpful in presenting a more inclusive theory regarding the democratic response to extremism, subversion and political violence. At the same time, their research still suffered from the lack of a comprehensive model which could account for additional levels of analysis and, in particular, the social level of analysis.

In this book - whose goal is the academic discussion and analysis of the Israeli democracy's response to the various challenges facing it - other than coping with the ethical aspect of this concern, an attempt is made to suspend, to some extent, the theoretical-normative aspect and instead to place the political-institutional frame, as well as the social frame of analysis, at centre stage. The combination of these two latter frameworks carries the potential to take us a step further toward understanding whether the 'golden path' does in fact exist - whether there is a course enabling democratic systems of government to effectively protect themselves without crossing the legal and ethical boundaries on which they are founded.

\section{The defending democracy: the search for a definition}

In the attempt to address dilemmas encountered in the democratic response to extremism and violence, scholars, and particularly those affiliated with judicial schools of thought as well as judges and policy-makers, have searched for a terminology that would accurately describe democratic polities caught up in the struggle against powerful extremist elements. The first term of note is the militant democracy prescribed by Loewenstein to indicate certain polities which held sway in the period between the two world wars. This designation carried normative implications and was intended to define the legal measures deemed worthy of use by European democracies in order to deal with the growth of fascism. ${ }^{7}$ Another term meriting attention is wehr-hafte Demokratie, associated with the democratic constitution adopted by Germany in the wake of the Second World War. In English, the term indicates a 'defensive', 'protective' or 'watchful' democracy. The statutory-judicial interpretation of this construct in Germany 
was: 'wehr-hafte Demokratie is one that dos not open its doors to acts of subversion under the cover of legitimate parliamentary activity'. ${ }^{8}$

This brief definition leaves the student of political science who wishes to put it to academic use somewhat at a loss. Do subversive elements, which in fact pose a threat to democracy, take on the guise solely of parliamentary organisations, to wit, political parties? Furthermore, what is the genuine intention behind keeping the doors of democracy shut in the face of the same subversive groups? Does the wehr-hafte Demokratie disbar these organisations from taking part in elections? Or, even more stringently, does it outlaw them and imprison their members?

These questions, for the greater part, are left unanswered despite the efforts of Carlo Schmid, chairman of the committee in charge of consolidating the German constitution following the Second World War, to invest the construct with more meaning:

It is not part of the concept of democracy that it creates the preconditions of its own destruction. I would even like to go further. I would like to say: democracy is more than a product of utilitarian considerations only in those places where the courage exists to believe it as something indispensable for the dignity of man. If this courage exists, we should also have the courage to be intolerant towards those who wish to use a democratic system in order to kill it off. ${ }^{9}$

These words are indicative of the conventional approach assumed by democratic forms of government according to which a democracy has an absolute justification to protect itself from insurgents, whoever they may be. Still, the key question remains: using what kinds of methods? Are all ways and means legitimate in a democratic state's struggle for its existence?

In the effort to find resolution to this question, I have elected to appropriate a second term - the defending democracy. This notion is also a derivative of the judicial school of thought and is associated with the State of Israel and its decision, in the mid-1960s, to prevent the Arab Socialist List from taking part in parliamentary elections. The 'defending democracy', according to the Israeli court of law, is defined as: 'the state [that] possesses an implied power, similar to self-defence, to fight against subversive attempts designed to destroy it'. ${ }^{10}$

Prima facie, this definition is a significantly softer rendition than is the German wehr-hafte Demokratie. Yet review of the statements issued by Israeli Justice Zusman, who made broad use of the term 'defending democracy', shows that the difference between the two concepts is minimal. According to Justice Zusman:

Just as a man does not have to agree to be killed, so a state too does not have to agree to be destroyed and erased from the map. Its judges are not allowed to sit back idly and to despair from the absence of a positive rule of law when a plaintiff asks them for assistance in order to bring an end to the state. Likewise, no other state author- 
ity should serve as an instrument in the hands of those whose, perhaps sole, aim is the annihilation of the State. ${ }^{11}$

Regardless of the fact that his conclusions are not very useful in bringing sharper relief to the definition, Zusman's assertions do provide an answer of sorts to the question regarding the measures which the democracy is entitled to use in its efforts at defending itself. Zusman clearly states that in a "war like any war', the democratic polity has the right to exercise its power, even in the absence of empowering legislation, if that power is applied in self-defence.

Surprisingly, the appropriation of the 'defending democracy' concept from the judiciary and its application to the sociological realm by two of the leading political sociologists in Israel, Dan Horowitz and Moshe Lissak, has neither assisted in developing the various dimensions of the concept nor relieved us of its ambiguity. The defending democracy is defined by Horowitz and Lissak as 'a democracy which excludes from the democratic game groups whose aims or actions may endanger the state, its political regime or its basic national consensus'. ${ }^{12}$

This formulation indicates that these two social scientists chose to pursue the same path laid down by legalists while expanding it on two counts. First, as Horowitz and Lissak see it, a democracy has the right to exclude all dangerous groups from the political system, that is, they do not limit a democracy's jurisdiction of defensive action only to political parties. Second, groups that may be excluded from the democratic process are not only those allegedly endangering a state or a polity's stability, but also those that threaten its basic national consensus.

From the above, it appears that a majority of scholars agree that democratic systems of government have the right to exclude from the political arena those organisations, and especially political parties, whose ideology or actions may endanger, first and foremost, the actual democracy and, in certain cases, also the system of principles forming its basis of legitimisation.

An attempt to apply the construct of the 'defending democracy' in its present form for the analytic purpose of inquiring into democracies' responses to extremism, subversion and violence will apparently not yield the anticipated result. Accordingly, the term must be elucidated, the elements which comprise it must be underscored, and the distinctions among them highlighted. For this purpose, I submit a theoretical framework based on both the political-institutional level and the social level which spells out the guiding principles and tools used by democratic countries in their struggle against perceived adversaries.

\section{The defending democracy: a framework of analysis}

Before introducing the framework employed in this analysis, a methodological reservation in regard to the use of the term 'defending democracy' is in place. 
The coupling of the word 'defending' with the word 'democracy' may in fact be misleading because it produces an idiom the reader may think is a type of democracy along the lines of the 'liberal democracy' or 'consensus democracy' - and this is not the case. 'Defending democracy' and its various derivatives do not indicate a form of governmental system but rather the course chosen by a democracy in its efforts to protect itself. Assuredly, this does not disallow the possibility that the nature of the democracy may in fact dictate the nature of its response to provocation (often, certain courses of counteraction are identified with certain types of democracy); however, for the sake of clarity and to avoid confusion, modes of response should not be treated as part of the definition of the political system. Therefore, it is to be assumed that all democratic systems endeavouring to protect themselves in the face of radical and violent elements do indeed fulfil the requirements of the general framework of the defending democracy. Having said that, it should be stressed that this term alone does not suffice toward understanding the various types and degrees of response. Hence, I propose that the notion of the 'defending democracy' in effect represents a continuum extending from a more belligerent, that is 'militant', approach to the other extreme, the 'immunised' approach. Of course, these two exemplary approaches signify ideal types, ${ }^{13}$ which are not necessarily empirically proven concepts but, at the same time, they represent a continuum along which can be found the responses of the majority of democratic polities facing serious challenges.

The basis for the operative definitions of the 'militant' and the 'immunised' routes of counteraction draws principally on the various theoretical references to barriers or controls used by a democracy against antagonists, but it also derives from an inductive review of the practices of Western countries against elements constituting a threat to their regime. In the light of this, four principal categories of controls are offered that will later on serve as the basis for the definition of the various orientations:

\section{Legal and judicial controls}

Legal and judicial controls include measures at the disposal of democratic countries implemented in their struggle against extremist insurgents, whether speaking of political parties, social movements or individuals. This network of controls includes, inter alia, constitutions or statutes stipulating under what conditions partisan political activity can be restricted, as well as laws establishing which tools are legitimate and which are not, in instances of antigovernmental protestation such as incitement or subversive action. Included in this category are also those legal barriers regulating the relations among the different groups in society and, in particular, controls intending to restrict racist or other expressions which may offend various social groups. The notable aspect 
of these barriers is that they are most often predicated on constitutional or legal frameworks and are subject to continuous judicial review. Barriers of this type carry the potential for suppressing challenges posed by anti-governmental extremist factions, but at the same time they have the power to check and restrain the governmental response to those same extremist elements, thus preventing the undermining of the democracy's ethical foundations.

\section{Administrative and intelligence controls}

Contrary to legal and judicial barriers, which are distinguished by a complete adherence to the frame of the "rule of law', ${ }^{14}$ there are other more flexible measures often extending beyond the limits of state laws, in fact occasionally disregarding the basic liberties inherent to the democratic idea, such as civil liberty, the freedom of expression and the freedom of assembly. Despite the sharp contradiction between these orientations and the liberal democratic paradigm, there is abundant testimony of their use, particularly when the polity senses its stability is in significant jeopardy. ${ }^{15}$ Under extreme circumstances, these measures may include the use of army forces against seditious elements, although in many cases the security services or secret police are assigned the responsibility for dealing with them. Unlike the police forces, whose actions are bound by strict codes regarding all aspects of the nature and the range of its operations, the secret services, in democratic countries as well, enjoy a broader field of operation and in many cases also have access to 'grey' means of control at variance with the tools at the police's disposal. ${ }^{16}$ Additional evidence of controls of this nature can be found in those cases where the state devises a broader 'semi-legal' infrastructure with the intent of paving the way for a more forceful policy of response to seditious events. This infrastructure may include emergency legislation, the use of administrative regulations, modifications to the legal process in order to facilitate a smoother conviction of extremist elements and occasionally, in fact, the creation of special courts of law whose specific role is to preside over concerns related to subversive violence and, principally, terrorists.

\section{Educational controls}

This area is of considerable significance because, by exercising educational means, the state is able to contend with the challenges of extremism a good while earlier than their materialisation into political alternatives. To be specific, with the aid of the education system and particularly, but not exclusively, civic studies, the future citizens of a state can be introduced to the key notions fundamental to the democratic system of governance. Moreover, in many democracies, civics' pedagogy consists of a diversified curricula based on instruction in basic democratic rights such as freedom of expression and assembly, freedom 
of religious expression, freedom of property, the right to own property, the right to privacy and to take political action. In addition, most pupils are exposed to the formal aspect of the governmental process, i.e. the constitutional and statutory processes that form the basic structure of the liberal state, as well as to the social aspect, i.e. the complex of groups comprising society, the rights of these groups, the prominent cleavages dividing society and the major political concerns of the day. In this fashion, pupils become acquainted with the guiding principles of the polity in which they live, its basic essentials, the problems confronting it and the political modus operandi of its country.

\section{Social controls}

Another social domain historically absent from the discourse on the 'defending democracy', yet one that in recent years has maintained a high profile in the discussion of the factors contributing to the normal functioning of democratic polities, is the 'civil society'. In the view put forward here, and as noted in the past, ${ }^{17}$ together with the other functions filled by the 'civil society' in the democratic system, it holds a central role in the protection of democracy. The regulating mechanism formed by the 'civil society' is manifested in the actions of social organisations which are non-governmental yet concerned about the expansion of extremism in society and the flagrant acts of provocation against the democratic foundations of the governing state. 'Civil society' organisations can operate in either political or community frameworks by employing educational and informational campaigns; or they may publicly respond to acts of extremism. In certain cases, they may mobilise efforts to influence governmental authorities. In these aspects, we find an additional contribution to the fortitude of the democratic government. The 'civil society' enjoys both worlds - it is able to voice objection to provocateurs and, alternatively, it may form a system of accountability aimed at restraining over-aggressive governmental counteraction by mobilising public opinion and/or going to law against undemocratic activities in the name of upholding democracy. The goals of these organisations and the tactics employed by them may tend to vary, yet the emergent prodemocratic social controls positioned in-between the state and subversive factions may, on the one hand, carry significant potential in reducing the threats confronting the state, and, on the other, may limit countering governmental action to a more democratically tolerable standard.

\section{The defending democracy:}

\section{in between the 'militant' and the 'immunised' route}

In order to classify these numerous controls and measures and help elucidate the ideal types of response, they are categorised according to two criteria: scope 
and intensity. Scope indicates the democracy's range of responses, that is, whether the state limits its response to extremist elements alone or whether it extends policy to the social level as well? Intensity denotes the types of mechanism utilised by the state. That is, does a particular democracy choose to respond to extremist challenges by using the more moderate means of countermeasure, such as education, expanding civil society activity, and imposing minimal statutory restrictions on antagonistic elements? Or, on the contrary, does it find that more drastic steps must be taken which may entail stretching the idea of the 'rule of law'? An arrangement of the controls and methods of action employed by democracies trying to protect their dominion brings into prominence the two polarities, the 'militant' and the 'immunised' routes, which democratic systems may choose in their struggle against subversive elements. Between these two axes, there is a broad continuum along which it is possible to pinpoint the majority of democratic countries and estimate, in this fashion, the extent of their 'militancy' or 'immunisation'. Furthermore, this continuum enables a diachronic analysis of isolated cases and, principally, an estimation of the movement of single countries along the axis of time from one type of response to another. The following chart represents in more detail the features of the routes of response.

The chart demonstrates that at one end of the continuum the 'militant' route is to be found. Borrowing from the definitions presented above, this denotes a political system whose goals are very narrow and one that is principally restricted to defending the state from manifestations of political extrem-

Figure I.1 The defending democracy and its different routes

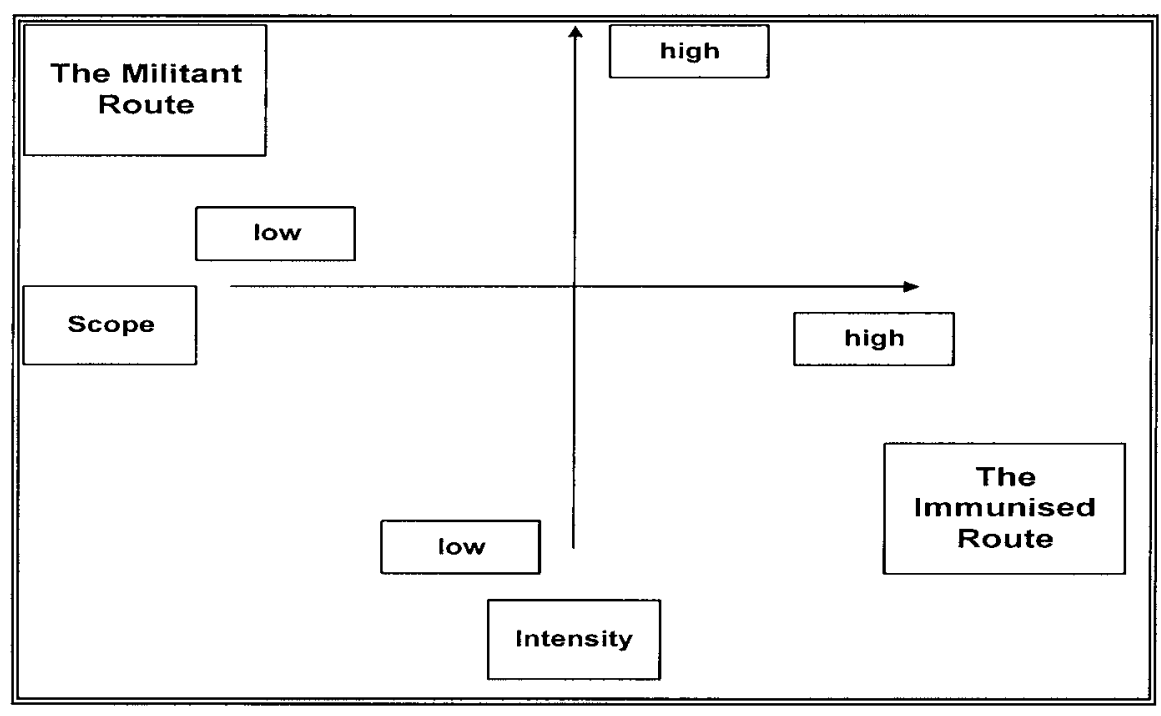


ism, incitement and violence. At the other end we find the 'immunised' route. The state adopting this route in effect seeks to shore up its governmental system against subversive acts of defiance, and if and when these provocations in fact are realised it deploys defensive means which form a more comprehensive treatment of those elements. At the same time, it still accounts for the liberal principles of freedom of expression and action, and the 'rule of law'.

In order to help draw comparisons among the guiding principles of either model, a medical metaphor is proposed. The 'militant route' adopts methods of treatment targeting the symptoms of the 'illness of extremism'. These symptoms are principally political parties, radical movements and manifestations of incitement, sedition and political violence. Particularly strong medication must be prescribed by the 'militant route' for these same symptoms, with the result that the patient - that is, the polity itself - will most likely suffer from severe sideand after-effects. This medicinal plan includes a list of unconventional measures which circumvent standard legal and judicial processes.

The 'immunised route', on the other hand, assumes a more holistic view by treating both the symptoms and the illness's aetiology. This orientation focuses primarily on preventive medicine whose goal is to maintain a steady stream of antibodies against the spreading of disease, mostly by the inculcation of democratic values and tolerance, and by providing the opportunity for the "civil society' to take an active role in the political theatre. Nevertheless, the holistic approach does not neglect the treatment of the symptoms of the illness in the event that, after all the preventive measures have been taken, extremism and violence still break out. However, in that case, since we are speaking of a more immunised body, the medical measures applied are more conventional; that is, they are within legal limits and do not threaten to subsequently weaken the body.

With regard to its policy towards radical parties, the 'immunised route' underscores the legal-judicial aspect. In other words, the state employs constitutional and statutory measures which benefit from a broad consensus and the essential principles of the 'rule of law' in its deliberations regarding a party's disqualification or the prevention of its registration. As for extra-parliamentary movements, the 'immunised route' renounces the approach based on an extensive use of administrative procedures, i.e. the enforcement of regulations and injunctions outlawing these movements, their definition as terrorist organisations and also the restriction of their members' freedom of movement regardless of the conventions of state criminal law. The democracy that chooses the 'immunised route' will act against subversive movements using the same practices mandated by criminal law while also maintaining a meticulous and invariable scrutiny of the judicial authority.

Summing up the distinctions drawn between the two routes, it is argued here that although in the short run the 'militant' course may be more effective 
in dealing with various manifestations of extremism and violence, the "immunised' route is still the more effective in the longer term. This assumption is listed primarily in the 'immunised' model's strong connection to the public and is based on the perception that in order to successfully fight extremism its roots must first be detected. Next, two flaws inherent to the 'militant route' impair its effectiveness in the longer run. The first shortcoming is related to the aforementioned paradox, that the more a democracy adopts the more 'militant' mode of distinction, the more it undermines its own liberal principles, a fact that may eventually lead it to become an authoritarian regime under the name of democracy. The second drawback pertaining to the 'militant' strategy becomes clear when the ethical perspective is replaced by the practical-tactical perspective. Examination of the 'militant route' from this perspective, together with the test of consequences, demonstrates that the effectiveness of this route is indeed questionable. A case in point is Germany, ${ }^{18}$ where labelling a particular political movement 'illegal' may lead to a 'self-fulfilling prophecy'. That is to say, the same movement that has so far operated in full view is now forced 'underground' and will radicalise its operations in order for its goals to remain on the public agenda. On the other hand, in the absence of persistent enforcement, outlawing the movement can be just minimally effective because parties and movements have the ability to adapt and adjust themselves to changing circumstances. A movement which has been legally banned can occasionally assume various other guises by changing its name or the composition of its key activists, and, in the long run, can make things more difficult for the democracy.

In sum, using the theoretical constructs elaborated above, an attempt is made in this book to illustrate the changes in the response of the State of Israel to its internal adversaries in the last fifty-three years. This treatise will focus on the transition from a heavy-handed and often, in democratic terms, problematic policy of counteraction which marked the State in the first decades of its existence to a more moderate response whose confinement to democratic and even, at times, liberal boundaries, characterises it with the advent of the present decade. Each chapter attends to a different domain of the State's reaction and explicates the changes in its reaction, including the forces accelerating or decelerating it. The ultimate goal is to present the construct of the "defending democracy' to the reader as a broad, holistic and operational framework, embodying a number of different levels of analysis found in constant interaction among themselves, and enabling the transference of the construct to the scrutiny of other nations and states as well as comparative research.

\section{The Israeli political context}

In order to evaluate the changes in the Israeli response to Jewish extremism and violence, I begin by presenting the discussion of those particular political char- 
acteristics of the State of Israel which have, to a significant degree, shaped it as a 'defending democracy'. Concurrently, the depiction of the extremist and violent events the State has had to contend with are also presented.

\section{Israel: a non-liberal democracy}

The first topic to be addressed regarding Israel's status as a 'defending democracy' is the non-liberal character of the Israeli State's system of governance or, in other words, the democratic status of Israel in the procedural more than bona fide sense of the term. ${ }^{19}$ The reason for this is that while the formal foundations of a democratic system - free and fair elections, inter-partisan competition, periodic governmental rotation, etc. - are maintained, other essential components of the democratic epitome, such as the protection of fundamental rights, including the freedom of expression, freedom of assembly and freedom of religious expression, are all, to varying extents, flawed.

Like Yoav Peled, Uri Ben-Eliezer and Yael Yishai, I too find the construct of the 'non-liberal democracy' to be the terminological frame most suited to defining the political reality that has emerged since Israel's inauguration. ${ }^{20}$ In contrast to the liberal democracy, whose first priority is the individual and his/her rights, the 'non-liberal democracy' puts a strong emphasis on the collective or the community. Democracies of this type stress uniformity at the expense of diversity, and unity over pluralism. This reflects a type of collective regime, where the principles of equality and harmony are predominant among those who belong to a certain group and aspire to its common goals. State offices do not exist in order to form an institutional safeguard of the individual's privacy, but rather as means for furthering the 'general good' of the people. In 'nonliberal democracies', not all voices have an equal opportunity to be heard, and not everyone is equally encouraged to enter the political arena. Participation is more a privilege than a basic right and is therefore reserved for those who act in the collective interest. This type of participation is not a potential vehicle for challenging the 'powers-that-be' but is rather a means of processing and enforcing the general will of a country. ${ }^{21}$ From this definition, it can be concluded that there are two principal aspects inherent in the Israeli 'non-liberal democracy': its values and operative implications. The operative aspect indicates the active and centralised character of the state. One expression of this aspect in Israel is evident in the fact that, for many years, the powerful state apparatus has prevented the development of an effective autonomous 'civil society'. In terms of values, the non-liberal democracy concentrates on the ideological-national foundations of the state and, in the case of Israel, on the Jewish nature of the country.

An interesting point is that the majority of social scientists currently engaged in the study of Israeli politics tend to direct the bulk of their efforts on 
the values' aspect (and its resultant practices) typical of the non-liberal nature of the democracy. Among these researchers, there is general agreement that Israel is still a far cry from the Western liberal democratic model, but there is a lack of consensus regarding the precise nature of Israel's form of government. Neuberger, for example, argues that Israel is a 'blemished' liberal democracy. ${ }^{22}$ Others, going one step further, contend that by virtue of the asymmetrical relations between the Jewish majority ( 82 per cent of the population) and the Arab minority, Israel should be classified as a (Jewish) "ethnocracy' ${ }^{23}$ or in fact a "nondemocratic ethnic state'. ${ }^{24}$

Between these polarities of ethnocracy and 'blemished liberal democracy', there lies an intermediate position maintaining that, in terms of its values, the Israeli 'non-liberal democracy' should be defined as an 'ethnic democracy', as suggested by Sammy Smooha. According to Smooha, the ethnic democracy

is a democratic system of government wherein rights are granted to all citizens while, concurrently, a favoured status is conferred upon the majority. It is predicated upon two conflicting principles: democracy for all and the majority's structural subordination of the minority. The establishment of the state on these two opposing principles occasions irresolvable conflicts and dilemmas. According to democratic principles, the state belongs to the majority and this by inference does not include all of its citizens. For the [in the case of Israel, Jewish] majority, the state is a means for furthering its interests and national goals while the [in Israel, Arab] minority is faced with the inevitable predicament of being disloyal to the country, for it cannot attain full equality and national identity. At the same time, the democratic system allows the minority to ardently campaign and struggle to better its conditions without fear of governmental crackdown or oppression by the majority. However, the state imposes a variety of restrictions and a general regulation of the minority in order to prevent disorder, instability and subversion. ${ }^{25}$

Indeed, the non-liberal and ethnic characteristics of the State of Israel have held sway over the formation of almost all the social realms of life in this country. In terms of the present analysis, these characteristics are inseparable from the notion of the 'defending democracy'. The (Jewish) ethnic character of the country has engendered, as noted by Smooha, an extensive system of regulatory measures for controlling the Arab populace, which, furthermore, is looked upon with suspicion and has been defined as a 'hostile minority' or the 'fifth column'. ${ }^{26}$ Although the present work does not deal with the response to Arab extremism, it is worth noting that procedures enforced by the State against Jewish extremists tend to have been of a significantly more moderate nature than those to which Arabs have been subjected. One cannot avoid the fact that these same political, judicial and security factors were appointed by the State to deal with acts of provocation perpetrated by both populations. Apparently this led, in the nature of things, to the same ideas and measures used against Israeli Arabs being used also in the State's struggle with Jewish extremism. 
However, there is more to the role of the State's ethnic character in the 'defending democracy'. In effect, there is an inherent tension between the principles of the 'non-liberal democracy' and the notion of the 'defending democracy'. This tension is mainly due to the fact that the institutionalised preference of one ethnic group over another - typical of the non-liberal 'ethnic democracy' - provides fertile grounds for the flourishing of ethnocentric, ultra-national and in fact xenophobic manifestations. These circumstances are strikingly apparent in the field of education, which has been deeply affected by the ethnic character of the Israeli democracy and, in my opinion, may still prove to be the principal control for the State's aspiration to curb extremism in Israeli society. Both prior to the State's establishment and in the years following, the Hebrew education system has served as a pawn in the hands of the Zionist national movement which, like other national movements, worked to instil among its future citizens a (Jewish) national worldview. The values and principles of the Israeli 'ethnic democracy' are intended to perpetuate the Jewish community's uniqueness, its legitimate control over the country and its role as a centralised state in charge of the education system and its various sectors. This approach laid the grounds for reinforcing Jewish identity among most pupils of the State's schools and creating the affinity between the Jewish and Israeli national identity. The country's efforts to inculcate among its pupils a strong national and ethnic identity stood in stark contradiction to Western liberal democratic views. This fact was not overlooked by the designers of Israel's education system, who chose to minimise, and at times completely exclude, liberal discourse from the State education system in Israel. ${ }^{27}$

The last domain where the effect of the non-liberal Israeli democracy is significantly felt on its status as a 'defending democracy' is related to the existence - or, more correctly, the non-existence - of the 'civil society' in Israel. Gidron puts forward the view that, in the pre-State era, a period when the British Mandate avoided becoming involved in the internal affairs of the Jewish population, 'civil society' organisations did exist, and in fact flourished. They provided the population with social services as well as cultural, educational, sports, health and occupational services. Yet, with the establishment of the State, and especially in the early 1950s, an expedited construction of state institutions was put into effect, the intention of which was to replace the voluntary networks. The sovereignty, or 'statehood', orientation took root in this country. Its leading proponent was Prime Minister David Ben-Gurion, who subscribed to the view that the satisfactory absorption of 'Israelis' immigrating from the numerous and varied countries of the Diaspora required a coalescence of the different sectors and the cultivation of a political-sovereign perception. According to this view, the State's interests stand above all organisational interests or groups making up these bodies. ${ }^{28}$ In operational terms, the 'statehood' 
idea found expression in the suppression of initiatives to establish organisational frameworks not associated with the government or political parties. Even the more institutionalised 'civil society' structures which nevertheless managed to survive the 'statehood' era were assimilated by the government by making them dependent on the State budget, subsequently turning them into State affiliates. ${ }^{29}$ Galnoor's remarks on the State's position in regard to the 'civil society' are even more trenchant. He depicted it as outright government hostility toward the autonomous participation of non-institutionalised groups of citizens. $^{30}$

The first signs of the renewed growth of the 'civil society' in Israel became evident in the late 1960s. At first, this prompted resistance on behalf of the State which fought the challenges posed by the evolving 'civil society', though by the early 1980s the picture began to change. From that stage on, according to Yishai, the Israeli political apparatus began to retreat from its involvement in the 'civil society' and instead sought to preserve a fragile co-existence with this non-political sphere. ${ }^{31}$ Yishai's portrait is highly relevant to the relationship between the 'civil society' and the 'defending democracy'. Despite its potential, the role of the 'civil society' in the protection of the Israeli democracy from internal adversaries was, until the 1980s, completely marginal. However, the beginning of that decade ushered in a significant awakening of civil organisations that set their goals on shoring up the status of democracy in Israel in various ways.

\section{Jewish political extremism and violence in Israel}

Unlike many countries which have undergone manifestations of political radicalism and ideological insurgence, Israel's nature as an 'ethnic democracy' and the Jewish public's sweeping consolidation around the Jewish national sentiment also shaped and delimited, to a certain degree, the features of Jewish political extremism and violence in the country. Even in the early days following the establishing of the State, and despite profound ideological differences, it was clear that all political currents fighting for the State's independence were united in the belief that the Jewish State must be sustained and empowered. Therefore, the main arguments revolved around the ways in which this should be accomplished. The passage of time saw the entrenchment of what may be called constructive radicalism. This type of radicalism implies a radical and occasionally violent political stance that is not interested in disrupting the status quo but rather seeks to reinforce it. There were some isolated incidents, mostly linked to anti-Zionist factions in ultra-orthodox society or the radical left wing (peripheral elements, both in terms of size and operational capacities). Apart from these, all Jewish extremism and violence in Israel has resulted from the desire 
to reinforce and establish the Jewish character of the State and to expand its boundaries.

Ehud Sprinzak, the political scientist who charted the features of political extremism and violence in Israeli society, submitted three principal axes responsible for the bulk of these phenomena. The first is the political-ideological axis, and the second centres on the conflict between the ultra-orthodox and the secular. The third axis pertains to the ethnic-social issue, principally, the antiestablishment struggle of Jews from Mediterranean and North African countries, consequent to persistent ethnic-socioeconomic divisions and the ensuing feelings of discrimination. ${ }^{32}$ An additional axis complementing Sprinzak's model pertains to the professional-economic conflicts that occasionally took on a violent character in the wake of the increasing extremism of professional union activities.

For the purposes of the present thesis, this discussion primarily addresses the first and second axes. In its early days, the State did in fact respond with severity to events stemming from social motives, such as in the violent suppression of the Seamen's Revolt in 1951, which began as a professional disagreement that spilled over into the political arena. Another example was the 1959 riots waged by Jews of North African descent in Wadi Salib, Haifa, which were forcibly put down by the police. However, over the course of time, a novel orientation took hold among the heads of State, implying that violent expressions stemming from social or economic hardship do not pose a significant threat to the State and therefore do not require new or special coping strategies.

According to the originator of the security services in Israel, Isser Harel, the key factor perceived by the State's rulers to be a danger to its stability goes back to its earliest days, to the severe ideological disputes among the various political currents and, principally, the rift between right and left. ${ }^{33}$ This is exactly the same factor plaguing those responsible for state security five decades later. In the view put forward by Carmi Gillon, who was the Shabak (General Security Service - GSS) chief during the time of the assassination of Prime Minister Yitzhak Rabin, heads of state and the security services estimate that the factors threatening internal security near the end of the 1990s remained the dispute between right and left while, over the years, messianic religious threats have been added to the picture. The combination of religious messianism and, in the wake of the Six-Day War, an increasingly entrenched ideological cleavage between hawks and doves, ${ }^{34}$ appeared to security functionaries as the greatest danger posed by the Jewish public to the State. ${ }^{35}$ In view of these assertions, chapter 1 attempts to elaborate upon the features of the ideological and religious axes, and emphasis is put on the growing convergence over the years of these two dimensions to a point of almost complete congruence. 
Extremism and violence and the ideological cleavage between right and left

Political extremism and violence, the source of which is the ideological cleavage between right and left in Israel, has earned much academic attention, and not without reason. Despite the fact that most of the research on this topic concentrates on the period following the Six-Day War, the roots of the ideological clash between these two wings date as far back as the pre-State era, residing principally in the rivalry between the Labour Movement's camp and the right-wing underground movements of Etzel (National Military Organisation, also known as the Irgun) and Lehi (Israeli Freedom Fighters, also known as the 'Stern Gang'). The peak of pre-State contention became evident in the 'Sezon affair', when members of right-wing underground movements were detained and a number of them were in fact handed over to the authorities of the British Mandate. Shortly after the State's inception, Prime Minister David Ben-Gurion's command to sink the Etzel's ship Altalena, and eliminate rightist underground movements, was even more striking testimony to the struggle among the various ideological factions.

Sprinzak argues that in the years following the State's establishment the tension between right and left subsided, at least in terms of extremist and particularly violent manifestations. In those years, the ideological cleavage more often could be felt in the parliamentary forum. Still, amid the expressions of protest and violence, which nevertheless did crop up in the 1950s, mention should be made of the underground movement Brit Hakanaim (Covenant of the Zealots), which incorporated radical Jewish ultra-orthodox elements combined with an extreme right-wing heritage bequeathed by Lehi. In addition, there was the Zrifin Underground (also known as the 'Kingdom of Israel'), which operated under the inspiration of the writings of Dr Israel Eldad, one of the leaders of the Lehi, and the fierce demonstrations mounted by Etzel veterans against BenGurion's plan to accept compensation from Germany in place of Jewish property seized by the Nazis. Finally, there was the assassination of Dr Rudolph (Israel) Käsztner, a prominent leader of Hungarian Jewry at the time of the Holocaust. He was accused of befriending Nazis and turning in many members of his community in exchange for rescuing other Jews from their deadly grasp. ${ }^{36}$ Käsztner's murder was in effect the final chord in the violent confrontation between right and left during the State's earlier years.

The resurgence of the sharp division between right and left came in direct consequence of the Six-Day War and was chiefly due to the fact that during the brief course of battle the Israeli army conquered many Jewish holy sites including, foremost, the Temple Mount in Jerusalem. Prior to the Six-Day War the dispute between proponents of the Greater Land of Israel and territorial compromisers remained theoretical. Then, the consequences of this war presented the Israeli public with a new reality pierced by the deep conflict regarding the 
future of the territories occupied in the war. In the past, the left-wing camp and, primarily, the Labour Movement had always enjoyed an easy majority among the Jewish public. However, in the years subsequent to the Six-Day War Jewish society in Israel became split and the yawning gap between the hawkish right and the dovish left in effect became the force responsible for shaping the political programme in Israel for the ensuing decades.

The acts of extremism and violence relating to the future of the territories are associated primarily with those to the right of the political map who introduced the struggle into the halls of Parliament as well as the extra-parliamentary arena. However, while parliamentary factions representing the notion of the 'Greater Land of Israel' were slow in getting organised, and in effect began to flourish only in the 1980s, with the appearance of parties such as Tehiyah (Renaissance), Tsomet (Crossroads), Moledet (Homeland) and the radicalised National Religious Party (or Mafdal, the Hebrew abbreviation), in terms of extraparliamentary politics the issue of the future of Judea, Samaria and Gaza became a pivotal concern as early as the 1970 s. ${ }^{37}$ The beginning of the momentum in the active entrenchment of Israeli control over the lands of Judea, Samaria and Gaza can be marked by the launching of the Gush Emunim (Bloc of the Faithful) movement in 1974. This movement, which signified a close affiliation between territorial maximalism and religious, and in fact messianic, notions, adopted an illicit programme whose main expression was the struggle with the State's law authorities over the right to settle the conquered territories. ${ }^{38}$ By the same token, Gush Emunim, which in due course gave rise to the Jewish terrorist organisation (subsequently known as the 'Jewish Underground'), represented the most prominent example of loyalty to the State and to the premiss of radical Jewish constructivism. Leaders of the movement and their supporters held the belief that their intentions and actions were aimed at empowering the State and not to cause it harm. And, indeed, despite the fact that in its first years of operation Gush Emunim's activities were marked by severe confrontations with the government, activists of this movement never theologically questioned its legality or authority. The movement indeed honoured the Israeli sovereign institutions of the Knesset, the government and, above all, the army and security system. ${ }^{39}$

As the years passed, various elements within the movement underwent additional degrees of radicalisation, primarily manifested in the terror perpetrated against Palestinians by the Jewish Underground. This, in effect, signified the fall of Gush Emunim when, following the detection of the Jewish Underground, it became subject to a deep ideological crisis, indicating the downfall of the radical constructivist perspective. The void left by the decline of Gush Emunim was quickly filled by even more extreme hawkish elements which, at the time of the peace process spearheaded by the second Rabin administration, cast serious doubt on the government's legitimacy and launched a campaign of 
de-legitimisation against the incumbent leader of that administration. Surprisingly, both these movements, and even Yigal Amir, the prime minister's assassin, believed their actions would lead to the salvation of the people of Israel. Of course, at the time the question of accepting a democratically elected and secular government's authority was not yet a concern.

\section{Extremism and violence and the cleavage between secular and religious}

As already noted, to sharply distinguish between the ideological rift and the secular-religious cleavage in the Israel of the third millennium would be quite unfeasible. This problem was not so prominent in the State's early days. Religious extremism in those days was mostly allied with the ultra-orthodox public and, in particular, the Natorei Karta (Guardians of the City) movement, which fundamentally rejected a Zionist government and, in practice, voiced outright protest and cut itself off from it. ${ }^{40}$ Still, it became evident, already at that time, that not all ultra-orthodox factions tended toward isolationism, and this was prominently expressed in the activity of the 'Covenant of the Zealots' underground, which, as noted previously, drew its inspiration from the fervently Zionist Lehi.

Generally speaking, the cleavage between secular and religious in the Jewish population of Israel is interesting due to the absence of a dichotomous component. That is to say, a great part of the Jewish population can be found in-between secularity and religiosity, and in fact defines itself as traditional. The conventional solution for those studying the political as well as the violent facets of the cleavage is to focus on three distinct groupings: ultra-orthodox; national religious; and secular. ${ }^{41}$ Traditionally, the acts of extremism and violence committed by the Haredi (ultra-orthodox) public were portrayed as a direct outcome of the State-religion controversy, whereas the extremist and violent actions perpetrated by the fringes of the national religious public were linked to the struggle over the control of the hawkish agenda.

Among large sections of Haredi society, and contrary to other groups in the population likely to engage in political violence, there is an inherent repudiation of the State of Israel in its present form, anchored in the anticipation of redemption and the erection of a religious state based on Halakhic rulings. Indeed, various groups from this subculture continue to pursue the tradition that evolved with the State's establishment, which repudiates the legitimacy of the Israeli government and its various authorities and instead answers solely to the Halakhic law based on the fundamental premiss of dinah demalkhuta dinah (Aramaic, meaning 'the law of the government is the law'). The implication of the above is that these religious orders regard the State of Israel and its institutions as a foreign government analogous to the governing bodies of other foreign countries around the world where Jews live. ${ }^{42}$ This position has its roots in the 
assumption that the Jewish People is 'separate from history', that it is under the sole protection of divine providence, and no secular national movement, such as the Zionist movement, will be the one to redeem it. ${ }^{43}$ That said, there has been recent concurrence among most researchers that the Haredi society consists of a variety of groups and while a small part in fact holds radical attitudes toward the State, among the Haredi mainstream the prevailing disposition is more pragmatic. This novel perspective, which has gradually taken root over the years, considers, for example, that participation in the parliamentary arena is a legitimate means of accessing resources. ${ }^{44}$

However, taking part in Israeli society and politics in order to procure resources has its consequences. Beginning in the early 1990s, the academic literature reports of the appearance of Hardal (abbreviation for Haredi together with the initials of 'religious nationalism'), or the national ultra-orthodox, ${ }^{45}$ a new bloc in ultra-orthodox society in Israel consisting of two tendencies. On the one hand, there is evidence of a Haredisation of various religious Zionist groups. On the other hand, there is the adoption of a national if not ultra-nationalist identity among some Haredi elements, and this has led to an increasing convergence of the Haredi and hawkish publics in terms of their attitudes as well as in operative joint-efforts. ${ }^{46}$ Research conducted towards the end of the 1990s demonstrates that the most hawkish population among all the Jews in Israel is the ultra-orthodox population. ${ }^{47}$

These developments found political representation already in the mid1980s in the crystallisation of parliamentary alliances, such as the Morasha (Heritage Party), which integrated hawkish elements descending from the religious Zionist school of thought together with Haredi factions. At the start of the 1990s this tendency grew as the ultra-orthodox Habad movement took an active role in the events organised by the political right in protest at the Oslo Accords. Eventually, the affiliation between the Haredi sector and the hawkish political camp grew so close that the distinctions between them became no longer discernible.

Incidental to the discussion of extremist and violent manifestations related to the religious-secular division, it is important to note the case of Rabbi Meir Kahane and the Kahanism which took root in the State of Israel in the early 1970 s, proving retrospectively to be the most blatantly racist and antidemocratic phenomenon Israel has ever known. Remarking on this phenomenon in the same breath as the secular-religious cleavage is apposite because, to a great extent, Kahanism constituted a singular and purified instance of the fusion of Haredi radicalism and the messianic right-wing extremism of Gush Emunim. The lifestyle of Kahane closely resembled that of the Haredi and, like them, he demonstrated great hostility towards the secular leadership of the State and toward the Western lifestyle of the bulk of the Israeli population. However, as did the members of Gush Emunim, Kahane saw divine intervention 
in the founding of the State of Israel and more so in the triumphant results of the Six-Day War, which symbolised both for him and for the followers of Gush Emunim the beginning of the salvation of the People of Israel. ${ }^{48}$

All in all, this book posits that the political camp which evolved in the wake of the Six-Day War - whose boundaries were indeed unclear but whose feelings and actions showed distinctive elements of religious and ideological zeal - constitutes the most prominent threat to Israeli democracy in the last decades, both from the perspective of scientists studying Israeli political violence as well as from that of statesmen responsible for the security of the country. This same alliance of religion, territorial expansionism and enmity towards Arabs characterised the most fanatical and violent of the right-wing parties, Kach, as well as Gush Emunim, the Jewish Underground, and Yigal Amir, the assassin of Israeli Prime Minister Yitzhak Rabin. It also accounted for several violent movements and isolated incidents which have surfaced in recent decades. Moreover, other threats confronting Israeli democracy deserve mention, including political incitement on behalf of the radical left, and the appearance of groups and individuals who engaged in violence of different degrees stemming from ethnic or messianic motivations, not necessarily related to the hawkish-dovish cleavage. The most significant of these groups was the sect led by the charismatic Rabbi Uzi Meshulam. In 1994, the rabbi and his group barricaded themselves in his house in the city of Yehud in demand for an inquiry into the 1950s' disappearance of Jewish children of Yemenite descent. The story of that sect as well as of other groups is recounted in detail in chapter 2 .

\section{Outline of book contents}

The five chapters which follow expand on the Israeli response to Jewish political extremism and violence while employing the construct of 'defending democracy' and analysing the State's movement along the axis from the 'militant route' to the 'immunised' route.

Chapter 1 focuses on the historical campaign undertaken by the State of Israel against extremist parties, beginning with the 'Socialist List' in 1965 and concluding with the Yemin Yisrael ('Israel's Right') party in 1996. A central object of this discussion is Rabbi Meir Kahane's party Kach, whose ideology, proposed patterns of action and leader's rhetoric have played a key role in shaping the normative legal defensive measures devised by the Israeli democracy. The principal aim of chapter 1 is to trace the changes in measures taken by Israel in its struggle with extremist parties and to indicate the gradual transition from a 'militant' to an 'immunised' model of response.

Chapter 2 puts forward a chronological synopsis of the Israeli response to extra-parliamentary radical elements, and begins with the weapons' ship Altalena affair, sunk by the IDF close to a month after the declaration of the 
State's independence. The chapter then deals with the dismantling of Etzel and Lehi, two principal right-wing underground movements active before the establishment of the State which constituted, at least from the perspective of the young State's leadership, a considerable threat to the nascent regime's stability. Following the discussion of the incidents accompanying the State's earliest days, the review continues on to the events of the 1950s. Reference is then made to the 1970 s, a period marked by a burgeoning of illegal right-wing organisations as well as several notable acts of leftist sedition, and the changes in the State's response to these events. The central part of the chapter is devoted to the Israeli reaction to those far-right elements which emerged during the 1980s and flourished during the course of the 1990s. The major loci of discussion are the Kach Movement, the 'Jewish Underground', the assassination of Prime Minister Yitzhak Rabin, and the evolving character of the State's response towards each of these phenomena. A considerable part of the chapter is devoted to a review of the state of emergency that held sway in Israel for many years and to the legal infrastructure deriving from this predicament which, in effect, enabled the State, in its struggle with violent and insurgent elements, to employ means that would often deviate from the acceptable rule of law in a democratic state. A strong emphasis is also placed on the pivotal role filled by the Shabak in the battle against insurgency. With this as background, the question is raised as to why, ironically, an undercover organisation, noted for methods which often encroached upon basic democratic liberties, was nevertheless allocated the task of countering extremism in place of the legislation-bound police. As in chapter 1 , this chapter also records the general developing tendency - the gradual transition from 'militant' routes of response to 'immunised' strategies. However, contrary to the development of this type of response to extremist political parties, the shift to 'immunised' mechanisms with regard to extra-parliamentary organisations is much more piecemeal, problematic and hesitant.

If, until this stage of the book, the degree of intensity of the Israeli response to extremism and violence is a main motif, then from chapter 3 on the book begins to discuss the extension of this response to other areas, namely the degree to which Israel expanded its struggle against extremism and violence to the social sphere. The focus in chapter 3 is on civics education. By means of a historical and textual analysis of school curricula on the subject of civic studies in the State of Israel in the first decades of its existence, I try to demonstrate that the State did not attempt to reinforce its democratic character but in fact took steps to weaken it. The education system of the newly born State set about the task of nation-building, to a great extent by means of underscoring particularistic nationalist qualities while banishing universalistic liberalist strains to the margins of the education curricula. In this fashion, the country inculcated among its future citizens dominant nationalist attitudes, which in many cases digressed into nationalist ethnocentrism. Then the chapter focuses on the State's 
response to the incidental ultra-nationalist repercussions of this policy. A short while after the election of the racist Rabbi Meir Kahane to the Knesset in the mid-1980s surveys confirmed the prevalence of ethnocentric views among many Israeli students. In this regard, the State's leadership and the Ministry of Education were faced with a quandary for, on the one hand, they desired to reinforce the democratic structure of the State yet, on the other, they did not want to forgo the education of Jewish nationalist values. The chapter traces the efforts made by the State in the late 1980s and during the course of the 1990s to contend with this convoluted issue. Finally, the reform of the civic education curricula toward the end of the 1990s is scrutinised and an estimation is given of its chances of weakening the radical underpinnings of Israeli society and, in turn, perhaps reinforcing the 'immunised' character of the democracy.

Chapter 4, which aims to complete the investigation into the 'immunised' potential of the State of Israel, presents the reader with the connection between 'civil society' and the 'immunising' process of the Israeli democracy. Put forward in this chapter is the position that the 'civil society', because of its state-free status, carries the potential for playing a central role in the transition to the 'immunised' model. As already noted, in recent years, Israel has opened its gates to the 'civil society', allowing it a greater degree of freedom of operation. Among the associations currently appearing, a large group can be classified under the heading of the 'pro-democratic civil society'. These bodies have employed various modes of operation in the effort to instil democratic values in the country, foster the tolerance of various populations, promote political debate within legitimate as well as constitutional limits and encourage constructive public criticism of the State's response. Public relations material and newspaper items reporting the various accomplishments of the Israeli "pro-democratic civil society' would not methodologically suffice as the sole source of information. Therefore, chapter 4 is also based on findings compiled from a survey distributed among the entire group of associations mentioned above. This project laid the grounds for a general and unprecedented typology of the "prodemocratic civil society' in Israel. The survey was designed to examine its features and strategies of action, and it enabled an investigation of the degree of its effect on the 'immunising' of Israeli society as perceived by its representatives, on the one hand, and surveyed public opinion, on the other. The chapter's conclusion underscores the awakening of the 'pro-democratic civil society' in Israel and profiles a number of notable successes which can be chalked up to its credit. That said, a comparison with Western European countries and, in particular, the United States, demonstrates that 'civil society' in Israel still has a long way to go before the Israeli democracy can reach that other point on the compass - the 'immunised' model of response.

The final, and summarising, chapter of the book can be divided into three main sections. The first part presents the reader with the accumulated body of 
facts with regard to the Israeli response to extremist phenomena and political violence throughout the history of the State of Israel. Beginning with the State's establishment and leading up to the advent of the new millennium, it estimates the degree to which the country has been successful in departing from the "militant' type of response in favour of the 'immunised' course. It queries the conceivability of a 'golden path', i.e. protecting democracy from antagonists, on the one hand, while avoiding the slippery slope into retaliatory strategies that may easily deviate from the legal and ethical foundations of the democratic state, on the other. The concluding discussion refers to each level of analysis listed in the preceding chapters and evaluates, with the help of a more comprehensive perspective, whether the shift towards the 'immunised' model is relevant to all levels of analysis, or whether at certain points the Israeli case still adheres to the "militant' end of the spectrum and which factors either support or restrain this transition. The second part of the chapter assumes a comparative perspective between the Israeli response and that of other Western democracies, principally, the United States and Germany. Placing the Israeli case in a comparative perspective exemplifies, first, the potential of the theoretical perspective proposed in this book, a perspective which in fact makes comparative analysis feasible. Second, widening the scope beyond the Israeli case study underscores the challenges which confronted and still confront the society and the State of Israel in contrast to other societies and makes it possible to estimate the effectiveness of the tools wielded by the State in comparison to those of other countries. The third part of the chapter highlights the theoretical developments accompanying the analysis and submits questions which remain unresolved and worthy of future investigation.

\section{Data sources and methodology}

The theoretical extension of the concept of 'defending democracy' from philosophical and judicial domains - to which it is generally limited - to other disciplines and, in particular, the social sciences requires an adaptation of the methodological tools employed in its research. Henceforth, data sources and methodology can be arranged into two principal categories: qualitative and quantitative.

The first portions of the book are based primarily on qualitative sources and tools of analysis, so that, for example, the main sources for the analysis of Israeli policy regarding political parties were the protocols of Knesset proceedings and Central Elections Committee hearings as well as official committee and party registrar correspondence. Additional sources were the verdicts handed down by the Supreme Court which, in its role as high court of justice either ratified or rejected resolutions passed by its subordinate bodies. In order to fully understand the factors leading to decisions regarding various parties, in-depth inter- 
views were also conducted with representatives of the parties in question as well as with members of the bodies responsible for decision-making on this matter. Another corroborating source was the compiled data regarding the respective parties on file in the archives of the Central Elections Committee.

The attempt to investigate permutations in the Israeli response to extremism and violence in the extra-parliamentary realm met with more difficulty due to the fact that the majority of hearings in reference to these organisations take place behind the closed doors of various governmental offices and, in particular, those of the Shabak whose proceedings and recorded minutes are conducted far from the public eye. Consequently, significant use was made of the writings of Israel's policy-makers and executive authority. To augment the picture the documentation of events in the daily newspapers was reviewed and in addition, in-depth interviews were conducted with policy-makers as well as with representatives of the organisations and movements subject to the State's enforcement of its varied measures.

The evolving policy on instruction in civics in Israel's schools was much easier to investigate because Ministry of Education archives are open to the general public, thus allowing access to all its protocols and correspondence. An additional source of information consisted of interviews with politicians who over the years had devised the civic studies curricula and Ministry of Education employees who had carried out this policy. Nonetheless, the review and discussion of policy changes in the delivery of citizenship studies in Israel in itself does not answer the question of whether the inculcation of democratic values does indeed have an 'immunising' effect on Israeli society. In order to address this question, quantitative tools of research were necessary, specifically a closedquestion survey which was administered to a large sample of secondary-school pupils in northern Israel. The object of this survey was to answer the question: to what degree does a relationship exist between the instruction in citizenship and the ensuing diversity of political attitudes and behaviours indicative of the internalisation or rejection of democratic values.

The study of the evolution of the 'pro-democratic civil society' in Israel was the most difficult assignment of all, especially because this phenomenon is a fairly recent development, the literature documenting it is inadequate and the ability to detect the groups comprising it is limited. In order to identify as many groups as possible, an extensive comparison of findings from a number of sources was conducted and a list was drawn up of the associations whose alleged goal was the empowerment of the democracy in Israel. These organisations were sent questionnaires designed to get a general impression of the "pro-democratic civil society', to examine the principal fields in which they were active, and to attempt an estimate of the degree to which these groups were successful in fulfilling their goals.

Throughout the book the findings of an additional survey are presented. 
This was a telephone survey conducted during February 2001 which included approximately 500 adult Israeli citizens. It examined the attitudes of the Israeli Jewish population in relation to the defence routes implemented by the State as well as the degree of consensus regarding particular routes. Therefore, the questionnaire includes reference to each cluster of types of response as they are demonstrated in the different parts of the book.

\section{NOTES}

1 John Stuart Mill, On Liberty (Indianapolis: Hackett, 1982).

2 Karl Popper, The Open Society and its Enemies (London: Routledge \& Kegan Paul, 1962), Vols 1, 2.

3 John Rawls, 'Liberty, Equality and Law', in Sterling M. McMurrin (ed.), The Tanner Lectures on Human Values (Cambridge: Cambridge University Press, 1987), pp. 1-87.

4 Piero Ignazi, 'Reaction to Thoughts by Giovanni Capoccia on Doctoral Research in Progress', ECPR News, 10:3 (1999), p. 39.

5 As far back as 1937, Loewenstein wrote two papers as a result of which the term 'militant democracy' became popular and laid the early foundations for the politicalinstitutional analysis of the democratic battle against fascism. See Karl Loewenstein, 'Militant Democracy and Fundamental Rights, I', American Political Science Review, 31:3 (1937), pp. 417-32 and, especially, Karl Lowenstein, 'Militant Democracy and Fundamental Rights, II', American Political Science Review, 31:4 (1937), pp. 638-58. Additional works by Loewenstein in which he developed the legal-judicial aspect: Karl Loewenstein, 'Legislative Control of Political Extremism in European Democracies, I', Columbia Law Review, 38 (1938), pp. 591-622; Karl Loewenstein, 'Legislative Control of Political Extremism in European Democracies, II', Columbia Law Review, 38 (1938), pp. 725-74. A significant elaboration of the discussion has been submitted by Capoccia who presents an exhaustive study of the various European countries' strategies for dealing with radical parties which took root during these years, and focuses on the successes and failures of the different countries in their confrontation with those parties. See Giovanni Capoccia, 'Defending Democracy: Reactions to Political Extremism in Inter-War Europe', European Journal of Political Research, 39:4 (2001).

6 For example: Peter Chalk, 'The Liberal Democratic Response to Terrorism', Terrorism and Political Violence, 7:4 (1995), pp. 10-44; Raphael Cohen-Almagor, 'Combating RightWing Political Extremism in Israel: Critical Appraisal', Terrorism and Political Violence, 9:4 (1997), pp. 82-105; Ronald D. Crelinsten and Alex P. Schmid, 'Western Responses to Terrorism: A Twenty-Five Year Balance Sheet', Terrorism and Political Violence, 4:4 (1992), pp. 307-40; Giovanni Capoccia, 'Repression, Incorporation, Lustration, Education: How Democracies React to Their Enemies. Towards a Theoretical Framework for the Comparative Analysis of Defense of Democracy', paper presented at the ECPR Joint Sessions of Workshops, Grenoble, 6-11 April 2001.

7 See note 5 above.

8 Raphael Cohen-Almagor, The Boundaries of Liberty and Tolerance in the Struggle Against Kahanism in Israel (Gainesville: University of Florida Press, 1994), p. 184.

9 Quoted in Hucko M. Elmar, The Democratic Tradition: Four German Constitutions (Leamington: Berg Publishers, 1987), p. 75.

10 Cohen-Almagor, The Boundaries of Liberty and Tolerance, p. 184.

11 Cohen-Almagor, The Boundaries of Liberty and Tolerance, p. 183. 


\section{Introduction}

12 Dan Horowitz and Moshe Lissak, Trouble in Utopia: The Overburdened Polity in Israel (Tel-Aviv: Am-Oved, 1990), p. 197 (Hebrew).

13 For more details about ideal type analysis please refer to: B. Peters Guy, Comparative Politics: Theory and Methods (New York: New York University Press, 1998), pp. 105-7.

14 An extensive discussion of this term can be found in Menahem Hofnung, Israel - State Security vs. Rule of Law, 1948-1991 (Jerusalem: Nevo, 1991), pp. 11-20 (Hebrew). In order to distinguish between the militant and immunised models, it would be easier if we adopted the definition submitted by Amnon Rubinstein, according to which the meaning of the formal conception of the rule of law is that predetermined statutory provisions are responsible for dictating binding prohibitions and concessions. Accordingly, the rule of law stipulates three principal requirements: (1) that the law be applied; (2) that it be enforced by the public authorities; (3) that according to the law and the law alone, civil rights will be determined. However, with regard to the immunised model, there must be a more substantial interpretation of the rule of law, including three applicable principles: the right to equal protection before the law; the clarity of the law; and the public display of the law. See Amnon Rubinstein, The Constitutional Law/Legislation of the State of Israel (Jerusalem and Tel Aviv: Shoken Publishers, 1991), Vol. A, pp. 262, 272 (Hebrew). For an extensive discussion of the rule of law and its implications for the struggle against political extremism and violence, see chapter 2 .

15 Crelinsten and Schmid, 'Western Responses to Terrorism', pp. 334.

16 In Germany, for example, there is extensive public criticism of surveillance systems used by the Federal Bureau for Constitutional Protection (BfVS) against parties listed as constitutionally hostile. Although these steps in most cases receive constitutional endorsement and judiciary review, criticism has been aimed chiefly at the fact that employing undercover police against citizens may cause grave harm to the same liberties purportedly upheld by the democracy. For a more in-depth discussion, see Gillian More, 'Undercover Surveillance of the Republikaner Party: Protecting a Militant Democracy or Discrediting a Political Rival?', German Politics, 3:2 (1994), pp 284-92.

17 See, for example, László Szôcs, 'A Tale of the Unexpected: The Extreme Right vis-à-vis Democracy in Post-Communist Hungary', Ethnic and Racial Studies, 21:6 (1998), pp. 1096-115.

18 Uwe Backes and Cas Mudde, 'Germany: Extremism Without Successful Parties', Parliamentary Affairs, 53:3 (2000), pp. 457-68.

19 Yonatan Shapiro, Democracy in Israel (Ramat-Gan: Masada, 1977) (Hebrew).

20 Yoav Peled, 'Ethnic Democracy and the Legal Construction of Citizenship: Arab Citizens in the Jewish State', American Political Science Review, 86 (1992), pp. 432-43; Uri Ben-Eliezer, 'The Meaning of Political Participation in Non-Liberal Democracies', Comparative Politics, 25 (1993), pp. 397-409; Yael Yishai, 'The Guardian State: A Comparative Analysis of Interest Group Regulation', Governance: An International Journal of Policy and Administration, 11:2 (1998), pp. 153-76.

21 Ben-Eliezer, 'The Meaning of Political Participation in Non-Liberal Democracies'; Peled, 'Ethnic Democracy and the Legal Construction of Citizenship'; Yishai, 'The Guardian State'.

22 Benyamin Neuberger, Democracy in Israel: Origins and Development (Tel Aviv: Open University, 1998) (Hebrew).

23 Oren Yiftachel, Keeping a Watch Over the Vineyard (Tzofit: Research for the Study of Arab Society in Israel, 1997) (Hebrew).

24 Asad Ghanem, 'State and Minority in Israel: The Case of Ethnic State and the Predicament of its Minority', Ethnic and Racial Studies, 21:3 (1998), pp. 428-48. 
25 Sammy Smooha, 'Israel as an Ethnic Democracy: Jewish-Democratic State', in Sarah Ozacky-Lazar, Asad Ghanem and Ilan Pappe (eds), Seven Roads: Theoretical Options for the Arabs in Israel (Givat Haviva: Jewish-Arab Centre for Peace, 1999), p. 24. (Bracketed explanations are mine.)

26 Gad Barzilai and Ephraim Yuchtman-Yaar, The Israeli Supreme Court and the Israeli Public (Tel-Aviv: Papyrus Tel-Aviv University, 1994), p. 87 (Hebrew).

27 Orit Ichilov, Citizenship Education in Israel: Current and Pre-State Trends of Development (Tel Aviv: Sifriat Poalim, 1993), pp. 91-4 (Hebrew).

28 'Statehood' was an ethos, the purpose of which was to grant legitimacy to the consolidation of the country's sovereignty following the events of 1948. The statehood perspective indicated a transition from sectoral interests to general interests, from semivoluntarism to total commitment, from a foreign government to political sovereignty (Peled, 'Ethnic Democracy and the Legal Construction of Citizenship'). Further elaboration on the 'statehood' era can be found in Peter Y. Medding, The Founding of Israeli Democracy (New York: Oxford University Press, 1990).

29 Benyamin Gidron, Non-Profit Organisations in Israel - 1991 (Jerusalem: Central Bureau of Statistics, 1996), pp. 22-3 (Hebrew).

30 Yitzhak Galnoor, 'The Israeli Democracy and Electoral Participation', Molad, 41 (1982), pp. 71-87 (Hebrew).

31 Yael Yishai, 'Civil Society in Transition: Interest Politics', Annals of the American Academy of Political and Social Science, 555 (1998), pp. 147-62.

32 Ehud Sprinzak, Brother Against Brother: Violence and Extremism in Israeli Politics from Altalena to the Rabin Assassination (New York: Free Press, 1999), p. 320.

33 Isser Harel, The Truth about the Käsztner Murder (Jerusalem: Edanim Publishers-Yediot Aharonot, 1985) (Hebrew).

34 Ehud Sprinzak, 'Extremism and Violence in Israel: The Crisis of Messianic Politics', Annals of the American Academy of Political and Social Science, 555 (1998), pp. 114-26.

35 Carmi Gillon, Shin-Beth Between the Schisms (Tel-Aviv: Yediot Aharonot Books and Chemed Books, 2000) (Hebrew).

36 Sprinzak, Brother Against Brother, chs 1 and 2.

37 Sam Lihman-Wilzig, Public Protest in Israel, 1949-1992 (Ramat Gan: Bar-Ilan University Publications, 1992), pp. 57-60 (Hebrew).

38 Ehud Sprinzak, The Ascendance of Israel's Radical Right (New York: Oxford University Press, 1991), p. 43-51.

39 Sprinzak, The Ascendance of Israel's Radical Right, pp. 32-4.

40 Sprinzak, Brother Against Brother, pp. 87-94.

41 Sprinzak, Brother Against Brother.

42 Binyamin Neuberger, Religion, State and Politics (Tel-Aviv: Open University Press, 1994), p. 20 (Hebrew).

43 Menachem Friedman, The Haredi Society: Origins, Trends and Processes (Jerusalem: Jerusalem Institute for Israeli Studies, 1991) p. 19 (Hebrew).

44 Friedman, The Haredi Society; Binyamin Neuberger, 'Religion and the State of Israel: Comparative, Historical and Ideological Background', in Binyamin Neuberger (ed.), Religion, State and Politics (Tel Aviv: Open University Press, 1994), pp. 7-52 (Hebrew); Yishayahu Leibman, 'Some Thoughts on the Relations Between Religious and Non-Religious Jews', in Yishayahu Liebman (ed.), Living Together (Jerusalem: Keter, 1990) pp. 187-200 (Hebrew); Eliezer Don Yehia, The Politics of Arrangement: Settling Conflicts on Questions of Religion and State (Florisheimer Institute for Policy Studies, 1997) (Hebrew).

45 Yishayahu Leibman, 'Religion and State in Israel', Zmanim, 50-1 (1994), pp. 13344; Yair Sheleg, The New Religious: A Current Perspective of Religious Society in Israel 


\section{Introduction}

(Jerusalem: Keter, 2000) (Hebrew); Yishayahu Liebman, 'Religion and Democracy in Israel', in Ehud Sprinzak and Larry Diamond (eds), Israeli Democracy Under Stress (Boulder, CO: Lynne Rienner Publishers, 1993), pp. 273-92.

46 Ephraim Yuchtman-Yaar and Tamar Hermann, 'The Latitude of Acceptance: Israeli Attitudes toward Political Protest Before and After the Assassination of Yitzhak Rabin', Journal of Conflict Resolution, 7:6 (1998), pp. 721-43.

47 Ilan Shahar, Haredim LTD (Jerusalem: Keter, 2000) (Hebrew).

48 Sprinzak, 'Extremism and Violence in Israel', p. 119. 


\section{The Israeli response to extremism: the parliamentary arena}

\footnotetext{
$\mathrm{F}$
} ROM THE START of the twentieth century, the political party became a pivotal institution in politics. The decline of the elite party model and the ascendance of the mass party model changed the structure of political procedure in many European countries; it afforded representation to groups previously deprived of political power and promoted the democratisation processes of many systems of contemporary governance. ${ }^{1}$ However, along with the expansion of the mass party model, another type of political party took root. The effect on European politics of this new type, and especially on the processes of democratisation, turned out to be significantly less constructive. Political scientists called this a devotee party ${ }^{2}$ and its main features included mobilisation around extremist ideologies, chiefly communism and fascism, and the unconditional commitment of party members to the partisan apparatus and often to the leader as well. By means of devotee parties, fascist and communist ideologies succeeded in changing human history in the first half of the twentieth century, often leading countries far astray from any democratic framework. In consequence, Western countries in the post-Second World War era became somewhat apprehensive of the party institution and tended to look upon these extremist parties as a substantial threat to democracy. ${ }^{3}$ A review of the German Basic Law drafted in the wake of the war confirms this apprehensiveness over the potential threat of radical parties and the democracy's efforts to defend itself in the face of this threat. Section 21 of the Basic Law (Political Parties) states:

1 The political parties shall participate in the forming of the political will of the people. They may be freely established. Their internal organisation must conform to democratic principles. They must publicly account for the sources and use of their funds and for their assets.

2 Parties which, by reason of their aims or the behaviour of their adherents, seek to impair or abolish the free democratic basic order or to endanger the existence 
of the Federal Republic of Germany, shall be unconstitutional. The Federal Constitutional Court shall decide on the question of unconstitutionality.

3 Details shall be regulated by federal laws. ${ }^{4}$

This section of the constitution does not leave much room for doubt that the German democracy chose to keep a close guard on political parties emerging in post-war Germany. Its intention was to prevent the recurrence or reappearance of anti-democratic parties that had abused the tools provided by the democratic system in order to undermine those very same foundations.

However, not only were constitutional restrictions imposed on parties structural restraints were also used. The electoral system designed at the end of Second World War clearly indicates a preference for the principle of stability over that of representation. The likelihood of small parties being able to penetrate the German Parliament is minimal, due to the required 5 per cent minimum threshold vote of all the valid ballots cast, or, alternatively, a mandatory victory in at least three of the electorate's regions. A retrospective glance demonstrates that the combination of these stringent structural and constitutional barriers has helped Germany forestall representation of extremist parties at the federal Parliament level over the course of years and, in turn, has also helped stabilise the democratic system.

\section{The socio-political underpinnings of the response to extremism in Israel}

Both prior to the establishment of the State of Israel and in the years following, the party institution constituted a pivotal factor in the political processes involved in the nation's construction. However, the role of the Israeli political party went far beyond the boundaries of Parliament. Political parties took part in policy-making and security, in school and youth movement education, religion and culture, agriculture and settlement, health and welfare, ${ }^{5}$ and, in this fashion, in effect held sway over state institutions on the one hand and social institutions on the other. The significant power held by Israeli parties gave the State the name parteienstaat (party state). ${ }^{6}$

Unlike the countries of Western Europe, which were then searching for ways to defend themselves from certain types of political party, the situation in Israel in the 1950s and at the beginning of the 1960s was completely different. Despite the depth of the ideological cleavages dividing the various political factions, all parties, except Maki (the Communist Party) and the ultra-orthodox parties, were wholeheartedly committed to the Zionist and 'statist' ideal. Furthermore, the predominance of the Mapai (acronym in Hebrew for 'Party of the Workers of the Land of Israel', which eventually became the Labour Party) in 
the first decades of the State's existence, which had control of Parliament as well as over the majority of state institutions, did not leave much room for any kind of genuine challenge by the opposition parties.

However, the Israeli political system was designed in a fashion that in fact emphasised the principle of representation, thus encouraging small parties to take part in elections to the Knesset. After the founding of the State, Israel promptly adopted the 'proportional' representation electoral system and placed the qualifying threshold of entrance to the Knesset (consisting of 120 members) at only 1 per cent of all the valid ballots. ${ }^{7}$ As a result, no less than twelve parties gained representation in the first Knesset, and since then, throughout Israeli parliamentary history, the number of parties in the House of Legislature has never dropped below ten, and in certain instances even reached a high of fifteen. ${ }^{8}$ The emergent electoral structure in Israel became one of the central issues on the State's agenda for a long while and in fact underwent a number of reforms. True, the fear of extremist parties was not the immediate concern guiding these reforms, yet some already saw in the emerging electoral conditions a potentially destabilising factor with regard to the democratic polity in Israel. $^{9}$

In the view put forward by Doron and Maor, despite the low threshold required for becoming a member of the Knesset, there were during Israel's early years other barriers restricting admittance to Parliament which had a role in fortifying the polity's stability. These 'barriers of de-legitimisation' prevented those parties remaining outside the Mapai-galvanised consensus from gaining access to positions of power. Prime Minister Ben-Gurion took advantage of his (and his party's) substantial power in order to dictate the political groundrules. He determined that all parties were entitled to take part in elections to the Knesset; however, not all of them were eligible to be partners in a coalition government. In this fashion, Ben-Gurion spearheaded a process of de-legitimisation which prevented the rightist Herut movement led by Menachem Begin, on the one hand, and the Communist Party, on the other, from becoming coalition partners for many years. ${ }^{10}$ Of course, this was an unofficial rule, which relied basically on Ben-Gurion's powerful role as the first prime minister of Israel; indeed, with the growing institutionalisation of the Israeli political system - a factor that steadily made inroads into the hegemony of the Labour Movement elite - the ability of that same movement to install such political barriers became increasingly undermined. ${ }^{11}$ Subsequently, in 1965 , and only seventeen years after its declaration of independence, the State of Israel was obliged to confront the question of depriving a political party of the right to run for office. The case in point was the rejection of the 'Socialist List's' candidacy for the sixth Knesset elections. 


\section{Disqualifying the 'Socialist List': predominance of the 'militant route'}

The 'Socialist List', principally a left-wing Arab list, displayed a programme based on the premisses of its predecessor Al-Ard, which was dismantled according to Section 84 of the Defence Regulations (Emergency), 1945. Although it did not constitute a substantial threat to Israel's security, the 'Socialist List's' programme conveyed a message contesting the Jewish character of the State. This fact provided the chair of the Central Elections Committee, Justice Landau, with cause for disqualifying the party from running for Parliament, on the grounds that it seemed inappropriate for a democracy to provide its adversaries with the means to destroy it. ${ }^{12}$ The significance of disqualification at that time was embedded in the fact that Israel had in effect adopted a severe 'militant' model which substantially impaired its democratic foundations. This argument is supported by two considerations.

First, in its decision to disqualify the 'Socialist List', Israel was not acting in the interests of democracy but rather against it: the 'Socialist List's' programme did not subscribe to the undermining of the country's democratic foundations. On the contrary, it petitioned against the Jewish character of the State, although its chances of being elected to parliament - not to speak of acquiring any political thrust - were altogether minimal. In spite of these extenuating circumstances, the State chose to block it from taking part in the elections and by this move essentially thwarted a basic democratic liberty.

The second factor is that the State at that time possessed neither the constitutional nor the legislative measures for the disqualification of political parties. Therefore, the Central Elections Committee (CEC) decision was based on an extension of the Elections Law and the Knesset Basic Law and mainly on the ground that these laws held an implied provision according to which an association already found to be illegal could be forbidden to stand for elections to the Knesset.

The CEC resolution on this matter was endorsed by the Supreme Court of Justice which, by a majority of two justices to one, weighed in favour of ratifying the List's disqualification. The grounds for this ruling, according to most of the justices, was that the character of the 'Socialist List' stood in stark contrast to election goals. An interesting point is that Justice Shimon Agranat, president of the Supreme Court at the time, ruled that the list contested the very existence of the State. The State's existence, its continuity and future, in his view, were closely linked to its Jewish character, thus implying that a list whose programme embraced a disputation of the State's Jewish character should not be allowed to stand for Parliament. ${ }^{13}$

Surprisingly, it was in fact during the Supreme Court debate on the disqualification of the 'Socialist List' that Justice Zusman chose to define the 
State of Israel as a 'defending democracy', thus drawing a comparison with Germany's post-Second World War efforts at safeguarding itself from any party whose programme was in defiance of the democratic nature of the government. ${ }^{14}$ This issue brings into sharper relief the problematic nature of the nonliberal character of the Israeli democracy and is an indication of how difficult it is to bridge between the ethno-nationalist and the democratic principles on which the polity was founded. That said, and despite the 'militant' step taken by Israel with regard to the 'Socialist List', a point meriting attention is that in the wake of this resolution, and even after the State in fact did possess the legislative means to disqualify parties challenging the Jewish character of the State, not one list has ever been disqualified on that basis. ${ }^{15}$

\section{Attitudes to far-right parties: between the 'militant' and the 'immunised' route}

Between the years 1965 and 1981, the State of Israel endured events that would leave very strong impressions and deep scars. This chain of events began with Israel's victory in the Six-Day War, carried on with the trauma of the Yom Kippur War and its ensuing social crises and eventually culminated in the 1977 parliamentary upset, when, for the first time in Israeli history, the Likud (an alliance of right-wing parties with the Herut at its forefront) was successful in superseding the Labour Party as the party in control of government. During the course of those years, the need for party disqualification did not arise. However, the profound changes that Israeli society went through prepared the ground for political extremism. In the long run, this led the country into confrontation with a racist and anti-democratic party that declared its intentions to essentially change the State's character by abolishing democracy, deporting its Arab citizens and establishing a Jewish theocracy. The advocate of such a programme was Kach, led by Rabbi Meir Kahane.

\section{Kach and Israeli politics - the early years}

Meir Kahane, leader of the militant Jewish Defence League in the United States, emigrated to Israel in September of 1971 and brought with him a new rhetoric and violent political style previously unknown to Israeli society or political life. Upon his arrival in Israel he declared that it was not his intention to become involved in Israeli politics, but rather that he would like to devote his time to education. However, one month later, a change in the rabbi's plans became evident. ${ }^{16}$ Kahane rented an office in Jerusalem and initiated the formalities necessary to allow the Jewish Defence League to operate in Israel. ${ }^{17}$

At that time, the Israeli political establishment did not consider Kahane as a threat of any kind. In fact, the opposite was true: Kahane came over as a 
warrior liberated from the 'Jewish ghetto mentality' image of Jews in the Diaspora. The violent actions for which he and his followers were noted in the US were carried out in the defence of and for the guardianship of Jews, as he vehemently declared. Most of the appreciation for his deeds came from Israeli right-wing and religious circles. However, once he began an attempt to enter the political system, neither rightist nor religious parties wanted to integrate him with one of the existing frameworks. This forced him to concentrate on launching an independent organisation much like the one he had led in the United States; indeed, the first period of Kahane's efforts in Israel appeared to be a direct sequel to the labours of the Jewish Defence League. At first, the rabbi-leader and his supporters mounted demonstrations against the Soviet government and began to wage war against Christian proselytism and the 'Black Hebrews' of Dimona. However, in August 1972, Kahane redirected the goals of his organisation to concentrate on the group which would eventually become the principal object of his 'attentions' - the Arabs. That same year, he launched an operation entitled 'The Arabs Don't Belong Here, They Must Go'. The goal of this operation was to encourage Arab emigration in exchange for property remuneration. According to Kahane, the deportation of Arabs was the only feasible course towards a genuine resolution for the future of the Jewish nation. In his view, two nations could not occupy the same land. ${ }^{18}$

In December 1972, his fledgling party decided to participate in the elections for the eighth Knesset. The timing was fairly on target, because Jewish ethnocentrism in Israel had surfaced sufficiently for Kach to chalk up 12,811 votes which constituted 0.81 per cent of all the valid ballots cast. However, it was not enough merely to cross the threshold. Kahane and membership in the Knesset were still separated by a small percentage. ${ }^{19}$ In the 1977 elections, Kahane once again registered his List, but this time results were significantly weaker. He thereupon preferred to dedicate his time to writing and publishing his ideas and devising grandiose schemes on the subject of the salvation of Israel, while at the same time his followers took sporadic action against the Arabs.

The State of Israel, which reacted to Kahane's extra-parliamentary activities in those years with a variety of measures (elaborated on in chapter 2), ignored the fact that, concurrent with these repeated acts of provocation, a persistent political apparatus remained in operation and continued to run in every subsequent election year for the Knesset. A main reason for the country's lack of concern was perhaps due to the low percentage of support for Kahane in the ninth Knesset elections in 1977. In addition, Kahane was not successfully integrated with Israeli society, nor was he able to mobilise an adequate supporting public, and so, while he was assigned the image of a violent and dangerous political activist in terms of his extra-parliamentary exploits, it was still believed that he had no real chance of being elected to the Knesset. 


\section{Elections to the tenth Knesset: 1981}

The turning-point indicating the crucial change in the Israeli establishment's attitude toward Kach came during May 1981, following the party's publication of a full-page advertisement in the widely circulated daily paper Maariv. Beneath the caption 'She is a Daughter of Israel. ${ }^{20}$ Perhaps Your Sister, Your Daughter or Granddaughter', the ad's text spelled out:

But are you sure that she will marry a Jew? Are you wondering? What a question! Well then, you are invited at nightfall to visit places such as Tiberias or Acre, Beit She'an or Nazareth Ilit, Haifa, Be'er Sheva or Dimona, Tel-Aviv or Jaffa and also the holy city of Jerusalem. You are invited to watch the Arabs roaming about the streets of Jewish cities in pursuit of the Daughters of Israel. Their pockets are overflowing with money because they do not serve in the IDF and while we are busy defending the homeland, they are intent upon making great profits. We have heard the wail of lamentation emitted from the hearts of Jewish parents whose daughters have fallen victim to Arab seductive wiles. They live together with the Arabs, they marry with the Arabs. Was it for this reason that the Jews of Morocco emigrated to Israel, as well as the Jews of Algiers, Libya, Tunisia, Egypt, Yemen, Iraq, Kurdistan, Syria and all the other ethnicities? Was it in order to assimilate and be defiled in, of all places, the holy land, that these good, warm Jews left the Diaspora? And who feels the pain of this abomination? That same prime minister and those same leaders of the country who cry out to the very heavens against assimilation abroad, yet fear to raise their voices against the plague of Jewish-Arab relations here in Israel, because these are our 'goyim' (gentiles) and in a 'democratic' country, it is forbidden to object to assimilation and uncleanliness ... We, the Rabbi Meir Kahane and the Kach Movement, will avenge the honour of the Daughters of Israel. With the help of G-d, upon our election to Knesset, we will propose a law that will put an end to the disgrace of our Nation and the breaking of the hearts of thousands of families in Israel: Draft law: 1. In order to put an end to the plague of assimilation spreading throughout the Land, we propose that the Ministry of Education initiate compulsory courses in schools all over the country regarding the distinctiveness of the People of Israel and forbidding the abomination of assimilation and communion with goyim. 2. In order to deter those that come to entice the Daughters of Israel to consort and assimilate, we propose an unconditional and mandatory prison sentence of five years with no chance of commuting neither [sic] the verdict nor [sic] the term of imprisonment for every Arab who has sexual relations with a Jewish woman. 3. In order to reduce the possibility of commingling and assimilation, we propose that all members of the United Nation Forces who are not filling a direct order be restricted to their bases and be ordered by their commanders not to engage in any type of relations with the Jewish population. The same edict goes for the nonJewish foreign workers residing in Israel ... In order to prevent a perpetuation of the deterioration, we demand to put an end to all the Ministry of Education's plans encouraging social relations between non-Jews and Jews and to conduct studies only in separate schools for Jews and Arabs. And this is only the beginning. For, it is evident that the genuine solution is the Kach programme to compel the Arabs of 
the Land of Israel to emigrate to their countries. Is there any other list running for Knesset which possesses the strength and courage to declare such words? If you wish for Jewish representatives in Knesset to propose such a bill - vote Kach. This time - Rabbi Kahane. ${ }^{21}$

This notice, which expressed severe racism, blatant anti-democratic views and populist rhetoric, had an immediate public effect. Political parties, 'civil society' organisations and individual citizens appealed to the Central Elections Committee demanding that the Kach list be disqualified from taking part in the elections to the tenth Knesset scheduled to take place that same year.

In the wake of the surge of appeals which flooded his office, the chairman of the CEC, Justice Dr Moshe Etzioni, decided to raise before the Committee the question of Kach's qualification to take part in the elections. Dr Etzioni's statements regarding this issue revealed open discomfort because there was no law giving the Committee the authority to disqualify a political party from running in the elections on the basis of its programme. Instead, he therefore had to rely on the precedent of the disqualification of the 'Socialist List', as well as the fact that Kach ideology stood in stark contradiction to the norms established by the State of Israel's Proclamation of Independence, stipulating full and equal social and political rights for all its citizens without difference of religion, race or gender, and, finally, on Israel's commitment to remain loyal to the principles of the United Nations Charter. ${ }^{22}$

Although shocked at how the guiding principles of the Kach Movement indeed violated the State of Israel's Proclamation of Independence, Justice Etzioni was appalled, it seems, by the 'Nazi' style of Kach propaganda, as he himself described it. In his view, the advertisement implied that the Kach list wished to introduce the Nüremberg Laws to the State of Israel. Etzioni, who was well aware of the difficulty of disqualifying a political party in the absence of the explicit stipulations of a law, was required to use, according to Justice Vitkon's precedent verdict which stated:

No free system of government will give a hand to, nor acknowledge, a movement seeking to undermine this same polity, for it happened not only once in the chronicles of certain countries headed by functioning democratic systems of governance, that various fascist and totalitarian movements rose against them - while using those same rights of freedom of speech, press and assembly granted by the state in order to engage in destructive action under the patronage of these rights. Those who have witnessed such a thing in the days of the Weimar Republic will never forget the lesson. ${ }^{23}$

With these words, Etzioni tried to find historical as well as ethical justification for banning Kach from competing in the elections. However, in view of the constitutional implications resulting from a ruling which disqualifies a party from taking part in the elections in the absence of legislative substantiation, the 
chairman of the CEC allowed Kach representatives enough time to prepare their defence, including submitting a plea to the Supreme Court of Justice. Members of Kach, who reported to the Committee in compliance with Etzioni's summons, were very surprised to hear that banning their list from the elections to Knesset had been proposed. CEC session protocols reveal that representatives of the Kach List had not realised that the danger of disqualification hovered over their movement and accordingly were unprepared for debate on this subject. Further evidence of Kach's complacency in this regard can be found in the fact that Kahane himself did not attend the hearing, and in fact did not send any legal representative on his behalf.

The hearing itself focused principally on the notice published by the party in the newspapers and its election platform. Among the profusion of ideas presented there was a paragraph that advocated acts of terrorism against Arabs. The thrust of the Kach representative's efforts to defend their party platform was based on the argument that contrary to the Al-Ard group, which campaigned under the banner of the destruction of the State of Israel, their own party strove to sustain, defend and build up the Jewish land of Israel. As had Justice Etzioni, the Kach defence turned to the Proclamation of Independence in order to find justification for their ideology. The party advisor specifically referred to the section in the Proclamation establishing that the State of Israel was to be founded on the fundamentals of liberty, justice and peace, in reference to the visions of the Prophets of Israel. The Kach interpretation of the prophecies was that they emphasised the need to prevent assimilation and to build up a state which in essence was Jewish. However, the Kach's members did not rest their case only on the Proclamation of Independence. They also turned to Israeli matrimonial law which, because it is anchored in Halakhic law, does not in effect acknowledge the legality of marriages between Jews and non-Jews, and that made the law a principle conforming to Kach tenets. Party representatives summed up their arguments by saying that if their list was to be labelled as racist then they were glad to accept this. However, in their view, the meaning of racism here did not indicate the Nüremberg Laws or South Africa's apartheid but rather guaranteed the Jewish essence as well as the protection of the Jewish people and the Jewish State. ${ }^{24}$

Ultimately, and mostly because the lack of a legal reference, members of the CEC chose to avoid disqualifying Kach, and with a majority of 14 to 5, the proposal was dropped from the agenda. ${ }^{25}$ Even efforts by journalist Moshe Negbi to prevent Kach from taking part in the elections by appealing to the Supreme Court of Justice were unsuccessful. The Court refrained from conducting a hearing on the details of this affair on the technical ground that only a list which had been disqualified from running in the elections had the right to appeal against its disqualification, whereas, in this case, the Kach List had been 
approved and therefore there was no basis for Court intervention in this matter. $^{26}$

The State's moderate attitude toward the Kach Movement at that time was somewhat surprising due to the considerable importance attributed by the authorities to this party in comparison to its handling of the 'Socialist List'. However, a liberal attitude and adherence to the law were not the only factors which prompted members of the CEC to block Etzioni's attempt to disqualify Kach. Careful scrutiny of the protocols of the hearings leading to this decision shows that several CEC members in fact wrestled with issues such as the freedom of expression, the legal jurisdiction of the CEC, and even with the tension between the principle of representation and the democracy's stability. However, other members, mostly those from the religious and ultra-orthodox lists, rose up against Etzioni's disqualification proposal. This was because they identified, in varying degrees, with elements of Kahane's programme, particularly regarding the issue of assimilation, and feared that the identification of Kach publications as 'racist' would malign the ideas accepted by major parts of their electorate.

The Mafdal's representative on the Committee, Tzvi Bernstein, illustrated the stand taken by the religious lists in the most distinct fashion:

The Kach publication speaks of what they have to offer if they will be in the Knesset, if the law is passed by a Knesset majority ... So, everything is kosher and nothing can be claimed against them and it does not go against the constitution. If the law is not passed then I haven't heard that if people want to pass a law through legal channels, they will be disqualified . . The main motif is the issue of assimilation mixed marriages. Although Kach is in competition with the Mafdal, we agree that the State should take steps to prevent assimilation ... It is legitimate to want the expulsion of Arabs or the attempt to motivate them to emigrate from this country but [it must be done] in a way that does not worsen the relations between the two nations in this country. ${ }^{27}$

Despite what these words indicate, it is highly likely that the decision allowing Kach to compete in the elections was based on reasons which do not all come from the desire to empower the democratic foundations of the State of Israel. Still, consequences prove that, to a significant degree, the State decided on a very restrained response with regard to this party and avoided 'militant' steps which might have led to the erosion of democratic principles.

However, as elections to the eleventh Knesset in 1984 approached, the situation changed completely. Kahane, who utterly failed in the tenth Knesset elections and won only 5,128 votes, which constituted 0.3 per cent of the valid votes, was much better prepared in 1984 and public empathy with him was on the rise. For the first time in the history of this country, a genuine possibility existed that a racist party would penetrate the halls of the House of Legislatures. 


\section{Elections to the eleventh Knesset - 1984}

Justice Gabriel Bach, chairman of the eleventh Knesset CEC, whose desk was flooded with requests for the disqualification of Kach and other parties as well especially the 'Progressive List for Peace', a nationalist Arab party headed by Mohammed Miari - knew, like his predecessors, that a sensitive and highly explosive state of affairs awaited him. Already in his opening statements before the CEC, he spoke of the great difficulties encountered by the democratic polity in seeking to limit the rights of its citizens in elections to political office. Furthermore, the problem was aggravated many times over when there was no clear legal provision in regard to the procedure for disqualification of political parties.

Nevertheless, and despite the constitutional and moral complexities with which he had to contend, Bach explained to the members of the CEC that, in view of the gravity of the evidence found against Kahane and his movement, it seemed, even in the absence of a specific law detailing the proscription of certain parties from taking part in the elections, that the essence of Israeli law and the fact that there were substantial restrictions on various forms of assembly in fact indicated that Israeli democracy did not tolerate undemocratic organisations whether they are extra-parliamentary or political parties. ${ }^{28}$

Quite unlike the session that was conducted in the CEC plenum for the tenth Knesset, the meeting that took place this time was more comprehensive and profound. This was to a large degree due to the fact that during the years since the previous session, a great deal of evidence had been gathered regarding Kach's programme and its leader's declarations. Kahane's own provocative appearance in front of members of the Committee did not help him gain their support. Kahane reiterated his racist teachings and his views challenging the democratic nature of the State, and in this fashion provoked the anger of many of those present. As in the previous circumstances, in this session, too, it appeared that the position of members of the Committee toward Kahane was based ultimately on their political persuasion. While representatives of left-wing parties sharply rebuked Kach and urged its immediate disqualification, the right-wing and Haredi factions tried to moderate the tone of the stance taken against Rabbi Kahane.

One of the more compelling issues raised during the session addressed the very heart and core of the notion of the 'Jewish ethnic democracy'. Contrary to liberal democracies that take care to sidestep issues pertaining to the private domain, such as matrimonial matters, the State of Israel not only defines how a Jew is to marry and to whom, it actually exhorts against intermarriage between Jews and non-Jews. The strong words of persuasion delivered by many CEC members about how assimilation is forbidden and dangerous were successful in dampening, to a certain extent, the earlier perceptions of the 'racist' 
character of Kach's political programme. Committee member Yehuda Elinson, of the Mafdal, expressed his sentiments most explicitly:

I would not have believed that during my lifetime in the State of Israel there would be talk in favour of assimilation. The Israeli people spend billions against assimilation all over the world and here we are presented with an advertisement, what does it say here, that a Jew should not marry an Arab. What are we talking about here? So this is called fascist... Is this racism? The Jewish Nation loses on a daily basis hundreds and thousands of the people of Israel because of assimilation. Do you want this also here in Israel? What are you rising up against? Is this fascism? Is this Nazism ${ }^{29}$

These words are once again evidence of the underlying values contributed by the non-liberal democracy to the growth of ethnocentrism and racism, and also of how difficult it is to confront these phenomena in the context of a country whose liberal components are weaker than its nationalist components.

The appearance of Rabbi Kahane himself was the provocative event that forestalled discussion of the key principles of the affinity between the State of Israel and the ways of the Jewish people and brought the debate back to the future of his party. Kahane did not spare the members of the Committee and, for the most part, candidly displayed for them the principles of his political doctrine. First, he declared that if elected to the Knesset, he would act quickly to pass a law the goal of which would be to deprive the Arabs of their Israeli citizenship and then embark upon the immediate expulsion of those who would resist giving up their citizenship, all of this in order to preserve the Jewish character of the State. ${ }^{30}$ Second, with regard to the accusations made against his racist propaganda, Kahane attempted to mobilise the support of the traditional and religious members of the Committee and therefore argued that his position on the issue was rooted in the Jewish scriptures, and the Jewish scriptures alone, which stressed the importance of maintaining the unique essence of the Jewish people. $^{31}$

Several members of the Committee presented tough and trying deliberations regarding the question of whether it was fitting to deny Kahane the opportunity to express his views in the Knesset - particularly providing for the situation in which they were not at all sure if they were authorised to prevent his candidacy. Yet it appears that Kahane's appearance before the CEC had a sobering effect on most of the members. Thus, in contrast to the position taken by members of the CEC for the tenth Knesset, which established that the Kach List should not be disqualified from running in the elections, members of the CEC for the eleventh Knesset agreed to the disqualification by a majority of 18 to 10 , with 7 abstentions. ${ }^{32}$

The letter written by the CEC chairman to Moshe Neiman, the Kach representative, included the following: 
I hereby inform you that in the session which took place on 17.6.1984, the Central Committee for the Elections to the 11th Knesset refused, by a clear majority, to approve your list, the Kach list, on the grounds that this list espouses racist and antidemocratic principles which stand in contradiction to the Proclamation of the Independence of the State of Israel, openly supports acts of terror, attempts to stir up hatred and hostility among different sectors of the population in Israel, intends to cause offence to the feelings and religious values of a part of the country's citizens, and whose goals include the negation of the core foundation of the democratic system of governance in Israel. Implementation of the principles of this list would constitute a threat both to the democratic polity in Israel and is also liable to give cause to the breakdown of public order. ${ }^{33}$

However, the hard evidence associated with Kach's activities which had served as the occasion for the CEC to take the 'militant' step of denying a political party its right to participate in the elections was not enough to persuade the justices of the Supreme Court. There, in response to Kach's appeal against its disqualification, a unanimous majority determined that the list must be allowed to take part in the elections. Four out of the five justices who sat in court called attention to the fact that the principal impediment in disqualifying Kach was the lack of a formal law authorising such a measure. The fifth justice, today's president of the Supreme Court, Aharon Barak - who was inclined to agree with the idea that the Court is qualified to adopt a creative approach under the special circumstances of the absence of a formal legislative provision - declared, in the same vein as his colleagues, that in such a decision it is preferable that there be a formal legislative basis. ${ }^{34}$

It can therefore be concluded that while the CEC opted for a 'militant' line of action, that is, it preferred to uphold Israeli democracy even if that meant executing measures whose legality was questionable, the Supreme Court favoured, in this case, the fundamental liberties imparted by the democracy to its citizens despite the fact that this move essentially condoned the parliamentary representation of a man who advocated racist and anti-democratic notions. Notwithstanding, the justices intimated to legislators that if there had been a law defining the limits of the tolerance of the Israeli democracy towards those intent on causing it harm, the Supreme Court would have seriously considered restricting Kahane's party from running in the elections.

And so, following an exceptionally provocative propaganda campaign, Meir Kahane was able to realise his dream and become a member of the Israeli Parliament. The number of voters casting their ballot for his party reached 25,907, thus granting him 1.2 per cent of the valid votes and enabling him to easily cross the minimum threshold of representation of the Israeli political system. Upon hearing the results of the elections, Kahane announced that he would not conform with the Knesset rules and that he would use his parliamentary immunity and the public platform now made available to him in order to champion 
the tenets of his party, his highest priority being the deportation of the Arabs from Israel.

The day after the elections, Kahane and his supporters launched their victory rally. They marched to the Western Wall in Jerusalem, purposely parading through the crowded market of the Moslem Quarter in the Old City and celebrating their triumph in the violent fashion typical of their mentor and rabbi. Brutally, they made their way through market alleys, upending vegetable stands, striking passing pedestrians and promising local residents that the programme intended to bring about their final removal from the holy land had indeed begun. ${ }^{35}$

\section{Kahane in the Knesset}

Much like the CEC and the Supreme Court, the Knesset was at a loss for democratic tools which would help it deal with the new and not exactly routine Member of Parliament. Therefore, the Israeli response to Kahane the MP in his first years inside the Knesset halls could be classified in terms of democratic criteria as 'militant', improvised and problematic, to say the least. Although elected according to the rules of law and he was now the representative of a political list in the legislature, the Knesset and other governmental authorities executed a number of actions against Kahane which had significantly limited his basic rights as a citizen and member of Knesset.

In the first stage, and as a consequence of the provocative actions instigated by Kahane in the Arab towns he visited shortly after his election, the Knesset, on the grounds of paragraph 9(a) of the Immunity of Knesset Members Act, had decided to restrict Kahane's immunity and prevent him from accessing certain places, primarily areas of Arab inhabitation. The decision handed down against Kahane won a majority both in the House Committee and in the House Plenum. In this case, unlike the examples presented later, Kahane did not appear before the Supreme Court of Justice and therefore the resolutions passed by the Knesset institutions did not undergo judicial review. However, apart from the restriction on Kahane's freedom of movement, results show that the decision was also problematic regarding the goals it had set for itself.

The Israeli Police, who were ordered to clamp down on Kahane's movements, prevented him from delivering a talk on 10 March 1985 at the University of Bar Ilan, an institution associated with the ideological school of religious Zionists. The explanation was that such a lecture would be very provocative and incite the Arab students. However, two weeks earlier, Kahane had been given the opportunity to lecture at the Hebrew University in Jerusalem where the percentage of Arabs was considerably higher. ${ }^{36}$ In general, the modus operandi preferred by Kahane was one of soapbox sermonising and, as far as he was concerned, giving up his provocative excursions to Arab towns was no great loss 
as long as he was able to speak in the peripheral Jewish towns where he enjoyed notable popularity. In fact, since first achieving parliamentary office and then later having his immunity restrained, the number of demonstrations organized by Kach had actually begun to grow and, by the same token, so did support for the leader and his party. In many cases, these rallies served as fertile ground for severe acts of incitement against Arabs and assisted in the sanctioning of terror against them. In a lecture given in Haifa, a city with a large resident Arab population, Kahane stated: 'No one can comprehend the soul of these animals [the Arabs], these cockroaches. We must slash their throats or throw them out. ${ }^{, 37}$ In consequence, we can easily classify the lifting of Kahane's immunity as a step corresponding to the 'militant' route of action. Yet, contrary to what would be expected from a decision to employ this course of action, and despite the State's forceful response to Kahane, its results were minor. For, this measure had little effect on his patterns of activity, on the incitement and violence aimed at the Arabs and on the swelling support for him and his views among the Israeli public.

Another illustration of the considerable restriction placed on Kahane's liberties was the Israeli Broadcast Authority's decision to censor his speeches and activities. The IBA 'News Forum' resolution, which was later authorised by the Authority's managing committee, ${ }^{38}$ determined that television broadcasts relating to Kahane would be limited to news items alone. The motive behind this decision was the inclination of the IBA - which at the time was a monopolistic state-run body encompassing all of the Israeli electronic media - to prevent Kahane from expressing his views and taking advantage of state-run media in order to recruit support for his views. The News Forum's closing statement established that the

screen and the microphone are not supposed to become a type of confrontation between the radical fringes. The new political scene imposes a great responsibility upon us ... [We believe] that everything should be caught on film and recorded; [but] not everything must go on the air. The standards of what ought to be broadcast should meet the criteria of the factual items printed on the front page of a newspaper. ${ }^{39}$

This decision carried the potential to cause fatal harm to Kahane's objectives. $\mathrm{He}$, like other politicians, communicated a great deal about his activities to the public via the media. Kahane realised the implications of this threat to his public campaigning and so put this 'improvised' ruling of the IBA's managing committee to the test of a Supreme Court appeal, and won. In this case, Justice Aharon Barak adopted an approach which safeguarded the freedom of expression and which essentially tried to stretch the boundaries of this freedom of expression as far as possible while restricting them only when there was evidence of the risk of genuine and grave harm to the public's safety. In his words: 
'The petitioners' views and opinions make me shudder with repulsion, but I insist on their right to be made public. This does not imply an endorsement of their opinions. In my view, they are anathema, but my ruling does give license to the petitioners' right to make these anathemas be heard provided they do not pose a threat to the public order. ${ }^{40}$ Justice Gabriel Bach took a more rigid position regarding the criteria for establishing freedom of expression, but at the same time agreed with his colleague that the IBA had exceeded its authority when it boycotted Kahane. ${ }^{41}$

In the months that followed, Kahane continued to test the boundaries of Israeli democracy and in doing so actually contributed to their demarcation. In practice, this meant a consistent and recurring process in which Kahane would first present a provocation to the Knesset institutions, to which the Knesset would in turn respond with 'improvised' measures. As a result, Kahane would appeal to the Court's legal judgment, and the Court would then evaluate the Knesset's authority to limit his liberties.

As he had pledged upon being elected to Knesset, Kahane attempted to exploit the advantages of his new position to the full in order to promote the interests of his party. That he became one of the most active Members of Parliament, as indicated by, inter alia, the number of speeches he delivered at the podium, his proposals for no-confidence motions against the government and the bills he sponsored which were loyal to his party's programme. As a parliamentary member Kahane's first truly significant clash with the Knesset's speaker came when the latter refused to allow him to submit no-confidence motions against the government on the grounds that Knesset members representing single-member factions were not at liberty to do so.

In the verdict handed down by the Supreme Court, Kahane's petition against the Knesset's speaker's decision was accepted in full. The court's ruling attests to the considerable complications involved in the type of procedure proposed by the speaker. Speaker Shlomo Hillel of the Labour Party did not attempt to remove Kahane's rights as an MP on the basis of his actions or views. Instead, he ventured to establish a general ruling regarding all single-member factions, because at that time Kahane represented such a faction. ${ }^{42}$ Apart from the fact that Knesset Regulations did not provide a basis for this kind of decision, had the ruling in fact been accepted, it would have turned out to be a problematic step in terms of democratic principles. The denial to smaller factions of the right to submit no-confidence motions essentially harms the legislature's ability to contain the executive's authority. As with the other measures mentioned above, this step also is evidence of the panic felt by those in Israel's political system over Kahane's election. It also shows the Knesset's speaker's readiness to violate basic democratic principles in the attempt to suppress Kahane's activities.

Another step taken by the speaker to restrain Kahane was the decision to prevent him from placing individually sponsored bills on the Knesset's speaker's 
desk. This decision was a direct outcome of Kahane's persistent efforts to advance bills which aimed at stripping Arab Israelis of their citizenship and promoting racial segregation between Jews and Arabs. In effect, the parliamentary speaker and his deputies were working to spare the Israeli Knesset from the great embarrassment which could follow a publicised parliamentary discussion on proposed laws of this type. The absence of clear-cut regulations defining the measures necessary to prevent an MP from proposing certain laws left the House Presidium with a solitary option, i.e. to appeal to an extended interpretation of the authorities vested in the speaker by Knesset Regulations.

Once again, the Supreme Court of Justice was faced with a democracy struggling to resist the most blatant form of racism and anti-democratic sentiment the country had known until then. However, the democracy attempted to protect itself with methods which greatly overstepped limitations that were specified and anchored in the law. Therefore, in this case as well, Kahane once again benefited from the Supreme Court's decree, which rebuked the extended authority that the Knesset Presidium had appropriated to itself. This position in effect proved to be a sequel to the 1984 verdict which allowed Kach to take part in the eleventh Knesset elections. The Supreme Court ruling stipulated that as long as a political party was deemed legal and qualified to run in the elections, then, by the same token by which it gained representation, it was thereby vested with the rights of a parliamentary faction, including the right to propose laws in accordance with its party platform. In the same way as in the question of the participation of a political party of this type, so too regarding its parliamentary activity, the Court ceded responsibility to the legislature. It established that in order to contend with parties in the judicial realm the Court should be able to rely on a legal framework appertaining to this issue. The legislature, which at this point was well aware of the potency of the Kahanist phenomenon and its implications, did not delay in adopting the Court's recommendation to modify Knesset Regulations in order to support the speaker in his struggle with Rabbi Kahane, MP. Accordingly, a large majority passed Article 134 of the Knesset's Regulations which stated that the Knesset's Presidium ${ }^{43}$ was authorised to rescind bills that included incitement to racism or an undermining of the democratic and Jewish principles of the country. ${ }^{44}$

Kahane opposed the Knesset's ruling and once again filed an appeal for assistance. He petitioned the Court to instruct the House Presidium to allow him to proceed with his law proposals. His argument this time was basically technical and focused on the fact that the new amendment to Knesset Regulations was introduced after the Supreme Court's earlier verdict requiring the speaker to allow Kahane to submit his bills to the House. However, in this particular event, the Court declined Kahane's plea and determined that in its earlier verdict it had not instructed the Knesset's speaker to allow Kahane's bills to reach the floor of the House. Rather it had cited the instance of the existing law and the fact that 
it was unfeasible to infer from that law the authority to prevent Kahane's proposals. ${ }^{45}$

This Supreme Court judgment reflected the change the judicial system had undergone in relation to Kahane's pleas as soon as it was vested with the lawful authority to limit his actions. Kahane did not acknowledge that change and continued to pursue Court assistance. In his third and final petition to the Supreme Court, he argued that the restrictions imposed on his actions as a Member of Parliament had to be anchored in the law and not only in Knesset Regulations. The president of the Supreme Court ruled in his verdict that the Regulations and the procedures were the very same rules that gave rise to a Knesset member's right to initiate new laws, and they also defined the boundaries of that right. The Court, as the words of the ruling disclose, can intervene only in exceptional cases where an essential flaw has been uncovered in the Regulations' provision - and those were not the present circumstances. ${ }^{46}$

In conclusion, despite the fact that its intention was to essentially restrict Kahane's freedom of expression and freedom of action, the modification of the Knesset's Regulations nevertheless prevented the general imposition of arbitrary restrictions on a Knesset member. Kahane's right to submit bills was not indiscriminately restricted but rather was placed under the review of the Knesset's Presidium, a body that largely represents the consensus of the legislature. Furthermore, Kahane still retained the right of appeal to the Supreme Court of Justice, to request that it determine the degree of lawfulness of each and every one of the Knesset Presidium's decisions. Therefore, the renunciation of 'improvised barriers' raised in response to a specific incident, and the eventual adoption of 'regulatory barriers' or 'legal barriers' which would help devise a framework and define clear-cut criteria regarding the response to extremist phenomena - all this can be seen as an important step in the State of Israel's movement in the direction of a more 'immunised' route.

\section{The amendment to the Basic Law: The Knesset}

A few months prior to the modification of the Knesset's Regulations, the House passed an even more fundamental resolution. This was the amendment to the Basic Law - The Knesset, where the aim was to prevent a recurrence of the Kahanist phenomenon in the Israeli Parliament. Kahane's conduct as a parliamentarian was a warning to Knesset members that the use of various 'improvised barriers' provided at most an isolated and ineffective treatment for a much more profound problem. Therefore, MPs were required to address the Supreme Court's distinct bidding to create a legal infrastructure that would provide a basis for Israeli judicial procedure with regard to racist and anti-democratic phenomena.

The Knesset chose two principal legislative courses in order to deal with the 
issue. The first, at the criminal level, was the amendment to the Penal Code dealing with incitement and its extension to include incitement to racism. ${ }^{47} \mathrm{The}$ second and more fundamental course was the amendment to the Basic Law The Knesset, restricting political parties from running for office.

The decision to institute a legal basis for the struggle against extremist parties was not an easy one for the majority of MPs, some of them Holocaust survivors. They found it difficult to deal with Kahane's actions - and with the notion that burgeoning within the Israeli legislature was a phenomenon that many tended to link to the darkest of political events of the twentieth century. The soul-searching shared by many members of the Israeli Parliament prior to the consolidation of the bill can be detected in the following statement, delivered by Moshe Nissim, the minister of justice:

We introduce this law symbolically, educationally, and not in order to solve a problem. The solid foundations of the struggle against such phenomena can be first of all found in education; through education, it is necessary to fight against any phenomena alien to the Israeli heritage. But, gentlemen, there is also a constitutional foundation. The importance of the constitutional foundation is basic to the democratic system of governance. When we prepared the bill called Basic Law The Knesset (amendment no. 12), we found ourselves accountable and took upon ourselves a weighty responsibility knowing that this kind of law is designed to deny people their basic right to submit a list to Knesset in order to take part in democratic elections and to be elected, and after all this is one of the mainstays of human rights in Israel. However, we nevertheless take upon ourselves the responsibility, knowingly and fully aware, because, despite the gravity of this law, its necessity prevails over its gravity. And as I have already noted, with open eyes we hold the view that there is cause for a number of constitutional dictates in the law books which will determine who will not be allowed to enter the House of Legislature in Israel. $^{48}$

Nissim's statement articulates an orientation which strives to strike a balance between the liberties guaranteed by the democracy on one hand and the safety of its existence on the other. His words reflect a holistic approach in the struggle against extremism and feature, for the first time, an Israeli parliamentary effort to choose a novel and more measured and balanced route in the war against extremism.

The law draft - as it was passed by the Knesset - also reflects the same standpoint: 'A list of candidates will not take part in the elections to the Knesset if their goals or actions include, explicitly or implicitly, one of the following: 1. The negation of the existence of the State of Israel as the state of the Jewish People; 2. The negation of the democratic character of the State; 3 . Incitement to racism. ${ }^{49}$ One of the prominent indications attesting to the restraint exercised in the legal amendment is its full subjection to judicial review. The justice minister's speech, prior to the passing of the law, sought to placate those who feared 
that the legal feasibility of disqualifying political parties would be exploited in the interest of certain elements. He therefore notified the Knesset that there were no grounds whatsoever to the fear of general arbitrariness, or the permeation of CEC decisions by partisan sentiment or politics on account of the provision included in the law enabling an immediate appeal to the Supreme Court concerning the Committee's decisions, and which in effect empowered the Supreme Court to overturn the disqualification procedure instated by the CEC. ${ }^{50}$

However, despite the overall cautionsness and the numerous checks and balances found in the legal wording, after the law's approval by the Knesset, a number of fundamental arguments were raised against it on different levels. The first criticism, stemming from an ethical perspective, was put forward by Peled, stating that the law clearly reflects the ethnic character of the Israeli democracy. Indeed, the phrasing of the law indicates that while attempting to defend democracy from its adversaries, at the same time it perpetuates the secondary status of the Arab minority in Israel and in fact entails restrictions of their basic liberties (article 1) ${ }^{51}$ Further reproach was issued by Barzilai, who argued that, in procedural terms, the broad scope for manoeuvre accorded to the CEC and the Supreme Court does not necessarily imply the empowerment or 'immunisation' of the democracy in Israel. In his opinion, the sweeping phrasing of article $7 \mathrm{a}$ enables, in principle, the disqualification of almost all political parties in Israel, and that decision can rest on each of the three provisions made by the law. ${ }^{52}$ Similar reservations were raised by Cohen-Almagor as well as Bendor, who stated that it was inappropriate that the first legal instance of the disqualification of political parties be conducted by the CEC, which is itself a political body and could turn out to be an arena for partisan attacks by one party on another. ${ }^{53}$

Although these reservations are understandable, even thought-provoking, a retrospective glance at the exercise of the law since its inauguration indicates that the gloomy forecasts about the amendment have, at least for the time being, been unfounded. First, and despite the fact that it appears to have indeed confirmed the ethnic character of the democracy in Israel, article 1 of the law, concerning goals or actions involving the negation of the existence of Israel as the State of the Jewish People - which could be applied to all of the Arab parties in Israel - has not once been enforced. Furthermore, the appeal submitted by the Likud faction against the CEC's ruling authorising the 'Progressive List for Peace' to take part in the twelfth elections to the Knesset in 1988 was rejected out of hand by the Court.

Second, actions taken by the State of Israel against the 'Socialist List' and Kach prior to the acceptance of the law's amendment were distinguished by 'militant'-type responses which embodied a very liberal conception of the 'rule of law', sufficient in fact, often to undermine it. Since 1985, a legal barrier has existed in Israel, reflecting a fairly broad consensus among the parliamentary 
factions, which defines the qualifications for the participation of a political party in an election campaign and also provides for continuous judicial accountability. Indeed, what goes for Arab parties goes also for Jewish extremist parties for, since the passing of the law, the rulings of the CEC as well as the Supreme Court have featured balanced and in-depth deliberations with a preference for democratic principles instead of entrenching parliament against extremist parties. The four elections to the Knesset that took place after the publication of article 1 demonstrate this more balanced approach while only the parties for which the law was designed, i.e. Kach and its derivative, Kahane Hai ('Kahane is Alive') were disqualified from competing, in accordance with the legislative directive. The conclusion to be drawn, therefore, is that despite the justified reservations voiced by those critical of the law, the events described in what follows show that the State of Israel and its various institutions have tended to make prudent use of this law, exercising restraint and deliberation. In effect, from the moment the law was passed, the State's tendency towards impromptu improvisation in its response to political parties turned into a thing of the past, another fact attesting to its process of 'immunisation'.

As a footnote to the discussion regarding article $7 \mathrm{a}$ of the Basic Law - The Knesset, it should be mentioned that during the debate preceding the legislation of the Basic Law amendment, a number of Knesset members offered to impose restrictions on extremist factions, not by dint of legal barriers but rather by structural changes in the parliamentary elections' process, and also by raising the threshold of representation that stood at a low 1 per cent of the sum of the valid votes. However, this issue was quickly struck from the agenda due to the fact that in the multi-party system typifying the Knesset the smaller factions, which possessed significant leverage because the coalition would often count on their support for its stability, adamantly refused any substantial change in the threshold percentage. ${ }^{54}$

\section{Elections to the twelfth Knesset: 1988}

Rabbi Kahane, who before the ratification of the amendment submitted provocative bills and gave troubling speeches before the Knesset and the public, did not change his tune even after the amendment's approval. Among the racist and belligerent law proposals that he placed on the Knesset's desk after the summer of 1985, note should be made of the 'three tolls bill' (1985) which rejected the civil status of Israeli Arabs and supported the forcible expulsion of those not willing to concede their civil rights. ${ }^{55}$ Also noteworthy is the death penalty for terrorists' bill (1987) which called for an immediate death sentence, without judicial deliberation, for every person who de facto murders, or attempts to murder, or is implicated in an act of murder or in an attempt to murder a resident of the State of Israel, or a Jew even if he or she is not a resident. ${ }^{56}$ 
The persistent Kach propaganda, the Party's proposed bills, Kahane's declarations to the media and from the Knesset's podium and the fact that public opinion polls at the time confirmed that the party was going to augment its parliamentary power by a few hundred per cent - according to some estimates, close to five seats in the Knesset ${ }^{57}$ - all of these in effect ruined Kach's chances of persuading the twelfth Knesset's CEC that it would be possible to usher in Kahane's party past the new-founded legislative filtering mechanism.

The party's efforts to bring before the CEC compelling arguments against the numerous appeals for its disqualification were futile. In reply to the allegation that it was undermining the State of Israel's democratic character, Kahane stated that 'democracy' was a broad concept and subject to many interpretations, and therefore his party must be regarded as a political body which in fact fully endorsed the notion of democracy. However, in this case what he was speaking of was a Judaistic democracy with a structural preference for members of that religion over those of other religions. In support of this claim, Kach's attorney provided several illustrations from other democratic countries which restricted citizenship rights for immigrants. Similar arguments were raised by the party with regard to their imputed racism. As Kach saw it, its position with regard to the Arab population was based on both a security imperative and a central Jewish halakhic premiss. Kach attempted to prove that its justifications for discriminating against another ethnic group had absolutely nothing in common with racist attitudes. ${ }^{58}$

The debate conducted by the CEC this time was significantly different from all its precedents. The only members who remained loyal to Kach at this stage were representatives of the two religious factions, Mafdal and Morasha, whereas other right-wing parties such as Likud and Tehiyah either joined the proponents of disqualification or refrained from voting. Ironically, the position of the CEC chairman, Justice Eliezer Goldberg, merits additional attention. The gist of Goldberg's remarks reveals a genuine trepidation regarding the harm to basic democratic liberties on account of the unwarranted use of article $7 \mathrm{a}$.

Goldberg repeatedly warned CEC members of the extreme cautiousness they must exercise before voting in favour of the disqualification of a list. He urged members to avoid an inclusive interpretation of the authority imparted to them by power of law and to consider each case independently, based on judicial principles and free from political interests. Furthermore, the CEC chair placed the onus of proof of the party's ineligibility on the petitioners for its disqualification, and added that any doubts that may arise must work in favour of the list under consideration. ${ }^{59}$ Goldberg's final request from Committee members was to include in their list of deliberations an additional, probabilistic test. He asked them to consider the question of whether there was in fact a genuine and immediate or foreseen danger to the democracy if the party were to be allowed to run for office. ${ }^{60}$ 
Despite the numerous reservations listed by the CEC chair, the results of the CEC members' vote reflected the attitude towards Kach of the majority of the represented parliamentary factions. Twenty-seven members voted in favour of the party's disqualification on the grounds that it undermined the basic principles of democracy, 6 members objected and 3 abstained. With regard to its status as a racist party, 28 supported its disqualification, 5 objected and 3 abstained. ${ }^{61}$

The legal dictate authorising the CEC to bar a party from running made it possible this time for the Supreme Court of Justice to reject Kach's petition objecting to its disqualification. The Court recognised the CEC's authority to disqualify Kach; it justified the grounds leading to its disqualification and in fact argued that there was no evidence that the CEC's decision was influenced by nongermane deliberations. ${ }^{62}$

The commentary issued by the former president of the Supreme Court of Justice, Meir Shamgar, with regard to article 7a during the discussion of Kach's petition is evidence of the degree to which this amendment to the Knesset's Basic Law contributed to the 'immunising' of the democracy in Israel. In his words:

Article $7 \mathrm{a}-$ whose exclusive interest is the goals and actions and their features - is not therefore a 'technical' provision, prima facie, enforced under given factual circumstances in absence of an interpretative guiding line. The essence of the issue at hand, that is, the constriction of a constitutional basic right, carries with it by the same token, both the standard according to which the interpretation of the law would be duly precise, narrow and limited and, in view of it, the provisions of article 7a will not be exercised except for in the most extreme cases. This interpretative approach does not in any way contradict that which is written in the written law; it is a corollary of our understanding of the original legislative objective, which did not intend to diminish from the protection of liberties but rather protect them in the face of a genuine danger. ${ }^{63}$

Elsewhere, he explained:

In devising the fundamentals of article 7a, the legislator did not include the stipulation of the existence of a clear and immediate danger or the probabilistic eventuality of the danger as a result of the actions of this list, or any other similar test examining the connection of the condemned act to the possibility of its realisation. These are therefore the guiding principles for the purpose of implementing the aforementioned article 7a:

- The goals or actions of a list of candidates, including one of the fundamentals introduced in paragraphs (1), (2) or (3) [of the law].

- The alleged goal amounts to a central and dominant goal and is not an insignificant and marginal subject. It is a definitive expression of the list's nature; the same applies to any of the modifications upon the matter, when speaking 
of an action as distinct from a goal. Here, too, the alleged action must amount to a prominent, serious and dominant expression of the identity and essence of the list.

- The list operates on behalf of the realisation of its goals and in order to convert them from ideas into actions.

- Taking part in the elections is a means towards the realisation of the goal or the intensification of the action.

- The negative elements - as specified in paragraphs (1), (2) and (3) [of the law] are manifested in a grave and extreme fashion.

The evidence for the existence of all the above must be compelling, lucid and unequivocal.

Throughout the verification, whose principal stipulations are listed above, one must always remember that the safeguarding of liberties is preferred to their restriction. ${ }^{64}$

Shamgar's conclusions indicate that in the commentary to the new article of the law provided by the Court, the scales were clearly tipped in favour of the freedom of political action over its restriction. The stringent criteria for enforcing the article established by Justice Shamgar confirm the view that the State of Israel elected to adopt the most effective tools in its struggle against extremist parties, as long as these accorded with the most rigid framework of democratic acceptability. Shamgar's position also conveys, once again, sentiments that strive to offset criticism of the law, particularly regarding the concern that the CEC might make decisions on the basis of political considerations. The fact that each ruling is subject to rigorous judicial review, grounded in clear-cut criteria of an explicitly democratic nature, forestalls the argument warning against the politicisation of the disqualification process.

Evidence of the robustness of the disqualification process as prescribed in article $7 \mathrm{a}$ and the attrition of the political option of capitalising on the instruments provided by this article, can be found in the fact that, with the passage of years, there has been a significant reduction in the number of parties seeking to exploit the article for 'vindictive' purposes. Immediately following its passage into law, and prior to the twelfth elections to the Knesset, seventeen requests were submitted in pursuance of the disqualification of seven parties, in addition to Kach's appeal to disqualify twelve parties. In contrast, prior to the fifteenth Knesset elections, only one request for disqualification was submitted - against the Balad, a party headed by Azmi Bishara, and this request as well was rejected outright. ${ }^{65}$ Further support for the assessment that the legislation of article $7 \mathrm{a}$ of the Basic Law - The Knesset did not harm the strength of the Israeli democracy, but rather reinforced it, can be found in a comparison of the case of Kach with that of Moledet.

Moledet, a far-right party, was conceived shortly before the elections to the twelfth Knesset by Major-General (res.) Rechav'am Ze'evi, a revered war hero, 
who in the years following his retirement from the military became concerned about the national security of Israel and principally the demographic balance between the Israelis and the Palestinians. ${ }^{66}$ Ze'evi considered the demographic scales to be tipped in favour of the Palestinians to be a peacetime threat to the existence of the State of Israel. In time he came to the conclusion that the only solution to this danger was to effect a policy of 'transfer' against the Palestinians living in Judea, Samaria and Gaza. Therefore, on 28 June 1988, he announced the founding of a new party to carry the flag of the 'transfer' of the Arabs living in the territories. ${ }^{67}$ As anticipated, the appearance of Moledet on the political arena elicited extreme attitudes and spurred numerous bodies to appeal to the CEC seeking to disqualify this new party from running in the elections on the grounds that the notion of 'transfer' was essentially racist and anti-democratic. The representative of the Ratz faction, Yossi Sarid, MP, was emphatic when pronouncing the same judgement for Moledet as for Kach, arguing that, in effect, one was speaking of identical lists. ${ }^{68}$

Early in the debate before the CEC, it was obvious that Ze'evi would do everything in his power in order to distance his party's tenets from the standard conditions for disqualification according to article 7a. Indeed, while putting forward his arguments, the leader of Moledet succeeded in instilling doubt among members of the Committee regarding the justifications for the disqualification of his party. He did this by employing two key strategies. First, he diffused the acrimony of the idea of the 'transfer'. As Ze'evi put it, his party was speaking of a humane principle of dividing two nations in order to bring an end to the Israeli-Arab conflict. Furthermore, the use of the word 'transfer' does not imply expulsion but rather an agreement among countries concerning the exchange of populations. ${ }^{69}$ Second, Ze'evi succeeded in creating an affinity between the Moledet ideology and the consensual origins of Zionist thought, and principally the history of the Labour Movement. He argued that in the early period of the State's establishment, the 'transfer' idea was accepted by leaders of the Labour Movement and was in fact carried out by them. ${ }^{70}$

Whether Ze'evi was successful in persuading members of the CEC by the weight of his arguments, or whether the members took upon themselves the full brunt of the responsibility dictated by article $7 \mathrm{a}$, it appeared that their position regarding the Moledet List was different from their attitude to Kach. Haim Ramon, Labour Party representative, argued that, despite his objection in principle to Ze'evi's standpoint, there was no legal justification to enforce the disqualification procedure against him. Hillel Ashkenazi, left-wing Mapam member, went a step further as he expounded:

It appears to me that in the balance of interests between the necessity of maintaining a democratic polity where everybody is equal before the law on one hand 
and the need to defend the country from incitement to racism and causing harm to the democracy on the other, one must always consider the circumstances in which use should be made of the radical enforcement of the legal - albeit, in fact, undemocratic - process of disqualifying the list. I must say that I have not been convinced that the requests calling for the disqualification of the Tsomet, Tehiya [two other rightist factions whose bids for disqualification were discussed at the same hearings] and now Moledet lists justify the radical enforcement of disqualification, as I have already mentioned. For, in my opinion, and despite the evidence ... the Kach verdict does not apply to these movements as well as in this particular case of the Moledet movement. I reiterate; employing the process of disqualification has to be carried out with the utmost precaution and with minimal legal interpretation. ${ }^{71}$

The position of the clear majority of CEC members regarding Moledet, and the overwhelming decision not to disqualify its list, signify an internalisation of the desired balance between the defence of democracy and the protection of its boundaries - and, by the same token, are further proof of the rejection of the argument that article 7a was intended to be used for the purpose of political sparring.

A retrospective glance at Moledet's actions over the ten years of its existence as an independent party and later as a member of the Ha'ichud Ha'leumi ('National Unity') alliance reinforces the feeling that the CEC's ruling on this party indeed reflects the golden path bridging between the protection of fundamental liberties on the one hand and upholding the democratic system, on the other. From its very first day in the Knesset, Moledet indeed turned out to be an extreme right-wing measuring stick on anything relating to the borders of the land of Israel and the peace process with the Palestinians. Still, a review of the proceedings of the twelfth-fifteenth Knessets reveals that neither Moledet's actions nor its statements included straightforward racist messages or a genuine challenge to the democratic system, such as was the case with Rabbi Kahane in his term as an MP.

\section{Elections to the thirteenth Knesset: 1992}

The policy of the CEC of the thirteenth Knesset, which included the disqualification of the Kach and the Kahane Hai Lists and once again allowed Moledet to compete in the elections, demonstrates that the 'immunised' route of the Israeli democracy, which began with the legislation of article $7 \mathrm{a}$, had been upheld also on the second occasion that it had been put to the test.

The prohibition of Kach from running in the 1988 elections proved to be a strong blow to Kahane and his activists who - ironically during the years 1988-1990, when there was a genuine potential for a broadening of support 
for their party in reaction to the Palestinian intifada in the Judea, Samaria and Gaza territories - were thus fated to limit their activities to the extraparliamentary sphere. On 5 November 1990, approximately a year-and-a-half prior to the elections to the thirteenth Knesset, the party suffered the worst setback it could have conceived of when its leader and the figure most identified with the movement, Rabbi Meir Kahane, was murdered in New York. In the wake of his death, bitter dissension broke out between Rabbi Kahane's devotees and his son Binyamin regarding the question of the party's prospective leadership and the title to its assets. These differences eventually led to the splitting of Kach and, as a result, it submitted candidacy for the thirteenth Knesset presented two descendants - Kach and Kahane Hai. The new-founded version of Kach was led by Kahane's underlings Baruch Marzel and Noam Federman, whereas Kahane Hai was headed by his son Binyamin, who was supported by a number of activists from the settlement of Kfar Tapuach in Samaria.

Despite their ideological kinship, the arguments of these two parties before the CEC were very different. Kach, wiser from the lessons of the past, refrained from mentioning the Arabs in its election campaign. In effect, the party's central counterclaim to the requests for its disqualification was that, despite its disagreement with the substance of article 7a, it took it upon itself to adhere to the dictum of the law and therefore forfeited from its programme any clause which may have been construed as at variance with it. ${ }^{72}$ However, most members of the CEC saw this as a fairly transparent attempt by the party to gain the CEC's stamp of legitimacy and approval to take part in the elections while, basically, the true intention of the party leadership was to return to its original platform if and when the party achieved parliamentary representation. The profusion of evidence indicates that concurrent with the so-called transformation undergone by the party its leadership, in practice, continued its traditional course of provocative activities. This did not make it easy for the Kach representative to persuade members of the CEC of the integrity of the party's intentions, and consequently the list was disqualified by a considerable majority. ${ }^{73}$

Kahane Hai, on the other hand, in fact chose to address the Arab issue and defended itself armed with the argument that, unlike Kach, its members were speaking of a new list, one which should not be judged according to the "past sins' of Kach. ${ }^{74}$ An additional explanation submitted by the party's representatives was that they did not wish to conceal their intentions regarding the Israeli Arab population, for the simple reason that their position towards this population had originated in Jewish Halakha, which constituted the base for the party's platform. With this reasoning, representatives of Kahane Hai hoped that the CEC would stumble and fall into the polemics of the existing tension between the 'Jewish' and the democratic principles of the State of Israel. ${ }^{75}$ However, these efforts to sow seeds of doubt among CEC members did not fare well at all and 
the list's disqualification was passed by an even larger majority than in the case of Kach. ${ }^{76}$

Immediately after the disqualification ruling was passed, both lists petitioned the Supreme Court of Justice in their appeals that it rescind the CEC's decisions. However, in contrast to the discussions of principle on the subject that were conducted in the previous elections, this time the judicial discussion was relatively simple and the Court ratified the rulings issued by the CEC. In Kach's case, and in view of the abundant evidence presented before the judges, it was decided to reject the appellant's claim that since it had been disqualified from running in the twelfth Knesset several years earlier the party had undergone substantial transformation. ${ }^{77}$ As for Kahane Hai, the Supreme Court refrained from entering the arena of the party's Halakhic arguments and elected instead to focus on the question of whether this party's tenets clashed with article $7 \mathrm{a}$ of the Knesset's Basic Law. According to the Court, the answer to this question was affirmative. ${ }^{78}$

Another point worthy of mention is that appeals for the disqualification of the Moledet List were also submitted to the thirteenth Knesset's CEC. The chair of the CEC, Justice Halima, stressed before the CEC that the utmost caution must be observed while discussing article $7 \mathrm{a}$ and by this step adopted the tactic of his predecessor, Justice Goldberg, as well as that of the Supreme Court of Justice President, Justice Shamgar, in the verdict regarding Kachs' petition against the twelfth Knesset CEC's ruling. ${ }^{79}$ The majority of Committee members accepted the chair's position and in the absence of evidence indicating a deviation in principle on the part of Moledet from the strict interpretation of article 7a, they permitted its participation in the elections by a large majority. ${ }^{80}$

The disqualification of Kach and Kahane Hai, on the one hand, and the granting to Moledet of a license to run in the elections, on the other, both conform, in my view, to the principles of the 'immunised route'. In the 1992 Knesset elections, also, negotiation regarding the qualification of all lists was conducted according to a stringent interpretation of article $7 \mathrm{a}$, while at the same time the arbitrating or judicial bodies exhibited a clear preference for partisan participation over any temptation to rid the Israeli political arena of radical notions. Moreover, it appeared that many Committee members wholly disapproved of the Moledet position, yet most of them did not exercise partisan political considerations but rather addressed the essentials. The same applies to their position regarding Kach and Kahane Hai. Despite Kach's attempts to try to change its image and Kahane Hai's efforts to argue before the Court that its political programme was in effect a derivative of the Jewish Halakha, it was obvious to members of the CEC that these were stratagems and nothing more. The network of evidence presented before the CEC persuaded its members that these parties sought to undermine the foundations of democracy and therefore their camouflage tactics were to no avail. 
The parties law

A significant additional step forward in the 'immunising' process of the Israeli democracy was taken on 10 April 1993, when the Parties Law (1992) came into effect. Apart from the fact that, for the first time, this law defined the status of political parties in Israel, it also included a circumscription of the goals and actions of registered parties. Article 5 of the law determined that

A party will not be registered if its goals or actions include, explicitly or implicitly, one of the following: 1. negation of the existence of the State of Israel as a Jewish and democratic state; 2 . incitement to racism; 3 . reasonable grounds for the inference that the party is going to be used as a front for illegal activities. ${ }^{81}$

Contrary to the position put forward in this book, according to which article 5 constitutes a significant component in the 'immunising' process of the democracy, the article was subject to severe criticism by other social scientists, including Barzilai, Avnon and Cohen-Almagor. In their view, the restrictions imposed by this article were excessive and encroached upon basic liberties even more than did article $7 \mathrm{a}$. First, it authorised the party registrar to disqualify a party even before it had begun to function. Second, this article confers a permanent disqualification, unlike article 7 a which enables parties to return and approach the CEC prior to each election. Hence, as they saw it, this article entailed grave restrictions on the fundamental democratic right of freedom of assembly. ${ }^{82}$

The most effective way to assess to what degree the Law has in fact adversely affected basic liberties is to once again make use of the test of consequences. The first party that was most liable to encounter difficulties subsequent to the Parties Law's approval was Moledet. Like all other parties in Israel, Moledet was requested to enlist with party registrar and to present the registrar with, among other things, a list of its principles. In order to avoid a judicial tangle on account of article 5, the party's leader, Rechavam Ze'evi, decided to omit the 'transfer' scheme from the clause outlining the party's goals. ${ }^{83}$ Despite the fact that its principles were well known, Moledet encountered no great difficulties and was given the registrar's stamp of approval. However, it is important to note that its qualification, granted twice before by the CEC, undoubtedly helped pave the way for the registrar's present authorisation. Therefore, it seems appropriate to proceed to the discussion of a more problematic example, specifically that of Yemin Yisrael.

Yemin Yisrael was an extreme right-wing list led by Professor Shaul Guttman. Its members had left Moledet subsequent to personal disputes and ideological differences of opinion. The most prominent divergence from Moledet's way of thinking was related to Ze'evi's readiness to drop the idea of 'transfer' from the list of the party's main premisses in order to avoid conflict 
with article 5 of the Parties Law. ${ }^{84}$ With the elections for the fourteenth Knesset approaching, Guttman and his colleagues sought to present the Israeli voter with a right-wing alternative more radical than Moledet. Directly following Yemin Yisrael's request to be registered as a party, the party registrar received three lawsuits, all intent on preventing its registration on the grounds that the party was racist and anti-democratic. Furthermore, appellants intimated that this list was distinguished by an affiliation with the Kach movement which, at that time, had already been defined by the State as a terrorist organisation. Because of the grave misgivings associated with article 5, the party registrar elected to approach this list along the lines of Justice Shamgar's interpretation of article $7 \mathrm{a}$ from the second Neiman verdict, meaning an interpretation which was as sparing as possible and which stressed democratic liberties. ${ }^{85}$

Following an evaluation of all the requests, and having subjected them to the rigour of the provisions of the law and the principle of freedom of assembly, the party registrar chose to affirm Yemin Yisrael's registration. ${ }^{86}$ Even the appeals served by two of the petitioners to the Supreme Court of Justice enjoining the Court to revoke the qualification of Yemin Yisrael were rejected by the verdict of the three judges who sat in trial. The ruling issued by the Supreme Court President Aharon Barak stated that if the interpretation of article 7a provided the State with a very narrow range of action when considering the prevention of a list from participating in the elections, then the non-registration of a party was even more restrictive for, inter alia, the hearing which decided the party's registration took place prior to the party's actual establishment and therefore before its actions could even be evaluated. The fact that the non-registration of a party is at the authority of the party registrar - a conventional administrative body as opposed to the CEC, which is a kind of 'Knesset in miniature' and chaired by a justice of the Supreme Court - also invites extra caution ${ }^{87}$ These deliberations, and others, led the Court to assume an approach that was as liberal as possible with regard to the registration of this party. The Ratz faction's appeal to the CEC with the intention of preventing Yemin Yisrael from taking part in the Knesset elections also did not fare well. However, in this specific case, the appeal was rejected on procedural grounds. ${ }^{88}$

Hence, the conclusion to be drawn is that despite the serious concerns regarding the substantial restrictions of freedom inherent to the Parties Law, in the first real test to which the State was subject regarding that law it did not display a rigid and problematic position in democratic terms ${ }^{89} \mathrm{In}$ fact, quite the opposite is true. The Israeli political organisation most closely affiliated to Kach was fortunate to be registered as a party, and even tried its luck, albeit with little success, in running for Parliament. This illustration represents a prominent example of the restraint exercised by the State of Israel in relation to the restriction of the liberties of political parties and demonstrates a clear preference for liberal principles over the restriction of political liberties. 


\section{Conclusions}

This extensive account of the Israeli response to extremist challenges in the parliamentary arena indicates an evolving tendency in the State's political and judicial policy towards extremist parties. In its early years, the State of Israel lacked structural or legal barriers which could have limited the participation and representation of extremist parties, a fact made prominent in the case of the 'Socialist List' in which the CEC as well as the Supreme Court were impelled to take extreme and highly problematic measures in democratic terms. However, the decision to disqualify the 'Socialist List' from running in the elections did not lead the Knesset to firmly establish the Israeli response to radical parties in a legal framework. Consequently, with Meir Kahane's appearance in the political arena in Israel, the State's authorities found themselves in a similar situation. However, in Kahane's case, despite the repugnance he evoked and the strong desire of CEC members, and later of the Knesset's speaker and the managing committee of the IBA, to clamp down on his activities, the Supreme Court chose to uphold his liberties as a citizen and an elected representative. At the same time, it gave the legislature a clear sign regarding the need for statutory measures which would make it easier for them to deal with the Kahanist phenomenon. Thus, in the years prior to the amendment of the Knesset's Basic Law, this phenomenon led to strain between representatives of the legislature who sought to restrict Kahane - even if that involved an abuse of democratic principles - and representatives of the judiciary who endeavoured to protect democratic principles even when the cost was the protection of Kahane's freedom of action.

The first productive joint-enterprise between the legislative and judicial authorities in this regard was passing the amendment to the Knesset's Basic Law. This amendment defined the qualifications and limitations necessary for a party competing in the elections, and opened a window of opportunity for an extensive legislative system on this issue. A short while after the amendment to the Knesset's Basic Law, new clauses were added to Knesset Regulations with regard to the limitations on the legislature's forbearance regarding racist and anti-democratic expressions; and seven years later the Parties Law was passed as well. The 'immunising' process of the Israeli democracy with regard to extremist political parties was completed in 1998 with the approval of article 28 of the Law of the Local Authorities (Elections). Article 39a of that amendment in effect applies the qualifications which appear in article $7 \mathrm{a}$ of the Knesset's Basic Law also to parties running for office in the local authorities, and accordingly, following the November 1998 elections to the local authorities, a list that denies the democratic character of the State or incites to racism cannot take part in the elections. ${ }^{90}$

Evidence of the link between the creation of the new legal structure and 
the 'immunising' of the Israeli democracy can be found in the fact that even the gloomy forecasts regarding the political use of this legal framework were proven wrong. The CEC's members and the party registrar have so far displayed a balanced and responsible approach in their legal interpretation, an evaluation validated by the Supreme Court which established highly stringent criteria whenever it was necessary to restrict any of the liberties of political parties.

However, the simplest way to estimate the quality of the change in Israeli policy regarding radical political parties is by conducting a retrospective survey of the debates and rulings issued in respect of the various political parties. Such a review once again pulls the rug out from under the pessimists who predicted the erosion of the democratic foundations of the State. In contrast to the projection arguing that the existence of legal barriers, placed at the State's disposal, would inevitably lead to their exploitation, consequently raising many difficulties for political parties seeking to register or compete in the elections, a reality check in fact proves otherwise. Only two parties were prevented from taking part in the elections: Kach and Kahane Hai. This fact becomes the more significant when it is juxtaposed with the increasing radicalism that has developed among the diverse walks of life comprising Israeli society. This radicalism finds expression in the elongated boundaries of the discourse conducted in the Israeli Parliament and in the increasing representation of radical and militant political parties in this institution.

Subsequent to the elections to the fifteenth Knesset in 1999, the parliamentary system in Israel could be defined as a form of 'polarised pluralism'. In that Knesset, certain Jewish political parties gained representation which did not hesitate to challenge the democratic government, and its various institutions, and to preach against ethnic groups. Side by side, there were Arab parties, including the Islamic Movement, which openly objected to the existence of Israel as the State of the Jewish people. Of course, anti-democratic or ethnocentric expressions in Parliament are not auspicious phenomena in themselves, but the very fact that these parties gained representation in the context of a sustained democratic framework gives an indication of an ability to strike a balance between the imperative of affording representation to the whole complex of currents and ideas found in Israeli society at large and the necessity to safeguard democratic values and structures.

At this juncture, I wish to differ with Cohen-Almagor who argues that a state must take on the obligation of restricting anti-democratic parties, no matter what their shade or colour, for the reason that, in the absence of any such action, the administration in effect becomes an accessory to the consolidation of anti-democratic notions. In his view, there is no need for incriminating proof that a particular party indeed constitutes a genuine threat to the democratic polity - the very fact that it practises violence and that its beliefs 
undermine the democratic character of the state is reason enough for its disqualification. ${ }^{91}$

My critique of Cohen-Almagor's approach focuses on two main points. First, including the element of violence while deliberating the disqualification of a political party seems needless in this era of the third millennium. To wit, in the first half of the twentieth century, the preponderance of anti-democratic parties in Europe featured prominent violent distinctions, whereas a glance at the Western political theatre today demonstrates that even the most extreme of parties appears to refrain from involvement in violent action - a fact which does not necessarily attest to an empathic relationship with democracy but more likely indicates an instrumental volition to avoid conflict with the authorities. Second, the non-liberal context of the Israeli democracy and the divisive cut of its society create by inference a fertile ground for the growth of extremist parties. Furthermore, Israel's character as a Jewish and democratic state engenders fundamental complications at all stages in the disqualification process of political parties. The majority of religious and ultra-orthodox parties would prefer Israel to be a Jewish state while foregoing its democratic principles, and most Arab parties would rather see Israel as a democratic state while relinquishing its 'Jewish' component. Subsequently, if disqualification were to have been determined on the basis of party programmes and statements made by their leaders, then the sword of disqualification would have come down on the heads of many parties. Therefore, in my opinion, a democracy which chooses the 'immunised route' is obliged also to consider the question of the real threat a party poses because, without that measure, the right of representation would be denied to many social groups in Israel.

Although, in view of the above developments, it would seem that the Israeli democracy is fairly close to the 'immunised' polarity of response in terms of its attitude towards extremist parties, one question remains unanswered: to what degree is there an underlying base of public support for these changes in the State's policy towards extremist parties? This question is particularly important due to the growing tension over recent years between judicial elites in Israel who, by the disposition of their verdicts, are leading the Israeli democracy in liberal directions, and large parts of the population who object to this inclination.

In a survey conducted for the purposes of this study, participants were presented with three statements appertaining to the policy the State must adopt in its attitude towards extremist political parties. Almost 60 per cent (59.8) of the respondents agreed with the first statement: 'It is the democratic polity's duty to disqualify extremist parties even if there is no law which defines how to go about it'. The second statement, 'The Israeli law which enables the disqualification of political parties is not sufficiently enforced in this country', was supported by 55.5 per cent, while 56.2 per cent expressed their support for the 
notion that 'It is appropriate to enforce the idea of the disqualification of political parties on other levels, for example, elections for local authorities'.

From these findings we can draw the following conclusion: while the State's authorities and, in particular, the Supreme Court tend towards moderation of the restrictions imposed on political parties and appear to confine the range of response to particularly narrow boundaries, the public, oddly enough, displays tendencies of a more 'militant' nature. At the base of this tendency, there is a desire to impose a more expansive system of control over political parties and to reduce the range of representation. These findings point to a fairly wide gap between the public's attitudes and those of the State. This fact may increase the apprehension that, despite the 'immunised' tendency spearheaded by political and judicial elites, a broad public under-structure in support of this tendency is lacking. In chapter 3, which deals within the State's efforts to 'immunise' Israeli society in terms of its basic values, findings are submitted to help assess whether Israeli society is inclined in the immediate future in more liberal directions or whether it will remain deeply implanted, firm in the non-liberal tradition.

\section{NOTES}

1 Kay Lawson, 'When Linkage Fails', in Kay Lawson and Peter Merkl (eds), When Parties Fail: Emerging Alternative Organisations (Princeton, New Jersey: Princeton University Press, 1988), pp. 13-38.

2 Maurice Duverger, Political Parties: Their Organisation and Activity in the Modern State (London: Methuen, 1964), p. 50.

3 It is worth mentioning that during the time of the Weimar Republic steps were taken to drive extremist parties out of Parliament; however, such means were not enforced against the National Socialist Party. In the Israeli context, see Talia Einhorn's, booklet Statutory Proscription of Political Parties that Have Racist Platforms: Article 7a of the Basic Law: Ha-Knesset (Jerusalem: Israeli Association for Parliamentary Issues, 1993), p. 15 (Hebrew).

4 Elmar M. Hucko (ed.), The Democratic Tradition: Four German Constitutions (Leamington Spa: Berg, 1987), p. 202.

5 Benyamin Neuberger, Political Parties in Israel (Tel-Aviv: Open University, 1997), p. 32 (Hebrew).

6 Benjamin Akzin, 'The Role of Parties in Israel Democracy', Journal of Politics, 17:4 (1995), p. 114.

7 Just prior to the thirteenth Knesset elections in 1992, the minimum percentage was raised to 1.5 of the valid votes. Prima facie, this was in order to reduce the number of represented factions, and in the 1992 elections only ten parties were in fact elected. However, the electoral reform Israel underwent prior to the fourteenth Knesset in 1996 - based upon the new method of splitting the vote between the prime minister and the Knesset - led to a renewed growth in the number of represented parties and, even more so, to the growth in the power of the smaller parties in relation to the large parties. This also led to a change from a dual-bloc parliament to a form of polarised pluralism.

8 This number does not include factions which split off from parties after their election to Parliament. See Avraham Brichta, Democracy and Elections - On Changing the Electoral and Nomination Systems in Israel (Tel-Aviv: Am-Oved Tarbut Vechinuch, 1977), pp. 43-54 
(Hebrew); Gideon Doron and Moshe Maor, Barriers to Entry into Israeli Politics (Tel-Aviv: Papyrus Tel-Aviv University, 1989), pp. 76-93 (Hebrew); Benyamin Neuberger, 'The Stabilization of Democracy in Western Germany - Lessons to the State of Israel', in Bernard Susser (ed.), The Political System in Israel Proposals for Change, unpublished report (1987), pp. 43-61 (Hebrew).

9 Avraham Brichta, Political Reform in Israel: The Quest for Stable and Effective Government (Brighton, East Sussex: Sussex Academic Press, 2001).

10 Doron and Maor, Barriers to Entry into Israeli Politics, pp. 83-4.

11 In this context, it is worth mentioning that despite the fact that over the years the Herut party (subsequently Likud) became a coalition partner and later, in fact, the ruling party among the Jewish parties in Israel, the custom excluding Arab parties from the coalition became entrenched.

12 Raphael Cohen-Almagor, The Boundaries of Liberty and Tolerance: The Struggle against Kahanism in Israel (Gainesville: University of Florida Press, 1994), pp. 206-7.

13 Raphael Cohen-Almagor, The Boundaries of Liberty and Tolerance, pp. 181-3.

14 For a critical discussion of the comparison between the Socialist List and the case of the Weimar Republic, see Ruth Gavison, 'Twenty Years Since Yardur's Ruling - the Right to Be Elected and the Lessons of History', in Aharon Barak, Ruth Gavison and Mordechai Kremnizer (eds), Shimon Agranat Reaching the Age of 80 (Jerusalem: Hebrew University, 1986), pp. 145-213 (Hebrew).

15 In 1984, the left-wing Jewish-Arab party the Progressive List for Peace, led by Mohammed Miari and Mati Peled, was disqualified; however, the Supreme Court of Justice rescinded the ruling and gave the list permission to run in the elections. In 1988, the party surmounted the barrier posed by the Central Elections Committee as well as the Supreme Court's ruling. In 1996, the Supreme Court authorised another list, the Arab Movement for Change, headed by Dr Ahmad Tibi, to take part in the elections. See: Raphael Cohen-Almagor, Speech, Media and Ethics (Basingstoke, Hampshire: Palgrave, 2001), pp. 60-4. In 1999, Balad (abbreviation for Democratic National Alliance), led by Dr Azmi Bishara, was successful in hurdling the Central Elections Committee barrier, whereas, in the present case, the request for disqualification of this party did not pertain directly to its effort to gain parliamentary representation, but rather to Dr Bashara's intention to run for prime minister (from an interview with Tamar Edri, director of the Central Elections Committee, the Knesset, 16 April 2001).

16 Robert I. Friedman, 'The Sayings of Rabbi Kahane', New York Review of Books, 23:2 (1986).

17 Yair Kotler, Heil Kahane (New York: Adama Books, 1986), p. 122.

18 Ehud Sprinzak, The Ascendance of Israel's Radical Right (New York: Oxford University Press, 1991), pp. 52-5.

19 Raphael Mergui and Philippe Simonnot, Israel's Ayatollahs: Meir Kahane and the Far Right in Israel (London: Saqi Books, 1987), pp. 29f.

20 'Daughter of Israel' is the literal English translation of the biblical Hebrew idiom meaning 'Jewish woman'.

21 Advertisement: 'She Is a Daughter of Israel. Perhaps Your Sister, Your Daughter or Granddaughter', Ma'ariv, 29 May 1981.

22 Protocol no. 18, from the plenary session of the Central Elections Committee (4.6.1981), p. 5.

23 Protocol no. 18, from the plenary session of the Central Elections Committee (4.6.1981), p. 5.

24 Protocol no. 18, from the plenary session of the Central Elections Committee (4.6.1981), pp. 6-8. 


\section{The parliamentary arena}

25 Protocol no. 18, from the plenary session of the Central Elections Committee (4.6.1981), p. 21.

26 Moshe Negbi v. Central Elections Committee. Verdict 344/81 of the Israeli Supreme Court.

27 Protocol no. 18, from the plenary session of the Central Elections Committee (4.6.1981), p. 9.

28 Protocol no. 14, from the plenary session of the Central Elections Committee (17.6.1984), pp. 4-15.

29 Protocol no. 14, from the plenary session of the Central Elections Committee (17.6.1984), p. 34.

30 Protocol no. 14, from the plenary session of the Central Elections Committee (17.6.1984), pp. 38-9.

31 Protocol no. 14, from the plenary session of the Central Elections Committee (17.6.1984), p. 40.

32 Protocol no. 14, from the plenary session of the Central Elections Committee (17.6.1984), p. 48 .

33 Letter from Gabriel Bach, Supreme Court justice and chair of the Central Committee for the elections to the eleventh Knesset, to Mr Moshe Neiman, Kach representative (17.6.1984).

34 Cohen-Almagor, The Boundaries of Liberty and Tolerance, pp. 210-11.

35 Ehud Sprinzak, Political Violence in Israel (Jerusalem: Jerusalem Institute for Israel Studies, 1995), p. 92 (Hebrew).

36 Cohen-Almagor, The Boundaries of Liberty and Tolerance, pp. 219-23.

37 Robert I. Friedman. 'The Sayings of Rabbi Kahane', New York Review of Books, 23:2 (1986).

38 Entry no. 18 from proceedings of the IBA managing committee session (1.8.1984).

39 Proceedings of the News Forum (29.7.1984).

40 Hadashot (daily Israeli newspaper), 28 July 1987.

41 Cohen-Almagor, The Boundaries of Liberty and Tolerance, pp. 223-9.

42 Cohen-Almagor, The Boundaries of Liberty and Tolerance, pp. 229-30.

43 An office including the Knesset's speaker and his or her deputies, which represented many of the House factions.

44 Protocol of the 137th session of the eleventh Knesset (13.11.1985). Amendment of article 134 of Knesset Regulations. The full protocol is available at: www.knesset.gov.il/knesset/hebframe.htm

45 Cohen-Almagor, The Boundaries of Liberty and Tolerance, pp. 233-4.

46 Kahane v. Knesset Speaker and his Deputies. Supreme Court of Justice appeal 669/85, 24/84 (13.1.1986), pp. 399-400.

47 Penal Code, 1977-86 amendment, clause 144.

48 This passage is taken from the protocol of the 108th session of the eleventh Knesset on Tuesday 9 July 1985, Jerusalem, the Knesset; Basic Law Proposal: The Knesset (amendment no. 12), Penal Code Proposal (amendment no. 24), 1985 (first preliminary reading). These proceedings can be found at 'Knesset Proceedings':

www.knesset.gov.il/knesset/hebframe.htm

49 Basic Law: The Knesset, amendment no. 9, Book of Laws (Dr R. Gideon, publisher, 1985), vol. 14, 66770 .

50 From the protocol of the 108th session of the eleventh Knesset on Tuesday 9 July 1985, Jerusalem; Basic Law Proposal: The Knesset (amendment no. 12), Penal Code Proposal (amendment no. 24), 1985 (first preliminary reading). These proceedings can be found at 'Knesset Proceedings': http://www.knesset.gov.il/knesset/hebframe.htm 
51 Yoav Peled, 'Ethnic Democracy and Legal Construction of Citizenship: Arab Citizens of the Jewish State', American Political Science Review, 86:2 (1992), pp. 432-43.

52 Gad Barzilai, 'The Decline of the Parties and Judicial System', in Dani Korn (ed.), The Demise of Parties in Israel (Tel-Aviv: Hakibbutz Hameuchad, 1998).

53 Raphael Cohen-Almagor, 'Israeli Democracy During the 1980s: A Critical Review', Democratic Culture, 2 (1999), pp. 79-100 (Hebrew); Ariel Bendor, 'The Right of Candidacy to Knesset Elections', Mishpatim, 18 (1988), pp. 269-96.

54 In the mid-1980s and the early 1990s, the Knesset was distinguished by a closely matched dual-bloc structure. According to the law, the faction leader with the best chances of raising a coalition was assigned the role of doing so, a stipulation which turned the smaller parties - often those representing single-member factions - into players wielding great manipulative leverage due to the fact that the governmental structure was often dependent upon their decision to support this or that coalition.

55 Draft law (21.12.1987).

56 Draft law (19.10.1987).

57 Surveys conducted by the daily newspaper Yedioth Aharonoth on 7 and 21 October predicted 3-4 mandates. The daily Ma'ariv, on 7, 14 and 21 October, expected 3-5 mandates.

58 Protocol no. 17, from the sessions of the CEC (5.10.1988).

59 Protocol no. 17, from the plenary session of the CEC for the Knesset for the disqualification of the Kach List (5.10.1988), p. 48.

60 Protocol no. 17, from the plenary session of the CEC for the Knesset for the disqualification of the Kach List (5.10.1988), p. 51.

61 Protocol number 17, from the plenary session of the CEC for the Knesset for the disqualification of the Kach List (5.10.1988), p. 57.

62 Neiman and Kach List v. Chair of the CEC for the twelfth Knesset, Supreme Court Ruling EA $2 / 88$.

63 Neiman et al. v. Chair of the CEC for the twelfth Knesset, Supreme Court Ruling 1/88, verdict 42 (4) $187 \mathrm{c}$.

64 Neiman et al. v. Chair of the CEC for the twelfth Knesset, Supreme Court Ruling 1/88, verdict 42 (4) 177, 187, 196; Ben Shalom et al. v. CEC for the twelfth Knesset et al., Supreme Court Ruling 2/88, verdict 43 (4) 221.

65 From an interview with Tamar Edri, director of the CEC, the Knesset (16.4.2001).

66 In October 2001, the Minister for Tourism Mr Rehavam Ze'evi was assassinated at the Hyatt Hotel in Jerusalem by Arab terrorists.

67 Ha'aretz, 29 June 1988.

68 Protocol no. 20, from the plenary session of the Central Elections Committee (9.10.1988), p. 28.

69 Protocol no. 20, from the plenary session of the Central Elections Committee (9.10.1988), pp. 36-7.

70 Protocol no. 20, from the plenary session of the Central Elections Committee (9.10.1988), p. 33.

71 Protocol no. 20, from the plenary session of the Central Elections Committee (9.10.1988), p. 57.

72 Protocol no. 17, from the plenary session of the Central Elections Committee (28.5.1992), pp. 53-60.

73 Protocol no. 17, from the plenary session of the Central Elections Committee (28.5.1992), p. 81.

74 Protocol no. 17, from the plenary session of the Central Elections Committee (28.5.1992), pp. 83-5. 
75 Protocol no. 17, from the plenary session of the Central Elections Committee (28.5.1992), pp. 86-92.

76 Protocol no. 18, from the plenary session of the Central Elections Committee (3.6.1992), p. 6.

77 Kach v. Chairperson of the CEC to the 13th Knesset, EA 2805/92, paragraph 6.

78 Kahane Is Alive Movement v. Chairperson of the CEC to the 13th Knesset, EA 2858/92, paragraph 4.

79 Protocol no. 17, from the plenary session of the Central Elections Committee, 28.5.1992, pp. $24-8$.

80 Protocol No. 17, from the plenary session of the Central Elections Committee, 28.5.1992, pp. 40-1.

81 Parties Law, Book of Laws (Dr. R. Gideon, 1992) vol. 22, 11185.

82 An elaboration of the critique regarding article 5 of the Parties Law can be found in: Barzilai, 'The Decline of the Parties and Judicial System', pp. 122-4; and in Dan Avnon, 'Law and Democracy in the Parties Law', in Dan Avnon (ed.) The Parties Law in Israel: Between a Legal Framework and Democratic Norms (Tel Aviv: Israeli Democratic Institute, Kibbutz Hameuchad Publishing, 1993), pp. 37-63. In addition, a reference to the restrictions arising from the law can be found in Raphael Cohen-Almagor, 'Disqualification of Political Parties in Israel: 1988-1996', Emory International Law Review, 11:1 (1997) pp. 67-109.

83 From an interview with Professor Shaul Guttman, formerly Member of Parliament on behalf of Moledet and one of the founders of Yamin Yisrael (Israel's Right) (4.5.1997).

84 From an interview with Professor Shaul Guttman (4.5.1997).

85 Office of the party registrar (14.11.1995). Request for the registration of Yamin Yisrael in the parties' ledger and three objections to it, pp. 9-11.

86 Office of the party registrar (14.11.1995). Request for the registration of Yamin Yisrael in the parties' ledger and three objections to it, p. 23.

87 The Supreme Court of Justice in Jerusalem (7.3.1996). Request for permission to appeal against the party registrar's ruling, N452 7504/95 (14.11.1995). Ghanem Yasin, party registrar, pp. 70-1.

88 Protocol no. 15, from the plenary session of the Central Elections Committee (30.4.1996).

89 Mention should be made of the fact that both the party registrar and the Supreme Court arrived at a similar conclusion regarding the Arab Movement for Change, and gave their consent for its registration.

90 Local Authorities Law (Elections), amendment no. 28. Proceedings, Book of Laws, p. 1682.

91 Raphael Cohen-Almagor, Speech, Media and Ethics: The Limits of Free Expression (Basingstoke, Hamphire: Palgrave, 2001), pp. 64-5. 


\section{The State's response to extremism: attitudes towards subversive movements and violent organisations}

\section{$\mathrm{T}$}

He DEMOCRATIC POLITY's struggle against manifestations of extraparliamentary extremism and political violence is accompanied by a similar and perhaps even more acute quandary than its contest with political parties. In this struggle the government possesses the means to substantially restrict the freedom of expression and association of its citizens, consequently harming a number of their democratic rights. However, in its struggle against extremism, violence and, at times, even terrorism, the democracy is sometimes impelled to employ means that may engender restrictions on the most fundamental liberties, including the right to life.

Not without reason did Peter Chalk, whose intention was to delineate the democratic boundaries of the fight against terrorism, put forward an argument almost identical to that of the 'paradox of the defending democracy'. According to his reasoning, the elusive challenge confronting every democracy was to find the means that would be most effective against insurgent factors while, at the same time, maintaining moral conformity with liberal democratic traditions. ${ }^{1}$ However, the search for these means continues, and the democracy's predicament in its fight against violence and terrorism continues to provide ample grist for the academic mills of numerous social scientists. ${ }^{2}$

Intensive research in this field, particularly in recent decades, has spawned a number of theoretical designs. Two ideal types, the 'war model' and the 'criminal justice model', have gained notable prominence. Not surprisingly, we can easily apply these models to the general discussion of the various facets of the 'defending democracy'. The first type, the 'war model', is analogous to the notion of the 'militant route'. This model takes on the goal of eradicating violence and terrorism, whereas the confinement of its actions to democratically accepted limitations, in its books, is a marginal factor. Alternatively, the 'criminal justice model', assuming more of an 'immunised route', regards the preservation of democratic guidelines as the cornerstone in its doctrine of struggle against violence, even at the expense of the effectiveness of this campaign. 
Operationally, these models can be distinguished by a number of principal aspects. First, through the lens of the 'war model', political violence and especially terror are perceived as revolutionary and belligerent acts, whereas the 'criminal justice model' looks upon them as criminal offences. Commensurately with their differentiated approaches to political violence, these models espouse different modes of response. The 'war model' gives the job of tackling political violence to the military forces, which may utilise any of the means at their disposal in order to strike at or suppress subversive elements. The "criminal justice model', on the other hand, places the onus on the police forces while confining its actions to state criminal legislation, ${ }^{3}$ as further elaborated by Crelinsten:

In a criminal justice model, the rule of law is paramount, while in the war model, it is the rules of war that prevail. In the criminal justice model, it is the police who exercise the state's monopoly on the use of violence. The rules of engagement, so to speak, involve the use of minimal force, which requires an exercise of judgement on the part of the officer(s) involved. Military rules of engagement, on the other hand, require the maximal use of force designed to overpower the enemy. ${ }^{4}$

It is no coincidence that Crelinsten posits the 'rule of law' as the key distinction between the two models. The 'rule of law' in its rudimentary form is the bedrock of liberal democratic political culture. The liberal interpretation of the 'rule of law' extends well beyond the minimal requirement of the state for effective law enforcement. According to liberal premisses, laws must be circumscribed and, when enforced, the impairment of basic human rights or arbitrary discrimination among citizens should be avoided. ${ }^{5}$ This approach obligates the liberal democracy to confine its struggle against political violence to very narrow boundaries, a fact that does not necessarily coincide with empirical reality in many liberal democratic polities, let alone non-liberal democracies.

A consideration of the campaigns waged by democracies against violence and terrorism indicates that, in most cases, the governing body does in fact uphold the rule of law, albeit in its formal aspect and not in the far-reaching liberal sense. Given the above, the use of the 'war model' in its academic - ideal - form, is rather uncommon. Most democracies facing a considerable threat or a pending crisis tend to forsake the rigid confines of the 'criminal justice model'. However, as noted by Crelinsten and Schmid, they still do not cross the line and de facto embrace the 'war model'. Rather, they customarily adopt countermeasures that avoid a total rejection of the 'criminal justice model'. These means include drafting specific anti-terror legislation, the extension of police authority, modifications of judicial processes with the intent of expediting terrorist prosecution and, in certain cases, special courts for terrorists. ${ }^{6}$ In this fashion, the state maintains adherence to the law and at the same time enjoys a greater field of manoeuvre in its battle against subversive elements. 
Given the above, it is therefore posited that, in practice, the two polarities demarcating the arsenal of countermeasures to violence and terrorism at the disposal of most democratic polities are as follows: on one hand, there is the 'narrow criminal justice model', which features the liberal interpretation of the 'rule of law'; and, on the other, we find the 'extended criminal justice model', which relies on the procedural interpretation of the 'rule of law'. The latter version makes it feasible for democracies to take more extreme countermeasures against insurgent elements while still avoiding a decline into the "war model'; yet the question remains of whether a system employing the means of this model can in fact remain, and be called, 'democratic'.

As reflected in its approaches to extremist parties and its responses to extraparliamentary radical and violent acts of provocation, Israel has a history of continual revision. The general gist indicates a gradual transition from the 'militant route' or course of action - in this case, the 'war model' and the 'extended criminal justice model' - to an 'immunised' course, i.e. the 'criminal justice model'. This chapter reviews the permutations through which Israeli counterinsurgent policy has gone, from the State's inaugural years through to the third millenium. First, I consider the predominantly 'militant' route characteristic of Israel's early days; then the relationship of the new-born State's judicial system to the operational aspects of the "extended criminal justice model' is examined; the move, from the 1970s on, to a 'criminal justice model' comes under scrutiny; and the chapter culminates with a look at the factors involved in a transition to an 'immunised' form of response.

\section{Israel's early days: the predominance of the 'militant' route}

At surprising odds with the fact that in its struggle against political parties the inchoate Government of Israel suffered from a dearth of measures in its effort to protect itself from radical political manifestations, we find that in regard to (extra-parliamentary) extremist movements and violent uprisings Israel tended, even in its early days, to adopt highly rigorous forms of warfare against subversive groups. This approach is given prominence in the words of the first prime minister of Israel, David Ben-Gurion, only a short time after the founding of the State:

Democracy will cease to exist - if we debilitate it, render it incapable, powerless and devoid of effective defensive measures. So that ... if democracy in Israel seeks to continue to exist and last for many days, it must be equipped with self-defensive means and tools of action and implementation that will prevent minorities - and not only non-Jewish minorities, but rather Jewish minorities as well - from gaining control by use of internal or external force. ${ }^{7}$

Israel's intolerant disposition at the time towards manifestations of Jewish violence derived from events in the struggle to establish its sovereign State; but it 
was also an outcome of developments which took place during the pre-State period. The years prior to the founding of the State of Israel were marked by the Zionist movement's struggle to lay the foundations of the Jewish State. Like other nationalist undertakings, violent steps and strategies formed an indispensable part of this project. Of the movements associated with ultranationalist right-wing notions, the Etzel and the Lehi were the most noteworthy in their use of violence and terrorism. Such violence gave rise to much concern and dispute among the different political currents in the Jewish Yishuv (settlement) and continued unabated even after the dismantling of the British Mandate in Israel and the State's inauguration in the spring of $1948 .{ }^{8}$

The most noteworthy evidence of the persistence of this ideological polarisation after the State's establishment occurred approximately one month after the declaration of independence. The nascent State's political leadership, affiliates of the Labour Movement, elected to adopt the more radical of counterinsurgent options at its disposal in an attempt to put an end to the internal struggle over sovereignty, as well as to bring about the dissolution of the militant Etzel and Lehi movements. The incident strikingly illustrating this critical step toward the assimilation of the 'militant route' or 'war model' was the affair of the weapons' ship Altalena.

On 22 June 1948 the army's chief of operations ordered his soldiers to open cannon fire on the S.S. Altalena with the resolute intention of sinking the ship. This momentous incident took place not far off the shores of Tel Aviv. On deck there were members of Etzel and in its hold were abundant stocks of weapons brought from France by the organisation. This drastic step by the State invites the question - which continued to perturb the political echelons for a long while after the incident - whether in fact the weapons' ship Altalena was such a threatening element that it left the decision-makers with no alternative but to employ the most extreme measure at their disposal.

The answer to this question is multifaceted. Behind the scenes of the Altalena affair, there was the attempt by the month-old State to quickly raise an army to contend with the overall state of war that existed at the time. In order to organise such an army, it was necessary to combine all the clandestine elements that were in operation prior to the State's establishment into one common national framework. ${ }^{9}$ However, to hastily unite several factions, often divided by vast ideological chasms and a history of bitter confrontation, in a common framework was no mean feat. Furthermore, the various elements of the new army less than willing to surrender their respective distinctions and forgather under a single national framework in which the Labour Movement had a highly dominant role. The Etzel, for example, strove to maintain a degree of autonomy in the new State-run army context and asked that its members be accorded a favoured status in the distribution of weapons seized from the Altalena. ${ }^{10}$ The State leadership saw this as a genuine threat because, specifically, they were 
fearful of an armed, ideological militia operating within army ranks. This threat, as perceived by the State leadership, was in line with the conventional explanation of countries deciding to adopt strategies of the 'militant route'. ${ }^{11}$

As the ship drew closer to the shores of Tel Aviv, the sense of threat to the leadership grew, for the latter were of the opinion that members of Etzel were attempting to form an alternative power centre with the intention of challenging the authority of the leadership of the new-formed State. ${ }^{12}$ These considerations raised the odds favouring a military option. In the meantime, those members of Etzel who had been conscripted into the budding national army abandoned their posts and made their way to the location at which the ship was expected to berth, thereby exacerbating the feeling of imminent threat, already prevalent, among the executive leadership. This sense of apprehension might explain why they did not listen to the Etzel leader Menahem Begin who, in response to the escalation, attempted to reach a compromise with this same leadership and thus prevent the sinking of the ship and the consequent loss of life. Instead, Prime Minister David Ben-Gurion's ministers chose to accept the stark picture portrayed by Ben-Gurion, that of Etzel as an immediate and unacceptable challenge to the new sovereign Government. ${ }^{13}$ In the end, the ship was bombarded and scuttled, the list of fatalities including 16 Etzel members and 3 IDF (Israeli Defence Forces) soldiers.

At this juncture, the question debated by many scholars studying BenGurion's actions at the time should be raised. Was his decision to use such military force due to the feeling that the sovereign Government was indeed in grave jeopardy, or was this simply an opportunity to disable his political foes? Horowitz and Lissak elect to confirm the assumption that applying 'war model' tactics to the Altalena affair and the elimination of Etzel were steps taken in order to consolidate governmental stability. From their point of view, Israel's aggressive policy toward the S.S. Altalena was only another variation on a universal theme according to which a group seizing power, within the context of the institutionalisation of nationalist and social revolutions, must apply force in order to rid itself of any radical elements carrying the potential to undermine the regime's stability. ${ }^{14}$ Departing from this view, Barzilai submits a more critical stance and argues that a political act was in fact effected: Ben-Gurion's real concern was to prevent the build-up of hostile political forces and potential adversaries to his own party's Government. ${ }^{15}$

Whether Ben-Gurion's motives were driven by sectarian considerations or were in the national interest, the Altalena affair signified the advent of an extensive campaign whose aim was to crush oppositional militarist factors in the country. The operation included army raids on all Etzel military installations, a sweeping arrest of the movement's leaders, and, in effect, the total dismantling of its military capacities. ${ }^{16}$ 
With the dissolution of Etzel, the era of the deployment of the 'war model' against Jewish political violence in fact came to an end. The higher ranks in charge of the infant State of Israel began to edge towards the adoption of the 'extended criminal justice model' which, at least in the first years of its implementation was characterised by an ambiguous frame of operation and an inclination to occasionally slide back toward the 'war model'.

\section{The State of Israel from the 1950s to the 1970s: the institutionalising of the 'extended criminal justice model'}

\section{Constitutional and legislative foundations of the 'extended criminal justice model'}

To reiterate: whereas the 'war model' in its simplest form relies on the rules of war rather than any constitutional or legislative basis, in contrast the 'extended criminal justice model' is bound to the principles of some sort of formal legal foundation. The legal system that evolved in the State of Israel served as fertile ground for the institutionalisation of a model of this type. Except for the United Kingdom, Israel is the only democracy which does not have a written constitution ensuring basic liberal rights, including the freedom of speech and freedom of association. Notwithstanding the internal political reasons forestalling the adoption of such a constitution, the budding State was under a genuine threat from its Arab neighbours, and that fact consolidated a sweeping public consensus on the issue of the precedence of security and military matters over civil rights. However, the sense of foreboding has persisted and this 'security complex' continued to dominate policy and political discourse for many years. Therefore, it should come as no surprise that over the course of its fifty-three years of existence, Israel has not adopted a constitution, nor has it ever retracted the state of emergency under which it has operated for all those years, making it possible to effect far-reaching extensions of the notion of the 'rule of law'. ${ }^{17}$

The existence of a state of emergency in Israel constitutes a key factor in understanding the institutionalisation of the 'extended criminal justice model'. Hofnung argues that a 'state of emergency' is a governmental declaration of the existence of an exceptional set of circumstances, therefore requiring the adoption of extraordinary measures. ${ }^{18}$ The principal manifestation of the state of emergency in Israel was the adoption of a complex system of regulations intent on preserving state security, even at the expense of basic individual rights. An attempt to make sense of this tangled web of regulations will have to distinguish between three types of emergency legislation:

1 Defence (Emergency) Regulations, 1945: inherited from its predecessor, the British Mandatory Authorities in Palestine, these regulations grant a great 
deal of power to the military command. High-ranking officers are authorised to order house demolitions, impose curfews, make arrests, carry out searches and detain suspects without judicial restraint. The enforcement of these regulations within Israeli borders - especially with regard to Jews - is uncommon and has been carried out only with the approval of the highest levels of the executive authority (the cabinet or the minister of defence).

2 Section 9 of the Law and Administration Ordinance, 1948, which authorises the executive authority to suspend, revoke or alter parliamentary legislative measures in cases of emergency.

3 Parliamentary emergency legislation. ${ }^{19}$

For the purposes of this discussion, presented here are seven major operational courses, deriving principally from the 1945 Defence Regulations, which have helped lay the formal foundations for the adoption and institutionalisation of the 'extended criminal justice model': ${ }^{20}$

- Administrative detention. Intended to prevent threats to state security or public safety, the exercise of this measure was not contingent upon the commission of a felony or the suspicion of involvement in one. In the Defence Regulations, an administrative detention was defined as the authorisation to arrest a person, without trial, for a period of up to six months. The minister of defence and, under special circumstances, the chief of staff, were vested with the authority to impose such detentions.

- Restriction on freedom of expression. Its principal manifestation was the existence of a military censor who possessed the authority to prohibit the publication of any items, including daily newspapers which, in his opinion, posed a threat to national security.

- Restriction of the freedom of association. The most severe measure available to Israeli governments, whose purpose was to limit the freedom of association, is provided in the 'unlawful association' clause of the Defence Regulations. This clause stipulates that unlawful organisations are those that recommend, or incite towards, the eradication of the Israeli or governmental constitution with the use of force, or who are responsible for the incitement to hostilities against the government of Israel or one of its ministers, or the destruction of the property of the government of Israel or acts of terrorism aimed at the government or its employees. The maximum penalty to be imposed upon a member or supporter of such an organisation is ten years' imprisonment.

- Restriction on freedom of movement. An individual suspected of subversive activity may, according to the powers vested in the State by the Defence Regulations, be subject to a restraining order that will confine him or her to his or her area of residence and require that he report daily to the police station. 
- $\quad$ Special courts. Defence Regulations authorise the chief of staff to set up special courts for individuals suspected of activity which may jeopardise state security. Another legal proceeding is putting such suspects on trial in a civil court of law on condition that those courts sustain verdicts in accordance with emergency legislation. ${ }^{21}$

- Ordinance for the Prevention of Terrorism. One of the principal legislative measures available to courts trying suspects of subversive offences is the Ordinance for the Prevention of Terrorism No. 33, 1948. According to paragraph 8 of the ordinance, the executive authority is responsible for determining whether or not a political movement is a terrorist one. An illustration of the rigidity of the ordinance is found in paragraph 2, which determines that an individual taking part in the establishment or activity of a terrorist organisation, or even in dispensing propaganda in any form, will be guilty of an offence for which the maximum sentence is twenty years' imprisonment. $^{22}$

- Special legislation regarding the occupied territories. Territories occupied by Israel in 1967 are not subject to state laws (apart from East Jerusalem and Golan Heights, which have been annexed by law), in which case those areas are subject to international laws of occupation, thus authorising the regional military commander to take any measures necessary to maintain control of, and order in, those territories. ${ }^{23}$

Such measures were most often exercised against the Palestinian population, though, as Cohen-Almagor has pointed out, Jewish settlers were also occasionally subject to administrative detention orders. ${ }^{24}$

From the above, it seems that there was a situation in which the lack of a constitution necessary for safeguarding civil rights combined with the state of emergency which existed, entailing the potential enforcement of a wide array of decrees and regulations that substantially digressed from the notion of the 'rule of law' in its liberal democratic sense. This combination provided Israel with the tools needed to administer a model of response that, despite what appeared to be couched in a legal framework, was still a far cry from the more demanding requirements of the 'criminal justice model'. Further evidence of its deviation from the limits of the 'criminal justice model' could be found in the decision, which in due course became ossified into tradition, to place the brunt of the response to extremism and political violence upon an operational intelligence body (counterintelligence) and not the police force.

\section{The status of the General Security Service (GSS)}

Contrary to expectations set forward by the ideal type of the 'criminal justice model', which puts the full onus for the fight against extremism and violence on 
the shoulders of the police, the central body dealing with threats of extremism, subversion and political violence in Israel is the Shabak. Police services are employed principally in the final stages of the investigation, that is, in the arrest of felons and their arraignment in court.

Once again it is possible to see how the State institutionalised a model of response which kept the army away from any involvement in political violence and terrorism within Israel's boundaries. At the same time, it ensured the exclusion of the police force as well. Appointing the Shabak as the institution responsible for contending with these incidents is clearly indicative of the State's attempt to adhere to some sort of framework within the 'rule of law' - yet not in the liberal perception of this notion.

Unlike the Israeli police force, the legal status of the Shabak is indeterminate. ${ }^{25}$ Furthermore, unlike in other countries such as the United Kingdom, where there is a system of robust public control over the secret services, ${ }^{26}$ in Israel there is a lack both of the legislation necessary for defining the limits and methods of the Shabak and of public accountability on the part of the GSS. ${ }^{27}$ A frail constitutional infrastructure enables the widespread existence of the phenomenon Crelinsten calls 'provocative policing', i.e. actions not necessarily designed to collect anti-terrorist evidence for the sake of prosecution, but rather in order to serve intelligence aims of the security forces. ${ }^{28}$ Moreover, the lack of a viable system of accountability also opens the door to actions verging on the illegal or what Carmi Gillon, former head of the Shabak, calls operating in the 'grey' areas. ${ }^{29}$ Among the 'grey' tools at the Shabak's disposal - but denied to the police - are wiretapping, gathering under false pretences information about individuals, investigations which include the use of physical and mental coercion, and liberal access to the data banks of various authorities with reference to, inter alia, the State's citizenry.

Contrary to the legal developments which, in recent years, encouraged the State of Israel to proceed toward a more bona fide interpretation of the 'rule of law' (a theme discussed later), in point of fact the status of the Shabak has changed little since the 1950s. Efforts also recently invested in the late 1990s to pass 'Shabak legislation' and, in general, to more clearly define the mandate of the organisation's action, have raised some knotty questions. Paragraph 7 of the law proposal discussing the goals of the GSS and its roles, determines that

the Service is in charge of protecting the State's security, the order of its affairs and its institutions from threats of terrorism, espionage, breaching of secrecy and other activities that may cause it damage. The Service is also responsible for the protection and promotion of other vital sovereign interests of the State as determined by the government. ... ${ }^{30}$ 
In their comparative review of legislation concerning the activities of the secret service, Zimerman and Kremnizer find support for the inference that this type of institution almost naturally tends to extend its range of operations to those so-called 'grey' areas which stand in contradiction to the rule of law. Therefore, the essence of a law pertaining to the secret service would need to regulate the organisation's activities and chiefly set the limits of its authority by means of a clear mandate and by maintaining an effective system of accountability. The ambiguous wording of the legislative proposal with regard to the Israeli Shabak, as far as Zimmerman and Kremnizer are concerned, undermines this plausibility and removes the law in its current rendition from the realm of democratic acceptability. ${ }^{31}$

In the first decades of its existence, the State of Israel therefore engendered a quasi-legal framework for its counterextremist activities. The generous conditions of prosecution and the fact that an institution of counterintelligence, benefiting from a lack of accountability, was assigned this function, provided the State with a broad and almost limitless field of operation in its struggle against radical and violent elements.

\section{The operational aspects of the 'extended criminal justice model'}

The first sign of genuine transition from the 'war model' to the 'extended criminal justice model' became evident already in the last stages of the dissolution of Etzel and in the administrative detention of five leaders of that organisation. These former commanders were granted the right to appeal to the Supreme Court, ${ }^{32}$ a fact which proved that the security forces were liable to the civil court system, even if this subordination was still partial. However, the most significant step towards the adoption of the 'extended criminal justice model' and the repudiation of the 'war model' became apparent in those actions taken to eliminate the smallest and most zealous underground right-wing organisation at that time, the Lehi. The incident that prompted this process was the assassination of the Swedish diplomat and United Nations mediator for Palestine, Count Folke Bernadotte.

Bernadotte was killed on 17 September 1948, in a well-planned ambush by Lehi members. The State's immediate response to the assassination was more in compliance with the 'war model'. Soldiers from the Palmach (elite army squads) unit raided Lehi military camps, closed down Lehi offices and arrested dozens of its members. ${ }^{33}$ However, the next significant step was more moderate, conforming to the judicial frame that took shape under the state of emergency. Three days after the murder, the Government declared Lehi a terrorist organisation, thus expediting the process of the indictment of Lehi-affiliated members, including those who had not been active participants in its operations. Where 
evidence was found to be less incriminating, members were subject to arrest and administrative detention.

These steps were an indication that the State of Israel had become an established reality and therefore a sovereign entity bound to a system of rules, albeit an initially frail judicial structure. Every use of military force against civilians now had genuine potential to harm the public legitimacy of the new Government. The 'extended criminal justice model' was consequently acknowledged as an option often necessary for governmental stability both in order to gain legitimacy and to justify the expulsion of violent antagonists.

As for the motive behind the identification of Lehi as a terrorist organisation, Barzilai argues that the decree was more inclined towards the de-legitim of - and thus subduing - governmental opponents than it was based on the rationale of taking counterterror stabilising action. ${ }^{34}$ Notwithstanding the sound basis of this argument, it seems that the disavowal of the 'war model' in favour of the 'extended criminal justice model' demonstrates how Ben-Gurion, in his efforts to undermine his political opponents, in fact chose a more restrained approach and ended the rigid methods employed in the earlier stages of the struggle against Etzel.

The decision to shift the responsibility for dealing with Jewish extremism and violence from the army to the Shabak was another indication of the institutionalisation of the 'extended criminal justice model' as the dominant doctrine in the struggle against Jewish terror. Isser Harel, founder of the Shabak, began the process of segregating the GSS from the army, thus reinforcing its status as an autonomous non-military body. According to Harel, this made it easier to reconcile between security operational needs, on the one hand, and the legal constraints of a democratic political system, on the other. Harel also attempted to set the ground rules for GSS operations. As he saw it, the role of the organisation in the struggle against terrorism should be limited to preemptive surveillance and interrogation. Evidence, once gathered, would then be transferred to the police for further investigation and prosecution, if necessary. ${ }^{35}$

On the face of it, it seemed that Harel's aspiration, to judge from his descriptions, was to limit Shabak's role to 'reactive policing' in relation to Jewish terrorism, a move Crelinsten regards as intended to keep counterterrorism within the rigid restraints of the 'criminal justice model'. However, both the test of reality as well as allegations tendered by Carmi Gillon, who directed the Shabak forty years after Harel, prove that the course chosen by Harel and his successors was undeniably 'provocative policing'. For example, security agents would regularly identify targets - including political movements - as potential threats to subsequently shadow them and to pursue the actions of their leaders in order to gather information. ${ }^{36}$

The early 1950s witnessed a number of events which helped provide the means for the institutionalisation of the 'extended criminal justice model'. Three 
radical movements sprouted at that time: Brit Hakanaim (Covenant of the Zealots), Hamachaneh (The Camp), and the Zrifin (the name of the prison where members were held) Underground. ${ }^{37}$

The first two movements eventually merged under a common leadership composed of militant Haredim (members of the ultra-orthodox) who objected to the Zionist character of the State but, ironically, received most of their inspiration from Lehi operations. At first their actions amounted primarily to hooliganism and damage to property, therefore making Shabak involvement unnecessary. However, when it reached the stage where the police found themselves quite powerless in restraining the organisation, the Shabak was asked to assume responsibility for dealing with this group, and so took on the task of quelling its operations. Harel, the Shabak's head at the time, planted two agents among its ranks whose mission was to monitor and report member movements. After receiving intelligence reports regarding the intention of the organisation to step up its actions and engage in more militant tactics of terror, the Shabak launched a comprehensive campaign against the group and its supporters, and twenty suspects were put under administrative arrest. ${ }^{38}$

The handling of the Zrifin Underground, or Kingdom of Israel Underground, is an even more striking example of the increasing entrenchment of the 'extended criminal justice model'. The Underground, whose members were also chiefly inspired by the Lehi tradition, began its foray into terrorism in the winter of 1953, and on 9 February of that year it carried out its most violent and bold attack. A large bomb was detonated at the Soviet embassy building in Tel Aviv and three diplomats were injured. Following an investigation coordinated by the GSS and the police force, the Israeli Government decided to enforce the Ordinance for the Prevention of Terrorism against the group. ${ }^{39}$ In addition, for the first - and, in effect, the only - time in the history of the State of Israel, a special military court was set up to adjudicate the allegations made against members of a Jewish terrorist organisation. ${ }^{40}$

By the mid-1950s, the number of violent threats made by the Jewish public began to wane. It would be hard to categorically determine whether the enforcement of the 'extended criminal justice model' led to this decline, or whether other factors were responsible, such as the processes of institutionalisation which the country was undergoing, or the unrelenting tension with Arab countries that substantially contributed to the consolidation of the Jewish public of this State in its attitude to its political leadership and national symbols. That said, and refraining from an attempt to determine a causal relationship between the two, it could be inferred that the attenuation of threats was also accompanied by a substantial change in the assorted toolkit of counterinsurgency adopted by the State. 


\section{The State of Israel from the 1970s until the new millennium: towards a model of criminal justice}

\section{Modifications to the legal basis}

With the advent of the 1970s, a legislative infrastructure began to take form in Israel. Its goal was to contain the complex of state reactions to the challenges it was faced with in a more democratically stable legal framework. This infrastructure addressed three essentials of the democratic system: human liberty; freedom of expression; and freedom of assembly.

- Liberty. In 1979, the procedure of administrative detention secured legal status by power of the statute of authorities, emergency provision (arrests). It differed from the earlier Defence Regulations by imposing a limited judicial review on the minister of defence's decision to exercise administrative detention. The new enactment stipulated that the administrative detention warrant be presented before the president of the district court within fortyeight hours of the act of detainment. Despite this adjustment, the rationale behind the idea of administrative detention remained unchanged: namely, the State takes upon itself the right to impose restrictions upon an individual's freedom as 'preventive measures' and without arraignment before a court of law. Moreover, the law set forth special instructions regarding the concealment of evidence held against the detainee, which authorise the minister of defence to prevent the detainee from examining the evidence compiled against him or her, including information often constituting reasons for his or her arrest. ${ }^{41}$

- Freedom of expression. The decrees prohibiting sedition and incitement, as well as incitement to racism (amendment, 1986) of the Penal Code, 1977 were in effect intended to establish judicial grounds for existing limitations on the freedom of expression. It should, however, be noted that the offence of sedition as set down in the Penal Code is currently under the constant criticism of judicial and liberal factions. Their main objection is that these enactments provide the State with too much of a free hand when taking severe steps against radical political activists, a predicament that, according to the Association for Civil Rights in Israel, puts freedom of expression in the country in considerable jeopardy. ${ }^{42}$ Further confirmation of this approach is submitted by Kremnizer and Gnaim, who underscore the liberal approach by arguing that making sedition a criminal offence deviates from the conventional boundaries of a democratic system, overly restricts the freedom of expression and does not accord with the principles of legality and clarity. They propose replacing this offence with a number of penal restrictions defined in an explicit and lucid fashion, and of a more limited nature, which also may help avert unrestrained enforcement during times 
of crisis. ${ }^{43}$ However, while the charge of sedition remains a point at issue, the ruling against incitement to racism appears to be a law constrained by a well-balanced system of checks and balances, enabling it to be included under the bona fide definition of the 'rule of law'. On the one hand, the law makes it possible to protect society at large from the scourge of racism; and, on the other, the law tends to significantly restrict administrative retaliation in regard to its violators. The maximum penalty for an offence of incitement to racism cannot exceed five years' imprisonment and, furthermore, unlike for other criminal offences, clause 144e of the ruling stipulates that in each case where the State intends to file suit for crimes of incitement to racism a written agreement from the attorney general must be obtained. ${ }^{44}$ At the end of 2000, a strong effort was made to push forward additional legislation on the subject of incitement, this time in reference to incitement to violence. The purpose of this legislation was to replace the use of clause $4 \mathrm{a}$ of the Ordinance for the Prevention of Terrorism. ${ }^{45}$

- Freedom of assembly. The Penal Code, 1977: Illegal Assembly significantly curtailed the range of areas decreed illegal by the Defence Regulations and in fact incurred substantial reductions in penalties (a maximum of three years' imprisonment in contrast to the ten-year sentence originally ordained by the Defence Regulations). Like the conviction for incitement, the right of indictment with regard to illegal assembly was given solely to the Attorney General. Another law related to the freedom of assembly was the Law of Associations, 1980, whose purpose was to regulate civil associations in Israel. Clause 3 of the law determines that an organisation will be denied formal registration if one of its aims is incompatible with the existence of the State of Israel or its democratic character, or if there is reasonable cause to believe that the association may be used as a front for illegal activities. ${ }^{46}$ This law does not outlaw the existence of assemblies of this type but it denies them the rights granted to formally registered associations.

The above legislative efforts regarding the freedom of expression and assembly are indicative of Israel's attempt to confine its struggle against extremism and violence to an acceptable democratic framework. It nonetheless appears that the fact that it had not, at the very outset, sought to eliminate the practice of administrative detention or completely abolish the option of exercising the Defence Regulations (which can be replaced by the above-mentioned laws) shows that the State preferred to retain a wide range of operation and counteractive means which continue to deviate from common democratic principles. A survey conducted for the purposes of the present study indicates that the State's predisposition to retain these forceful means of response is broadly endorsed by the Jewish population in Israel. Seventy-four per cent of the respondents agreed with the statement asserting that the Emergency Regulations existing since the 
State's establishment are vital for the preservation of its security. Sixty-nine per cent supported the notion that administrative detention is a legitimate tool to be employed in the interests of state security. Another 54 per cent agreed that the Shabak, and not the Israeli police force, is the appropriate agent for dealing with ideological delinquency perpetrated by the Jewish extremists.

As outlined above, the State of Israel has an equivocal approach regarding the measures to be employed in the operational struggle against extremism and violence. This is a significant factor in determining that a regression to extreme response tactics marked by a substantial extension of the conception of the rule of law' still occurs in many cases, even though there does seem to have been a gradual improvement in sustaining the unadulterated rule of law.

\section{Issues accompanying the contraction of the 'criminal justice model'}

In this section, I scrutinise Israel's response to five instances of Jewish extremism and violence of the last three decades. The examples are as follows: the Kach Movement; the Israeli radical left; the 'Jewish Underground'; Rabbi Uzi Meshulam's violent group; and the events preceding the assassination of Prime Minister Yitzhak Rabin. The comparative analysis of these events demonstrates not only the different responses to these respective threats, but elucidates the factors encouraging and inhibiting the toughening or moderation of each response.

\section{The Kach movement}

Kach appeared in Israel in late 1971 and was in effect an offshoot of the violent and vigilante American organisation the Jewish Defence League. When the leader of the movement, Rabbi Meir Kahane, emigrated to Israel, it seemed that his intention was to import the League's violent methods to this new arena. As early as 1972, Kahane and his followers proved to be a significant challenge to the State of Israel when, in the August of that year, Kach simulated a public show trial incriminating the mayor of Hebron, Mohammed Ali Jabari, for his part in the 1929 massacre of Jews in this city and the later events of the 1948 War of Independence. In order to carry out this trial, Kahane and his adherents defiantly entered the mostly Arab city, thus creating significant potential for violent confrontation. However, the security forces quickly intervened.$^{47}$ Soon after, Kahane stepped up his actions and his people became involved in smuggling weapons to Jewish terrorists with the aim of causing damage to the Libyan embassy in Brussels. ${ }^{48}$

A retrospective look at the evolution of the Israeli response to the Kahane phenomenon indicates that in his first years in Israel the security forces had a problem evaluating the charismatic Rabbi's intentions. The culture of extrem- 
ism and violence which he and his followers brought with them into Israel substantially differed from anything previously experienced in the country. Therefore, enforcement authorities preferred to look upon him more as a provocateur than as a terrorist. In 1973, for instance, he was given a two-month suspended sentence on routine criminal charges for conspiring to commit offences in the United States. The conviction was based on evidence from letters he wrote to his adherents encouraging them to engage in acts of terror. ${ }^{49}$

Seven years later, the security forces had formed a more concrete assessment of his terrorist potential and, in consequence, began to treat him differently. The Kach leader became a principal object of surveillance by the security services, ${ }^{50}$ and an extensive system of intelligence was employed by them against Kach. Some of the information compiled by these means ultimately led to the administrative detention of Kahane in 1980 for a period of four months consequent to his organisation's designs to fire a long-range missile at the Dome of the Rock Mosque on the Temple Mount. ${ }^{51}$ During the years 1984-88, when Kahane served as a Member of Parliament, Shabak suspended its surveillance due to a provision that prohibits the policing of elected public officials. Nonetheless, his supporters and party members remained under strict observation both during his service as MP and also after the disqualification of his party just prior to the 1988 elections and his subsequent return to extra-parliamentary activities. $^{52}$

In the November of 1990, a fatal blow was delivered to the Kach Movement. The murder of the Rabbi in New York completely devastated his organisation and led to the dispersal of his followers among two minor movements - Kach and Kahane Hai. An interesting point is that, despite the peripheral status of these political movements in terms of the Israeli political discourse of those years, they still remained a main target of undercover work.

In March 1994, and in the wake of the massacre perpetrated by Dr Baruch Goldstein at the Tomb of the Patriarchs, the Government decided to enforce the Ordinance for the Prevention of Terrorism against these two movements. This governmental resolution strikes one as quite dramatic considering that only two small splinter groups were the alleged concern. Notwithstanding the occasionally aggressive element in these movements, ${ }^{53}$ their ranking on the list of violent extremists at the time was minor, particularly in view of the radicalisation of the Israeli right, which included either collective or individual blatant acts of defiance against the rule of law and governmental legitimacy. Still, as if the enforcement of the Ordinance for the Prevention of Terrorism was not enough - making it significantly easier to detain and prosecute radical activists - a short while after the Goldstein bloodbath, the Government issued warrants for the administrative arrests of nine Kach and Kahane Hai members. ${ }^{54}$ This gesture reinforces the feeling that the State of Israel had indeed resolved to take especially stringent measures in this case. Israel's approach, in terms of its policy of 
reprisal for extremism and violence, propelled the State many years backwards to its early years.

The enforcement of the Ordinance for the Prevention of Terrorism specifically against these movements and the arrest of its members seem quite out of proportion to the alleged threat that they posed; and the pretext for this decision appears peculiar. Baruch Goldstein was identified as a 'lone wolf' at the time he committed the massacre at the Tomb of the Patriarchs of his own accord, unassisted by any organisation, a fact that was later substantiated in the findings of the State Commission of Inquiry set up to investigate the events of the slaughter at the Tomb of the Patriarchs. ${ }^{55}$ That being so, why did the Government take such forceful and disputable action? Cohen-Almagor submits the following explanation for its actions: exercising the Ordinance for the Prevention of Terrorism against these organisations was an inevitable development simply because the Government of Israel had no other means to deal with these movements. ${ }^{56} \mathrm{He}$ bases his conclusion on a number of theoretical tests. One of them is the examination of consequences. This type of analysis adopts contrasting assumptions. The first assumption, which questions the very need for the ordinance, argues that its enforcement will not be particularly effective because the radical movement core will continue to survive and its members will remain active, perhaps under a different name and exercising more caution. Another consideration, and no less important, is that the enforcement of the order would draw the political system close to a slippery slope in terms of its ethical foundations. The second assumption supports the need for the ordinance and views its use as a formidable declaration and rejection of the legitimacy of these organisations and as an attempt to expel them from the licit boundaries of society. ${ }^{57}$

A review of these events shows that the State of Israel has indeed reached the precipice at the end of this slippery slope. On the one hand, the execution of the Ordinance for the Prevention of Terrorism has perilously eroded its liberal foundations and, on the other, the movements that were affected by the ordinance remain active and almost unperturbed by its implementation. At the November 2000 rally in tribute to Rabbi Kahane ten years after his assassination, the helplessness of the authorities of the law was apparent in respect of the enforcement of the ordinance. Throughout the memorial ceremony, activists cited excerpts from Rabbi Kahane's publicly outlawed manifesto and wore shirts embossed with the rabbi's visage and party insignia. Two months later, following the murder of the rabbi's son and leader of Kahane Hai Binyamin Kahane (who was a random target of Palestinian terrorists), these movements proved once again their resilience to the State's measures, and also gave indication of their expanding membership. In significant numbers, activists from the two banned movements showed up for the younger Kahane's funeral proces- 
sion, which quickly transformed into a display of force. Followers of the two movements committed acts of brutal violence against Arabs encountered during the course of the funeral procession, waved their flags and called for revenge. ${ }^{58}$ Itamar Ben-Gvir, one of the more prominent activists of Kach, summed up things by saying that 'trying to make the Movement illegal is simply a joke'. ${ }^{59}$

In effect, the slide down the slippery slope and the State's estrangement from the fundamental conception of the 'rule of law' have been more painful than Cohen-Almagor anticipated. He argued that the enforcement of the ordinance was supposed to have prevented the use of administrative procedures which, in his view, were in any case illegitimate means in the struggle against terrorism. The fact remains that activists from dismantled movements continue to be under the constant surveillance of the security services and the exercise of administrative procedures has not become any the less popular. Since the use of administrative detention, for Kahane's devotees, was renewed in the wake of Tomb of the Patriarchs' slaughter, warrants for the restriction of movement and arrest of activists in Judea and Samaria have been issued on a regular basis, ${ }^{60}$ and these are additional to the measures assigned to the State by the Ordinance for the Prevention of Terrorism. ${ }^{61}$ That said, it should be noted that the judiciary, having a more liberal approach, tends to prefer the freedom of members of Kach and therefore, the number of actual convictions remains disproportionately low in comparison to the number of prosecution referrals. Furthermore, judges have consistently admonished prosecuting attorneys for their over-zealousness in bringing charges against members of these movements and for the numerous charge-sheets they continue to serve against violators of the Ordinance for the Prevention of Terrorism. ${ }^{62}$ This posture assumed by the courts presents the judicial authority as a critical mainstay in the struggle to uphold the principles of 'the rule of law' vis-à-vis an executive authority which prefers to sacrifice those values on the altar of 'security protection'.

Attempts to explain what persuaded Israel to respond with such severity to these organisations at a time when it seemed that the use of the "criminal justice model', in its narrowest terms, would have sufficed, lead to the conclusion that first and foremost, the very feasibility of this Ordinance stemmed from these movements' marginality. By exercising the ordinance in relation to these two radical groups, the State was able to send out a forceful message against those elements of terrorism indicated above by Cohen-Almagor. The timing of this decision was also significant. The whole affair took place in the first few months after the signing of the Oslo Agreements, at a time when a number of powerful right-wing elements were coordinating huge demonstrations - some of them violent - against the Government. Kach and Kahane Hai were ideal targets, allowing the State to deliver an ostentatious message to all sides involved. Their 
considerable political marginality made their denunciation possible without risking severe public dissent or the mobilisation of a parliamentary lobby for their cause.

Another explanation for the ironhanded and isolated governmental response to these two movements in particular can be found in the security system's outdated and entrenched perspective. Over the years, state leaders and security services have regarded Kach and Kahane Hai as the most extreme and violence-prone factions on the fringes of the far right. In retrospect, particularly following the assassination of Rabin, this policy has turned out to be misguided ${ }^{63}$ In any case, these movements proved to be easy targets for the enforcement of a policy of brash response, a posture readily adopted by intelligence factors that preferred to adhere to their outmoded perspective instead of extending their view in the direction of the more genuine threats taking root at that time.

In conclusion, the Supreme Court's decision to convict Binyamin Kahane of seditious offences one month prior to his murder is, paradoxically, indicative of how Israel elected to moderate its stance toward the Kach Movement. This conclusion is due to the fact that Kahane, who was tried for the distribution of a pamphlet proclamation in 1992 in which he called for the bombing of the Arab city of Um el-Fahm, was convicted in accordance with clause 134(4) in the Penal Code appertaining to the offence of sedition. Theodore Or was the Supreme Court Justice responsible for prosecuting Kahane, and on that same day he also acquitted journalist Mohammed Jabarin, who had been accused of publicly supporting the intifada (the Palestinian uprising) in Judea and Samaria. His explanation for these rulings was that while Jabarin was sentenced according to paragraph 4(a) of the Ordinance for the Prevention of Terrorism, which prohibits public praise for grave acts of violence, Kahane's trial was standard criminal procedure. Moreover, Or determined that while paragraph 4(a) of the ordinance "is a draconian clause which is hard to accept in an enlightened society where freedom of expression is highly esteemed', the offence of sedition as defined in the Penal Code was intended to promote the heterogeneous existence of an Israeli society comprised of a diverse populace. In addition, the legal formulation of the sedition offence was very restrained; that is, in order to convict a person of acts of sedition, it must be proven that there is a "considerable' degree of sedition and that there is a high probability of the commission of violent acts subsequent to the defendant's proclamation. ${ }^{64}$

At this stage, in order to avoid unduly simplified conclusions, we are compelled to redouble the effort to be cautions. Indeed, the assumption at the base of the notion of the democracy's 'immunising' policy posits that responses limited to legal frameworks are more acceptable than responses anchored in administrative regulations or special procedures. Certainly, the lesson taught by experience with regard to the party political system indicates that, in the major- 
ity of cases, Israeli-drafted laws whose goal was to contend with incidents of political extremism can be seen as weighed and balanced structures subject to scrupulous judicial commentary. However, as already noted, the law enabling conviction for offences of sedition deviates, according to some, from the accepted standards of the democratic system. The legal advisor Professor Miri GurAryeh specifically took issue with Justice Or's approach in his verdict regarding Kahane and, in effect, represented a line quite similar to the general arguments raised by Gnaim and Kremnizer. In Gur-Aryeh's view, there is justification for convicting a person who has initiated a discourse with the potential to fuel a violent atmosphere. She argues that conviction should be aimed against violent acts, whereas public speaking with the potential to create a violent climate must be dealt on a level other than the criminal. ${ }^{65}$ In sum, I do not retract the approach that conviction by dint of law indicates restriction of the democratic response to the boundaries of the 'immunised route'. However, at the same time, it seems a justifiable assumption that judicial frameworks should also be liable to critique and renewed evaluation from time to time, and that, in any case, the law should be clear and transparent and include only the minimal limitations essential for upholding democracy.

\section{The radical left in Israel}

Another group significantly marginal to the Israeli political scene, and hence also considerably vulnerable to policies along the lines of the "extended criminal justice model', is the radical left. Despite Sprinzak's argument that, in comparison to left-wing European organisations, the radical left in Israel has proved to be a relatively benign element because it rarely engages in violent action, ${ }^{66}$ Israeli policy-makers tend to view organisations such as Hanitzotz ('The Spark') and The Revolutionary Communist League and, later, Derech Hanitzotz ('The Path of the Spark') as terrorist factions. The reasoning was that these movements did not recognize the State of Israel's right of existence and, moreover, were financially endorsed in part by George Habash's Popular Front, Ahmad Jibril's Democratic Front and Naef Hawatmeh's Maoist-orientated organisation. Therefore, these movements were branded as Shabak intelligence targets and their members were closely watched. Furthermore, apprehended members of these bodies were tried and convicted under the Ordinance for the Prevention of Terrorism, and not according to standard criminal procedure. Of significant interest, and confirming the thesis that marginal groups are more susceptible to strong state counteraction, is the fact that Carmi Gillon, one of the intelligence leaders in the struggle against them, addressed them as 'a completely marginal phenomenon, having no effect whatsoever on society and a phenomenon which never threatened the fragile consensus in this country'. ${ }^{67}$

If that was truly the case, why were organisations identified as only mini- 
mally subversive subject to the same policy as those that persistently engaged in political violence? The following example shows both how this factor of marginality comes into play here and also how the 'politicisation' of the fight against terrorism reflects the Israeli State's general orientation toward the radical left. According to Barzilai, a prominent example highlighting the political use of the Ordinance for the Prevention of Terrorism is found in the amendment made to the ordinance in 1986 (paragraph 4h). The purpose of this modification (championed by the Likud Party) was the prevention of meetings between Israeli leftwing activists and Palestinian representatives. Ultimately, the Supreme Court had to decide the matter and, choosing to avoid political confrontation, it imposed prison sentences on the leftist activists who took part in such meetings. The almost laughable incongruity of this matter became acutely evident when, during meetings between Rabin Administration and PLO representatives in Oslo in the summer of 1993, official delegates of the Israeli Government found themselves in violation of the regulations of the Prevention of Terror Ordinance. ${ }^{68}$ This incident lends further credence to the assumption that groups suffering from weak political backing are more likely than those with stronger backing to be labelled 'terrorist' regardless of the degree of threat they pose to the country. By the same token, it is apparent that counter-terrorist policy and the enforcement of counter-terror measures are substantially influenced by political interests and, in this particular instance, the political sway of one party over another in the attempt to preserve a coalition balance of forces.

\section{The Jewish Underground}

Further confirmation of the above assumptions from a reverse ideological angle is exemplified in the case of the Jewish Underground, which sprang from the settler movement in Judea, Samaria and Gaza - Gush Emunim. Devoted to the ideology of the 'Greater Land of Israel' and inspired by the theology of Rabbi Kook, ${ }^{69}$ its principal mode of action - implemented immediately upon its formation - was the construction of illegal settlements in Judea and Samaria, occasionally leading to confrontation with the law authorities, as in the case of the Sebastia settlement in July $1974 .{ }^{70}$ Despite that flagrant civil disobedience, the attorney general, with the endorsement of Prime Minister Yitzhak Rabin, chose to avoid bringing the settlers to (criminal) trial.

Gillon's thesis implies that the decision to refrain from the prosecution of these settlers was not free of political interests: legal considerations were subordinated to the prime minister's aim to avert needless political confrontation, especially in view of the strong political lobby backing the settlers. ${ }^{71}$ Gillon adds that the decision not to enforce the law against these offenders in effect opened a path toward the radicalisation of several members, eventually leading to the 'Jewish Underground', the most sophisticated Jewish terrorist organisation in 
Israeli history. Among other actions, its members were responsible for severely disabling the mayors of Ramallah and Nablus in the summer of 1980 by sabotaging their $\mathrm{cars}^{72}$ and also for the attack on the Islamic College in Hebron about three years later.

In consequence of these acts of aggression, Prime Minister Menahem Begin ordered the security services to take forceful action against the perpetrators. The Shabak was assigned the mission, but, in this instance, the organisation elected to adhere to a more moderate modus operandi defined by limited goals. The GSS proceeded to gather all evidence possible in the attempt to bring the culprits to trial. Then, following intensive investigation and the collection of sufficient incriminating evidence, the police and Shabak carried out the bulk of the arrests and began to interrogate suspects, who complied to the full. An interesting fact is that both Gillon, who led the investigation, and Haggai Segal, one of the detainees, reported that the interrogation of suspects was conducted in a civilised manner and without the use of Shabak's standard methods. ${ }^{73}$

It can therefore be surmised that despite the involvement of the GSS in the investigation of the Underground, it would be difficult to classify this as a case typical of the 'extended criminal justice model', because the Shabak's role in this case was in effect restricted to standard police procedures. The process of convicting the organisation's members also backs up the assumption that, in this instance, the State preferred to remain faithful to a more light-handed, so to speak, policy of counteraction. Unlike its the treatment of the underground movements of the 1950s, Israel elected this time not to use the legal methods of the 'extended criminal justice model'; in other words, it did not declare the movement to be terrorist, nor did it establish a special court or exercise other administrative measures against members and supporters of the Jewish Underground. All members of the movement stood criminal trial and were brought before a criminal court of law.

A short while after they were convicted (the gravest offence was murder), a great deal of political pressure was applied to grant them pardon. This pressure was so effective that in a matter of years not one member of the Underground remained behind bars. This is clearly illustrative of the reason for Israel's adherance to the 'criminal justice model'. The State's relatively liberal response to the most sophisticated and brutal Jewish terrorist organisation the country has known was a result of exactly the same circumstances which led it to react to marginal and minimally threatening movements with much more severity and ironfisted measures.

The ruling elite and the designers of Israeli defence policy opted not to respond to the Jewish Underground on account of the threat it posed or the severity of its actions, but rather on the basis of the political and public clout to which it had access. The Underground benefited from broad public support, principally among religious Zionists and right-wing parties, e.g. the Mafdal and 
the Tehiyah, and even the former Prime Minister Yitzhak Shamir unreservedly supported the pardoning of organisation members. ${ }^{74}$

An additional factor helping to solve this analytic puzzle is the security forces' and the State's adherence to certain conceptions, in this case cultural conceptions. Members of the religious Zionist camp, who also formed the wellspring of the Underground, had struck a positive chord and earned a dependable reputation in Israeli political discourse. Many ordinary Israeli citizens, as well as politicians, found them to be a rejuvenated image of the authentic Zionist pioneer. ${ }^{75}$ Unlike members of Kach, who had mostly emigrated from the United States and the USSR, and were therefore strangers to Israeli culture, followers of the Jewish Underground represented the very heart and core of the Zionist-Israeli experience. ${ }^{76}$ These devotees even 'captured the hearts' of their interrogators. According to Gillon,

The atmosphere in the interrogation of the Jewish Underground suspects was quite exceptional. Most of the people arrested were considered all-round 'excellent boys', they were officers in the IDF and many of them had served in units which had worked closely with the Shabak. Now, unexpectedly, there was a situation of interrogator and suspect and they were sitting on the side of those being interrogated, in the role of the accused. ${ }^{77}$

Hence, despite the gravity of the acts committed, the personal background of the terrorists, as well as their political backing, were factors responsible for almost completely upending the type of counter-terror tactics enforced against them.

\section{Uzi Meshulam's group}

Use of the 'criminal justice model' in Israel in its purest form can be detected in the State's response to the 'Yehud Affair'. This incident began in the winter of 1994 when a religious sect, led by the charismatic Rabbi Uzi Meshulam, began to barricade themselves in the rabbi's house. The declared goal of this sect was to urge the Government to launch an investigation into the 1950s' disappearance of Jewish Yemenite children, a social wound that had yet to heal. ${ }^{78} \mathrm{In}$ order to cast off all doubt with regard to the group's unquestionable militancy and potential for terror, the words of the incumbent Police Inspector-General Assaf Hafetz at a governmental session speak for themselves. Hafetz described the Meshulam coterie as an 'unprecedented and extreme nationalist terrorist group'. He added that actions committed by the group cannot be anticipated and may lead to disastrous consequences, ${ }^{79}$ and this evaluation later proved to be not far from the truth. Meshulam's group confirmed its dangerous potential even in the first days of their fortification, when adherents threatened to use live weapons if and when security forces took action against them. 
But, as noted above, the Israeli response was to handle them with much restraint and to remain within the narrowest limits of the "criminal justice model'. The takeover of the group and arrest of its members were conducted by the Israeli police forces who opened fire at the barricaded building only after the first volleys had been discharged by the building's occupants. After their arrest, Meshulam and his followers stood trial under standard criminal procedure. During the course of the trial, there were reports that Meshulam devotees were dispersed at locations around the country and were intent upon attacking law officials and engaging in vengeful acts of violence in wake of the verdict. ${ }^{80}$ These reports, too, did not lead policy-makers to implement the Ordinance for the Prevention of Terrorism against this group, nor to take administrative measures against its members. However, the police exhausted every inch of its authority within the standard criminal procedure in order to investigate group members and use the rigour of law against them. ${ }^{81}$

An effort to grasp why the State chose this course of reaction and continued to adhere almost totally to the 'criminal justice model' leads the reader once again to the contentions raised above. As for the marginality-based explanation, Uzi Meshulam and his believers did not benefit from a broad base of support similar to that enjoyed by members of the Jewish Underground. Nonetheless, they were successful in prescribing the public agenda by brandishing an issue that touched a raw nerve in the collective memory of Israeli society. Subsequent to the group's entrenchment in the Meshulam residence, a political front emerged consisting of public figures and Members of Parliament who demanded a State-run commission of inquiry into the Yemenite children affair. Scrutiny of the political reasons behind this policy reveals that the State of Israel was indeed interested in dropping the matter of the abducted Yemenite children from the political agenda for fear of ethnic riots. If these occurred, any aggressive action taken by the State against Meshulam and his people might serve to keep the issue in the political spotlight and subsequently lend credence to their claim that the State was trying to keep them quiet.

As for the adherence to outdated conceptions - our main argument for the authorities' handling of this case, Uzi Meshulam's group operated out of socioethnic motivations, traditionally not considered by security forces to be associated with political violence. Policy-makers' adherence to the notion that Jewish terrorism is solely a result of the ideological cleavage between right and left prevented them from regarding the fortification of an armed sect with a charismatic religious leader as a terrorist threat. Therefore, in this instance, the special security services and more rigorous counter-terror measures were forsaken, and instead the 'criminal justice model' was implemented in full.

In view of the outcomes of the above events, it appears that the "criminal justice model' has proved itself to be the most efficacious in comparison to other models employed by the State of Israel. In the July of 1999, Uzi Meshulam was 
released from prison after serving nearly five-and-a-half years of his sentence, on condition that he would be responsible for severely restricting the number of people allowed in his house and limiting his connections with the media. ${ }^{82}$ At the time of writing, two years after Meshulam's release from prison, the leader remains in retirement from political action and his group is dispersed.

\section{The assassination of Prime Minister Yitzhak Rabin}

The traumatic incident that brought down the fragile 'house of cards' of the Israeli response to political extremism and violence and returned the State to more extended counter-terrorist operations was the assassination of Prime Minister Yitzhak Rabin. On 4 November 1995, at the conclusion of a mass peace rally organised by the Israeli left-wing, the prime minister was shot by a Jewish religious assassin, Yigal Amir, a student of law at the Bar-Ilan University, who regarded the Oslo Agreements as a disaster for the people of Israel and considered Yitzhak Rabin to be a traitor to his country.

The murder of the prime minister was the culmination of an Israeli extremist right-wing crusade spearheaded by nationalist and ultra-orthodox religious factions, which began shortly after the signing of the Oslo Agreements between Israel and the PLO in September 1993. The mounting extremism was marked by severe infractions of the law and clearly illustrates the factors influencing the change in Israeli policies of counter-violence.

In general, the Israeli response to extremism associated with the Oslo Agreements can be divided into two main time-frames. The first, prior to the prime minister's assassination, was distinguished by a fairly indifferent approach on the part of the law's authorities to extremists, especially with regard to incitement offences and serious provocations against the legitimacy of the ruling Government. The second, post-assassination, frame, was marked by the persecution of agitators and the use of a variety of measures at government's disposal against those who had incited and rebelled against the Rabin Government. ${ }^{83}$ The hasty shift from an initially fairly indifferent standard to a position bordering on panic demonstrates the lack of a clear and consistent policy to counter extremist and violent elements. Furthermore, the running of the country in the first few months after the prime minister's violent death was a prominent indication of the considerable problems involved when a state, on one hand, lacks a fixed policy of enforcement and, on the other, has recourse to a wide array of legal and semi-legal measures in its response to extremist phenomena.

The events of the first days following Yitzhak Rabin's assassination were instructive of the depth of the shock to the security system and institutions of law and enforcement. Three days after the assassination, the headline 'Steps to Be Taken Against Extremists' was spread across the front page of the widely 
circulated Israeli daily Yediot Aharonot. The item reported the convening of an emergency council of the Ministry of Justice in reaction to the demand for a more severe penalty against inciters and the need to launch a criminal investigation against individuals who had extolled Rabin's murder. ${ }^{84}$ In fact, a short while after the murder, the Integrated Law Enforcement Task Force against Incitement and Sedition Offenders was instituted. The composition of the force, which included appointees from the army, police, the Shabak and the state attorney, was already enough to indicate the State's regression from the 'criminal justice model'.

The most interesting conclusion drawn from an overview of the procedures undertaken by enforcement agencies following the assassination is that while standard criminal proceedings as prescribed by the 'criminal justice model' were applied to the murderer and his accomplices, the State's position regarding the system that formed the conceptual foundations of the murder was fundamentally different.

The extensive assortment of measures exerted upon far right-wing activists, who the State found responsible for providing the religious-idealist license for the murder, found its expression a few weeks after the tragic event. Rabbi Yitzhak Ginsburg, head of the Zealot-oriented yeshiva Ohd Yosef Hai ('Joseph Still Lives On'), was arrested at the start of 1996 by order of the prime minister and the minister of defence and was put under administrative custody for a period of nineteen days. ${ }^{85}$ The rabbi was arrested on account of a pamphlet that he had distributed in September 1994 in praise of the murderer Baruch Goldstein. Shmuel Sitrin and Aryeh Freidman, extreme right-wing activists who expressed support for the murder of the prime minister, were also placed under administrative detention by dint of a warrant signed by the brigadier-general of the Central Command. ${ }^{86}$

In contrast, when David Belhasan, a resident of Kiryat Arba (a Jewish settlement near the city of Hebron), in an interview with the CNN television network, committed a similar offence by expressing joy at the death of the prime minister on the day of his funeral, he was convicted under the Ordinance for the Prevention of Terrorism of declaring words of praise, sympathy and encouragement for a violent act. Belhasan received a suspended prison sentence of three years. ${ }^{87}$ The State's approach with respect to the case of Belhasan - even according to Talia Sasson, director of the state attorney's Department of Special Duties - was marked by 'overstated justice' due to the stormy climate, fomented by the prime minister's assassination, among members of the prosecution. ${ }^{88}$ Indeed, four years after his conviction, Belhasan was acquitted by the Supreme Court. His acquittal was predicated on precedents decreed by Justice Or in his verdict in respect of the journalist Jabarin, according to which the Ordinance for the Prevention of Terrorism may not be applied in the conviction of offences of incitement. ${ }^{89}$ 
Generally speaking, it seems that in the period following the assassination of the prime minister, enforcement of the Ordinance for the Prevention of Terrorism - also against individuals having no connection with the organisation to which the Ordinance was applied - became the preferred counteractive stratagem of the State. In November 1997, the extreme right-wing activist Michael Ben-Horin, who prepared the book Baruch Hagever ('Baruch the Man', and Goldstein's first name) for publication, was sentenced to eight months in prison. This book is entirely devoted to words of praise regarding the actions of the murderer Baruch Goldstein. As a result, Ben-Horin was accused of incitement to racism under paragraph $114 \mathrm{~b}$ of the Penal Code, but, at the same time was convicted for supporting a terrorist organisation under the ordinance. ${ }^{90}$

Avigdor Eskin, an ex-Kach activist who cast the kabalistic death-wish, the pulsa denura (Aramaic, meaning, approximately, '[to smite with] fiery lashes'), upon Yitzhak Rabin and who, after the latter's death, told television photographers that the curse had been completely fulfilled and that he was planning next to curse the incumbent Prime Minister Shimon Peres, was also convicted under paragraph 4 of the ordinance, and was sentenced to four months in prison and one year suspended. ${ }^{91}$ In October, 2000, he was once again convicted, in compliance with the Ordinance for the Prevention of Terrorism, for commending an act of violence. Found in Eskin's possession were stickers with the following words printed on them: 'He will redeem us' ('will redeem' in Hebrew is yigal, also the first name of Rabin's assassin; the meaning of the sticker, therefore, was that the assassin 'Yigal will save the People of Israel').$^{92}$ In view of the Jabarin precedent and the Belhasan acquittal, the prosecution also withdrew charges levelled against Eskin and acquitted him in both cases. ${ }^{93}$

The Ordinance for the Prevention of Terrorism was not the only means employed in this case. Enforcement authorities also tended to utilise the criminal law whenever an opportunity arose. In the months preceding the prime minister's assassination, Moshe Feiglin, leader of the Zu Artzenu ('This Is Our Country') movement, preached as well as practised civil disobedience, primarily by blocking central intersections and carrying out illegal attempts at establishing settlements. For these acts, he was convicted of sedition and for publishing seditious material,,${ }^{94}$ and was confined to a half-year in prison and received a one-year suspended sentence. ${ }^{95}$ Rabbi Ido Elba, on the other hand, who distributed among his students in April 1994 an article whose theme was 'Inquiry into the (Halakhic) Principles of Killing Gentiles, ${ }^{96}$ was sentenced to two years in jail and received a two-year suspended sentence on the grounds of committing an incitement to racism offence as stipulated in the Penal Code. ${ }^{97}$ Two extreme right-wing activists, who brandished signs showing Prime Minister Yitzhak Rabin in SS uniform during an anti-government demonstration in October 1995, were also brought to trial after the murder. In this case, as well, the trial remained within the confines of the criminal law, and they were convicted of 
libel $:{ }^{98}$ however, at the same time, other right-wing activists who were indicted in the same charge-sheet were accused and convicted of the offence of supporting a terrorist movement. ${ }^{99}$

A number of important conclusions can therefore be drawn. First, every one of the activists affected by state counteractive and penalising measures after the murder of Yitzhak Rabin came from the right-wing fringes and were not affiliated to any of the central political bodies of this camp. In effect, there is clear evidence of a pecking-order in terms of the measures enforced against the various activists of the camp: as activists are closer to the political centre, the State's means of reprisal becomes more moderate. This complies with the marginality thesis as well as the notion of the politicisation of the governmental response. It is especially interesting in view of the intensive involvement of the mainstream Israeli right in acts of incitement against the prime minister, ${ }^{100}$ yet not one single politician from this camp was interrogated in this matter. Further corroboration for the marginality explanation can be found in comments made by Professor Eyal Benvenisti of the Hebrew University, who strongly condemned the State's heavy-handed policy against offences of incitement, which remained in force even several years after the prime minister's assassination. In his words, 'the erosion of the commitment to freedom of expression is responsible for the danger of selective enforcement and the possibility that the bulk of indictments will be served against the weak and eccentric or people whose opinions and expressions may happen to rub the prosecution the wrong way'. ${ }^{101}$

A second inference pertains to the fact that while the State had a wide variety of statutory measures at its disposal for the purpose of accusing and arraigning extremists, in many cases, authorities still preferred to utilise precisely those measures that significantly diverged from the accepted legislative framework of the criminal process. This fact is of special importance because, according to Sasson, it is an indication of how the protection of basic democratic liberties - and, foremost, the freedom of expression - is very important to state enforcement agencies and, as a result, a greatly abbreviated policy was decided upon concerning all aspects of indictments pertaining to issues that might constrain such liberties. However, the test of consequences and Sasson's testimony itself demonstrate that members of the general prosecution do not make an adequately clear distinction between the more democratic tools such as the Penal Code and the less democratic measures such as the Ordinance for the Prevention of Terrorism and, therefore, often seek to convict a person or group of people under the two frameworks at the same time. Furthermore, decisions made by the general prosecution were not always a direct outcome of the impartial deliberation between the State's commitment to respond to extremism and the safeguarding of democratic principles. As argued above, extra-legal considerations, such as the prosecution's emotional state following the prime minister's assassination, had a significant effect on policy formation. 
The considerable sensitivity which developed among state prosecutors in relation to incitement offences in the wake of the prime minister's assassination sparked sharp debate among Israel's most prominent scholars as to the boundaries of the freedom of expression in the country. Locking horns with those who advocated the enforcement of laws restricting the freedom of expression, ${ }^{102}$ many senior Israeli jurists argued against the prosecution and the attorney general. They felt that the extensive regulation of expressions of opinion on the part of citizens and public appointees, whether on the basis of administrative rulings or various legal clauses, suppresses, to a great extent, the freedom guaranteed by the democratic system. These jurists demanded that the State differentiate between the legal and the legitimate: they called for a distinction to be drawn between actions deserving to be tried in a court of law and those warranting a 'social trial'. Ironically, legal scholars who had previously argued that extremist declarations should be treated using legal and judicial means, argued in this case that extra-judicial means - and, above all, the education system and civil society - are to be preferred. ${ }^{103}$ This orientation conforms with our a major contention of this book - to be discussed later - regarding the importance of the education system to democratic principles and to the vibrant functioning of the 'pro-democratic civil society' in the process of the transition from a 'defending democracy' to the 'immunised' trajectory of response.

In summation, the comparative perspective applied to the five cases presented above indicates that despite the appearance of a gradual tendency towards a more restrained policy of response, it seems that variables associated with political or security system considerations and conceptions are of notable impact still on the nature of the response. Hence, it can be posited that, even at the start of the third millennium, a clear-cut policy of counteraction is yet to materialise in Israel and that, in effect, the majority of the decisions reached by systems of security and enforcement are in response to a specific occurrence.

\section{Conclusions}

The emerging reality in Israel since its establishment indicates that in contrast to the policy regarding extremist political parties, which has undergone a perceptible process of 'immunisation', in relation to the policy of response towards radical and violent movements this process has proven to be more equivocal. However, one cannot overlook the far-reaching changes in the nature of the State's response to these phenomena in the fifty-three years of its existence. In legal terms, the State of Israel has endeavoured to steer retribution as much as possible in the direction of democratically acceptable frameworks, and therefore it has made an effort to replace emergency-empowered authorities with legal capacities listed in a parliamentary consensus. One of the more prominent 
manifestations of this was demonstrated during the Fifteenth Knesset's term in office with the launching of a commission whose role was to evaluate the plausibility of revoking the prolonged state of emergency. ${ }^{104}$ However, it seems that for as long as the State's executive order feels that the State is exposed to grave security threats, both outside and inside its borders, the chances are remote that the emergency state will be retracted or that the Shabak's role will be delimited in a type of legislation befitting a democratic system of government.

The more substantial modifications that took place in Israel's policy of counteraction reside in its operational aspects. In general, the State of Israel in its earliest years already discarded the use of the 'war model', that is, the approach which holds the army responsible for dealing with Jewish extremism. As time passed, and with the adoption of the 'extended criminal justice model', a more moderate trend became institutionalised, according to which it seemed appropriate to entrust the treatment of these phenomena to the Shabak and make use of administrative measures. However, in due course, and principally with regard to the case of the Jewish Underground, the State sought to refrain from overdoing the severity of its response and tried to limit it as much as possible to the narrower boundaries of the 'rule of law', i.e. to the 'criminal justice model'. This tendency reached a peak in the handling of the Meshulam 'affair' which was limited entirely to the bona fide realms of the rule of law.

What, therefore, is the likelihood that, with the start of the third millennium, the State of Israel will complete its 'immunising' process in the many respects of its response to Jewish extremism? Prima facie, the State's general tendency towards moderation, either in its attitude to extremist parties or in its approach to radical movements, can be seen as a deterministic process that will ultimately lead the Israeli policy of response to reside within genuine frames of the 'rule of law'. Still, a number of major obstacles in the path of this process must be accounted for.

First, it is again worth noting the relative weakness of the liberal tradition in Israeli political culture. ${ }^{105}$ In the absence of an underlying liberal culture, the conditions necessary for the adoption of modes of counteraction which respect the rights and liberties of the individual cannot prosper. Furthermore, the lack of a constitution which defines the State's principal tenets and ethical boundaries does not make it any the easier to determine which counteractive measures are legitimate and which are not. Inquiry into the Israeli public's attitudes to these questions reinforces the argument supporting the relatively modest status of liberal democratic values in the moral perspective of the Jewish society in Israel and reveals that the cultural underpinnings essential for significant change and the adoption of a liberal policy of counteraction are still shaky.

Although table 2.1 indeed indicates that the Jewish public in Israel tends to generally uphold the democratic framework of this country, however, a more 
Table 2.1 Commitment to democratic values and attitudes (findings appear as percentages and include the answers 'agree' and 'absolutely agree')

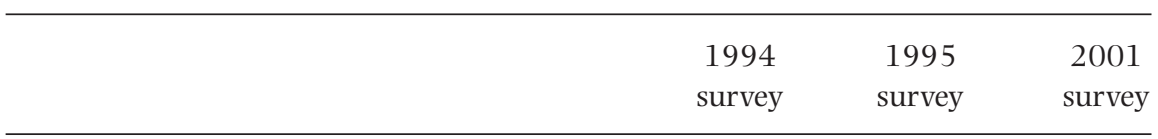

The State of Israel must uphold complete equal social and political rights for all its citizens regardless of religion, race or gender

In emergency situations as well, the government can be publicly and openly criticised

The lightest threat to state security is enough to justify serious restrictions of democratic rights

I prefer a democratic government whose opinions and actions are opposed to mine to a non-democratic government with whose opinions I agree

Source: 1994-95 surveys, Peres and Yaar-Yuchtmann 1998, pp. 237-9; the 2001 survey was conducted for the purpose of this study.

meticulous review of the results shows that in contrast to that disposition, a great part of the population (more than 25 per cent) rejects even the most basic democratic principles. Specifically, 41 per cent objects to the notion of equal social and political rights for all the country's citizens while, over the course of time, the percentage supporting the equalizing of rights is also gradually declining; 31 per cent objects to public criticism of the government in times of emergency; 62 per cent believes in imposing severe restrictions on democracy also in cases where there is a modest threat to state security; and, finally, 29 per cent prefers to live under a non-democratic government with opinions similar to theirs than to be ruled by a government that was democratically elected but does not represent their opinions.

This multi-faceted system of values has proven to be comfortable ground for the continued existence of Israel as a democracy, but it still underscores the more formal elements at the expense of substantial elements of the democratic polity. The ongoing Israeli-Arab conflict and the Israeli Jewish sense of apprehension regarding the State's Arab citizens constitute an additional key factor which may 
have a part in thwarting genuine reform in the Israeli response to extremism. Israeli society, which has been defined by sociologists as a 'society under siege', has developed, due to the protracted sense of looming peril, a considerable reliance on its security system and an attitude that comes close to being a veritable glorification of the Shabak and other elite units. A study conducted towards the end of 2000, despite the fact that it followed a lengthy period where the security establishment in general and Shabak in particular underwent noticeable erosion in their public image, fully confirmed the above assumption: 92 per cent of respondents expressed a strong belief in the Israeli Defence Forces (IDF), 90 per cent in Mossad and 85 per cent in Shabak. ${ }^{106}$ An opinion poll administered nine years earlier dealing with the attitudes of the Israeli public regarding the judicial system in general and the security context in particular, revealed that 46 per cent of Israeli citizens in this sample were absolutely opposed to judicial criticism served by the Supreme Court of Justice against the defence system's rulings. ${ }^{107}$ In a survey conducted for the purposes of the present research early in 2001, the 'index' now stood at 55 per cent of the population objecting to this type of censure. In this case, the Israeli security establishment continues to enjoy the almost complete and unreserved trust of the Israeli public, a fact which provides it with a very generous mandate for its operations.

One point that is of special concern, and which is a direct outcome of the non-liberal character of the Israeli democracy, pertains to the fact that the general propensity of the State's Jewish residents is for security considerations over democratic ones with regard to internal security. However, a significant gap can be found between their attitude towards Israeli Arabs (militant) and their attitude towards Israeli Jewish residents (liberal). A substantial rejection of the 'war model' and, indeed, the 'extended criminal justice model' as the preferred responses to extreme right-wing-instigated violence is apparent among the Jewish population sector (only 28 per cent supported the use of military means against violent radical right-wing activists while 42 per cent supported the transition of responsibility for the treatment of these activists from Shabak to the police). It is noteworthy that the attitude towards the response considered appropriate for extremists among the State's Arab residents is inverse: 62 per cent endorsed the employment of military means in regard to radical and violent actions among Israeli Arabs and 64 per cent supported the notion that the responsibility for dealing with the Arab population continue to be assigned to Shabak and not the Israeli police force. A summary of the results presented above indicates that the Israeli Jewish public may in fact aspire to live in a democratic state, but in each case where there is a conflict between democratic values and security concerns, it exhibits a consistent preference for security interests. In addition, the figures indicating the public's willingness to apply a more moderate model of response against extremists in the Jewish right-wing bloc still does not indicate a liberal approach; rather, the opposite is true. That the findings are 
inverted with regard to Arab Israeli militants and that the majority of the public tends to support the employment of the 'war model' against this sector reinforces the assumption that the desire to respond more lightly to right-wing extremists comes from an identification with them and not from an adherence to liberal democratic values.

In conclusion, justice and enforcement systems in Israel would seem to be willing to continue the process, and to adopt the 'criminal justice model'. Its main principles consist of the liberalisation of the response to extremism and violence and a greater adherence to the fundamentals of the 'rule of law' in a democracy. There are, however, still major obstacles to the adoption of this 'model' as the Israeli doctrine of response.

The existence of such factors as the defence system's outdated conceptions, the intrusion of political interests and external events in decision-making on the policy of response and, furthermore, the absence from the immediate context of a distinct constitutional structure and especially its lack of a liberal democratic political culture, make it difficult for the ultimate transition of the Israeli response to Jewish extremism and violence to substantially democratic frameworks. In the ensuing chapters, I attempt to provide an answer to the question, to what extent is it possible to identify the potential for change in Israeli society, in particular concerning its attitude to liberal democratic values, a change which must also supply the social basis for the democracy's immunising process?

\section{NOTES}

1 Peter Chalk, 'The Liberal Democratic Response to Terrorism', Terrorism and Political Violence, 7:4 (1995), p. 17; Peter Chalk, 'The Response to Terrorism as a Threat to Liberal Democracy', Australian Journal of Politics and History, 44:3 (1998), pp. 373-88.

2 For example, see the following works of Peter Chalk: 'EU Counter-Terrorism, the Maastricht Third Pillar and Liberal Democratic Acceptability', Terrorism and Political Violence, 6:2 (1994), pp. 103-45; 'The Liberal Democratic Response to Terrorism', pp. 10-44; West European Terrorism and Counter-Terrorism: The Evolving Dynamic (Basingstoke: Macmillan, 1996); 'The Response to Terrorism as a Threat to Liberal Democracy', pp. 373-88. See also Ronald D. Crelinsten, 'Terrorism and Political Communication: The Relationship Between the Controller and the Controlled', in Paul Wilkinson and Alasdair M. Stewart (eds), Contemporary Research on Terrorism (Aberdeen: Aberdeen University Press, 1987), pp. 3-23; Ronald D. Crelinsten, 'Terrorism, CounterTerrorism and Democracy: The Assessment of National Security Threats', Terrorism and Political Violence, 1:2 (1989), pp. 242-69; Ronald D. Crelinsten, 'The Discourse and Practice of Counter-Terrorism in Liberal Democracies', Australian Journal of Politics and History, 44:1 (1998), pp. 389-413; Ronald D. Crelinsten and Alex Schmid, 'Western Responses to Terrorism: A Twenty-Five Year Balance Sheet', Terrorism and Political Violence, 4:4 (1992), pp. 307-40; Charles Dunlop, 'The Politisation of the Military', Journal of Political and Military Sociology, 27:2 (1999), pp. 217-32; Ariel Merari, 'Deterring Terrorists', a Paper presented at the 'Terrorism and Beyond . . . the 21st Century' conference, Oklahoma City, 16-19 April 2000; Fernando Reinares, 'Democratic Regimes, 


\section{The State and subversion}

Internal Security Policy and the Threat of Terrorism', Australian Journal of Politics and History, 44:3 (1998), pp. 351-71; Ken G. Robertson, 'Intelligence Terrorism and Civil Liberties', in Paul Wilkinson and Alasdair M. Stewart (eds), Contemporary Research on Terrorism (Aberdeen: Aberdeen University Press, 1987), pp. 549-69; Dan Schiller, 'The Police Response to Terrorism A Critical Overview' in Paul Wilkinson and Alasdair M. Stewart (eds), Contemporary Research on Terrorism (Aberdeen: Aberdeen University Press, 1987), pp. 536-48; G. Smith Davidson, Combating Terrorism (London: Routledge, 1990); Paul Wilkinson, 'Pathways Out of Terrorism for Democratic Societies', in Paul Wilkinson and Alasdair M. Stewart (eds), Contemporary Research on Terrorism (Aberdeen: Aberdeen University Press, 1987), pp. 453-65.

3 Crelinsten and Schmid, 'Western Responses to Terrorism', pp. 332-3.

4 Crelinsten, 'The Discourse and Practice of Counter-Terrorism in Liberal Democracies', p. 399.

5 Moshe Negbi, Above the Law: The Constitutional Crisis in Israel (Tel-Aviv: Am Oved, 1987), pp. 11-13 (Hebrew).

6 Crelinsten and Schmid, 'Western Responses to Terrorism', p. 334.

7 Shlomo Aharonson, David Ben-Gurion - Fallen Leader of the Renaissance (Beer Sheba: Centre for the Heritage of Ben-Gurion, University of Ben-Gurion, 1999), p. 307 (Hebrew).

8 Bruce Hoffman, Inside Terrorism (London: Victor Gollancz, 1998), pp. 48-56.

9 Dan Horowitz and Moshe Lissak, Trouble in Utopia: The Overburdened Polity of Israel (Tel-Aviv: Am Oved, 1990), pp. 59-60 (Hebrew).

10 Ehud Sprinzak, Brother Against Brother Violence and Extremism in Israeli Politics from Altalena to the Rabin Assassination (New York: Free Press, 1999), p. 22.

11 Chalk, 'The Liberal Democratic Response to Terrorism', pp. 17-18.

12 Horowitz and Lissak, Trouble in Utopia, p. 60.

13 Sprinzak, Brother Against Brother Violence and Extremism in Israeli Politics, p. 24.

14 Horowitz and Lissak, Trouble in Utopia, p. 60.

15 Gad Barzilai, 'Center versus Periphery: Law of "Prevention of Terrorism” Acts', Plilim, 8 (1999), pp. 229-50 (Hebrew).

16 Uri Brenner, Altalena (Tel-Aviv: Hakibbutz Hameuchad, 1978), pp. 393-6 (Hebrew), quoted in Sprinzak, Brother Against Brother Violence and Extremism in Israeli Politics, pp. $30-1$.

17 The Israeli legislature continues to extend the state of emergency every half-year despite the fact that, in the last few years, there has been vibrant discussion regarding the need to replace the regulations anchored in the state of emergency with an alternative, more accountable, system of legislation which will establish the idea of a fundamental rule of law in the State. Gideon Alon, 'The Knesset Extended the State of Emergency for Another Six Months', Ha'aretz, 22 December 2000 (Hebrew).

18 Menachem Hofnung, Democracy, Law and National Security in Israel (Aldershot: Dartmouth, 1996), p. 26.

19 Hofnung, Democracy, Law and National Security in Israel, pp. 50-1.

20 An expanded specification of these means can be found in Menachem Hofnung, 'States of Emergency and Ethnic Conflict in Liberal Democracies: Great Britain and Israel', Terrorism and Political Violence, 6:3 (1994), pp. 347-51. For a comprehensive discussion of Israel's emergency state and its implications please refer to Hofnung, Democracy, Law and National Security in Israel.

21 Hofnung, 'States of Emergency and Ethnic Conflict in Liberal Democracies'; Hofnung, Democracy, Law and National Security in Israel.

22 Available online at: www.ict.org.il/counter_ter/law/lawdet.cfm?lawid=11 
23 Hofnung, 'States of Emergency and Ethnic Conflict in Liberal Democracies', p. 351.

24 Raphael Cohen-Almagor, 'Combating Right-Wing Political Extremism in Israel: Critical Appraisal', Terrorism and Political Violence, 9:4 (1997), p. 90.

25 Hoffnung, Democracy, Law and National Security in Israel, pp. 193-7.

26 Chalk, 'The Response to Terrorism as a Threat to Liberal Democracy', p. 387.

27 Carmi Gillon, Shin-Beth Between the Schisms (Tel-Aviv: Yediot Aharonot Books and Chemed Books, 2000), p. 424 (Hebrew).

28 Crelinsten, 'The Discourse and Practice of Counter-Terrorism in Liberal Democracies', p. 402.

29 Gillon, Shin-Beth Between the Schisms, p. 425.

30 Ariel Zimerman and Mordechai Kremnizer, A Comparative Analysis of the General Security Service Law Proposal (Jerusalem: Israel Democracy Institute, 1997), p. 18 (Hebrew).

31 Zimerman and Kremnizer, A Comparative Analysis of the General Security Service Law Proposal, p. 18.

32 Sprinzak, Brother Against Brother Violence and Extremism in Israeli Politics, p. 31.

33 Author Unknown, 'The Searches and Arrests in Tel-Aviv are Continuing', Yediot Aharonot, 19 September 1948 (Hebrew).

34 Barzilai, 'Center versus Periphery', p. 239.

35 Isser Harel, Security and Democracy (Tel-Aviv: Edanim Publishers - Yediot Aharonot, 1989), pp. 162-5 (Hebrew).

36 Gillon, Shin-Beth Between the Schisms, pp. 407-12.

37 Sprinzak, Brother Against Brother Violence and Extremism in Israeli Politics, p. 61.

38 Anon., 'Emergency Laws were Implemented against the Zealots', Yediot Aharonot, 17 May 1951 (Hebrew).

39 Isser Harel, The Truth about the Käsztner Murder (Jerusalem: Edanim Publishers - Yediot Aharonot, 1985), p. 58 (Hebrew).

40 Anon., 'Bachar: 12 Years, Heruti: 10', Yediot Aharonot, 25 August 1953 (Hebrew).

41 Tali Ben-Gal, Dana Alexander, Ariel Bendor and Sharon Rabin (eds), Human Rights and Civil Liberties in Israel (Jerusalem: Israeli Association for Human Rights; 1992), vol. 3, pp. 437-8 (Hebrew).

42 Moshe Reinfeld, 'Kahane Must Also Be Acquitted', Ha'aretz, 28 November 2000 (Hebrew).

43 Mordechai Kremnitzer and Khaled Gnaim, Incitement, Not Sedition, Attitudinal Tract No. 7. ( Jerusalem: Israel Democracy Institute, 1997) (Hebrew).

44 Ruth Gavison, Hagai Shneidor and Tali Ben-Gal (eds), Human Rights and Civil Liberties in Israel (Jerusalem: Israeli Association for Human Rights, 1991), vol. 2, pp. 192-3 (Hebrew).

45 Eitan Hess Ashkenazi, 'The Government Has Passed the Law Against the Incitement to Violence: It Will Now Be Brought Before the Knesset', Ha'aretz, 8 January 2001 (Hebrew).

46 Gavison, Shneidor and Ben-Gal, Human Rights and Civil Liberties in Israel, vol. 2, pp. 366-71.

47 Ehud Sprinzak, Buds of De-legitimate Politics in Israel 1967-1972 (Jerusalem: Levi Eshkol Centre for the Study of Economics, Society and Policy in Israel, 1973), pp. 62-3 (Hebrew).

48 Sprinzak, Brother Against Brother Violence and Extremism in Israeli Politics, p. 190.

49 Yair Kotler, Heil Kahane (Tel Aviv: Modan Publishers, 1985), pp. 199-204 (Hebrew).

50 Gillon, Shin-Beth Between the Schisms, p. 91.

51 Kotler, Heil Kahane, p. 144.

52 Gillon, Shin-Beth Between the Schisms, p. 92.

53 See Sprinzak, Brother Against Brother Violence and Extremism in Israeli Politics, pp. 124-30. 


\section{The State and subversion}

54 Yossi Hatoni, 'Right-Wing Activists Pitch a Tent Outside the Sharon Prison in Protest of Administrative Detentions', Ha'aretz, 15 August 1994 (Hebrew).

55 Report of the State Commission of Inquiry in regard to the Slaughter at the Tomb of the Patriarchs in Hebron - 1994 (Jerusalem: Hamadpis Hamemshalti), pp. 61-3 (Hebrew).

56 Cohen-Almagor, 'Combating Right-Wing Political Extremism in Israel', pp. 85-6.

57 Cohen-Almagor, 'Combating Right-Wing Political Extremism in Israel', pp. 87-8.

58 Gideon Meron, 'Lynch, the Masses Called For', Yediot Aharonot, 1 January 2001 (Hebrew); Shlomo Tsenza, 'Mass Funeral and Arab-Bashing', Ma'ariv, 1 January 2001 (Hebrew).

59 'Hundreds Celebrated at the Rally 10 Years to the Murder of Kahane', news item on Israeli Channel 2, 16 November 2000. Further information can be found at www.israelnews2.co.il

60 Personal interview with Itamar Ben-Gvir, a leading activist of the ex-Kach Movement (1 March 1999).

61 Baruch Karah, 'Is That a Way to Persuade a Judge?’, Ha'aretz, 30 August 1999 (Hebrew).

62 Baruch Karah, 'The Prosecution Is Having Trouble Convicting the Kahanists', Ha'aretz, 6 March 2001 (Hebrew).

63 Gillon, Shin-Beth Between the Schisms, ch. 16.

64 Moshe Reinfeld, 'Why Was Kahane Convicted and Jabarin Acquitted', Ha'aretz, 28 November 2000 (Hebrew). However, it should be stressed that the offence of sedition itself as it appears in the Penal Code makes it easy for the State to take strong steps against radical political activists; a fact, which according to the Association for Civil Rights in Israel, endangers the freedom of expression in the country (Moshe Reinfeld, 'Kahane Must Be Acquitted', Ha'aretz, 28 November 2000 (Hebrew). Confirmation of this approach can be found in the claim put forward by Kremnizer and Gnaim. The latter adopt a liberal perspective according to which the offence of sedition as it appears in the Israeli law books exceeds the accepted limits in a democratic polity, it disproportionately constrains the freedom of expression and does not accord with the principles of lawfulness and clarity. They propose the replacing of the sedition offence with a number of circumscribed punitive restrictions which are defined clearly and explicitly and are meant to prevent indiscriminate enforcement during times of crisis. Mordechai Kremnizer and Khaled Gnaim, Incitement, Not Sedition.

65 Aryeh Dayan, 'The Attorney General Hears and Writes Down Every Word', Ha'aretz, 1 February 2001) (Hebrew).

66 Sprinzak, Brother Against Brother Violence and Extremism in Israeli Politics, p. 121.

67 Carmi Gillon, 'The Ideological Criminal and Israeli Society', in Eyal Yinon (ed.), The Rule of Law in a Polarized Society - Judicial, Social and Cultural Aspects (Jerusalem: Israeli Democratic Institute, 1999), pp. 55-7 (Hebrew); Gillon, Shin-Beth Between the Schisms, p. 70 .

68 Barzilai, 'Center versus Periphery', pp. 242-3.

69 See Ehud Sprinzak, 'From Messianic Pioneering to Vigilante Terrorism: The Case of the Gush Emunim Underground', Journal of Strategic Studies, 10:4 (1986), pp. 194-216; and The Ascendance of Israel's Radical Right (New York: Oxford University Press, 1991).

70 Yossi Bar, 'Since Morning, Hundreds of Soldiers Evacuated Settlers Without Resistance', Yediot Aharonot, 29 July 1974 (Hebrew).

71 Carmi Gillon, 'Ideologically Motivated Lawbreaking on the Extreme Right within the Context of the Israeli-Arab Conflict', thesis submitted in partial fulfilment of the requirements for the MA degree, University of Haifa, 1990, pp. 121-2 (Hebrew).

72 Eitan Haber, Taufik Huri, Gad Lior, Yisrael Tomer and Chaim Shibi, 'It Is Estimated that a Small Jewish Group Is Behind the Assassinations', Yediot Aharonot, 3 June 1980 (Hebrew). 
73 Gillon, Shin-Beth Between the Schisms, ch. 9; Haggai Segal, Dear Brothers (Jerusalem: Keter Publishing, 1987), ch. 17 (Hebrew).

74 Gillon, Shin-Beth Between the Schisms, p. 156.

75 Yair Sheleg, The New Religious Jews: Recent Developments Among Observant Jews in Israel (Jerusalem: Keter, 2000), pp. 25-9 (Hebrew).

76 Noami Gal-Or, The Jewish Underground: Our Terrorism (Tel-Aviv: Hakibbutz Hameuchad, 1990), pp. 38-40 (Hebrew).

77 Gillon, Shin-Beth Between the Schisms, p. 116.

78 The real motive behind the fortification was apparently an escalation of a quarrel between neighbours.

79 Reuven Shapira, 'Meshulam's People Wrote Up a "Hit List" which Included Peres, Shachal, Hefetz and Ben-Porat: This Is a Nationalist Movement the Like of Which Has Never Been Seen Before', Ha'aretz, 15 January 1996 (Hebrew).

80 Reuven Shapira, 'Fears in the Shabak that Meshulam's People Might Carry Out Exhibition Attacks', Ha'aretz, 17 February 1995 (Hebrew).

81 Interview with Tzadok Chugi, Uzi Meshulam's lawyer, 2 March 1999.

82 Nina Pinto, 'Uzi Meshulam Has Been Released from Prison', Ha'aretz, 8 July 1999 (Hebrew).

83 For further details, see Talia Sasson, 'The Prosecution's Policy of Enforcement in regard to Offences of Sedition and Incitement', in Eyal Yinon (ed.), The Rule of Law in a Polarized Society: Legal, Social and Cultural Aspects (Jerusalem: Israel Democracy Institute, 1999), pp. 107-23 (Hebrew).

84 Anon., 'Steps to Be Taken against Extremists', Yediot Aharonot, 7 November 1995 (Hebrew).

85 Judith Winkler, 'MP Zeevi Demands Improvements in Detention Conditions of the Head of Ohd Yosef Hai Yeshiva', Ha'aretz, 18 March 1996 (Hebrew); Sherry Makover, 'In Wartime, There Is No Time for Looking for Dirty Linen', Maariv, 12 January 2001 (Hebrew).

86 Gideon Alon, 'More People Are Summoned by the State-Comptroller Committee in Connection to the Issuance of Restriction Orders against Right-Wingers', Ha'aretz, 24 January 1996 (Hebrew).

87 Anon., 'Settler Who Expressed Joy at Rabin's Murder Was Convicted of Violating the Ordinance for the Prevention of Terrorism', Ha'aretz, 8 April 1997 (Hebrew).

88 Sasson, 'The Prosecution's Policy of Enforcement in regard to Offences of Sedition and Incitement', p. 111.

89 Moshe Reinfeld, ‘Individuals Accused of Publicly Praising Rabin's Murder Have Been Acquitted', Ha'aretz, 29 March 2001) (Hebrew).

90 Anon., 'Eight Months in Prison for the Author of the Book "Baruch Hagever", Extolling the Murderer Goldstein', Ha'aretz, 28 November 1997 (Hebrew).

91 Raphael Cohen-Almagor, Speech, Media and Ethics (Basingstoke, Hampshire: Palgrave, 2001), pp. 90-1.

92 Moshe Reinfeld, 'Eskin Was Convicted of Commending Violence by Carrying in His Possession Stickers with the Words "He Will Redeem Us"', Ha'aretz, 11 October 2000 (Hebrew).

93 Moshe Reinfeld, 'The Prosecution: Acquit Eskin from Commending Violence', Ha'aretz, 30 March 2001 (Hebrew).

94 Moshe Feiglin, Where There Are No Men (Jerusalem: Masada, 1997) (Hebrew).

95 Moshe Reinfeld, 'Half-Year in Prison for Moshe Feiglin and Four Months for Shmuel Sect, Leaders of the Zu Artsenu Movement', Ha'aretz, 12 November 1997 (Hebrew).

96 This article also appeared as a chapter in the aforementioned book Baruch Hagever. 


\section{The State and subversion}

97 Moshe Reinfeld, 'Halakhic Inquiry or Incitement', Ha'aretz, 7 October 1996 (Hebrew).

98 Cohen-Almagor, Speech, Media and Ethics, p. 85.

99 Sasson 'The Prosecution's Policy of Enforcement in regard to Offences of Sedition and Incitement', p. 117.

100 Michael Karpin and Ina Friedman, Murder in the Name of God (New York: Metropolitan Books-Henry Holt \& Co., 1998).

101 Aryei Dayan, 'The Attorney General Writes Down Every Word', Ha'aretz, 1 February 2001 (Hebrew).

102 Shlomo Avineri, 'It's About Capital Cases', Ha'aretz, 5 February 2001 (Hebrew).

103 Eyal Benvenisti, 'The Response Racism Deserves', Ha'aretz, 7 February 2001 (Hebrew); Alon Harel, 'Permission Granted, But Not Legitimate', Ha'aretz, 7 February 2001 (Hebrew).

104 Knesset Minutes, 'Recommendation of the Joint Committee of the Committee for Security and Foreign Affairs and the Committee of the Constitution, Law and Justice; Emergency Regulations', 135th Session of the Fifteenth Knesset (Jerusalem: The Knesset, 24 July 2000).

105 Benyamin Neuberger, Democracy in Israel: Origins and Development (Tel-Aviv: Open University, 1998), pp. 30-55 (Hebrew).

106 Findings are from a survey presented at the Herzliyah convention on 'The State of National Endurance and Security', 19-21 December 2000.

107 Gad Barzilai, Ephraim Yuchtman-Yaar, and Zeev Segal, The Israeli Supreme Court and the Israeli Public (Tel-Aviv: Papyrus, 1994), pp. 100, 216 (Hebrew). 


\section{The Israeli response to extremism: the social sphere}

$I^{2}$

WHAT FOLLOWs, the focus of the analysis of the 'defending democracy' shifts away from the legal and judicial domains extensively discussed in the previous chapter. Here, I examine the extent to which the democracy can generate 'antibodies' which will help stay the expansion of political radicalism in society and, in this fashion, also reduce the mobilising potential of organisations and political parties calling for an alternative to democracy. The most promising means by which to obtain such 'antibodies' is the process of political socialisation. Among all the agents of socialisation to which an individual is exposed throughout his/her childhood and youth, there is one which remains entirely faithful to the goals of the state: the state-run educational system. Moreover, the official conduit for the inculcation of democratic values among schoolchildren of all ages is the civic education curriculum. Any system of governance, no matter of which type, aspires to educate its citizens in the spirit of its beliefs. According to Michael Walzer, the aim of political socialisation is to unite citizens around national symbols and key values of the state. This is a necessary condition for guaranteeing the legitimacy of the governing polity and its stability. ${ }^{1}$ This process of socialisation applies to totalitarian forms of government that, by means of political indoctrination, succeed in somewhat reducing the need for the coercive-violent mechanisms at their disposal. Democracies, too, are interested in inculcating and sustaining, by means of both formal and informal socialisation, the political conceptions basic to the ruling polity. ${ }^{2}$

The discourse regarding education in values and democracy is fundamentally a volatile one and has been the subject of much criticism, particularly from liberal and postmodern theorists who have traditionally disapproved of state involvement in the individual's privacy and the political sovereign body's attempt to shape its citizens 'in its image'. Yet as Levinson ${ }^{3}$ observes, in the 1990s - a decade rife with ethnic conflict - violence and political extremism had resurfaced globally and, in consequence, liberal theorists began to reveal new interest in the subject of civic education after years of disregard and neglect. 
Many in this field now consider an education programme dedicated to citizenship to be a highly important factor contributing to the development of the "civil society' and the preservation of the liberal state's stability. ${ }^{4}$

However, conforming to a traditional liberal stance, the writings of most of these scholars evince a rather narrow approach regarding the essentials of this democratic education. The core concept conveyed by this area of education, according to the majority of the liberalist school, should be the inculcation of the basic ideal of tolerance. ${ }^{5}$ Others extend the programme to include education in mutual respect but, generally speaking, not too much more. ${ }^{6}$ Departing from this approach, Levinson proposes teaching a more comprehensive profile of civic qualities while remaining faithful to the narrow boundaries of the liberal tradition. In her view, pupils in liberal democracies should learn about fundamental democratic rights, such as the freedoms of speech, assembly and religious expression, rights attaching to ownership and property, the right to privacy and the right to engage in political action. However, pupils must also be taught civic duties in order to be exposed to the formal aspect of governmental processes, that is, the constitution and constitutional proceedings, which form the value basis of the liberal state. Furthermore, Levinson suggests, the ways and means of political exercise should be taught. To achieve this, certain skills must be cultivated that will help pupils become more aware of political issues, including casting a ballot and even taking action if necessary. Finally, according to this approach, the school civics' curriculum should aim to generate in learners the basics of the critical assessment of political alternatives. ${ }^{7}$

Research conducted in the last decade has shown that some of the ideas discussed by Levinson have already been taken up by many liberal democracies and included in their curricula. ${ }^{8}$ Several countries, such as the United States ${ }^{9}$ and, at a later stage, Denmark and Germany, ${ }^{10}$ have expanded the role of civic studies from a reduced procedural perspective, which considers the structures and functions of governmental institutions, while consciously avoiding more controversial issues, to the adoption of liberal and even post-materialistic values into the school curricula.

However, while liberal democracies continue to debate the acceptable degree of state intervention in the education process as well as the nature of the ideas taught and the methods of conveying them, the quandaries with which the non-liberal democracy must struggle are much more profound. As illustrated in the introductory chapter, one of the main features of the non-liberal democracy is its adherence to the more formal meaning of the democratic idea. Democratic rules of the game are maintained, including free elections and multi-party competition but, at the same time, this form of government is distinct from liberal democracy. Conceptually, this is because non-liberal democracy places the interests of one group of citizens over those of other groups, encroaches upon the social sphere and restricts civil liberties. The non-liberal 
democracy is therefore laden with numerous incongruities, and these are even more prominent in its education system.

Nearly all of Levinson's proposals regarding civic education, as well as those of many other liberalist scholars, provide a genuine challenge for the "nonliberal democracy'. Liberal tradition places a strong emphasis on the individual and his/her liberties and this emphasis conflicts with the collective, and often ethnic, interest of the 'non-liberal democracy'. Consequently, the paradox - and an inherent failing - of the 'non-liberal democracy' acquire added meaning when applied to the provision of citizenship lessons.

Incapable of reconciling the contradiction between the polity's democratic and non-liberal principles, the 'non-liberal democracy' - and especially one that must contend with extremist elements - meets head on with paradox. On the one hand, it will attempt to inculcate democratic values among its pupils, in particular the essentials it believes will prevent future citizens of the state from becoming enamoured with radical ideologies and anti-democratic ideas. It will try to direct them towards action within legal political frameworks and, in that fashion, reduce the impact of the challenges it will inevitably face and, in consequence, be able to moderate its response to these elements. On the other hand, in the paramount importance invested in the national ideal and through the mobilisation of the dominant ethnic collective in the interests of the state there is the risk that, in the very cultivation of nationalist tendencies among the majority, ethno-nationalist seeds are planted which eventually may burgeon and ironically foster these same radical elements.

In the ensuing parts of this chapter, I attempt to examine how the State of Israel has contended with these paradoxes and, by the same token, try to find an answer to the paramount questions. Has the state-run education system in Israel undergone a gradual transition towards an increased emphasis on democratic values in its school curricula, consequently leading to the reinforcement of the 'immunisation' of the 'defending democracy?' Alternatively, has the non-liberal element gained the upper hand, thus reducing the prospects for the complete abandonment of the 'militant' attitude in response to extremism?

\section{Civics education in Israel: the predominance of nationalist ideas in the first decades}

In her comprehensive review of the evolution and formation of citizenship education in Israel, Orit Ichilov distinguishes between two major periods: the years preceding the State's establishment (pre-1948) and those following it. ${ }^{11}$ In the pre-State period, the predominance of nationalist particularistic values and an almost complete absence of democratic tendencies were both prominent. However, this can be attributed to the non-democratic traditions among the majority of the Jewish population in Israel at the time. Many immigrant Jews 
came from Arabian, North African and Eastern European areas and, in the main, from countries which lacked democratic distinctions. ${ }^{12}$ Perhaps an even more significant part was played by the Zionist ideology, revolutionary processes and massive construction enterprises in Israel, all of which demanded universal consolidation around collective myths and national ideals. ${ }^{13}$

The concrete result of the subordination of civic studies to ethno-national dictates was evident in 'the education in Zionist citizenship', which formed an integral part of Hebrew pedagogy prior to the State's establishment. The essentials of 'education in Zionist citizenship' well represented ethno-national aims. They embraced the entire fabric of the Jewish pupil's life at school and were integrated into all class courses - particularly those subjects where it was easy to instil ideological strains, such as Moledet (geography of Israel, literally, "homeland') and Bible classes - but could even be found in mathematical studies. The subject matter of such citizenship studies underscored the absolute right of the Jewish people to the land of Israel, while disregarding the interests of local Arab residents or at the most revealing a patronising attitude towards them and depicting them as backward natives. ${ }^{14}$

The insemination of ethno-national principles by means of the education system did not end with the Proclamation of Independence in 1948. Approximately four years later, the ethnic component attained formal status in the educational system. As part of the first Prime Minister David Ben-Gurion's vision of Mamlakhtiut (statehood), education in Israel was nationalised, a process that led to the elimination of most of the more distinctive educational orientations instituted during the pre-State era. In paragraph 2 of the Statehood Education Act of 1953, the intentions of the nascent State to subject the national education system to the interests of the nation-in-the-making were transparent. 'The goal of Statehood education is to establish a basic education in this State upon the values of Israeli culture and scientific achievements, on the love of the homeland and loyalty to the State and Nation of Israel. ${ }^{15}$

This policy was put into practice by performing a twofold weeding-out process, in both the general education programme and, in particular, in civic courses. First civic studies was reduced to the formal procedural aspect of governmental institutions, and then the programme was marginalised in relation to other courses whose objective was, in part, to emphasise the ethnic spirit of the Israeli national ideal among Israeli students.

A review of the works of liberal scholars in a wide range of disciplines associated with civic studies reveals several subject categories. The leading category comprises the liberties espoused by democracy. The formal aspect of governmental or political proceedings and institutions comes some way down the list. The State of Israel, by its very nature a 'non-liberal democracy' and therefore unable to guarantee equal rights for all of its citizens, has consciously elected to avoid any debate regarding those rights or any other sensitive issue specific to 
Figure 3.1 A quantitative content analysis of the contents of Israeli civics education books Source: Ichilov 1993, p. 129, table 6.4.

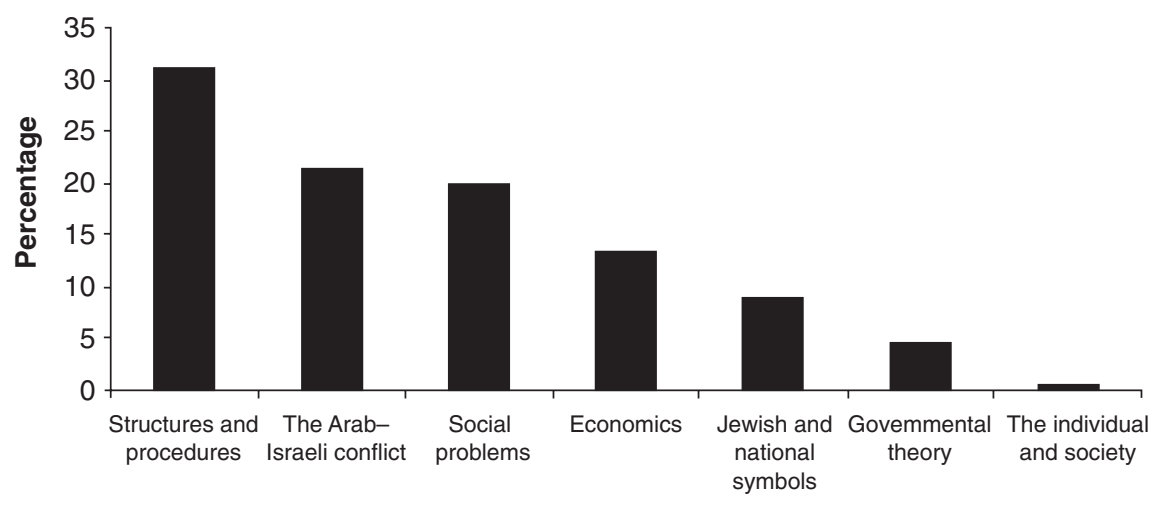

Subject matter

the non-liberal polity. ${ }^{16}$ As a result, Israeli pupils have been presented almost exclusively with the narrow procedural perspective of this subject. ${ }^{17}$ The primary goal was to establish the subject 'The Polity of the State of Israel' as the core field of the school curriculum. The topics constituting this educational chapter in effect merely displayed the formal 'appearance' of Israeli democracy: the proclamation of independence, legislative and judicial proceedings, elections procedures, the Knesset (the Israeli Parliament) and the government. Even when attempts were made to broach more substantial questions, such as the nature of Israeli citizenship, the (non-existent) constitution and the status of religion in relation to the State, the designers of the curricula and the matriculation exams in citizenship courses chose to focus upon the legislative procedural perspective instead of devoting an in-depth - not to speak of critical discussion of their sum and substance. ${ }^{18}$

In a quantitative content analysis of textbooks, including junior high and high school civics books from the 1970s and 1980s, empirical support for the preferred status of the formal element in the school curriculum was indicated by a significant disparity in favour of the procedural component over any other. Figure 3.1 is based on Ichilov's analysis, and demonstrates that political structures and procedures represented 31 per cent of the subject matter of these books, while the Arab-Israeli conflict took up 21.2 per cent, social problems 20 per cent and economics' topics only 13.4 per cent. As anticipated, with regard to the subject of the 'non-liberal democracy', Jewish nationalist principles also permeated civic studies' curricula and took up about 9.1 per cent of the topics appearing in the books. Another fact that comes as no surprise is the negligible status accorded to the rights of the individual in the State of Israel, discussion 
of which is likely to offer direct contradiction of the idea of the "non-liberal democracy', and therefore reached a proportion of merely 0.6 per cent. ${ }^{19}$

However, as noted earlier, it was not only textbooks that evidenced a focus on the formal aspect of Israeli politics. Bagrut (Israeli matriculation) exams on civics also reflected this tendency. A Bagrut exam from the summer of 1988, sampled for the purposes of the present study, shows that the weighting of the compulsory subject of 'The Political System of Governance in Israel' was 26 points. Pupils were required to answer one of these three questions:

1 The Knesset is the supreme legislative body of the State of Israel. Nevertheless, it is qualified to empower other authorities to enact subsidiary legislation. Why does the Knesset confer its legislative authorities to other authorities? What are the types of subsidiary legislation? Specify two forms of accountability for this legislation.

2 There are those who favour transferring many authorities from the central to the local government. Present two arguments in support of this position and two objections to it. Submit three examples of how the local government is accountable to the central government in Israel.

3 There is an argument positing that the national unity government in Israel in 1984 reduced the opposition's effectiveness. Explain what is the difference between the composition of a national unity government and that of a coalition government in Israel. Describe three parliamentary implements employed by the opposition in Israel. ${ }^{20}$

The complete reproduction of these questions is not intended to weary the reader but rather to present him or her with the picture in full. The formulation of these questions exemplifies how the compulsory element of the Bagrut exam in citizenship restricted the Israeli adolescent student to formal and, to a great degree, technical subjects found in the remote margins of Israeli political discourse. Even the third question, regarding the opposition's standing in a democratic government, has been almost completely drained of substance and forces the student to focus mainly on the mechanical aspect of the opposition's actions.

The precedence given to formal topics and the tendency of civic studies to avoid in-depth discussion of substantive issues were significantly sustained by the ongoing Arab-Israeli conflict. The conflict was taught as an optional topic in civic studies but often from the narrow perspective of the national narrative. In fact, in the Bagrut exam noted above, alongside a topic such as Tfutzot Yisrael (Lands of the Diaspora), which primarily underscored Israel's affinity with Jews living abroad, there was also an optional chapter on the Arab-Israeli conflict. The two questions under this heading, which, due to limited space, could not be presented here in their entirety, well reflected the traditional Israeli orientation regarding the rightness of the path chosen by the nation's leaders and the moral superiority of the Israeli side in the conflict. 
However, the most striking example of the defusing of the highly charged issue of the relations between Israel and the Arabs was ironically found in the optional topic 'The Arabs in the State of Israel'. The three questions encountered by the Israeli student (see below) are an indication of how the Education Ministry in Israel could exclude substantial issues from the discussion on the cleavage between the Jewish majority and the Arab minority and in their place focus on the lesser aspects of the said cleavage.

1 Since the State's establishment, there have been far-reaching changes in the Arab educational system, however, the system must still cope with formidable problems. Describe three key changes in the Arab educational system and explain their causes. What are the problems facing the Arab educational system in the 1980s?

2 Changes in the agricultural department of the Arab sector since the State's establishment have had a noticeable effect on Arab society in Israel. Describe three principal changes in the Arab agricultural department and explain how the changes you have presented have had an effect on Arab society in Israel.

3 Arab intellectuals in Israel have held a significant role in the progression of Arab society. What roles do Arab intellectuals fill in Arab society and how do they contribute to its advancement? Provide examples and explain three specific obstacles encountered by these intellectuals when filling these roles. ${ }^{21}$

Despite the fact that these questions reflect the conventional policy of an avoidance of the complexity of ethnic relations in Israel and, in particular, the question of the Arabs' minority status and their rights in a democratic state, it appears that the efforts of the authors to devise questions of a neutral nature did not fare well either. An additional perusal of the questions gives the impression that they were written from a paternalistic and, to a certain degree, ethnocentric standpoint. This conclusion is reinforced by Bar-Tal's research on the Israeli educational system's orientation toward Arabs. Bar-Tal found that although the delegitimisation of Arabs was indeed rare, textbooks presented them mostly in terms of negative stereotypes. ${ }^{22}$

Indeed, the reduction of civic studies to formal rudiments, as well as its detachment from social and political reality, considerably served the State in its attempts to instil in its future citizens the Conviction that Israel is, to all intents and purposes, a democratic state. However, this policy also obscured the contradictions embedded in the political system and at the same time repressed the critical capacities of those citizens.

Although it would be going too far to claim a causal relationship between the two, a 1999 study evaluating the attitudes of Israeli citizens regarding the quality of its democratic governmental system confirms the assumption that Israelis generally find little fault with the democratic nature of their State. ${ }^{23}$ Findings show that while subjects born and educated in Israel expressed high levels of satisfaction with the degree of the State's democracy, immigrants' levels 
of satisfaction (particularly those from the West) were much lower. In response to more specific questions, e.g. regarding the protection of civil rights in Israel, native-born Israelis expressed very high levels of satisfaction in comparison with immigrants ( 75 per cent of the Israelis strongly agreed that individual rights are respected in Israel, in contrast to 50 per cent of immigrants). These findings were replicated and found even more prominence over the issue of equal rights in Israel (61 per cent of Israelis claimed there were full equal rights in Israel in comparison to 22 per cent of immigrants). The significance of these findings is that while Israelis born and educated in this country adopted reigning attitudes regarding the democratic nature of the State, immigrants from Western democracies, wielding a broader perspective of the implementation of the democratic ideal, expressed a greater degree of scepticism regarding Israel's conformity to the liberal democratic model.

Yet, the State of Israel did not settle for the simple diminution of the contents of citizenship lessons, and another tactic was employed in the restriction and dilution of civic studies. As the next section demonstrates, the course was accorded a marginal status in comparison to other subjects, in particular those which reinforced the unity of the national identity.

\section{The status of civic studies}

Together with formal civics education, the Israeli education system made an effort to widely inculcate Zionist-Jewish values by means of subjects such as Bible studies, geography, Jewish history and Tushba (Oral Law). ${ }^{24}$ The first sign of the subjection of citizenship courses to national orientations was evident in the fact that the training of civics teachers was part of general academic history or the history of the Jewish people. This was because, unlike most other subjects, citizenship was not considered a discipline in itself requiring any special training. ${ }^{25}$ Therefore, a single teacher was responsible for subjects such as Jewish history or the history of Eretz Yisrael ('Land of Israel') - which reflected the ethno-national aspects of the State and served the purpose of constructing a common history and consolidation around the nation's symbols and myths together with subject matter that was supposed to be of a more liberal and universal nature. The findings of a survey administered to civic studies teachers indicated that despite their general willingness to teach more diverse subject matter, they themselves tended not to prefer universal values over national values. ${ }^{26}$ In the curricula of technical schools, the marginality of civic studies was even more pronounced. Civics was taught under the heading 'Study of Nation and State', or, in other words, a section of the curriculum that dealt with Jewish history. ${ }^{27}$

An additional indication of the marginality of civic studies in comparison to other subjects was evident in the number of school hours accorded to this 
subject. Citizenship courses in Israel are not taught at all in elementary school (grades 1-6), the schoolchild's first contact with the formal state education system. In junior high school (grades 7-9), few schools list the subject on their course programme, despite the fact that a special curriculum has been designed for pupils of this age. In addition to the personal preferences of school principals, a reason for the omission of this subject is rooted in its non-enforcement by the Ministry of Education. These tendencies reflected Ministry of Education policy, which has discouraged the exposure of pupils to potentially provocative and disputable issues.

Therefore, the first genuine contact of schoolchildren with civic studies subject matter has tended to take place only in their final year of high school, the grade 12. In that year, teachers are obligated to teach compulsory subjects for the matriculation exams, and, in consequence, devote all their time and energy to the instruction of the procedural aspects of the subject on which the exam has traditionally focused. ${ }^{28}$

The marginality of civic studies is additionally underscored in the Bagrut certificate for the Israeli adolescent student. Despite being an apparently compulsory subject, civic studies is equal to only one learning unit in the matriculation certificate. In comparison, subjects such as Bible studies, Hebrew, composition and literature - courses that are dependable conduits for the dissemination of national values - all benefit from a minimum weighting of two compulsory learning units. Translated into hours of instruction, this means that each of these subjects consists of a minimum of 180 class hours, in contrast to 90 hours of citizenship lessons. Furthermore, the Ministry of Education gave adolescent students the option of extending each of these subjects up to five learning units (450 class hours) for the final exam while civic studies was restricted to its original single unit.

Time and again, objections regarding the peripheral status of civic studies in Israel have been directed to the Ministry of Education. Professor Emanuel Gutmann, who was chiefly responsible for the design of the course programme in citizenship studies, appealed in the early 1990s to the Minister of Education and argued:

Citizenship courses have been assigned, according to the general school curricula, no more than 90 class hours (out of all the years of high school education). In the present programme, three subjects were taught in these 90 hours, each allotted 30 hours. 'The Polity of the State of Israel' was a requisite subject and this was supplemented by two additional courses out of five electives . . . For some years now, it has become quite clear to ministerial officials in charge of civic education that it is impossible to teach the course on Israeli polity in thirty hours and therefore, in reality, many more hours are devoted well and above this quota. The inevitable consequence was that in recent years, only two subjects in effect were taught, one requisite and one elective. ${ }^{29}$ 
The test of time has shown that this complaint, like numerous others tucked away in the Ministry of Education archives, was cordially acknowledged and then discarded in its dusty files.

To sum up, the above findings confirm that for many years, the Israeli pupil has been exposed to the subject of civics for a short period of time, and then only at a relatively late stage (grade 12). Moreover, out of the whole far-reaching and complex fabric of political and social life in Israel, he or she was introduced to only those aspects which were easy for authorities to deal with and which indirectly were intended to reinforce the younger generation's convictions about the legitimacy of nationalist ideals and the governing body. In this fashion, the education system served the State in its efforts to shape a collective consciousness based on the belief that Israel is a democratic state, in spite of the institutionalised dominance of the Jewish majority and the State's powerful station vis-àvis its citizens. What instruction took place was of course delivered without a discussion of the middle on grey areas which might evoke questions with regard to the essence of a polity of this type. In all, the inevitable and telling by-product of these circumstances has been the weakening of the democratic quality of the State.

Indeed, research conducted since the early 1980s demonstrated that political extremism, ethnocentrism and a regression from democratic values are deep-seated among youth and adults alike in this country. ${ }^{30}$ Most of these studies reveal significant support for undemocratic attitudes, e.g. curtailing the freedom of speech of political opponents, the exclusion of ethnic minorities from society and Israeli politics, a call for a strong leadership that can navigate the country as it sees fit and an increase in religious legislation. Comparative research further accentuates the extremist profile of certain sectors of Israeli society and reveals that adolescent Israeli students tend to score very highly on measures of ethnocentrism and authoritarianism in comparison to students abroad. $^{31}$

\section{Quandaries accompanying the efforts to reform civic studies}

Three pivotal events took place in Israeli political history during the 1980 s and 1990s. On the face of it, these events should have spurred the country's leadership to adopt a more 'immunised' route, which should have included, inter alia, an extensive reformation of the civic studies curriculum in Israel, an expansion of its framework and the incorporation of more liberal and humanistic principles. Chronologically, the events are as follows. First, there was the penetration of the 1984 Israeli Parliament by a racist party (Kach); later, the signing of the Oslo Agreements of 1993; and, more recently, the assassination in 1995 of Prime Minister Yitzhak Rabin.

In retrospect, it appears that these events did in fact inspire planners of the 
education system to change its traditional approach and submit an extensive and new-fashioned plan of action. The blueprint was built on shoring up democratic studies and a modification of civics course material in order to introduce the student to liberal democratic views (principally, a comprehensive schooling on the concept of democracy with an emphasis on human rights and liberties) as well as problematic and disputable issues (a broad and critical discussion of the ethnic character of the Israeli democracy and the political expressions of the cleavages that cut across it). However, the policy taken up by the State of Israel in respect of civic studies suffered from a lack of consistency. On the one hand, steps were indeed taken to bring about a broad and genuine change in civics education with the aim of strengthening a democratic liberal perspective. On the other, the non-liberal constraints on the State still prevented a smooth transition to a liberalised curriculum for civic studies and instead this process advanced quite unsteadily, punctuated by stops and starts and numerous diversions.

The inaugural efforts to liberalise civic studies can therefore be linked to the election of Rabbi Meir Kahane to the Israeli Parliament. Following Kahane's success in parliamentary elections and the many surveys and studies which confirmed that the racist rabbi's views had indeed begun to find a stronghold in the Israeli streets, a new sort of anxiety became apparent, both among policymakers as well as among the rank and file, regarding the future of democracy in Israel. Among the assortment of State responses, which have already been elaborated in preceding chapters, there was the undoubted influence of the Kahanist phenomenon on the chief executive body of the education system. A short while after Kahane's election to the Knesset, the Ministry of Education decided, for the first time since the establishment of the Israeli State, that priority must be given to the democratic element over the nationalist-particularist element in civics education. If, until the 1980s, documented material regarding the education of the Israeli citizen in democratic values was infrequent or coincidental in the Ministry of Education's archives (where the setting of goals remained abstract and the recommendation was predominantly the integration of the topic of democracy in various courses), then, after Kahane's election to the Knesset, the tone changed, and the emphasis shifted from an 'education in Zionist citizenship' to 'Democratic education'. In addition, the years 1986 and 1987 were declared years of democratic education. ${ }^{32}$

Nearly nine years after Kahane's achievement of Knesset membership, the Oslo Agreements between Israel and the PLO were signed. This second critical turning point was supposed to have led to the reform of school curricula. The Oslo Agreements were to mark the passage from the belligerent past to a new era of peace between Israel and the Palestinians, and, within this framework, both Israel and the Palestinian Authority were committed to altering their 
school curricula and removing all ethnocentric indications. ${ }^{33}$ The third and perhaps most traumatic event and milestone for Israeli society was the murder of Prime Minister Yitzhak Rabin by a Jewish perpetrator. Yigal Amir, graduate of the national religious education system, explained that he committed the murder out of the belief that not even a democratically elected government had the authority to make decisions which stood in stark contrast to the Jewish Halakha or the will of a sector of the nation.

In spite of the significant public outcry that arose in the wake of these events and proclamations heralding a new direction in the curricula of civic studies, a retrospective analysis of the steps taken to translate words into action reveals many setbacks in the attempt to bring about substantial reformation in this area. Obstacles preventing the liberalisation of civic education due to the failings of the non-liberal democracy can be examined according to three principal levels of analysis: structural; policy-making; and policy implementation.

\section{Structural level}

One of the first steps taken by the Ministry of Education, in 1985, immediately subsequent to Rabbi Meir Kahane's election to Parliament, was the establishment of a special division for the advancement of democracy and coexistence in Israel. The inherent tension between the democratic and non-liberal components of this country could already be felt in the making of this decision. The new resolution was in effect an official acknowledgement by the Israeli Ministry of Education that formal civics education in Israel - contrary to other countries where the term 'civics education' includes concepts which address both general democratic values as well as the country's system of governance - had not fulfilled its role in strengthening democratic values.

The called-for step was a broad reform of the civics education programme, entailing an increase in class hours and the replacement of formal subject matter with discussion of more substantive democratic principles. However, this type of reform could be tolerated only under one condition - a change in the State's attitude. Still loath to abandon the ethnic, anti-liberal, character of Israeli democracy, the State opted for a more innovative agenda in democratic studies. The course of formal instruction on citizenship remained in its traditional form and a complementary programme was initiated for teaching democratic values. Although the formal course of civics remained marginal in terms of class hours and resources, in relation to democratic studies it still enjoyed a clear advantage. Traditional civics studies remained an integral part of the official Israeli school curriculum, whereas democratic studies, which focused more deeply on the relations between Jews and Arabs, the idea of 'rule of law' and 
civil rights, received extra-curricular status, ${ }^{34}$ making it an optional subject for the majority of school principals. They preferred to devote all available school hours to matriculation subjects.

In addition, not only was democratic studies assigned peripheral status, but the Division for Democracy and Coexistence (DDC) itself was considered a marginal body in the Ministry of Education and therefore a pawn in the hands of policy-makers. Shortly after the assassination of Prime Minister Yitzhak Rabin, elections were held in which the right-wing bloc, under the leadership of Benyamin Netanyahu, was victorious by a small margin. Zevulun Hammer, representative of the Mafdal, was appointed to the post of minister of education. Hammer, in line with the traditional position of his party, maintained there was no justification for promoting the democratic aspects of civics education without a similar expansion of Jewish nationalist values. He therefore decided on the establishment of the Board for the Education of Values (BEV) whose objective was to be an umbrella framework for the agencies responsible for the cultivation of Jewish studies, along with the Division for Democracy and Coexistence. Once again, the quandary inherent to the non-liberal democracy reared its notorious head. A single directorate of the Ministry of Education became responsible for both reinforcing Jewish national identity as well as the assimilation of liberal values. The practical implication was that these two conflicting initiatives now operated under the same organisational framework. The Education Ministry's budget proposal for the 1999 fiscal year illustrates this predicament. The proposal states that the Board for the Education of Values financially supports ninety voluntary organisations involved in Jewish Zionist education on one hand and ninety voluntary bodies associated with democratic education on the other. However, the Board gives priority to those institutions which combine the two fields. A close inspection of the proposal revealed that this type of body did not exist. ${ }^{35}$

After Minister Hammer's death and the appointment of Itzhak Levy, a member of the same party, to the post of minister of education, ministerial priorities were once again rewritten. Minister Levy decided to pare down the management and budget of the BEV, established by his predecessor. Levy understood the difficulty of running two segregated systems of instruction on similar subject matter, while only one of the two was anchored in the official course curriculum. According to him, the decision to cut back on the Board's activities was the outcome of two major predicaments: first, the significant financial expense of two coexisting systems; and second, the failure of the BEV to reach its projected goals. As the minister saw it, there was no way to force teachers and pupils disinterested in the Board's activities at their school to make the effort to teach and learn subject matter which was not an integral part of the formal school curriculum. ${ }^{36}$ Ultimately, a short while after left-wing Meretz member Yossi Sarid became minister of education, a final decision was issued to dis- 
mantle both the BEV and the DDC. Corroboration provided by the civics education supervisor reinforces the view that the status of these two councils as extraneous to the education system minimised their effectiveness. ${ }^{37}$

In this case, despite the official intentions of the Ministry of Education to give priority to the liberal-universal aspect in relation to the non-liberal ethnic aspect, policy-makers with the final say ensured that civic studies continued in its traditional procedural form. The initiative to elevate the standing of democratic studies with the formation of the DDC appeared to be a commendable venture but, in effect, it failed from the moment of its inception. This was a consequence, first, of its peripheral status and, later, of policy-makers' objections to the teaching of democratic values in isolation from national values.

\section{Policy-making}

The perspective of policy-making even more markedly reflects the symbiotic and inseparable connection that exists between the teaching of nationalist and democratic values in Israel. In March 1995, about one-and-a-half years after the signing of the Oslo Agreements and one year prior to Prime Minister Rabin's assassination, Professor Amnon Rubinstein, Meretz member and minister of education at that time, appointed a committee to advance the democratic reform of state-run civics education, to be headed by Mordechai Kremnizer, a professor of law. Its aim was the "development of a comprehensive initiative for the inculcation of citizenship in pupils as a moral and behavioural foundation shared by all citizens of the State'.$^{38}$ The panel consisted primarily of academicians and representatives of diverse ethnic, political and religious groups in Israeli society. It tried to learn the nature and roots of the problems in the civics curriculum and attempted to address the need for change in the instruction in political processes deemed responsible for instilling anti-liberal attitudes among pupils:

While the widespread public belief is that democracy is the government of the majority, the more liberal conception of democracy has not been sufficiently internalised, i.e., a political system placing at its centre the individual who has the power to shape and develop his or her personality as a human being in a society whose ultimate purpose is to defend individual rights and guarantee the protection of the rights of various groups in society. A noticeable weakness is in the lack of an internalisation of universalistic values detected, for example, in attitudes toward Arabs and ultra-orthodox, freedom of speech and the freedom of press . . There is an aspiration toward a homogenous and harmonious society while, in actuality, it is necessary to cultivate an awareness of the diversity and pluralism of this society, the legitimacy of partaking in debate, the positive aspects of debate and the guidelines for settling conflicts based on a tolerant approach, while using peaceful and democratic ways. ${ }^{39}$ 
In summation, the panel presented proposals for an extensive reform of civics education while granting a clear priority to liberal perceptions and, above all, individual rights over the rights of the Jewish collectivity. On the face of it, it seemed that this committee and its clear-cut policies indicated a consensus among Israeli policy-makers regarding the genuine necessity to liberalise civics education curricula. However, reality proved otherwise.

Four years earlier, in October 1991, the minister of education at that time, Zevulun Hammer (Mafdal), had nominated a committee with an almost identical composition, although the goal of this committee was to review the status of Jewish studies in state-run education. Even though the committee's conclusions demonstrated a relatively pluralistic tendency, the gist of its recommendations was straightforward - proposals for expanding Jewish studies and courses in the history of the Israeli people at all levels of instruction (from elementary to high school). Furthermore, the Shinhar Committee, named after Professor Aliza Shinhar who was placed in charge, reinforced the status of four Jewish subjects in the matriculation exams and also introduced new subjects. ${ }^{40}$

Once again, Ministry of Education officials were faced with the double imperative deeply embedded in the Israeli political structure: on the one hand, they were confronted with the need to bolster the State's democratic foundations by introducing liberal values; and, on the other, they strove to maintain the unity of the dominant Jewish ethnic group with regard to its nationalreligious symbols. The BEV was assigned the role of applying the recommendations of both reports, a fact that only exacerbated the state of paradox characteristic of the Board. After the Board was dismantled, two supervisors from the Ministry of Education were placed in charge of implementing proposals. Today, these two share a single desk in the Ministry of Education in Jerusalem, which seems to be another symbolic illustration of the inability to distinguish between liberal and national objectives.

\section{Policy implementation}

So far, the paradoxes involved in the efforts to steer the social base of the State of Israel in a more 'immunised' direction by formulating certain policies and promoting democracy studies in Israel at the institutional level have been presented. In point of fact, this same paradoxical picture was similarly repeated in the efforts to bring about structural change in the formal school civic studies curriculum.

Beginning in the mid-1990s, then later on with the Kremnizer Report and the failure of the DDC, there is evidence of attempts at the revision of compulsory topics of the civic studies programme. The Ministry of Education team responsible for this programme worked vigorously in order to present study cur- 
ricula that would address the essence of social and political life in the State of Israel and, by the same token, demote the formal procedural aspect from its dominant position. This approach constituted a challenge to the Ministry of Education's official policy over the years, where controversial topics were kept out of the school classes. ${ }^{41}$

An initial perusal of Being Citizens in Israel, the basis of the new curriculum and approved as the core textbook for the study of civics in the year 2001, indeed presents an in-depth review of the substantial issues of the State of Israel. These include the status of the Arab population, cleavages in Israeli society, the status of civil law vis-à-vis religious law, the rule of law in a democratic state and civil rights. ${ }^{42}$ This doctrinal turnaround and, in particular, the Ministry of Education's apparent renunciation of its commitment to national narratives in favour of liberal principles conforming with Levinson's tenets, supposedly reflects the same transition toward liberalism which, according to Shafir and Peled, ${ }^{43}$ Israeli society is presently undergoing.

However, a second, and more informed, scrutiny of the implementation of the curricular reform reveals otherwise. Civic studies, it appears, has never been able to liberate itself from its inherent failings since the State's establishment and, therefore, recent declarations on the liberalisation of values in Israel have turned out to be premature. A methodical survey of the programme's core issues and the degree of significance accorded to democratic liberal values proves that the resilience of 'Jewish ethno-nationalist tendencies' is not to be made light of. Examples are found in the chapter introducing students to the 'Principles of the Social Contract'. In contrast to what might be expected of a chapter with that title, much of it is devoted to the biblical pact drawn between Israel and $\mathrm{G}-\mathrm{d}$. Moreover, this text makes it quite clear that in the time of the prophets Ezra and Nehemiah the Jewish nation embraced the authority of the Oral Law as the standing constitution of the State and people of Israel. ${ }^{44}$ Therefore, despite the declared intentions of the new programme's designers to reduce the degree of the Israeli student's exposure to ethnic, religious and national values in the civic studies programme - values which he or she would in any case encounter in other classes - the role of the State in shaping the Jewish citizen who is above all loyal to his or her people and the Torah would not be completely abandoned.

However, this does not bring to an end the complexities of teaching civic studies in Israel in the new millennium. Apart from the difficulties created by the ideological hindrances noted above, reform also faced administrative obstacles. The new curriculum was supposed to include twice the number of civics class hours in order to provide enough time to teach all the subject matter of the programme in its new format. ${ }^{45}$ But, in reality, the number of class hours remained the same, that is, ninety class hours in the final school year. The cutback in the number of hours required screening out many topics from the 
intended programme, and most of the eliminated subject matter unfortunately happened to touch upon essential concerns of the State: the cleavages of Israeli society and the status of the Arab minority; freedom of speech in a democratic society; and elections in Israel. On the other hand, the formal aspect, provided by the chapter depicting the political system and governmental institutions, still enjoyed a central role in the new curriculum. ${ }^{46}$ According to the civics education nationwide supervisor, even after the removal of some of the course matter, the number of issues was still significantly higher than the time allotted for their delivery in class. This posed a problem because civics teachers, who, over the years, became accustomed to instructing in the formal aspect of the Israeli political system, preferred to stick to the course material with which they were familiar. In fact, in many cases, they felt comfortable enough to overlook the new and thornier issues such as the debate over the extent to which the State of Israel conforms to the definition of a democratic polity. ${ }^{47}$

There are still further problems. A new curriculum, currently under discussion by the Ministry of Education, proposes that several subjects, including civic studies, should no longer be included in the school curriculum as required subjects for the matriculation exam. According to the Ministry of Education supervisor responsible for the pedagogy of civics, this would lead to a situation where school principals would rather devote school hours to compulsory matriculation subjects than to allocate time to those subjects, such as civics, which no longer require a final exam. ${ }^{48}$ These new plans are in outright defiance of the recommendations of the Kremnizer Committee, which asserted that citizenship studies should be enhanced and taught as early as elementary school, and throughout junior high and high school, culminating in a matriculation exam equal to 3-5 learning units. Another factor weakening the effectiveness of a critical and universalistic study programme is the Ministry of Education's decision not to include a single social science subject (sociology, political science) in the list of compulsory matriculation exams.

\section{Educational reform in civics education in the new millennium: a quantitative assessment}

Notwithstanding the many paradoxes shrouding civic studies in general and the new curriculum in particular, I sought to examine the degree to which, if at all, it was possible to verify the effect of civic studies on adolescent students' attitudes. Interest centred in various topics pertaining to the wide gamut of democratic life, and whether civics courses still have the ability to help the State of Israel 'immunise' the social structure of the 'defending democracy'.

However, before presenting research findings, several theoretical issues pertaining to the relationship between instruction in citizenship and the internalisation of democratic values among students should be mentioned. From the 
early 1960s, beginning with an intensive research involvement in the education in democratic concepts, two main schools of thought have made their mark. The conclusions of both schools relied on empirical findings. The first, more senior, school, whose prominent representatives include Langton and Jennings as well as Niemi and Sobieszek, posited that correlations between an education in citizenship and the espousal of political knowledge and democratic attitudes are marginal. ${ }^{49}$ On the other hand, according to the second group of scholars, whose roots are planted in the works of much earlier researchers such as Merriam ${ }^{50}$ and V. O. Key ${ }^{51}$ (works which have, however, gained considerable reconfirmation in recent years), participation in citizenship courses, particularly in combination with additional factors such as an appropriate class atmosphere, is in fact found to be in positive correlation with the internalisation of democratic values. ${ }^{52}$

Under the present circumstances, it would be pretentious to try to bring this controversy to a resolution. Rather, by relying on the most prominent approaches of the second school in the last few years, which posit that the teaching of democratic principles at school necessarily has the effect of consolidating more democratic values among pupils, this section seeks to assess the degree of influence of the new civic study programme on the attitudes of youth in Israel.

The research design devised for this purpose was based on sampling the adolescent student population and administering questionnaires to 729 students in five state-run schools in northern Israel. The sample was made up of two groups. The first group consisted of 333 grade 12 students (students in their last year at high school, aged 17-18) who studied civics in their last year of school according to the new curriculum. These students constituted 45.7 per cent of the sample population. The second group consisted of 396 grade 11 students (aged 16-17) who had not yet been exposed to civics courses at high school. These students constituted 54.3 per cent of the sample population. Questionnaires were distributed during March 2001.

The aim of the research was to examine the effects of an education in democratic principles on the complex of perceptions associated with political and democratic issues, while conducting a comparison between the two groups. In order to minimise the effect of intervening variables, particularly sociodemographic variables, an attempt was made to ensure, while selecting the sample, representation of the various population sectors. Accordingly, the sample included 285 boys ( 39.2 per cent) and 444 girls ( 60.8 per cent). In terms of parental education there was some preference for students of parents with a higher education (father's education - 2.6 per cent elementary school, 36.9 per cent high school and 60.4 per cent higher education; mother's education -2.4 per cent elementary school, 32.5 per cent high school and 65.1 per cent higher education). ${ }^{53}$ However, with regard to students' ethnic origin, the distribution 
appeared proportional and commensurate with State population figures (father's country of birth -45.5 per cent Israel, 14.1 per cent Europe-America, 12.1 per cent Asia-Africa, and 25.1 per cent countries of the former USSR; mother's country of birth - 49 per cent Israel, 14.1 per cent Europe-America, 11.5 per cent Asia-Africa, and 25.4 per cent countries of the former USSR; student's country of birth - 77.6 per cent Israel, 3.5 per cent Europe-America, 0.7 per cent Asia-Africa, and 17.2 per cent countries of the former USSR).

While this study included one independent variable (that of exposure to civic studies, which distinguished between the two groups), there were five dependent variables in this study:

- democratic orientation;

- political cynicism;

- ethnocentric attitudes toward Arabs;

- political efficacy; and

- $\quad$ political knowledge. ${ }^{54}$

Underlying the rationale for the inter-group comparison was an assumption relying on prior research, ${ }^{55}$ which stated that if the civic studies programme in Israel not only conveyed formal knowledge but was indeed successful in affecting students' attitudes, then in comparison to those who did not learn this subject, students exposed to civic studies would demonstrate

1 a greater inclination toward democratic orientations in comparison to the control group;

2 lower levels of political cynicism in comparison to the control group;

3 a greater sense of political efficacy in comparison to the control group; and

4 lower levels of ethnocentric attitude toward Arabs in comparison to the control group.

And with the aid of the fifth variable, political knowledge, an attempt was made to focus the debate and examine which features of Israeli politics the Ministry of Education was successful in inculcating among its students. Was it knowledge related to the formal and technical aspects of the political system typical of past curricula, or was there also a familiarity with events in the system itself and Israeli political figures?

\section{Results}

Table 3.1 features the levels of support among civics students and noncivics students on items comprising the dependent variables, and elicits a number of findings which merit attention. With regard to all aspects of the democratic orientation items, it appears that students from both groups are inclined to express high support for the statements. However, upon closer 
inspection, the numbers reveal two interesting findings. The first pertains to the fact that most students, both those who did and did not study civics ( 87 per cent and 85 per cent, respectively), perceived political action as unnecessary when decision-making is believed to be in the hands of a competent leadership. The sweeping support for this statement indicates a weakness in the internalisation of the idea of the citizen's role in a democratic state and may be closely associated with the relatively low levels of Israeli citizen participation in 'civil society' organisations, a subject which will be elaborated in the next chapter. An additional important finding alludes to the significant correlation $(p=0.008)$ between the independent variable and the statement dealing with the democratic government's obligation to protect the rights of minorities. Granted, among both groups there was relatively high support for this statement; still, the gap in favour of those who participated in civics lessons is quite significant (89.4 per cent compared to 82.8 per cent among students that did not learn civics).

A review of the items constituting the measure of political cynicism demonstrates a reverse tendency of the above. Unexpectedly, not only did both groups express high levels of political cynicism, the level of cynicism on behalf of the civics group was consistently higher than that expressed by those who did not take the course. Although no significant correlations were found between the study of civics variable and these items, according to the descriptive data it is still possible to conclude (with some caution) that if participating in civics education has any effect on students, it only leads to an increase in cynicism with regard to the political system.

The profile emerging from the findings on students' views about political efficacy is a little more complicated. On the one hand, many students from both groups feel that generally there is a great breach between the individual and government and that government officials are not attentive to citizens of the State (63.1 per cent among civics learners and 61.8 per cent among non-civics learners). In addition, most students affirmed that politics and governance are too complicated for them and that they have difficulties understanding the workings of political procedures (57.2 per cent among civics learners and 58.7 per cent among non-civics learners). On the other hand, the majority of students are aware that numerous avenues of political action are available to them. This conclusion is based on the relatively large support for the statement on the right to express an opinion (59 per cent among civics learners and 50.3 per cent among non-civics learners) and also from the considerable support for the statement that there are other ways to express a political attitude aside from voting (54.7 per cent among civics learners and 47.4 per cent among non-civics learners). Another interesting finding is that there is a significant correlation between the last two statements and the independent variable $(p=0.016$ and 0.045 , respectively). An attempt to sum up this complex picture leads me to submit 
Table 3.1 Effects of an education in democratic principles: levels of support (in percentages) for different components of the dependent variables and comparison of mean grades for every one of the items among the two groups by means of t-test

\begin{tabular}{|c|c|c|c|c|c|}
\hline Variable & Item & $\begin{array}{l}\text { Supported } \\
\text { by civic } \\
\text { studies } \\
\text { students (\%) }\end{array}$ & $\begin{array}{l}\text { Supported } \\
\text { by non-civic } \\
\text { studies } \\
\text { students (\%) }\end{array}$ & $t$-value & Significance \\
\hline \multirow[t]{5}{*}{$\begin{array}{l}\text { Democratic } \\
\text { orientation }\end{array}$} & $\begin{array}{l}\text { Competition among } \\
\text { political parties } \\
\text { makes the political } \\
\text { system stronger }\end{array}$ & 57.91 & 57.10 & 0.048 & 0.825 \\
\hline & $\begin{array}{l}\text { Occasionally, a successful } \\
\text { political leader must also } \\
\text { make compromises } \\
\text { with his political } \\
\text { opponents }\end{array}$ & 92.54 & 90.62 & 0.890 & 0.345 \\
\hline & $\begin{array}{l}\text { Government carries the } \\
\text { responsibility for } \\
\text { protecting the rights } \\
\text { of the minorities }\end{array}$ & 89.47 & 82.80 & 6.988 & 0.008 \\
\hline & $\begin{array}{l}\text { Any individual or } \\
\text { organisation has the } \\
\text { right to organise } \\
\text { opposition or resistance } \\
\text { to any governmental } \\
\text { initiative }\end{array}$ & 86.97 & 85.71 & 0.246 & 0.619 \\
\hline & $\begin{array}{l}\text { Citizen participation or } \\
\text { involvement is } \\
\text { necessary even if } \\
\text { decision-making is left } \\
\text { in the hands of a few } \\
\text { trusted and competent } \\
\text { leaders }\end{array}$ & 13.00 & 15.00 & 0.404 & 0.525 \\
\hline \multirow[t]{4}{*}{$\begin{array}{l}\text { Political } \\
\text { cynicism }\end{array}$} & $\begin{array}{l}\text { Government officials } \\
\text { are not highly competent }\end{array}$ & 70.48 & 66.57 & 1.294 & 0.255 \\
\hline & $\begin{array}{l}\text { Governmental clerks } \\
\text { and officials do not } \\
\text { pay much attention to } \\
\text { citizens }\end{array}$ & 85.18 & 80.76 & 2.564 & 0.109 \\
\hline & $\begin{array}{l}\text { Political parties are } \\
\text { interested only in } \\
\text { winning the elections }\end{array}$ & 79.15 & 73.68 & 3.062 & 0.080 \\
\hline & $\begin{array}{l}\text { Government officials } \\
\text { usually do not perform } \\
\text { effectively and legally }\end{array}$ & 72.66 & 71.81 & 0.065 & 0.798 \\
\hline
\end{tabular}




\begin{tabular}{|c|c|c|c|c|c|}
\hline Variable & Item & $\begin{array}{l}\text { Supported } \\
\text { by civic } \\
\text { studies } \\
\text { students }(\%)\end{array}$ & $\begin{array}{l}\text { Supported } \\
\text { by non-civic } \\
\text { studies } \\
\text { students }(\%)\end{array}$ & $t$-value & Significance \\
\hline & $\begin{array}{l}\text { The government would } \\
\text { function better were it } \\
\text { not for political interests }\end{array}$ & 81.86 & 77.84 & 1.833 & 0.175 \\
\hline \multirow[t]{5}{*}{$\begin{array}{l}\text { Political } \\
\text { efficacy }\end{array}$} & $\begin{array}{l}\text { I think that public } \\
\text { officials care about } \\
\text { what people like me } \\
\text { think }\end{array}$ & 36.91 & 38.19 & 0.130 & 0.718 \\
\hline & $\begin{array}{l}\text { Voting is not the } \\
\text { only way that people } \\
\text { like me can have a } \\
\text { say about how the } \\
\text { government runs things }\end{array}$ & 54.73 & 47.38 & 4.000 & 0.045 \\
\hline & $\begin{array}{l}\text { Often, politics and } \\
\text { government seem so } \\
\text { complicated, however, } \\
\text { a person like me can } \\
\text { still understand what's } \\
\text { going on }\end{array}$ & 42.79 & 41.35 & 0.156 & 0.692 \\
\hline & $\begin{array}{l}\text { Election results are not } \\
\text { the only factor according } \\
\text { to which the state is } \\
\text { governed }\end{array}$ & 35.09 & 33.53 & 0.199 & 0.665 \\
\hline & $\begin{array}{l}\text { Regular people like me } \\
\text { have the right to } \\
\text { express an opinion about } \\
\text { governmental initiatives }\end{array}$ & 59.05 & 50.29 & 5.713 & 0.016 \\
\hline \multirow[t]{4}{*}{ Xenophobia } & $\begin{array}{l}\text { In the event of a nationwide } \\
\text { referendum on the subject } \\
\text { of the peace process, it } \\
\text { would be better if Arabs } \\
\text { did not take part }\end{array}$ & 48.00 & 48.67 & 0.033 & 0.855 \\
\hline & $\begin{array}{l}\text { Arab complaints of } \\
\text { discrimination are not } \\
\text { justified }\end{array}$ & 52.88 & 58.75 & 2.55 & 0.110 \\
\hline & $\begin{array}{l}\text { The Israeli Government } \\
\text { should encourage Arab } \\
\text { emigration from Israel }\end{array}$ & 54.49 & 55.16 & 0.003 & 0.951 \\
\hline & $\begin{array}{l}\text { Arabs are too demanding } \\
\text { regarding anything to do } \\
\text { with their rights }\end{array}$ & 67.59 & 70.50 & 0.725 & 0.394 \\
\hline
\end{tabular}


that whereas students - and particularly those studying civics - are aware of other avenues of political action in a democratic state, they still show little faith in their ability to understand the political system or have an effect on policy-makers.

Oddly enough, the statements referring to xenophobic attitudes reveal a more homogenous profile. In relation to all the items comprising this variable, there were only marginal differences in the attitudes of the two groups. With regard to almost all items a similar picture emerges, according to which more than half of the students express high levels of hostility towards Arab citizens of Israel, and object to their claims for civic equality. These findings stand in contradiction to the extensive student support for the statement that government is responsible for ensuring the protection of minority rights. Although it is not possible to establish a statistical relationship between the two, the contradiction between the acknowledgement, on the one hand, that the democratic polity is committed to protect minority rights and the outstanding support for a statement such as 'The Israeli Government must encourage Arab emigration from Israel', on the other, is an indication of the success of the Israeli education system and its traditional civics curriculum. This may be an indication that there are also other agents of socialisation in this country that are communicating to students the distinction between taught democratic values and the place of these values in Israeli democracy.

After an initial glance at the descriptive data, we attempted to examine the effect of the State's civic studies curriculum on the combined dependent variables featured above. For this purpose, we conducted a MANOVA procedure (see table 3.2). Analysis of the findings first show that the entire analysis is significant at a level of $p=0.001$. As for the variables themselves, we found significant differences between the two groups ( $p=0.00$ and 0.03 , respectively) for the variables of democratic orientation and political knowledge. With respect to the variable of political efficacy, we found marginal significance $(p=0.08)$. Therefore, already at this point, it is possible to assert that regarding the variables of political cynicism and xenophobic attitudes towards Arabs, the effect of civics education on student attitudes is not significant. Furthermore, the difference between the mean grades of the two groups is very small. However, it is important to point out that regarding xenophobia towards Arabs, despite the slight difference between the means, it appears that among civic studies learners there is, paradoxically, slightly greater support for these attitudes. This finding once more demonstrates the weak effect of civic studies courses on the formation of pluralistic attitudes towards minorities in Israel.

As noted above, in order to obtain further indication regarding the subject matter that nonetheless was internalised by students in the context of the civics courses, we took advantage of the index of political knowledge. A number of interesting facts regarding this index can be found in table 3.3, and additional 
Table 3.2 Multiple analysis of variance (MANOVA) for the assessment of the effects of civic studies in relation to dependent variables (comparison between civics learners and non-civics learners)

\begin{tabular}{|c|c|c|c|c|c|c|c|c|}
\hline Index & Reliability & Range & Group & Mean & $\begin{array}{l}\text { Standard } \\
\text { deviation }\end{array}$ & $\begin{array}{l}\text { ANOVA } \\
\text { value }\end{array}$ & $\begin{array}{l}\text { Significance } \\
\text { ANOVA }\end{array}$ & $\begin{array}{c}\text { Significance } \\
\text { MANOVA }\end{array}$ \\
\hline \multirow[t]{2}{*}{$\begin{array}{l}\text { Democratic } \\
\text { orientation }\end{array}$} & & $1-4$ & $\begin{array}{l}\text { Civics } \\
\text { learners }\end{array}$ & 3.320 & 0.543 & 11.07 & 0.000 & \\
\hline & & & $\begin{array}{l}\text { Non-civics } \\
\text { learners }\end{array}$ & 3.179 & 0.606 & & & \\
\hline \multirow[t]{2}{*}{$\begin{array}{l}\text { Political } \\
\text { cynicism }\end{array}$} & 0.550 & $1-4$ & $\begin{array}{l}\text { Civics } \\
\text { learners }\end{array}$ & 2.077 & 0.500 & 1.22 & 0.270 & \\
\hline & & & $\begin{array}{l}\text { Non-civics } \\
\text { learners }\end{array}$ & 2.118 & 0.516 & & & \\
\hline \multirow[t]{2}{*}{$\begin{array}{l}\text { Political } \\
\text { efficacy }\end{array}$} & 0.551 & $1-4$ & $\begin{array}{l}\text { Civics } \\
\text { learners }\end{array}$ & 2.454 & 0.630 & 3.07 & 0.080 & 0.001 \\
\hline & & & $\begin{array}{l}\text { Non-civics } \\
\text { learners }\end{array}$ & 2.372 & 0.632 & & & \\
\hline \multirow[t]{2}{*}{$\begin{array}{l}\text { Hatred of } \\
\text { Arabs }\end{array}$} & 0.783 & $1-4$ & $\begin{array}{l}\text { Civics } \\
\text { learners }\end{array}$ & 2.620 & 0.755 & 1.36 & 0.244 & \\
\hline & & & $\begin{array}{l}\text { Non-civics } \\
\text { learners }\end{array}$ & 2.554 & 0.780 & & & \\
\hline \multirow[t]{2}{*}{$\begin{array}{l}\text { Political } \\
\text { knowledge }\end{array}$} & & $1-4$ & $\begin{array}{l}\text { Civics } \\
\text { learners }\end{array}$ & 5.704 & 2.245 & 4.38 & 0.036 & \\
\hline & & & $\begin{array}{l}\text { Non-civics } \\
\text { learners }\end{array}$ & 5.357 & 2.245 & & & \\
\hline
\end{tabular}

confirmation of the limited effect of civic courses is evident from these data. A variance analysis shows that there was a significant difference $(p=0.00)$ between civics learners and those who had not learned civics only in relation to their knowledge of institutions of the political system. In comparison, regarding the other two factors (knowledge of political figures and of political processes), apart from the absence of significance between the groups, the means of students' knowledge were also almost identical, with only a small preference for civics learners. Therefore, it can be reasoned that while there appears to be no difference between the groups in respect of all the dynamic aspects of the political system and students' familiarity with the processes therein, citizenship courses nevertheless do have a considerable, if anticipated, effect on the assimilation of formal knowledge of this system. 
Table 3.3 Analysis of variance for the purpose of comparing between different levels of political knowledge acquired in civic studies courses (comparison between civic studies learners and non-civic studies learners)

\begin{tabular}{|c|c|c|c|c|c|c|}
\hline Index & Range & Group & Mean & $\begin{array}{l}\text { Standard } \\
\text { deviation }\end{array}$ & $\begin{array}{l}\text { ANOVA } \\
\text { value }\end{array}$ & $\begin{array}{c}\text { Significance } \\
\text { ANOVA }\end{array}$ \\
\hline \multirow[t]{2}{*}{$\begin{array}{l}\text { Political } \\
\text { figures }\end{array}$} & $1-4$ & $\begin{array}{l}\text { Civic studies } \\
\text { learners }\end{array}$ & 2.452 & 1.328 & 0.07 & 0.785 \\
\hline & & $\begin{array}{l}\text { Non-civic } \\
\text { studies learners }\end{array}$ & 2.426 & 1.338 & & \\
\hline \multirow[t]{2}{*}{$\begin{array}{l}\text { Institutions } \\
\text { and formal } \\
\text { procedures }\end{array}$} & $1-4$ & $\begin{array}{l}\text { Civic } \\
\text { studies } \\
\text { learners }\end{array}$ & 2.218 & 0.994 & 20.22 & 0.001 \\
\hline & & $\begin{array}{l}\text { Non-civic } \\
\text { studies learners }\end{array}$ & 1.878 & 1.074 & & \\
\hline \multirow[t]{2}{*}{$\begin{array}{l}\text { Political } \\
\text { system and } \\
\text { its process }\end{array}$} & $1-2$ & $\begin{array}{l}\text { Civic } \\
\text { studies } \\
\text { learners }\end{array}$ & 1.027 & 0.663 & 0.10 & 0.754 \\
\hline & & $\begin{array}{l}\text { Non-civic } \\
\text { studies learners }\end{array}$ & 1.011 & 0.711 & & \\
\hline
\end{tabular}

\section{Conclusions}

What conclusions can therefore be drawn from the above analysis regarding the efforts (and successes) of the 'defending democracy' to imbed antibodies in Israeli society, so that they might constitute a system of checks against the expansion of extremist and violent phenomena?

First, in order not to give the wrong impression, it should be noted that Israel's nature as both a Jewish and democratic nation state engendered a paradox, or 'inherent failing', in the educational system in the country, and occasioned its leadership quite a lot of discomfiture. Along with the effort to inculcate a democratic political culture among citizens, there was always an aspiration to deepen and fortify the status of national, ethnic and religious values designed to strengthen the ethno-national character of the State of Israel. The cost to the State of this 'inherent failing' was high indeed. The consistent exposure of youth to nationalist messages conveyed via various agents of socialisation, in the absence of the moderating effect of liberal and human- 
istic principles, would see their allegiance deteriorate from a commitment to a national ethos to the adoption of ultra-national and even racist ideas. Therefore, it appears that, in terms of the 'defending democracy', a kind of cyclical sequence developed. The State was the factor which fostered a national identity, and when that identity spilled over into ultra-nationalist margins it was again the State that had to deal with the ensuing extremism in its multi-faceted manifestations.

In summing up the ethno-national perspective, the Israeli state-run educational system chalked up not a few successes. Most outstanding was the consolidation of the Jewish populace around national symbols and values (even at times of deep controversy), and principally the collective consensus regarding the need to preserve the ethno-national character of the State and reinforce its Jewish essence. On the other hand, efforts at evaluating achievements in the education of democratic principles must be more cautious.

The leaders of the State, who in due course became familiar with the contradiction between its ethno-national and democratic elements, chose to deal with the need for instruction in citizenship by employing different practices aimed at diluting the subject. This dilution involved both a technical aspect, i.e. the reduction of the subject matter solely to the formal elements of government, and a time-restriction aspect, i.e. limiting classes to the minimum possible of one hour per week. However, despite the dramatic events experienced by the State of Israel and the resolutions made by its leadership to grant more import to the inculcation of democratic principles, there has been no real change. For every step taken to promote the democratic fundamentals proffered by the education system, another almost immediately followed, usually offsetting it, leading either to the reinforcement of Jewish national education or, alternatively, to various administrative restrictions preventing the institutionalisation of democratic values in the education system.

Only towards the end of the year 2000 did the first reformation take place in the nature of civics education as well as in its contents with the aim of solidifying the status of the democratic element vis-à-vis the ethno-national element. However, an assessment of the effect of this reform on student attitudes in relation to the variety of qualities associated with a democratic lifestyle revealed only partial success. The majority of students who took part in this research expressed high levels of support for attitudes reflecting both political cynicism and hostility towards the Arab minority in Israel, and no significant difference was found between the group which studied the civics course and the control group in regard to these variables. A possible explanation for this finding would be that the course curriculum did not sufficiently stress the importance of the values of tolerance and trust as part of the democratic worldview.

An additional indicator of the weakness of civics education in Israel is related to the weighting among the different topics that were supposed to be pre- 
sented to students. As already noted, the goal of reform was to liberate the civic studies curriculum from its technical-formal character and to introduce students to the more substantive essentials of political and social life in the State. However, the only topic where a significant preference was found in favour of students of civic studies over those who did not study this subject was that of political institutions and knowledge of formal procedures. This leads to the conclusion that, despite the declared intentions to reduce the weight of the formal element in course contents, in reality this element remained uppermost.

Nevertheless, two important findings should not be overlooked. Survey results indicate that the group of civic studies learners displayed higher and significant levels of support for issues related to democratic orientations as well as confidence in their ability to influence the political process (efficacy) than did the control group. Although differences between the group means are not dramatic, they are the first indications of the potential effect of civic studies in its new format.

The positive correlation between the reform in the civics curriculum and the internalisation of democratic orientations - despite being partial - implies a positive and untapped potential in the study of democratic values from the perspective of the 'immunising' of the 'defending democracy'. This inevitably raises the question of whether civic studies in its new format will indeed sink roots and lead in the near future to the promotion of basic democratic values, a reduction in levels of political cynicism and the adoption of a multicultural and tolerant attitude towards minorities, or, alternatively, whether the ethno-national tendency will again predominate so that the future identification of the Israeli citizenry with democratic values will only be weakened.

Any attempt to provide immediate answers to this type of question will amount to conjecture. However, a number of indications suggest that there are significant obstacles to the process of completing the reformation. Among these obstacles, the education system's organisational conservatism merits mention, as does the teachers' difficulty in adopting new study curricula. However, at the same time, we can assume that these hindrances are less problematic and more easily resolved than are the obstacles involved in policy-making, implementation and reformation of the system of values underpinning Israeli society. This last factor has proven to be a remarkably recalcitrant and entrenched barrier to substantial change.

To elaborate: Ministry of Education policy in regard to the nature of nationwide study programmes is to a great degree subject to the strength and influence of the head of the Ministry, who has the power to allocate or withdraw resources for a particular programme. In fact, during the years in which the Ministry of Education was managed by right-wing parties, there was a discernible preference by incumbent ministers to reinforce the status of ethno-national qualities over democratic principles. Yet ministers from left-wing 
parties, who were more aware of the importance of civic studies reform, likewise made insufficient effort to ensure its full implementation. So, for example, despite vouching for the implementation of reform in the 2001 school year, officials of the left-centre Ehud Barak administration were still speaking of only a partial reform during 2001, pertaining only to course topics, whereas the marginal status of the subject in terms of class hours and on the Bagrut exam was left untouched. The expansion of the course's topics, in the absence of funding for additional instruction hours, significantly hindered reform implementation because of the need to teach such a wide variety of subjects without changing the timetable. These unfavourable circumstances led the Ministry of Education, and many teachers as well, to forego precisely those new issues in favour of older and potentially less contentious topics.

Yet, the greatest obstacle thwarting nearly every effort to elevate the status of democratic principles in the education system invariably involves public sentiment towards reform. According to the survey conducted for this study, the Jewish public in Israel is still unrelenting in its desire to reinforce the unity around Jewish national values and symbols, and to inculcate these values by means of the state-run education system. So, for example, 66.9 per cent of the respondents agreed that the education system in Israel does not place enough emphasis on national values and on the affinity of the Israeli people to their country. This orientation was displayed also in relation to the instruction of the subject in citizenship, where 64.2 per cent of the subjects agreed with the statement that 'in civics lessons, first of all, the right of the Jewish People to Eretz Yisrael (the Land of Israel) must be given priority and only after that there should be the discussion of universalistic democratic values such as equality among all people and freedom of expression'. Furthermore, 40.2 per cent of the participants expressed support for the immediate abrogation of the civics education reform and a return to the earlier format.

These findings are an indication of the considerable difficulties facing the 'defending democracy' in Israel in its attempt to take the direction of the 'immunised' route. If the preceding chapters presented a somewhat optimistic picture implying that the barriers erected by state institutions in the battle against political violence and extremism are, over the course of time, gradually taking form in accordance with a liberal democratic vision, then in order to build up this tendency citizens of the State of Israel must learn the importance of maintaining a democratic framework and so bolster that tendency with a stronger infrastructure. However, in the light of the attitudes of policy-makers and the public at large towards the inculcation of democratic principles, it seems that the process of liberalising the response to extremism remains for the moment the prerogative of a small circle of elites, headed by the judiciary.

The prognosis for the role of civics education in the 'immunisation' of the Israeli democracy can be set out under two types of perspective. A quantita- 
tive perspective proposes that if reformation is fully implemented, a window of opportunity will be made available for students of in the state-run education system to eventually adopt a democratic orientation and become members of a social structure that, to a certain degree, will be 'immunised' against the expansion of the plague of extremism. On the other hand, a historical perspective suggests that the numerous obstacles thwarting efforts to implement such a reform considerably reduce the likelihood that it will in fact come to fruition.

\section{NOTES}

1 Michael Walzer, On Toleration (New Haven, CT: Yale University Press, 1997).

2 Kazimierz Slomczynski and Goldie Shabad, 'Can Support for Democracy and the Market Be Learned in School? A Natural Experiment in Post-Communist Poland', Political Psychology, 19:4 (1998), pp. 749-79, at p. 753.

3 Meira Levinson, 'Liberalism, Pluralism and Political Education: Paradox or Paradigm?' Oxford Review of Education, 25:1-2 (1999), pp. 39-58.

4 Stephen Macedo, 'Liberal Civic Education and Religious Fundamentalism: The Case of G-d vs. John Rawls?', Ethics, 105 (1995), pp. 468-96; William Galston, 'The Two Concepts of Liberalism', Ethics, 105 (1995), pp. 516-34; Callan Eamonn, Creating Citizens: Political Education and Liberal Democracy (Oxford: Clarendon Press, 1997).

5 Amy Gutmann, Democratic Education (Princeton, NJ: Princeton University Press, 1987); Galston, 'The Two Concepts of Liberalism'; Will Kymlicka, Multicultural Citizenship (Oxford: Oxford University Press, 1995).

6 Amy Gutmann, 'Civic Education and Social Diversity', Ethics, 105 (1995), pp. 557-79; Macedo, 'Liberal Civic Education and Religious Fundamentalism'.

7 Levinson, 'Liberalism, Pluralism and Political Education', pp. 43-4.

8 Orit Ichilov, 'Dimensions and Role Patterns of Citizenship in Democracy', in Orit Ichilov (ed.), Political Socialisation, Citizenship Education and Democracy (New York: Teachers' College Press, 1990), pp. 11-24; Orit Ichilov, Citizenship Education in Israel: Current and Pre-State Trends of Development (Tel-Aviv: Sifriat Poalim, 1993) (Hebrew).

9 Russel F. Farren, 'Integrating Political Science, Education and Public Policy', International Studies in Political Socialisation, 4 (1990).

10 Carole L. Hahn, 'Citizenship Education: An Empirical Study of Policy Practices and Outcomes', Oxford Review of Education, 25:1-2 (1999), pp. 231-50.

11 Ichilov, Citizenship Education in Israel.

12 Ehud Sprinzak, Every Man Whatsoever Is Right in His Own Eyes - Illegalism in Israeli Society (Tel-Aviv: Sifriat Poalim, 1986) (Hebrew).

13 Dan Horowitz and Moshe Lissak, Trouble in Utopia: The Overburdened Polity of Israel (Albany: State University of New York Press, 1989). Not surprisingly, a similar process can be detected in the construction of narratives, myths and national ideals in the textbooks devised by the Palestinian Authority in consequence of the Oslo Agreements. Raphael Israeli, 'Education, Identity, State Building and the Peace Process: Educating Palestinian Children in the Post-Oslo Era', Terrorism and Political Violence, 12:1 (2000), pp. 79-94.

14 Ichilov, Citizenship Education in Israel.

15 Statehood Education Act, paragraph 2, The Book of Laws, 131 (Jerusalem, 1953).

16 From an interview with Yitzhak Levy, former Minister of Education (13.8.2000).

17 Ichilov, Citizenship Education in Israel, p. 108. 
18 Evidence of this can be found in the following school textbooks: David Shachar, The Polity of the State of Israel (Tel Aviv: Yesod, 1986, a civic studies textbook for high school pupils); Avraham Yedidyah, The Polity of Israel (Herzliya: Kharuv, 1989), a civic studies textbook in question and answer format from the Bagrut - Israeli matriculation exam.

19 Ichilov, Citizenship Education in Israel, p. 129.

20 The State of Israel: Ministry of Education and Culture, Bagrut Examination in Citizenship, one study unit (Summer, 1988).

21 The State of Israel: Ministry of Education and Culture, Bagrut Examination in Citizenship, one study unit (Summer, 1988).

22 Daniel Bar-Tal, 'Reflections of the Intractable Arab-Israeli Conflict in Israeli School Textbooks', Megamot, 39:4 (1999), pp. 445-91.

23 This study was called 'Democracy in the Eyes of the Public' and was sponsored by the Israeli Democracy Institute. Complete details of the research available online at www.idi.org.il

24 Bar-Gal's research clearly shows the manner in which the geographical studies course was subordinated to national interests. Geography lessons at Israeli schools were employed largely as a tool the intention of which was to foster among pupils an orientation in which the geographical space of Israel belongs to the Jewish nation. See: Yorm Bargal, 'Boundaries as a Topic in Geographic Education - the Case of Israel', Political Geography, 12:5 (1993), pp. 421-35.

25 From an interview with Doron Shochat, formerly head of the Division for Democracy and Coexistence in the Ministry of Education (20.8.2000).

26 Ichilov, Citizenship Education in Israel.

27 From an interview with Hannah Shafir, the chief supervisor of civic studies in the Ministry of Education (20.8.2000).

28 From an interview with Doron Shochat (20.8.2000); from an interview with Hannah Shafir (20.8.2000); Mordechai Kremnizer et al., Being Citizens: Citizenship Education for All of Israel's Pupils, Interim Report of the Steering Committee for Citizenship Education (Jerusalem: Division for Study Programmes, Ministry of Education, Culture and Sport, 1996), pp. 13-14.

29 Correspondence from Professor Emanuel Guttman, Chairman of the Committee for Citizenship Programme, to the Minister of Education, Zevulun Hammer (15.11. 1990).

30 Michal Shamir and John Sullivan, 'Political Tolerance in Israel', Megamot, 29:3 (1985), pp. 155-69; Kalman Benyamini, 'In Regard to Political Tolerance: Political-Social and Psychological-Educational Studies', Psychology and Counselling in Education (1986), pp. 31-47; Sammy Smooha, 'Jewish Racism', Iton 77, 76 (1986), pp. 20-1.

31 Benyamin Neuberger, 'Education Is a Necessary (and Not Always Sufficient) Condition of Democracy', Psaifas, special supplement for the 25th anniversary of the Open University (2000), pp. 8-10; Judith Toreny-Purta, Abraham N. Oppenheim and Russel F. Farnen, Civic Education in Ten Countries (New York: Halsted Press, 1975), p. 225.

32 Ichilov, Citizenship Education in Israel.

33 Israeli, 'Education, Identity, State Building and the Peace Process'.

34 From an interview with Doron Shochat (20.8.2000).

35 Finance Ministry, Budgetary proposal for the year 1999.

36 Reyli Sa'ar, 'Levy Deprives the BEV of its Authorities: Education to Values Cannot Be Taught by Using Force', Ha'aretz, 23 April 1998; interview with former Minister Levy (13.8.2000).

37 From an interview with Ms Hannah Shafir (20.8.2000).

38 Kremnizer et al., Being Citizens, p. 5. 
39 Kremnizer et al., Being Citizens, p. 7.

40 Aliza Shinhar et al. The Jewish People and the World: Jewish Culture in a Changing World. Recommendations of the Committee for the Examination of Jewish Studies in State-Run Education (Jerusalem: Department of Publications, Ministry of Education, Culture and Sport, 1994).

41 Reyli Sa'ar, 'Citizenship Studies Were Significantly Cut Back - the Chapter on the President Was Removed from the Course', Ha'aretz, 29 August 2000.

42 H. Eden, V., Ashkenazi and B. Alferson, Being Citizens in Israel, a Jewish and Democratic State (Jerusalem: Ministry of Education, the Pedagogical Board and the Division for Study Curricula, 2000).

43 Yoav Peled and Gershon Shafir, 'The Roots of Peacemaking: The Dynamics of Citizenship in Israel, 1948-93', International Journal of Middle East Studies, 28:3 (1996), pp. 40910.

44 Reyli Sa'ar, 'There Just Happens to Be Enough Room for Ezra and Nehemiah', Ha'aretz, 30 August 2000.

45 Correspondence from Professor Michel Abitbul, Chair of the Pedagogical Secretariat, to Professor Emanuel Guttman (13.3.2000).

46 Correspondence, from Hannah Shafir, Ministry of Education civic studies supervisor, and Sarah Vidar, religious and state-run education history and civic studies supervisor, to civic studies teachers (12.5.2000); Ha'aretz, 29 August 2000.

47 Interview with Ms Hannah Shafir (20.8.2000).

48 Interview with Ms Hannah Shafir (20.8.2000).

49 See, for example, Kenneth P. Langton and Kent M. Jennings, 'Political Socialisation and the High School Civics Curriculum in the United States', The American Political Science Review, 62:3 (1968), pp. 852-67; Richard G. Niemi and Barbara J. Sobieszek, 'Political Socialisation', Annual Review of Sociology, 3 (1977), pp. 209-33.

50 Charles E. Merriam, The Making of Citizens (Chicago: University of Chicago Press, 1931), p. 8.

51 Valdimer O. Key, Public Opinion and American Democracy (New York: Alfred A. Knopf, 1963), p. 13.

52 See, for example: Toreny-Purta, Oppenheim and Farren, Civic Education in Ten Countries; David Denver and Gordon Hands, 'Does Studying Politics Make a Difference? The Political Knowledge, Attitudes, and Perceptions of School Students', British Journal of Political Science, 20 (1990), pp. 263-88; Carole L. Hann, 'Citizenship Education: An Empirical Study of Policy, Practices and Outcomes', Oxford Review of Education, 25:102 (1999), pp. 231-50.

53 Percentages adding up to less then 100 are a result of missing values.

54 Each of the variables examined in this study relied on validated indices which had undergone adaptation to the Israeli context.

The first variable, pro-democratic attitudes, was measured first by means of an integration of two indices, i.e. a pro-democratic approach and democratic attitudes. The range of answers for the new index was distributed along a five-degree scale $(1=$ completely agree, 5 = do not agree at all); the following statements were included: 'Competition among many political parties makes the political system stronger; Any individual or organisation has the right to organise opposition or resistance to any governmental initiative; A successful political leader will often need to compromise with his political opponents; Participation of people is not necessary if decision-making is left in the hands of a few trusted competent leaders (reversed item); The government has the responsibility to see that the rights of all minorities are protected'. Source for the Index of Democ- 
ratic Values: Arthur H. Miller, Vicki L. Helsi and William M. Reisinger, 'Reassessing Mass Support for Political and Economic Change in the Former USSR', American Political Science Review, 88 (1994), pp. 399-411; Source for the Index of Pro-Democratic Orientation: Arthur H. Miller, Vicki L. Helsi and William M. Reisinger, 'Comparing Citizen and Elite Belief Systems in Post-Soviet Russia and Ukraine', Public Opinion Quarterly, 59 (1995), pp. 1-40. As a result of the low internal reliability of the new index we sought to create, we combined only the two following items into an index of democratic attitudes: 'A successful political leader will often need to compromise with his political opponents; The government has the responsibility to see that the rights of all minorities are protected'. The Pearson coefficient for the two items indicated a significant correlation of a mediumstrong effect $(r=0.215, p=0.000)$.

The second variable, xenophobia towards Arabs, was measured on the basis of the following statements: 'In the event of a nationwide referendum on the subject of the peace process, it would be better if the Arabs did not take part; Arab complaints of discrimination are not justified; The Israeli Government should encourage Arab emigration from Israel; Arabs are too demanding regarding anything to with their rights.' (Cronbach's Alpha $=0.783$.) This index, which had been adapted for the Israeli context, is principally based on the Modern Racism Scale: John B. McConahay, Betty B. Hardee, and Valeri Batts, 'Has Racism Declined in America? It Depends on Who is Asking and What Is Asked', Journal of Conflict Resolution, 25 (1981), pp. 563-79.

The index of political efficacy was built on the basis of the following statements with a scale which offered two possibilities: $0=$ agree and $1=$ disagree: 'I think that public officials care about what people like me think; Voting is not the only way that people like me can have a say about how the government runs things; People like me don't have any say about what the government does; often, politics and government seem so complicated, however, a person like me can still understand what's going on'. (Cronbach's Alpha $=0.551$.) Source for the Political Efficacy Scale: Angus Campbell, Gerald Gurin and Warren E. Miller, The Voter Decides (Evanston, IL: Row, Peterson, 1954).

The variable of political cynicism was measured according to three statements. Two statements were omitted from the original scale. Answers ranged from $1=$ always to 4 = never: Government officials are not highly competent; Government clerks and officials do not pay much attention to ordinary citizens?; Government officials usually do not perform effectively and according to the law (reversed item).

(Cronbach's Alpha = 0.550.) Source for the Political Cynicism Scale: Enrique D. Baylora, 'Criticism, Cynicism and Political Evaluation: A Venezuelan Example', American Political Science Review, 72 (1979), pp. 987-1002.

The variable of political knowledge was assessed by questions relating to three main areas: familiarity with state political institutions; knowledge of prominent Israeli political figures; and knowledge of political issues and stances.

In order to evaluate the extent of the pupil's knowledge of political figures, he/ she was asked to reply to four questions regarding holders of political office in the country. Familiarity with the figure or his/her position earned the pupil one point (unawareness of the figure would give the pupil zero points). In all, the pupil would receive a sum of points ranging from 0 to 4 . Familiarity with state political institutions was measured according to four questions pertaining to formal procedures regarding legislation, the roles of Knesset committees, a no-confidence motion in the government, and the functions of the Supreme Court. The questionnaire was presented to the pupil in the form of a test consisting of four answers where only one was correct. Again, the pupil could accumulate a total ranging from 0 to 4 points. Knowledge of political issues and 
stances was measured using two questions addressing the attitudes of political parties in Israel on political and economic affairs. Questions were in the form of two answers, correct and incorrect, so that the total mark on this section ranged from 0 to 2 points.

55 Denver and Hands, 'Does Studying Politics Make a Differences?; Edgar Litt, 'Civics Education, Community Norms and Political Indoctrination', American Sociological Review, 28 (1963), pp. 69-75. 


\section{The role of 'civil society' in the 'defending democracy'}

1

HIS CHAPTER EXPANDS further on the construct of the 'defending democracy' by inquiring into the 'pro-democratic civil society' and its role in the context of the 'defending democracy' model. The following pages will underscore the significance of the actions of this non-state actor in the 'defending democracy's' transition from the 'militant' to the 'immunised' model. The fundamental argument here submits that, as a result of its isolation from the State, 'civil society' in Israel probably plays a threefold role in safeguarding Israeli democracy.

First, in a country such as Israel, the official authorities have not yet forged a clear-cut policy on the central principles by which its future citizens should be educated. Therefore, there is ample space for intervention by non-state institutions seeking to promote an education in democratic values either by means of school courses or less formal avenues. A no less important role is reserved for civil organisations hoping to bridge the various and gaping social abysses of Israeli society.

Second, these same non-state bodies, operating in the social sphere, are also capable of responding to the expansion of extremism. They are very open to those extremist movements responsible for fuelling the flames of extremism well before they have developed into a political alternative and a veritable threat to the government. Consequently, as 'civil society' becomes more effective, the State feels less threatened by extremist elements and subsequently finds less cause for exercising aggressive tactics against them.

Third, the 'pro-democratic civil society' is capable of responding to the challenges presented by extremism; it also has the option of setting its sights on the 'militant'-like ways of the State. That is, in order to bolster essential democratic values in circumstances where the State feels under attack, the latter must be protected both from its adversaries and from itself. This is because democratic governments under threat often tend to choose 'militant' routes of action 
against elements they perceive as extremist, as was broadly demonstrated in chapter 2.

The 'civil society' on the one hand strives to reduce levels of extremism and so limit its manifestations, and on the other it attempts to restrain the government's heavy hand in its fight against extremists. It is the bearer of one of the main keys to the solution of the 'paradox of the defending democracy'. However, before proceeding on to its role in the struggle against extremism, this 'civil society' and its ample virtues should first be defined.

The term 'civil society' is not new to the social sciences. Numerous political scientists, among others Hobbes, Locke, Montesquieu, de Tocqueville, Hegel, Marx and Gramsci, have made use of it at one time or another, and in almost every case the term was used in a different sense, a fact which led it to become one of the most pliable constructs in the mainstream social-scientific literature. ${ }^{1}$ In order to avoid the pitfalls and snares of the multifarious senses of the term, this discussion adopts the approach of Yishai who, as a first step, chose to define 'civil society' by a process of elimination. According to this approach, 'civil society' is a realm whose activities are distinct from those of the domain of law enforcement (the state), of primordial ties (the family) and of competition, where the aim is to maximise profits (the marketplace). If so, what then is 'civil society'? Yishai's definition proposes that 'civil society' consists of those activities occasioned within an organisational context, whether established or transient, but which do not fall within the context of the private domain. A necessary (albeit insufficient) condition for the existence of the 'civil society' is that its groups are voluntary and based on civilian readiness to contribute energy, time and resources towards the goal of cooperation with fellow citizens. ${ }^{2}$

Five principal types of organisation are featured in this definition of the 'civil society'. First, there is the interest group acting in order to further the vested - most often, economic-professional - interests of its members, and, second the self-help group, which caters for either the disadvantaged or a population with special problems promoting a cause in which its members have a close and tangible interest. These first two may be relevant to the 'defending democracy', whereas the other three certainly have an important role in it. These are: social movements seeking to effect changes in society or on the state's agenda; grassroots groups striving to influence their close environment and whose activities revolve around the community or neighbourhood; and, finally, volunteer associations consisting of citizens whose main objective is to help out and care for the welfare of their fellow men and women.

Debate on the notion of 'civil society' over the years has not been restricted to the attempt to delineate the boundaries of the concept. The main objective of the 'civil society', according to many scholars, derives from the assumption that groups and organisations included beneath its banner have a central role in bolstering the democratic process. The source of this assumption can be found in 
de Tocqueville's writings, according to which voluntary associations in the United States at the turn of the nineteenth century were perceived as the basis of democratic life. ${ }^{3}$ In recent years, this view has gained much support in the works of Robert Putnam, who indicated a relationship between an active "civil society' and a prospering democracy. ${ }^{4}$ Indeed, many studies based on this perspective underscored the contribution of 'civil society' to the democratic process as well as to processes of democratisation. It comes as no surprise, therefore, that recently there have been voices proclaiming the potential of 'civil society' in relation also to the safeguarding of new democracies from defiant elements whose source can be found in the extreme right. ${ }^{5}$

However, this optimism regarding the role of 'civil society' in the democratic process has also been the subject of much controversy. One leading criticism accuses Putnam, by following in de Tocqueville's footsteps, of neglecting the less democratic aspect of the 'civil society', specifically, its conflictual and violent aspect. In this latter context, Berman has demonstrated 'civil society's' part in the rise of the Nazi regime in Germany, ${ }^{6}$ and Weinberg and Eubank have presented a similar position in relation to the fascist regime in Italy. ${ }^{7}$ In view of all the above, Foley and Edwards chose to introduce an analytical division of the construct into two principal types. Putnam's use of the term was called 'civil society I', implying groups contributing to democratic life, whereas, 'civil society II' indicated the conflictual potential of 'civil society' associations. This second type included groups that were part of the social sphere and which engaged in organising opposition to tyrannical regimes. ${ }^{8}$ Booth and Richard supplemented the above classification with a third type, 'civil society III', or the 'uncivil society', in which they included active associations of a challenging and violent nature. The challenge in this case was not aimed at tyrannical regimes but rather targeted democratic systems of government. Examples of this type of association are the Ku Klux Klan, the white militias in the United States and the death squads of Central America. ${ }^{9}$

Despite the widespread assumption that 'civil society' groups of all types, regardless of their aims or range of activities, constitute an important factor in the democratic structure, ${ }^{10}$ this analysis seeks to focus on the phenomenon we will call the 'pro-democratic civil society', i.e. a group of associations all with one objective, namely, the empowerment of democracy. Apart from its typological importance, the classification of 'civil society' into three distinct types can be helpful in defining the status and functions of 'civil society' in terms of the 'defending democracy' (see Figure 4.1).

The first (civil society I) and the second type (civil society II) show significant promise in their ability to protect democracy because these groups are united under one common goal, the fortifying of democracy; yet, at the same time, the targets of their activities differ. In other words, while civil society I invests most of its efforts in society, civil society II directs the bulk of its activi- 
Figure 4.1 Pro-democratic civil society and the targets of its activities

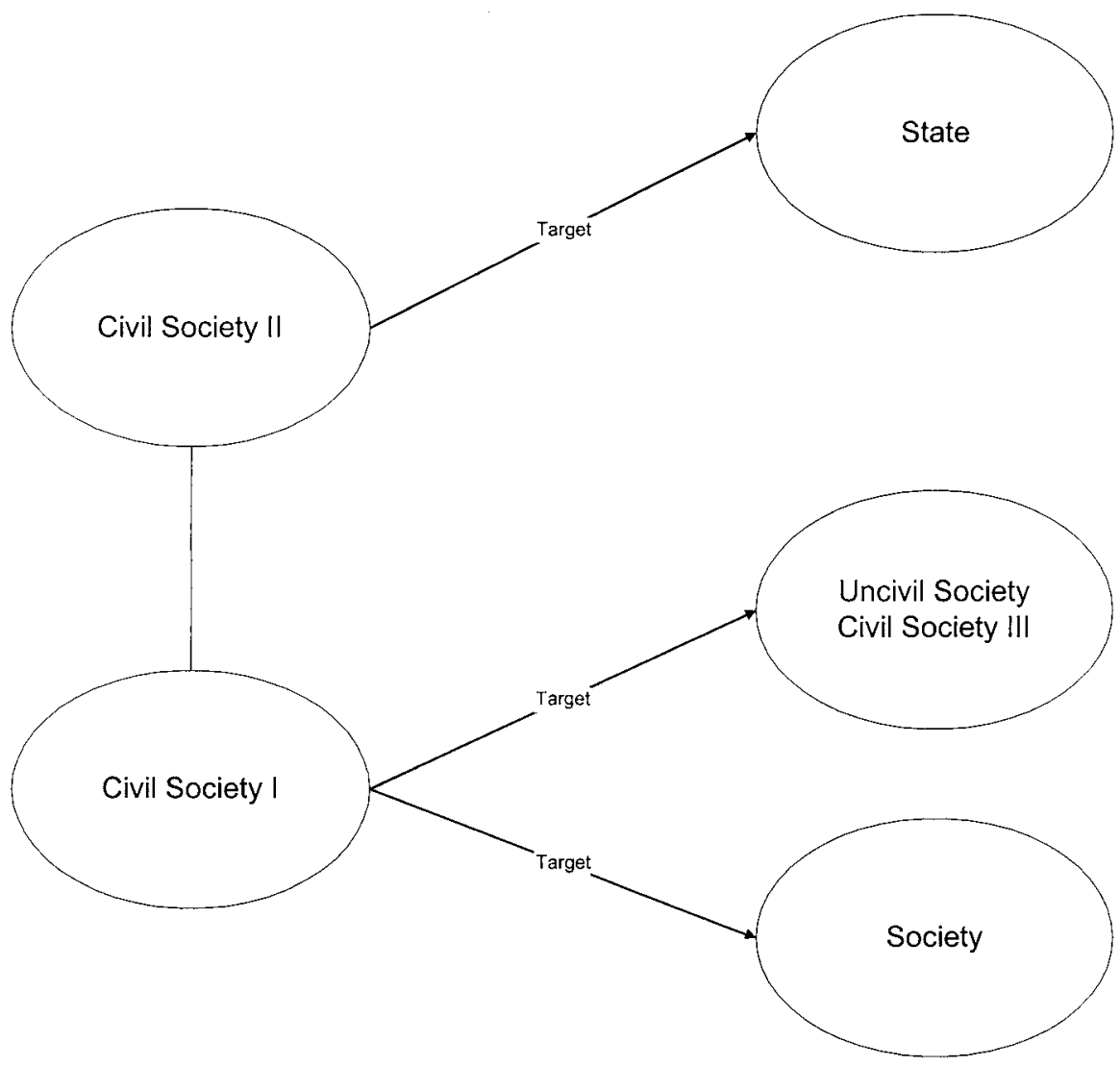

ties toward the state. The combination of the different targets of their activities is essentially that which grants valuable social facilitation to the 'defending democracy'.

To elaborate further, the function of civil society I is to abet democracy principally by means of the erosion of extremist infrastructures underlying society and by attempting to reduce the scope of activities of civil society III which builds on these underlying foundations. The principal means at the disposal of civil society I include the following: raising public awareness and mobilising support for the denunciation of extremist phenomena; tracking the expansion of extremism and violence; providing succour for the victims of extremism; and, finally, the reinforcement of the democratic base of society particularly by means of education. 
The role of the second type of civil society is no less important. Whereas the thrust of the efforts of type I organisations is aimed at dealing with extremist phenomena, the second type of 'pro-democratic civil society' directs all its activities towards limiting the state's response to a substantive conformity to the notion of the 'rule of law'. From the perspective of the 'defending democracy', state accountability is just as important as containing anti-democratic elements because, as noted earlier, in the absence of this type of accountability, state legitimacy as well as its moral stature is put at risk.

On the whole, the 'pro-democratic civil society' embraces the sum of organisations whose declared goal is the fortification of democracy. This group is internally divided into two subgroups according to the target of their activities, i.e. civil society type I and type II groups. Nonetheless, it is important to point out that despite this typology of organisations according to the target of their activities, attributes of both the first and second types may appear concomitantly in certain cases.

\section{'Civil society' in Israel}

Research dealing in Israeli state-society relations and on the interrelations between these two as far back as the first days of its establishment consistently generates one conclusion: for a long period of time, the State of Israel has been distinguished by a 'civil society' reduced in scope and influence. The main explanation for civil society's weakness in Israel is rooted, as put forward by Yishai, in the pre-State era when all Jewish settlement in Israel was governed by a political elite originating from Eastern Europe. Members of this elite brought with them a worldview according to which only a centralist and strong state capable of mobilising its people could lead to the realisation of national goals, foremost among which was the need to establish a stable Jewish sovereignty in the land of Israel. In line with this vision, a centralised and paternalistic state or, as termed by Yishai, a 'guided democracy', was instituted in Israel. It was David Ben-Gurion, the first prime minister of Israel, who encapsulated the distinctions of the 'guided democracy' in the words: 'It is not important what the people want, more important is what is necessary for the people.'11

Indeed, guided by Ben-Gurion's 'statehood' orientation, the State was successful in harnessing non-governmental bodies, among them, the Keren Kayemet L'Yisrael ('Jewish National Fund') and the Histadrut ('Labour Federation'12) to its exclusive interests and, by the same token, was almost completely successful in suppressing challenging groups, such as Shurat Hamitnadvim ('Line of Volunteers'), a group founded some years after the State's establishment and whose goal was to alert attention to and exhort against corruption in the governmental system. ${ }^{13}$

However, it was not only non-political oppositional bodies or movements 
that were absorbed by the State: political parties which were central actors in the Israeli political system in its early years ${ }^{14}$ also underwent a similar process. Although researchers such as Keane or Foley and Edwards ${ }^{15}$ perceive the institution of the political party to be part of the 'civil society', political parties in Israel proved to be instruments of the State and assumed an accompanying role in permeating many aspects of the citizen's life. ${ }^{16}$ The considerable centralism and ideological control of the State over Israeli society eventuated in a condition describes by Ben-Eliezer as one of 'democratic coma'. ${ }^{17}$

In the last few decades the State of Israel has undergone a series of changes that provided a window of opportunity for the emergence of an active yet at the same time somewhat detached 'civil society'. These were economic changes, manifested mainly in the form of reduced governmental involvement in the economy and an increase in the quality of life, as well as political changes and, especially, the decline of the old-guard party blocs of Labour and Likud, traditionally identified with the State. Further political changes included the burgeoning of smaller parties founded on sectoral interests (Shas, Yisrael B'aliyah, Shinui) which were more closely in tune with certain parts of society, and changes in the security situation, particularly the growing public fatigue with the state of incessant tension largely resulting from over-extended IDF control over the territories of Judea and Samaria. ${ }^{18}$

Changes in the Israeli 'civil society' are specified by Yishai according to six criteria:

1 A significant growth in the number of civil associations (non-profit organisations ${ }^{19}$ ) from 3,000 registered in 1982 to 27,000 in 1998;

2 a change in the profile of the 'civil society', manifested primarily in the decline of large groups closely affiliated to the State, on the one hand, and the development of grassroots social groups, both nationwide and local/community-based, on the other;

3 permutations in patterns of 'civil society' action and a significant increase mainly in public protest;

4 leaders of various movements gained increasing access to policy-makers and policy-making processes;

5 a greater degree of state response to the demands of the 'civil society'; and, finally,

6 the growing legitimacy accorded to the 'civil society' by the State.

Unlike times past, when the State fought head-on with 'civil society' organisations, the strategy adopted by the State towards the end of the 1990s was to recognise their legitimacy and to expand the scope of their activities. ${ }^{20}$

However, despite the rapid growth of the 'civil society' in Israel, both Yishai and Ben-Eliezer demonstrate redoubled caution when endeavouring to define its status, especially vis-à-vis the State. Ben-Eliezer adopts a critical stance and 
regards the recent flourishing of the many non-profit organisations (NPOs) in Israel as deceptive. The gist of his argument is that the hegemonic structure of the State of Israel was both versatile and prudent enough to absorb NPO politics, gradually reducing the gap between the State and 'civil society' to the point where the latter, in effect, has been deprived of one of its main roles. ${ }^{21}$ Yishai puts forward a somewhat less decisive view and attempts to demonstrate that while in regard to certain aspects of the 'civil society' - particularly, its opposition role to the government - the State imposes economic, legislative and even moral limitations on its activities, with regard to groups acting in the interest of the polity's stability the State in fact enables them to develop and fulfil their goals. ${ }^{22}$

From the perspective of the 'defending democracy', three questions arise. First, is there in fact a group of organisations in Israel which can be identified as constituting a 'pro-democratic civil society'? Second, if it is indeed possible to detect a viable 'pro-democratic civil society', will the bulk of its activities, in accordance with Yishai's assertion, be directed at the stability of society? And will those groups whose target is the State suffer from a lack of autonomy and remain ineffectual? Or, perhaps, in accordance with Ben-Eliezer's argument, will all organisations be rendered ineffectual and suffer inclusively from a lack of autonomy? And, third, with regard to the internal distinctions characteristic of this 'pro-democratic civil society' and its relationship to its environment, are there indications that one is speaking of a substantive body capable of establishing itself in a forthright manner as a central social actor at the juncture between the social and political systems, or is one simply speaking of a passing phenomenon? In order to answer these questions, I have chosen not to settle for one research method but rather have combined the findings of a qualitative analysis together with an analysis of the results from a survey conducted among associations of the 'civil society'.

\section{The 'pro-democratic civil society' and the 'defending democracy' in Israel}

Tracing the evolution of the 'pro-democratic civil society' in Israel turned out to be no easy matter, to a large extent because of the relative novelty of the phenomenon in question. The literature documenting it is sparse and the ability to detect the various groups comprising it is limited. In order to identify as many groups as possible, a cross-comparison of findings from a number of principal sources was conducted: the Israeli guidebook to self-help organisations, the guidebook to bodies operating in voluntary fields, the NPO Registrar, the list from the 'New Israel Fund' and a list of bodies supported by Shatil (Hebrew acronym for Empowerment and Training Centre for Social Change; literally, 'plant' or 'seedling'). After an initial classification according to their objectives and the targets of their activities, a list was drawn up of 156 associations which 
met the previously specified criteria of pro-democracy organisations. Each was sent a questionnaire, and out of 15680 ultimately responded, which constituted 51 per cent of the total population of associations. At a later stage, in-depth interviews were conducted with representatives of a number of prominent associations from various fields. ${ }^{23}$

Data analysis was performed in two stages contingent upon the questions we sought to answer and methodological constraints. In the first stage, based on the data gathered from associations and in-depth interviews with representatives of the various groups, our intent was to delineate "pro-democratic civil society' activities according to the target of its activities (society, 'uncivil society' and the State), and to evaluate which of these targets received more emphasis in practice. Moreover, we attempted to discern features of the interrelations among the various organisations on the one hand and between those organisations and the Israeli State and society on the other, and to gain insight into their degrees of success as reported by representatives in relation to their activities. The second stage was based on quantitative findings collected from all the relevant factions, and its main purpose was to put forward an additional perspective in our evaluation of the support which the 'pro-democratic civil society' could potentially provide to the 'defending democracy' in Israel. Included in this evaluation was an analysis of variables related to the "pro-democratic civil society' itself and variables pertaining to the relationship of these organisations with their external environment.

\section{The 'pro-democratic civil society' in Israel: targets and prominent organisations}

At first glance, both quantitative and qualitative data already provide at this stage a fair indication, albeit partial, of the answer to the first question, regarding the existence in Israel of the 'pro-democratic civil society'. Findings show that alongside 'civil society' associations in Israel which are intent on advancing various ends - and, as a secondary activity, also have a hand in promoting democracy - it is possible to detect a group of organisations (not particularly large, i.e. 10 per cent of the total population) whose declared objective is to defend and build up democracy while directing its activities at those same three targets included in the above definition of the "pro-democratic civil society'.

\section{Society-oriented organisations}

A close look at the internal classification of organisations according to the targets of their activities shows that there is a clear preponderance, more than 80 per cent, of associations which may be called 'society-oriented'. This large 
group has chosen as its goal the mitigation of the prospects of the extremism that most likely stems from the dangerous cleavages which divide Israeli society in general and Jewish society in particular. As for the features of the activities of society-oriented groups, the majority define their objective as an effort to strengthen the role of democratic values in Israeli society and to bridge the deep cleavages cutting across it. These bodies are distinguished by two principal aims: first, the effort to reduce alienation among different groups in Israeli society and, second, the dissemination of and education in democratic principles.

The group of organisations working to reduce alienation among various sectors of Israeli society is distinguished by a relatively low level of institutionalisation (reflected in certain practical features and their local nature, for the most part). The activities of associations of this type primarily focus on initiating meetings among Jewish and Arab citizens, and in the last few years - following the assassination of Prime Minister Yitzhak Rabin - have also attempted to foster dialogue among secular and religious domains. The combination of their local, oftentimes community, non-institutional character and the nature of their activities, i.e. encounters among various groups, places them low on the scale in terms of their potential for promoting Israeli democracy. The same cannot be said for the group of associations which aims at strengthening the democratic foundations of society through educational means.

The description in chapter 3 of the relatively marginal status of democratic studies in Israel can help explain the 'groundwork of opportunities' setting the way for the inception and activities of organisations of this type, particularly beginning in the mid-1980s, when there was an increase in the tendency towards political extremism among older and younger generations alike. One of the more prominent organisations at that time was the Adam Institute for Democracy and Peace, founded in commemoration of the peace activist Emil Greenzweig, who was murdered in 1983 by a Jewish perpetrator during the course of a demonstration against the war in Lebanon. The aim of this association was to devise and implement educational projects whose purpose was to promote democracy and peace, an education in active citizenship, an awareness of equal human rights, the prevention of violence and the resolution of conflicts in peaceful ways. ${ }^{24}$ Use was made of workshops geared to a more adult population whose primary aim was to promote discussion of the fundamentals of the democratic notion. Another, more central, activity was the delivery of instruction in democratic subject matter at state-run schools. The Adam Institute was one of the organisations to be adopted by the Division for Democracy and Coexistence in the Ministry of Education (eventually to become, the Board for the Education of Values) and, through this collaboration, educators working for the 'Adam Institute' were also able to make contact with school pupils. Although these educational activities were not officially part of the school system, the programme still presented school pupils with a forum for the 
discussion of democratic values that was almost entirely absent from the formal study programme..$^{25}$

The Adam Institute was not the only association to be favoured with the State's approval. The Institute for Democratic Education and the Foundations Institute similarly gained access to the formal education system. Much like the Adam Institute's programme, the Institute for Democratic Education sought to inculcate democratic values among school pupils. The Institute founded the periodical Panim L'khan U'l'khan (roughly, 'There Are Two Sides to Things') which intended 'to assist the educational system in reinforcing an education in citizenship and democracy, to foster a culture of dialogue, encourage involvement in current affairs, develop critical thinking, cultivate political education, encourage a tolerance of different opinions and cultivate a democratic personality'. ${ }^{26}$ Perusal of the journal's contents reveals that it indeed dealt with an impressive variety of subjects, including: democratic involvement, the civil status of Israeli Arabs, tolerance and ethics. ${ }^{27}$ According to Institute director Shlomo Tzidkiyahu 67 per cent of state-run schools made use of the periodical's subject matter within the context of their school programme, a claim that was true of the late 1990s. This fact, in his view, demonstrates the Institute's success at the time when he was director. ${ }^{28}$ The modus operandi of the Foundations Institute is somewhat different. Its target population is the religious-national public in Israel and members focus their efforts on introducing educators in religion to a more holistic worldview which integrates religious belief and values on the one hand with democratic principles on the other. Rabbi David Atzmon, a senior moderator of the Institute, uses utmost caution when attempting to evaluate the degree of Foundations' success, yet notes that evidence of the effect of its programmes can be detected in the promotion of pluralistic values among many educators from the national-religious education sector. ${ }^{29}$

However, the relative success of associations promoting education in democratic principles in establishing themselves and building closer ties with the object of their activities - Israeli society - gives rise to the problematic aspect noted by Yishai and Ben-Eliezer: specifically, the State's role as their custodian. Ben-Eliezer colourfully describes this phenomenon 'the State's paternal embrace' (his exact term is 'bear hug ${ }^{30}$ ); Dryzek refers to the process of 'inclusion' undergone by these groups. ${ }^{31}$

One of the main reasons for their survival and their ability to further their goals is that the state-run education system originally opened its doors to them, thus allowing them to operate in state 'territory'. This enabled the associations to increase the scope of their activities, while simultaneously fostering their institutionalisation because they were compelled to adjust the nature of their activities to conform with state dictates. The growing affinity between organisations and State was, however, manifested beyond their access to the education system. Several willingly fell victim to a process of inclusion with deeper roots: 
that is, they became financially dependent on the Ministry of Education and the activities of many of them were entirely reliant on governmental budgets. Indeed, in 1999, when the Ministry of Education introduced a policy discontinuing the funding of those associations engaged in school instruction, the Coalition of Organisations for the Empowerment of Democracy appealed to the minister of education and informed him that this decision to defer payments would in effect lead to a complete suspension of their activities. ${ }^{32}$

This led to a state of ambivalence, particularly for those same organisations wishing to operate in the fully state-controlled field of education. On the one hand, state cooperation was vital in order to gain access to school pupils but, on the other, as ties grew closer between the State and 'civil society', the autonomous status of the latter would suffer. If Israeli 'civil society' were to become dependent on the State for its budget, it would, in effect, assume the properties of a state affiliate, as claimed by Yishai and Ben-Eliezer, who base their argument on Dryzek's idea of inclusion, and units of this type were thus drawn away from the social 'civil' sphere and absorbed into the political one.

Results from interviews with these organisations' executives, as well as the quantitative data (see p. 156), demonstrate that although they did tend to be financially dependent on the State in the first years of their activities, in the course of time and subsequent to recurrent changes in Ministry of Education policy, they were able to increase their economic autonomy from the State of Israel, henceforth making it easier for them to operate independently. ${ }^{33}$

Nevertheless, still unresolved is the predicament in which organisations that are financially autonomous still depend upon the State for access to the education system. In the absence of other programmes providing education in democratic values, state-run schools remain the main objective for such associations, so that ultimately the State continues to wield significant power over them.

\section{'Uncivil society'-oriented organisations}

The circle of 'uncivil society'-oriented organisations represents an additional problem associated with the activities of the 'pro-democratic civil society' in Israel. In many European countries, it is often possible to detect earnest participation in the civil realm, manifested, for instance, in demonstrations by extremist and pro-democracy groups congregating on opposite sides of the street. North America is populated with large, well-established, associations which often engage in tracking and charting the operations of the 'uncivil society' and which subsequently offer ways of combating the phenomenon. In Israel, on the other hand, conditions are widely different and the fight against the 'uncivil society' in Israel has over the years been especially circumscribed. The reasons are varied; however, the most salient explanation appears to be that the divided 
nature of Israeli society make it difficult to determine which is the 'civil' and which the 'uncivil' side in the public debate taking place within the context of the Jewish and democratic State (and this latter definition is itself fraught with a number of paradoxes, several of which have already been discussed in previous chapters).

Therefore, even when we consider the imposing demonstrations launched by the Haredi public against the Israeli judicial system in early 1999 and the counterdemonstrations mounted by the secular public in support of the judicial system, to simply subsume these events under the general heading of the 'civil society's fight against the 'uncivil society' is problematic. In the first place, this is primarily because the above events reflect a struggle among political, religious and secular bodies, a struggle painted in bold partisan colours. Second, both sides display attitudes which to a great extent conform to state doctrine. While the secular public sought to support the judiciary and in this fashion underscore the importance of the democratic element in the State of Israel, the ultraorthodox public attempted to restrain judicial measures that in their view had great consequence for the priorities in the country, and in this way aimed to bolster its Jewish element.

Therefore, aside from the grassroots initiatives mounted against the various guises of 'Kahanism' which marked the second half of the 1980s and constituted an exceptional example of public protest against 'uncivil' elements, the majority of public action in Israel would be easier to classify according to the cleavages cutting across the society rather than on the basis of the analytic framework of the 'civil society versus the uncivil society'. ${ }^{34}$

Another explanation for the dearth of active public objection to 'uncivil society' tendencies is closely linked to the discussion presented in the second chapter, to wit, the state's close monitoring of extremist and violent elements and the exercise of significant force in cases when associations of certain types were considered dangerous. The almost absolute control of the State in response to 'uncivil society' activities leaves open only a narrow opportunity for 'civil society' associations which seek to be active in this realm. One of the problematic outcomes of extensive state control and the forceful nature of its operations is the ensuing damage to basic democratic rights and, in consequence, the great need for organisations of the type of 'civil society II' which will contest such forceful policy. The role played by these associations in Israel is discussed below.

An extensive examination of the entire population of organisations currently active in Israel brings to the fore one particular group: Keshev ('attentiveness', 'ear to the ground') - The Centre for the Protection of Democracy in Israel. Keshev's principal goal is the restraining of the 'uncivil society', and it concentrates on the documentation and exposé of trends, groups and activists which and who might pose a threat to democracy in Israel. Keshev was instituted 
by a group of intellectuals, attorneys, academicians and public figures in the wake of the Rabin assassination and it tenaciously protects its autonomy and finances its campaigns on donations alone. In this fashion, it prevents any gestures of inclusion proffered by the State and preserves its standing as a critical and a fairly state-defiant association. In operational terms, Keshev systematically collects information and investigates trends involving the delegitimisation of state institutions, groups with anti-democratic ideologies and practices, incidents of incitement to violence out of ideological motives, and the enforcement of the law on these issues. Accumulated information is then analysed and published by staff members in the form of investigative findings, reports and information sheets. Comparable to American 'civil society' organisations engaged in similar issues, such as the Anti-Defamation League, Keshev submits the reports it has prepared to government offices in order to draw attention to extremist tendencies and encourage the State to respond with law enforcement, to initiate new legislation, monitor policy or introduce changes in policy. Although the principal target of the group is the 'uncivil society', Keshev members do not settle for those activities alone, but, directs resources also towards the State and society at large. Within the context of its social activities, Keshev is involved in information campaigns, training and education; it takes part in study days and seminars, and it assists students and pupils wishing to research democracy and the threats it faces. Their activities in relation to the State are restricted to those cases where Keshev members find authorities remiss in enforcing legislation or when objects of enforcement are chosen on the basis of partial interests, such as political or ideological preferences.

As for its achievements, the managing-director of Keshev, Yizhar Be'er, much like his colleagues in other associations, brings up the difficulty involved in estimating its degree of success in implementing its goals. Still, in his opinion, the very existence of the organisation and its persistent efforts in detecting antidemocratic tendencies in the social sphere helps keep these issues on the public agenda in Israel and requires the State to respond accordingly. ${ }^{35}$ Be'er's cautious statements are certainly thoughtful and to the point. Although Keshev enjoys full autonomy and is a relatively well-established institution, it still provides an insufficient basis for the claim that significant action is in fact taken against the 'uncivil society' in Israel when, after all, that action is based on this single and not very large organisation.

\section{State-oriented organisations}

Compared to the highly circumscribed arena of organisations with 'uncivil society' tendencies, the state-oriented bodies and their activities are more substantial: 18 per cent of those included in the survey explicitly asserted that their actions were directed at the State in the attempt to impact and change policy on 
various issues. However, not all of them can be classified as 'civil society II' or oppositional organisations whose work is devoted to keeping the State's struggle against extremists within the limits of the 'rule of law' and in this fashion to make inroads into the non-liberal elements characteristic of Israeli counteractive policy. In effect, a great number of the organisations which aim to serve the interest of Israeli democracy, while directing their activities at the State have academic affiliations, such as the Israeli Democratic Institute and the Carmel Institute for Social Research, which conduct research and hold discussions in which the principal aim is to propose alternative policies designed to reinforce the status of state democratic institutions.

Yet, alongside these, there are more militant organisations whose primary goal is to keep state action within the limits of democratically accepted conventions. The Movement for Quality Government in Israel, for example, has set its sights on inculcating democratic norms among public representatives and government officials, on improving political culture as well as the ethical climate in the State, and on the assimilation of a scale of values based on foundations that include democratic principles, sound public administration, ethics and the rule of law. While the Movement employs information campaigns and even extra-parliamentary means of protestation, the main part of its activity is concentrated on the media and the judiciary. ${ }^{36}$ Despite the notable reputation earned by the Movement's deeds, its efforts at limiting state action to the substantive boundaries of the 'rule of law' do not apply directly to instances where there are 'irregularities' in the State's response to extremists. In this type of event, the Movement refers appellants to the Association for Civil Rights in Israel (ACRI) - the large and most active such organisation in Israel, which mainly concentrates on promoting the viability of democracy by means of restraining the government's heavy-handedness and by protecting civil rights.

The main rights which ACRI (established in 1972) fights for are equality, freedom of expression, freedom of religion and the right to a fair trial. ${ }^{37}$ The Association, whose moral dictates are based on the universal proclamation on human rights ratified by the United Nations Assembly in 1948, and also on the State of Israel's Proclamation of Independence, focuses the bulk of its efforts on the legislative (draft laws on the subject of human rights) and judicial (litigation for various legal instances, often before the Supreme Court) levels. ${ }^{38}$ Its defiant nature requires the 'Association' to maintain as much autonomy as possible from the State. Admittedly, in many cases, in order to move forward various legislative initiatives the help of Members of Parliament is needed, so that activists must frequent the corridors of power. However, there is no evidence of the 'inclusion' of ACRI by sundry governmental bodies, and all of its activities rely on state-independent sources of finance, whether one is speaking of supporting funds or membership dues. ${ }^{39}$ 
Much like other organisations, ACRI does not limit itself to specific targets of action. Granted, its principal target is the State and its goal is the attempt to constrain the nature of the latter's counteractive policy, but it still devotes a considerable part of its resources to social issues, particularly for promoting ideas related to civil and human rights both on educational and public levels. This is done by its publishing of study and didactic materials and the sponsoring of inservice training and workshops at universities and schools. Furthermore, ACRI operatives work with the security forces (army, police, prison services and border police) with the intention of raising awareness of and sensitivity to the rights of detainees and suspects in particular and civil rights in general.

Like the majority of groups which comprise the "pro-democratic civil society', ACRI reports significant accomplishments in the advancement of its goals. Freedom of expression and political action are two major fields in which the Association has scored significant points, particularly in the judicial sphere. As befits a movement which champions liberal values and is not affiliated with any particular political bloc, the Association has intervened on behalf of members of all protesting groups, no matter whether they are Arabs or Jews, secular or religious, left-wing or right-wing. In fact, it has even made efforts to protect the civil rights of Jewish settlers in the occupied territories and members of the Kach Movement. ${ }^{40}$ The achievements of ACRI underscore the vital importance of civil society type II groups in terms of helping the 'defending democracy' advance in the direction of the 'immunised' pole of the spectrum. The very fact that one is speaking of an organisation which advocates democratic-liberal values, and does not work under the auspices of any specific group, empowers its status and enables it to raise essential concerns related to the quality of democracy and place them on the public and judicial agendas of the State of Israel.

Following the establishment of ACRI, and in the wake of its successes, two additional associations with similar goals joined the "pro-democratic civil society' in Israel. The first is the Israeli extension of Amnesty International, famous for defending individual liberties and directing its actions at State authorities as well as society. The second organisation is B'Tselem, a local group which strives to protect human rights in Judea, Samaria and Gaza, so that the major part of its activities involves protecting the rights of Palestinians. However, as just mentioned, on occasion it will also act to defend the liberties of Jews who live in those areas. ${ }^{41}$

By this juncture, we should have some grasp of the dimensions of the "prodemocratic civil society' in Israel, having mapped out the range of its activities and demonstrated its prominent features. The above analysis points, however, to a particular obstacle standing in the way of the entire population of organisations in general and society-oriented ones in particular: the 'danger' of inclusion by the State and the subsequent weakening of the 'civil society'. But is 
one speaking of foregone conclusions? In what follows an attempt is made to describe a workable resolution to this obstacle, one which also has the potential of building up the status of 'civil society' associations. I refer here to a certain type of organisation, the foremost example of which is the New Israel Fund, whose main goal is to aid in the growth of the 'civil society' in Israel.

\section{Aid for the development of organisations}

Indeed, aside from the fact that, over the years the State of Israel has lessened restrictions originally imposed on 'civil society' activities, the most significant assistance which has contributed to the growth of the pro-democratic civil society in Israel has been related to the establishment of the New Israel Fund in 1979. The New Israel Fund, the dominant body in financial assistance for pro-democracy organisations, is a public body launched as a joint initiative by American and Israeli Jews. The Fund's main goals, in its own words, are to act in the interests of democracy, equality and social justice. The Fund's assets come from contributions donated by private individuals who find the goals of the Fund close to their hearts, and resources are then distributed to non-profit, non-partisan, organisations active in society and community. However, Fund activities involve more than best owing financial assistance. In 1982, directors of the New Israel Fund founded Shatil. The decision to set up Shatil crystallised after lessons were drawn from the experience of the first three years of its operation, that is, after the 'New Israel Fund' had financed a number of associations that proved to be only partially successful. The directors arrived at the conclusion that aside from making monetary contributions, there was also the need for professional consultation services which could provide assistance to organisations in the relevant areas, from their registration as an NPO and the initial raising of capital, to staff and work management, as well as promoting policy changes by means of lobbying and making use of the media. In view of the declared goals of the New Israel Fund, Shatil provides professional training services to NPOs which specialise in the following fields: civil and human rights; the rights of the Palestinian society in Israel; women's rights; Jewish-Arab co-existence; religious pluralism; social justice; and environmental issues. ${ }^{42}$

According to Itzik Shanan, media department director of the New Israel Fund, since its establishment in 1979 the 'Fund' has been successful in strengthening liberal elements of the Israeli democracy mostly by its considerable support for organisations which represent peripheral groups, including women, Arabs, Eastern Jews and in fact the homosexual minority of the country. However, the combined activities of the New Israel Fund and Shatil have also laid the ground for organisations seeking to constrain the State's actions and keep them within democratic limits. Approximately one-half of the ACRI 
fiscal budget, for example, has for many years been underwritten by the Fund's sources. ${ }^{43}$

We can therefore assume that the 'pro-democratic civil society's' future in Israel is rooted, to a great extent, in the ability of pro-democracy bodies to attract resources and establish their operations while, at the same time, remaining detached from the State's strong embrace. The New Israel Fund constitutes a propitious foothold for these same ventures, especially if they are grassroots associations which have to rely on limited financial resources. As more resources are made available to organisations such as the New Israel Fund or the Jewish Agency (which also has joined the group of benefactors providing financial assistance), the chances will increase that organisations belonging to the 'pro-democratic civil society' - especially those in the early stages of development - will attempt to attract financial support from independent funds rather than from the State and in this fashion help build up the autonomous status of the 'pro-democratic civil society'.

To sum up, a number of conclusions can be presented. For some years now, a perceptible 'pro-democratic civil society' consisting of organisations targeting the various objects included in the above definition has been at work in Israel. But, at the same time, it must be noted that this population consists of a relatively small number of initiatives which are disproportionately divided in terms of the targets of their activities. When speaking of activities in relation to the challenges of extremism in society, we can find a wide variety of organisations operating in different ways. However, the number of those challenging the State amounts to one-quarter of the total, and the sum of the organisations active against the 'non-civil society' comes to one.

In the nature of things, it can be assumed that the number of associations endeavouring to establish democratic values in Israeli society and which operate in various regions of the country will be greater than the number operating vis-à-vis the State. However, the almost negligible amount of activities aimed at 'uncivil' groups reflects the problematic tendency to blur the boundaries between the 'civil' and the 'uncivil' in Israel, and the confusion generated by the prescriptions of the 'non-liberal democracy' among its citizens. Active representatives also revealed in interviews a marked bias in estimating their organisation's ability to advance its objectives. In general, these officials reported degrees of success, albeit limited. A closer scrutiny reveals that one of the major pitfalls in their path concerns the operational as well as the ideological aspect of the 'non-liberal democracy'. Organisations whose objectives do not present a challenge to the State of Israel and instead aim to further causes which in many cases coincide with State objectives often find themselves in a delicate situation. They become primary targets for 'non-liberal democracy', which, because of its centralist nature, seeks to control as much as possible those activities which take place in both the political and the social sphere. In operational terms, the State 
attempts to assimilate this field of operations by creating an economic dependency on the State. In terms of values, the State endeavours to shape these organisations in its own image and thus in effect prevent them from presenting pupils with topics and subject matter which do not fully conform to the values that the State itself is built on and those it wishes to promote.

These conclusions present the reader with a relatively surprising finding. Contrary to Ben-Eliezer's assumption that the general population of organisations will fall victim to the State's 'bear hug', and perhaps even in contradiction of Yishai's position, that the more 'challenging' will be the major target of the State's arrows, the activities of the 'pro-democratic' groups demonstrate that by their very defiance of the State these associations of civil society type II maintain their distance from it and are therefore protected from its policy of inclusion while, in fact, society-oriented organisations (civil society type I), in need of the State's auspices, may be subject to its manipulations.

\section{Features of the 'pro-democratic civil society in Israel': quantitative assessment}

The next step was to take stock of the current state of affairs as well as to try to chart future implications. Therefore, on the basis of the organisations' survey results, an attempt was made to estimate the 'pro-democratic civil society's' utility in the 'immunisation' of the 'defending democracy' in Israel. ${ }^{44}$ The considerable methodological hindrance involved in the quantification and measurement of this facilitating potential and in particular the impact of prodemocratic groups on the robustness of the 'defending democracy' in Israel, ${ }^{45}$ led to the use of a number of variables derived from an index developed by Yishai to evaluate 'civil society's' contribution to democracy. ${ }^{46}$ This index includes predictive factors on two levels. The first level focuses on interorganisational variables, including the socio-demographic and political features of the organisations themselves. The second level deals in variables concerning the status of the organisations in relation to the external environment, including their degree of reported financial and operational autonomy in relation to political parties and the State, ${ }^{47}$ and the degree of cohesion among the different bodies which constitute the 'pro-democratic civil society'.

In the final stage, a comparison was conducted between activists' own reports on successes in advancing their goals, and the public assessment of the activities of these organisations based on an opinion poll that was devised specifically for this part of the research. As already noted, findings from the survey were compiled at the beginning of 2001 and therefore have the potential to provide a profile that is up-to-date and at the same time put the account of the evolution of the 'pro-democratic civil society' as portrayed above in a comparative diachronic perspective. 
The emergence of the 'pro-democratic civil society' in Israel

Before attempting to appraise the potential of the 'pro-democratic civil society' in helping the 'defending democracy', a finding which provides important insight to the evolution of the organisations included in this group is presented.

Figure 4.2, which charts these organisations' evolution according to the year they were founded, demonstrates that, regarding both the majority of 'civil society' organisations in Israel as well as the 'pro-democratic civil society', the initial significant growth in their number began in the early 1980s (33 per cent emerged in that decade in contrast to 6 per cent in the previous decade). This was the result of several prominent factors, foremost among which were the window of opportunity which opened following the State's resolve to allow more freedom of operation to non-state organisations, the commencement of New Israel Fund initiatives and, beyond doubt, the unfolding radicalisation in Israeli society that elicited a sense of discomfort among many population groups, which in consequence felt the need to respond to this tendency. Figure 4.2 also shows the gradual increase in number of these associations, while the 1990s proved to be the peak of growth in their number so far -49 per cent were founded between the years 1990 and 1999.

Figure 4.2 The emergence of a 'pro-democratic civil society' in Israel 1950-2000

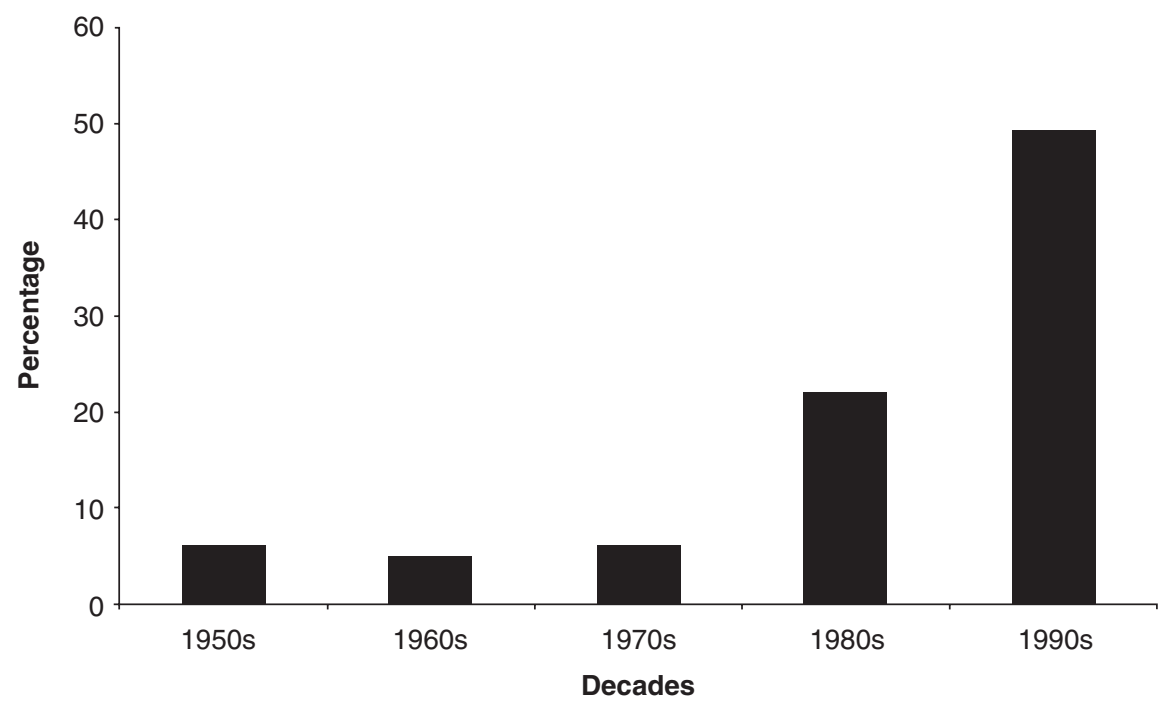




\section{Internal features of the organisations}

One of Putnam's central assertions regarding the civil society's capability in supporting democracy addresses the internal heterogeneity of organisations and the fact that 'civil society' guarantees 'political equality'. In other words, by virtue of their membership, all organisations are guaranteed equal rights, and relations among them are vertical and not horizontal. ${ }^{48}$ That being the case, we shall arrange the internal features of the organisations of the "prodemocratic civil society' according to two major categories. The first consists of the socio-demographic features of their members, in order to verify the extent of heterogeneity. The second attempts to gauge the nature of these organisations in order to see whether democratic practices are also practised internally.

\section{SOCIO-DEMOGRAPHIC FEATURES}

Survey findings indicate that the tendency of Israeli society in recent years to split into sectarian subgroups on the basis of ethnicity, religion and ideology, ${ }^{49}$ which, according to Madison and Olson, presents a threat to democratic states, ${ }^{50}$ has eluded the 'pro-democratic civil society'. All organisations participating in the survey reported high levels of heterogeneity among their ranks. Close to 72 per cent reported that the majority of members did not belong to the same age group; 73.7 per cent indicated heterogeneity in terms of ethnic origin and community of members; 75.3 per cent claimed that their association integrates native-born Israelis and new immigrants; 81.8 per cent reported that the majority of members do not live in one settlement; while 67.5 per cent stated that members did not belong in the same income group. The lowest finding, as anticipated, pertained to the question of nationality: only 45.5 per cent could claim that their organisation integrates Jews and Arabs. Surprisingly, even this low figure addressing the integration of Jews and Arabs in various contexts is indicative of a positive trend. Close to half reported cooperation between the two nationalities, and this in a society where there is an almost complete separation between these two sectors in all other walks of life. ${ }^{51}$

The next stage, despite the smaller population sample, which itself constitutes a methodological limitation, sought to examine the relationship between the variable of heterogeneity ${ }^{52}$ in an organisation and the other variables used. Indeed, there was a nearly significant correlation between heterogeneity and year of establishment $(r=0.211, p=0.067)$. This meant that the later the year of establishment, the higher the degree of heterogeneity among its ranks. This finding is perhaps a positive indication of the democratising processes to which organisations of the 'pro-democratic civil society' were subject to over the course of time and the possible effect of these processes on society. 
Another, no less important, finding concerns the degree of democracy within the organisations themselves: for, if they declare their support for democracy but at the same time do not practise a democratic organisational culture, this might raise suspicions regarding their true nature and their ability to support democracy. ${ }^{53}$ Furthermore, according to Putnam, 'civil society' organisations tend to instil among their members cooperative norms and motivate them to this effect. As a matter of fact, he calls these associations 'schools in democracy'. ${ }^{54}$ According to the statements made by some of their representatives who participated in the survey, the 'pro-democratic civil society' in Israel does in fact tend to adhere to democratic principles with regard to all aspects of organisational culture: 95 per cent of representatives reported that management is closely attentive to the needs of their members; 97.5 per cent reported that their members do not hesitate to express opinions that conflict with those held by the leadership. Nearly 79 per cent claimed that there was no one person or group in their organisation who or which asserted a dominant role in terms of decision-making.

Although it would be naive to assume that these associations are free of oligarchic tendencies, the high percentages of organisational democracy reported nevertheless give strong indication that one is speaking of a group which not only assembles under the banner of democracy but practises democratic procedures 'at home'.

Of the findings so far presented it can be concluded that, internally, organisations of the 'pro-democratic civil society' generally tend towards heterogeneity, that is, members from different population sectors take part in their activities and, as a result, in effect they serve as a bridge among the various segments of society. With regard to intra-organisational practices, it appears that from the high per centage of those reporting substantial leadership openness to members regarding the transmission of information and decision-making processes, one is speaking of organisational apparatuses distinguished by a very low pyramid structure. In other words, there is a very short distance between rank-and-file members and directorship, thereby allowing for greater access to democratic decision-making procedures.

\section{Organisations and their external environment}

There is wide agreement among scholars in the field that in order to promote the democratic process, organisations of the 'civil society' must enjoy autonomy in relation to the State. ${ }^{55}$ In accordance with Yishai's approach, this analysis will try to show that in addition to independence of state bodies, the autonomy of associations in the 'civil society' must demonstrate independence in respect of 
political parties in close proximity to the State ${ }^{56}$ However, an organisation's autonomy in relation to its surrounding environment does not include its autonomy in relation to other civil society organisations. In order to realise its goals, the 'pro-democratic civil society' needs to develop a 'cohesion' among associations which make up the 'society' so that it can broaden its contact with society, on the one hand, and increase its access to the State, on the other. ${ }^{57}$ So it is necessary to try to determine the extent of organisational autonomy in relation to the State and the political parties, and, at the same time, evaluate the degree of internal 'cohesion' among organisations of the 'pro-democratic civil society'.

ORGANISATIONAL AUTONOMY

One of the most significant obstacles in the path of the "pro-democratic civil society' in Israel - as already discussed at length - relates to the repeated efforts at inclusion by the State and the tendency of groups, in return, to welcome state initiatives. As noted, one of the most convenient and effective instruments at the disposal of a state interested in containing the 'civil society' is economic leverage. Broadly speaking, the majority of organisations active in the civil sphere are caught up in a constant search for donors or financial resources which will enable them to pursue their activities. The state, on the other hand, commands great resources, thus providing it with the means to lure organisations and include them under its wings. Therefore, to what degree do associations of the 'pro-democratic civil society' in Israel, in 2001, enjoy economic autonomy from the State? The answer to this question is not unequivocal; but, in general, an optimistic forecast can be made for these groups. Nearly half ( 45.5 per cent) reported that they do not receive economic support from any governmental office, local authority or quasi-governmental body. Another encouraging figure reflecting on most of the organisations is that 58.4 per cent reported that more than half of their revenues stem from various non-governmental funds (e.g. the New Israel Fund and the Jewish Agency) or contributions, while 22.1 per cent indicated that more than 90 per cent of their budget relies on these sources. On the other hand, only 10.4 per cent claimed that more than half of their annual budget relies on governmental sources, and of these only 2.6 per cent reported that their entire budget derives from state or state-affiliated authorities. However, the most significant finding in this regard emerges from an analysis of the relationship between the year of establishment and the inclination of its directorship - as they themselves reported - to depend on non-governmental sources of revenue. ${ }^{58}$ The correlation $(r=0.331, p=0.003)$ demonstrates a significant and substantial relationship between the two, leading to the probable conclusion that the newer the organisation, the greater the likelihood that it will choose to refrain from close ties with the State. This finding was reinforced during the course of face-to-face interviews with some of the directors. From their responses, it may be concluded that newer organisations have internalised 
the lessons of their predecessors about to the snares involved in the State's 'embrace' and henceforth elected an economic course that was autonomous as possible.

In view of the above, it can be concluded that only a minority of "prodemocratic civil society' organisations in Israel can in truth be called an 'appendage' of the State. These place the means for their very existence in the hands of the State by foregoing the recruitment of resources from other sources. A larger circle of associations combines both governmental and other revenues, while the decisive majority, and especially those more recently founded, rely on external (support funds) and internal (membership dues) sources of income. The conclusion to be drawn from the above is that notwithstanding its past successes in absorbing the 'civil society' and also numerous pro-democracy associations, the State's grasp does in fact gradually slacken. This leads to the potential increase of the 'pro-democratic' associations' contribution to the strengthening of the 'immunised' foundations of the 'defending democracy'.

\section{TIES WITH POLITICAL PARTIES}

A further indication of the 'pro-democratic civil society's' growing autonomy is found in the weak ties these organisations have with political parties. Granted, the research literature tends to wrestle with the question whether political parties themselves are not part of the 'civil society'. Still, in this period of the 'cartel party', particularly with regard to the Israeli 'party-state', it seems more probable that the parties' relation to the State is much stronger than their affinity to society and therefore, as far as the 'civil society' is concerned, a lack of dependence on political parties would be preferable. ${ }^{59}$ Indeed, 97.4 per cent of the surveyed groups declared that they never worked for a political party. Over 97 per cent reported that there was no political partisan involvement in organisational activities. Slightly more than 96 per cent stated that they were not engaged in any type of cooperation with political parties, while 70.5 per cent reported there was no affinity between their own goals and the aims of any one of the parties. This last finding, which is relatively low, does not necessarily imply the existence of any type of association between them and the parties, but is more likely an indication that an ideational resemblance exists among some of the organisations and some political parties.

\section{The degree of cohesion in the 'pro-democratic civil society'}

While organisational abstention from ties with the State and with political parties appears to be a factor contributing to their activities and potential in supporting democracy, at the same time, higher levels of cooperation among organisations themselves may in fact increase the potential impact of the 
'pro-democratic civil society' and, by the same token, help contribute to the process of the 'immunisation' of the democracy. Having said that, only 33.3 per cent reported cooperation with other groups, when approaching decisionmakers. Only 22.4 per cent collaborate with other civil society organisations in public action such as demonstrations, and only 22.1 per cent engage in joint information campaigns for the public at large. These findings, which clearly indicate low levels of cooperation, can be explained by the fact that many organisations perceive the empowerment of democracy in this country in different ways while, in addition, both their targets and their strategies of action may be diverse. These facts limit their ability to work together. Still, it appears that the tendency to collaborate increases when organisations confront the State. This finding can be explained by the assumption, perhaps made by the members themselves, that in order to take full advantage of their potential effectiveness and pressure, it is most profitable to approach authorities in joint forces. And, indeed, survey results confirm this last assumption. An examination of the correlation between the index of cooperation among organisations and the index of accessibility to decision-makers generated a significant and high figure $\left(r=0.445, p=0.001^{60}\right)$. That is to say, as the degree of cooperation among organisations increases, their level of access to the State improves as well. This finding is further corroborated by the positive and significant relationship between the index of accessibility and the degree of government response to their demands $(r=0.255, p=0.027)$. This means that high levels of cooperation among them were also found to be in high correlation with the State acceding to their demands.

A summary of the findings concerning organisations' activities and their environment shows that there is an impressive development of organisational autonomy in respect of both State institutions as well as the political parties closely enmeshed with those institutions. Autonomy in relation to the State is twice as important, in particular regarding pro-democracy associations operating against the non-liberal State. The more they are able to maintain their distance from the State, their ability to be critical of it increases without fear of reprisal. This is true for organisations whose target is society and who wish to introduce citizens to values different from those inculcated by the State. In particular, it applies to those whose goal is to constrain State activities. For associations of this sort to perform their role effectively, freedom from State controls is a necessary condition.

As for the low levels of cohesion among pro-democratic organisations, this can be an indication of the local nature of most associations. They are relatively small groups whose limited resources prevent them from searching for potential associates aspiring to similar goals. However, the correlations presented above demonstrate that, at least in terms of their activities vis-à-vis the State and despite the obstacle just noted, if they do in fact manage to increase 
levels of cooperation among themselves, they will be of greater assistance in the advancement of the goals of the 'pro-democratic civil society'.

\section{Organisational achievements}

The evaluation of the degree to which organizations fulfil their goals and, moreover, of their ability to help the 'defending democracy' move in a more 'immunised' direction is a complex task due to the nature of the dependent variable and the existence of numerous intervening variables which are liable to obscure the picture. Of course, it is possible to rely on statements made by the organisations' directors while attempting to assess the outcomes of their labours, as I did in the first part of the chapter. However, to obtain a clearer picture, it was decided to adopt additional indices which might at least provide corresponding indications of success. Therefore, the survey included an open question in which representatives were asked to estimate the degree of organisational success in reaching the goals they had originally set for themselves. The answers to this question indicate that the majority (more than 80 per cent), and in particular those whose main target of activities was society, tended to be satisfied with their degree of success in furthering their goals, although, as in the in-depth interviews, the bulk of respondents noted that there was still a long way to go before they could say that they had realised those goals. The target of their actions, Israeli society, also revealed relatively high levels of satisfaction about the activities of these organisations. This item is confirmed by the outcome of the survey, which included a representative sample of the adult Jewish population in Israel. The majority of subjects, 68.7 per cent, expressed high levels of satisfaction with pro-democratic voluntary activities which struggled to reinforce the promulgation of democratic values and which also made an effort to bridge the gaps dividing the various sectors of Israeli society. Furthermore, 17.5 per cent of respondents reported that they themselves were taking part (at the time of the interview), or had done, in activities fronted by organisation of this type. The composite of these findings proves that the Israeli public welcomes activities of civil society type I. The reason for the considerable show of support is, in my opinion, that these organisations by their very existence emphasise the importance of bringing people together and of providing an education in values, and as a result have acquired a more positive public image.

In terms of their activities vis-à-vis the State, organisations also report significant gains. Success, in this case, was measured according to the degree of organisational access to policy-makers and the extent to which the latter responded to their demands. ${ }^{61}$ In terms of accessibility, 52.5 per cent of representatives reported that they appeared at least once a year before one of the Knesset committees. As for contacts made with representatives of the executive 
authority, 85.7 per cent reported having met in the course of the previous year with a high-ranking governmental official: 59.7 per cent met with a directorgeneral or vice-director-general of a governmental office; 62.7 per cent met with a governmental minister; and 15.7 per cent with the prime minister himself. These findings demonstrate a relative openness on the part of the State and its various authorities towards organisations of the 'pro-democratic civil society'. But is this openness a type of lip-service or does it in fact reflect a willingness of the State to in fact meet the demands of these associations? The answer to that question is quite surprising, for 71.8 per cent of organisational officials reported that State authorities generally acceded to their demands and only 28.2 per cent reported a more indifferent response.

From the findings so far presented, a rather optimistic picture emerges which implies that both Israeli society and governmental elites display considerable tolerance to activities of the 'pro-democratic civil society' and in fact reveal a noticeable inclination to be of some assistance to them. However, the survey we conducted also produced one finding that may temper these optimistic results and is liable to raise doubt over the Israeli public's apparent wholehearted willingness to move in the direction of the 'immunisation' side of the continuum. This finding is an indication of the public's attitude to organisations attempting to constrain the State's heavy-handedness in its response to extremists and in particular its attitude to the Association for Civil Rights. About 52 per cent of the respondents stated that actions taken by associations such as ACRI, the aim of which is to constrain the State's response to extremism, pose a threat to state security. A prudent look at the data reveals that despite the apolitical character of ACRI and the many instances in which it laboured to defend the civil rights of radical right-wing activists, the political affiliation of the individual survey respondent influences his/her attitude to ACRI. Respondents who defined themselves as inclining toward the extreme right-wing, right-wing or centre of the political spectrum, displayed a greater degree of hostility toward ACRI's activities (57.7, 61.1 and 51.2 per cent, respectively) in comparison with left-wing and extreme left-wing supporters (37.3 and 11.1 per cent, respectively). ${ }^{62}$ Notwithstanding the political significance of this finding, it also underscores results presented in earlier chapters demonstrating that in Jewish Israeli society there is still a longing for a hard-line security establishment which is not obliged to adhere to liberal values and would be able to respond to political extremism as its sees fit. The most prominent finding, in my view, has to do with the fact that, ironically, a noteworthy per centage of respondents who described themselves as pro-left-wing and extreme left-wing expressed reservations regarding ACRI activities. This finding is further evidence of the weakness of the liberal component in Israeli society and its willingness to proceed only hesitatingly in the direction of the 'immunised' road to democracy. 


\section{Conclusions}

In the first part of this chapter, it was suggested that the "pro-democratic civil society' and its activities have significant potential in moving the 'defending democracy' from the 'militant' pole to the 'immunised' pole of the continuum. Despite the considerable difficulty in determining a causal relationship between the activities of the 'civil society' and the 'immunising' process of the 'defending democracy' in Israel, the findings presented here have important implications for this assumption. However, before discussing these results, a summary of the conclusions drawn from the findings is presented.

First and foremost, over the last few decades it has become evident that a group of organisations which can be called the 'pro-democratic civil society' has flourished in the State of Israel, and the rate of growth of these organisations is gradually increasing. A classification of this population of associations according to their targets and a review of their activities reveal that the decisive majority of these organisations work with their sights set on Israeli society, and their goals include an effort to bridge between the various sectors of the population and so strengthen the democratic foundations of society. A smaller group of organisations directs its work at the State in the attempt to constrain governmental responses to extremism and political violence within the accepted limits of the 'rule of law' in a democratic society. Finally, the smallest group, actually a single organisation, defines the 'uncivil society' as the principal object of its operations, which consist in raising the alarm about anti-democratic groups and working in opposition to them.

Still, the bare existence of the 'pro-democratic civil society' in Israel does not yet indicate whether it is capable of moving the 'defending democracy' from the 'militant' to the 'immunised' end of the continuum. Therefore, two questions were included in the survey to investigate the extent of this capability. The first question aimed to assess the degree of organisational autonomy in relation to the State and the effects of this autonomy on the civil society's potential 'immunising' capability. The second question was an elaboration of the first, and attempted to include, among the factors contributing to its 'immunising' potential, additional elements concerning the internal dimensions of organisations and the relations of organisations with their environment.

In order to reach conclusions that would help answer these questions, an additional - evolutionary - perspective appeared necessary because, as explained above, the State of Israel has for many years persistently acted to constrict the autonomy of certain bodies not within its custodial reach. It also carried out a similar policy with regard to organisations of the "pro-democratic civil society'. However, contrary to expectations, the group of associations that actively questioned state policy was not the group to suffer from the State's 'bear hug', which was reserved for the group whose goal was the assimilation of 
democratic values by Israeli society. Yet, a (diachronic) look to the future seems to imply some weakening of the State's strength. As figure 4.2 illustrates, the number of organisations populating the 'pro-democratic civil society' is significantly increasing. The more recently established organisations mentioned above are operating in a more favourable environment than had their predecessors. In the first place, this is because of the widening possibilities of financial backing provided by extra-state organisations. Second, newer groups have internalised the lessons of the past, and thus assume an attitude of 'respect and suspicion' towards the State while maintaining as great a distance as possible from the long arms of its 'paternal embrace'. Therefore, in answer to the first question, I would tender the view that the degree of autonomy of these organisations appears to be growing, thus improving the prospects of establishing a "pro-democratic civil society' in the State of Israel.

The second question raised above asked whether, in addition to their increasing autonomy, organisations also enjoyed conditions conducive to their development and which have an effect on the nature of the Israeli 'defending democracy'. The answer to this question is, in the main, positive. The survey shows that with regard to their internal characteristics, Israeli associations conform to the theoretical conditions posed by Putnam in respect of the 'civil society'. In the case of Israel, one is speaking - in socio-demographic terms - of a highly heterogeneous group and of organisations which adhere as much as possible to a democratic and egalitarian framework. As for their relation to the external environment, aside from their growing independence of the State, they also enjoy autonomy from political parties, a fact which reinforces the view that the 'pro-democratic civil society' has indeed chosen the path of self-sufficiency. But, this state of affairs also gives rise to the question: can one be speaking of too much autonomy? According to the results of our study, there is limited cooperation amongst organisations, a fact which may potentially weaken their presence and diminish their accomplishments. Indeed, figures indicate that high levels of collaboration are found to be correlated with high levels of accessibility to the State and its institutions, and there is no reason not to suppose that these concerted efforts will also be effective vis-à-vis society. Therefore, it seems that if the 'pro-democratic civil society' continues to maintain its autonomy from the State and state agencies and at the same time improves levels of cohesion among its various organisations, this may very well lead to a growth of its effective potential.

Yet, after the relatively optimistic appraisals of the civil society's potential impact on the 'defending democracy' in Israel, a number of reservations of not insignificant merit deserve attention. First and foremost, the 'pro-democratic civil society' in Israel consists of a limited number of organisations which, when classified according to the targets of their organisational activities, present us with a clearly unbalanced picture. A prominent example of this disproportion- 
ate profile concerns the single organisation whose object is the 'uncivil society'. As noted above, the reasons for the dearth in this category are numerous and complex, whereas the number of extremist groups is not small and the job of dealing with this sector remains entirely in the hands of the State, which is predisposed to 'militant'-like counteractive strategies, often substantially straying from the narrow confines of the idea of the 'rule of law' in a democratic society. This weak spot is liable to hamper the progression of the 'defending democracy' in the direction of the 'immunised' pole of the continuum.

Another principal issue, related to the emergence of the "pro-democratic civil society' in Israel, was articulated in the results of the public opinion survey. Despite the support professed by the adult Jewish population for the 'prodemocratic civil society', it appears that this approval is somewhat reserved and limited to those organisations dealing in educational and strictly humanitarian causes while, in the same breath, the public expresses considerable disaffection toward those groups which attempt to constrain the heavy-handedness of state security. These findings are similar to other attitudes evidenced by the survey which demonstrate that liberal democratic principles are not exactly at the top of the agenda of the Jewish public in Israel. This is particularly true when those principles clash with concerns related to state security or the country's Jewish nature.

A final point of reservation warranting attention derives from the integration of findings from chapter 3 with those of the present chapter. The expansion potential of the 'pro-democratic civil society' is contingent upon the evolution of a new generation of citizens who find democracy and its values dear to its heart. One of the principal ways of establishing such a generation, according to those engaged in the field of citizenship education, is via the education system. Results from a survey we conducted at Israeli high schools demonstrate that the mobilising potential of the 'civil society' among adolescent students from state-run schools is not substantial. As was described at length in chapter 3, despite receiving civics lessons at school, graduates of the Israeli education system are not characterised by high levels of support for liberal democratic values. This finding was even more pronounced among adolescents from the group that did not study civics. It is moreover pertinent to note here that for pupils in the Haredi-independent and national-religious education systems, the democratic component of their education is altogether marginal. The conclusion is that in the absence of further reformation of the study curricula in the country, a dark shadow will continue to hover over the prospects of establishing a 'pro-democratic civil society' in Israel.

NOTES

1 Adam B. Seligman, The Idea of Civil Society (Princeton, New Jersey: Princeton University Press, 1992). 
2 Yael Yishai, Civilian Society in Israel towards the Year 2000 - Between State \& Society (Jerusalem: Paul Baerward School of Social Work, 1998).

3 Alexis de Tocqueville, Democracy in America (New York: Vintage Books, 1954).

4 Robert Putnam, Making Democracy Work: Civic Traditions in Modern Italy (Princeton, New Jersey: Princeton University Press, 1993); Robert Putnam, 'Bowling Alone: America's Declining Social Capital', Journal of Democracy, 6 (1995), pp. 65-78; Robert Putnam, Bowling Alone - the Collapse and Revival of American Community (New York: Simon \& Schuster, 2000).

5 László Szôcs, 'A Tale of the Unexpected: The Extreme Right vis-à-vis Democracy in PostCommunist Hungary', Ethnic and Racial Studies, 21:6 (1998), pp. 1096-115.

6 Sheri Berman, 'Civil Society and the Collapse of the Weimar Republic', World Politics, 49:3 (1997), pp. 401-29.

7 William, L. Eubank and Leonard Weinberg, 'Terrorism and Democracy within One Country: The Case of Italy', Terrorism and Political Violence, 9:1 (1997), pp. 98-108.

8 Michael W. Foley and Bob Edwards, 'Escape from Politics: Social Theory and the Social Capital debate', American Behavioral Scientist, 42 (1998), pp. 550-61.

9 John A. Booth and Patricia Bayer Richard, 'Civil Society, Political Capital and Democratization in Central America', Journal of Politics, 60:3 (1998), pp. 780-99.

10 Robert Putnam, Making Democracy Work, pp. 83-120.

11 Yishai, Civilian Society in Israel towards the Year 2000, pp. 26-8.

12 Baruch Kimmerling, 'The New Israelis. Multiple Cultures Without Multi-Culturalism', Alpayim, 16 (1998), pp. 264-308.

13 Yael Yishai, 'Civil Society in Transition: Interest Politics in Israel', Annals of the American Association for Political and Social Sciences, 555 (1998), pp. $150 \mathrm{ff}$.

14 Benjamin Akzin, 'The Role of Parties in Israeli Democracy', Journal of Politics, 17 (1955), pp. 509-33; Emanuel Gutmann, 'Parties and Camps: Stability and Change', in Moshe Lissak and Emanuel Gutmann (eds), The Israeli Political System (Tel-Aviv: Am-Oved, 1977) (Hebrew).

15 John Keane, Democracy and Civil Society (London and New York: Verso, 1988); Michael W. Foley and Bob Edwards, 'The Paradox of Civil Society', Journal of Democracy, 7:3 (1996), pp. 38-52.

16 Yishai, Civilian Society in Israel towards the Year 2000.

17 Uri Ben-Eliezer, 'Is Civil Society Emerging in Israel? Politics and Identity in the New Associations', Israeli Sociology, 2:1 (1999), p. 64.

18 Yishai, 'Civil Society in Transition: Interest Politics in Israel'; Ben-Eliezer, 'Is Civil Society Emerging in Israel?'

19 A non-profit association or organisation (NPO) is an organisation registered in accordance with the Law of Associations (1980). A registered association enjoys various rights with regard to tax authorities, the right to hold property and the right to appear as a public body in court (Ben-Eliezer, 'Is Civil Society Emerging in Israel?').

20 Yishai, 'Civil Society in Transition: Interest Politics in Israel', pp. 155-61.

21 Ben-Eliezer, 'Is Civil Society Emerging in Israel?', p. 90.

22 Yael Yishai, 'Flaws in the Heaven of Complaisant Civil Society: Some Observations on the Legal Scene', a paper presented at the International Sociological Association Conference, 2000.

23 The main reason why many organisations did not respond is that the various lists included organisations which had suspended operations and were dismantled.

24 From an interview with Okie Miroshak-Kellerman, pedagogical coordinator, the Adam Institute (16.4.2001).

25 Interview with Okie Miroshak-Kellerman (16.4.2001). 
26 Panim L'khan U'l'khan (1999).

27 Panim L'khan U'l'khan (1999), pp. 39-40.

28 From an interview with Dr Shlomo Tzidkiyahu (16.3.1999).

29 From an interview with Rabbi David Atzmon, senior moderator, Foundations Institute (18.4.2001).

30 Ben-Eliezer, 'Is Civil Society Emerging in Israel?'

31 John S. Dryzek, 'Political Inclusion and the Dynamics of Democratization', American Political Science Review, 90:30 (1996), pp. 476-87.

32 Correspondence, 7 May 2000.

33 From an interview with Okie Miroshak-Kellerman, pedagogical coordinator, Adam Institute (16.4.2001).

34 For a classification of public protest in Israel, in view of the social cleavages in the country, which lends support to this argument, see Sam Lehman-Wilzig, Stiff Necked People, Bottle Necked System. The Evolution and Roots of Israeli Public Protest 1949-1986 (Bloomington: Indiana University Press, 1990).

35 From an interview with Yizhar Be'er, chairman of Keshev (18.4.2001).

36 From an interview with Shuki Lebanon, spokesperson, Movement for Quality Government in Israel (14.4.2001).

37 Yael Yishai, Interest Groups in Israel. The Test of Democracy (Tel-Aviv: Am-Oved, 1987), pp. 80-1 (Hebrew).

38 From an interview with Miriam Lidor, manager, Office for Foreign Relations, Association for Civil Rights in Israel (24.4.2001).

39 See ACRI website: www.nif.org/acri/acintro.html

40 Interview with Miriam Lidor, manager, Office for Foreign Relations, the Association for Civil Rights in Israel (24.4.2001). See ACRI website: www.nif.org/acri/achebrew.html

41 See B'Tselem website: http://www.btselem.org

42 From an interview with Itzik Shanan, public relations director, New Israeli Fund (18.4.2001).

43 Interview with Itzik Shanan (18.4.2001).

44 As noted above, the population included in the survey was relatively small $(n=80)$. Furthermore, and despite the fact that organisations could be distinguished according to the object of their activities (the State, 'un-civil society' or 'civil society'), most of them tended to cross the defined boundaries and aimed their activities at additional objects. These two conditions led the quantitative analysis to address all organisations as one population and not to make a distinction among them according to the object of their activities.

45 For a discussion of difficulties in measuring the influence of organisations, see Yael Yishai, Interest Groups in Israel: The Test of Democracy, pp. 29-30.

46 Yael Yishai, Civil Society in Israel (unpublished manuscript, 2001).

47 The effort to quantitatively assess degrees of autonomy was meant to complete the picture engendered by interviews with organisation representatives and to extend the concept of autonomy from the economic perspective to other perspectives.

48 Putnam, Making Democracy Work, pp. 88-91.

49 Gadi Yatziv, The Sectorial Society (Jerusalem: Bialik Institute, 1999); Baruch Kimmerling, 'Elections as an Arena for Struggle Over Collective Identities', in Asher Arian and Michal Shamir (eds), The Elections in Israel - 1996 (Jerusalem: Israel Democracy Institute, 1999), pp. 35-56 (Hebrew).

50 Mancur Olson, The Logic of Collective Action: Public Goods and the Theory of Groups (Cambridge, Mass.: Harvard University Press, 1965); Madison, quoted in Olson.

51 Falah Ghazi, 'Living Together Apart: Residential Segregation in Mixed Arab-Jewish Cities in Israel', Urban Studies, 33:6 (1996), pp. 823-57. 
52 The measure of homogeneity inside organisations was built on the composite of those questions which measured different aspects of heterogeneity. The measure produced a relatively high degree of internal reliability (Cronbach's Alpha $=0.707)$. Examination of the relationship with organisations' years of inception was conducted by means of Pearson's index.

53 Harry Eckstein, Divisions and Cohesions in Democracy: A Study of Norway (Princeton, New Jersey: Princeton University Press, 1966).

54 Putnam, Bowling Alone: The Collapse and Revival of American Community, p. 338.

55 Dryzek, 'Political Inclusion and the Dynamics of Democratization'.

56 Yael Yishai, Civil Society in Israel.

57 Yael Yishai, Civil Society in Israel.

58 The tendency of organisations to rely on non-governmental funding sources was examined according to the question: 'In your opinion, is the organisation dependent upon public sources of finance for its outlays or can it rely on other budgetary sources?'

59 Yael Yishai, Civil Society in Israel.

60 The index of accessibility was computed according to the combination of questions which appears later (pp. 161-162 and 164). The internal reliability of the index was found to be high (Cronbach's Alpha $=0.875$ ). The measure of cooperation was calculated according to the combination of questions which appeared above. The reliability of this measure was found to be high (Cronbach's Alpha = 0.796). A favourable attitude on behalf of the Government was measured on the basis of the statement, 'In general, our demands are favourably received by the Government'.

61 For employment of 'accessibility' and 'response' as measures for organisational success, see Yishai, Interest Groups in Israel, pp. 30, 179.

62 Findings are produced which were found to be significant: Chi-square $p=0.001$. 


\section{The 'defending democracy': from the 'militant' to an 'immunised' route?}

$\mathrm{T}$ HIS CHAPTER HAS three principal objectives. First, on the basis of the findings of the first four chapters, it will provide a synopsis of the Israeli response to Jewish extremism and political violence. This will extend from the early days of the State's existence until the beginning of the new millennium, with an emphasis on current developments. Such a historical perspective will enable us to assess the degree of success of the Israeli 'defending democracy' in moving from the 'militant' pole to the 'immunised' pole on the continuum of the policy of response. An attempt is made to find the 'golden path', that is, a middle way which reconciles between the state's duty of and right to self-protection in the face of its adversaries, on the one hand, and avoidance of a descent into counteractive strategies deviating from democratically legal and moral frameworks, on the other. Then, in the second part of the chapter, the Israeli response is viewed in a comparative perspective with policies of other democracies, specifically, the United States and Germany. Drawing a comparison with these countries will help clarify conclusions arising from previous chapters. It will also help answer the question: to what degree are these conclusions applicable to the response policies of other democracies? Finally, the theoretical issues deriving from this research are presented and several questions which remain unanswered and deserve further discussion are addressed.

\section{The ‘defending democracy' in Israel: developments and challenges}

In the Introduction to this book, I described the frustration I experienced in the wake of the murder of Prime Minister Yitzhak Rabin. This feeling was evoked by the thought that in the final decade of the twentieth century, the State of Israel had been subject to defeat on two fronts. State authorities had failed both in their fight against political extremism and in their efforts to keep the struggle against extremists within the boundaries of the 'rule of law' in a democratic country. 
Over the years, there have been many and varied threats to the country's democracy. However, it would seem that there has been a significant decrease in the intensity of the State's response to the manifestations of extremism (from political parties, extra-parliamentary and violent organisations, etc.), since its early days and up to the end of the twentieth century.

The foremost indication of the change in the State's policy of response can be seen in the new legal and judicial barriers stipulating delimited frames of democratic tolerance, and the growing emphasis on political liberties. These have replaced, in most cases, the administrative barriers the State used in its first decades. Their primary objective was the restraint and suppression of extremists without consideration of the cost of such actions.

Chapter 1 demonstrated the changes in the Israeli response to extremist parties and concluded with the optimistic assessment that, in terms of its governmental institutions, the State of Israel has indeed travelled a long and significant road. An extensive legal system has been created, intended to safeguard democracy from extremist political parties and, at the same time, impose numerous restrictions on authorities with the intention of ensuring the liberties and rights of those same political parties. In fact, the analysis of the characteristics of the response of the judicial and political systems in Israel toward extremist parties reveals a minimal enforcement of restraining laws originally adopted by the State. It demonstrates an earnest regard for the protection of democratic rights on behalf of the legislature but even more so on behalf of representatives of the judiciary's authority.

An extensive examination of the policies of the Central Elections Committee and the Supreme Court of Justice over the years provides ample grounds for the assertion that there is little danger of a substantive restriction of the boundaries of public discourse by the non-registration or disqualification of extremist parties of different shades and colours. Apparently, after opening up public discourse in Israel to a wide diversity of opinion, the authorities are now trying to contain this discourse within the acceptable limits of the law. For example, Justice Mishael Heshin, chairman of the Central Elections Committee for the sixteenth Knesset (scheduled for the year 2003), determined that an Arab list aspiring to change Israel into a state for all its citizens does not negate the existence of the State of Israel as a Jewish state. ${ }^{1}$ Of course, one may dispute the judge's conclusions. However, they are still in fact an indication of the judiciary's inclination to preserve the broad boundaries of public discourse in Israel and its intent to ensure representation in the legislature for as many sectors of the population as possible. These developments undoubtedly contribute to the 'immunisation' of the Israeli democracy.

It would seem, then, that in its policy towards extremist parties, Israel is at a relatively stable juncture. The profile presented in chapter 2 reviewed the State's response to extra-parliamentary and violent manifestations of political 
extremism. It stressed the dual nature of the State - torn between the inclination to anchor its response within the boundaries of the rule of law while maintaining the protection of its security even at the expense of harming democracy. As a result, steps taken by the State towards a more restrained policy of counteractivity have been hesitant and often marked by stops and starts. An example of the State's adherence to a legal democratic framework can be found in the substantial progress effected in the initiative to secure the Shabak's status in law. In the summer of 2001, the Shabak Bill was laid on the table of the Committee for Foreign and Security Affairs and the Knesset Constitution, Law and Justice Committee in preparation for a second and third reading, and thus its final passage into law. This law, even if flawed, has the potential to edge the State, even if only a few steps, in the direction of the 'immunised' pole by the very fact that, for the first time, the objective and powers of the Shabak, as well as the means of accounting for its actions, will now be more clearly defined. ${ }^{2}$

Another step in the same direction can be detected in the Ministry of Justice's repeated efforts to address state policy regarding the 'incitement to violence' offence and confine it to a legal framework, thus replacing the Ordinance for the Prevention of Terrorism and other widely used administrative measures. In the summer of 2001, the Government submitted a bill on its own behalf which stated that incitement to violence was a criminal offence. In the words of the law's proposal: 'An individual who publicly appeals for an act of violence or expresses support for such an act - whereupon the contents of the appeal or the circumstances in which it was made public are liable, with great likelihood, to bring about the implementation of such an act - will be sentenced to five years in prison.' The bill also mandates a sentence of one (unconditional) year of prison for an individual who has upon his or her person publication matter of a violent nature and who intends to distribute it. Although this draft law has provisions which may restrict the boundaries of freedom of expression in this country, it is still a noticeable improvement in relation to the current situation, in which the Ordinance for the Prevention of Terrorism is enforced as a principal measure in the prosecution of incitement offences. The new law will create a situation in which the prosecution of criminal incitement to violence will be a protracted procedure and subject to severe scrutiny by the judiciary. In such an event, there is greater probability that the courts of justice, where freedom of thought and action have proven in recent years to be guiding principles, will assign the law a narrow (more specific) interpretation and demand decisive proof regarding the actuality of the offence, as stipulated by the law, before declaring guilt. However, in order to invest this law with real authority, Kremnizer's approach, endorsed by Professor Ze'ev Segal, must be adopted. According to Kremnizer, concurrent with the passing of the said law, the 'offence of sedition' should be struck from the law books because it is too broad and sweeping, and is liable to lead to the unreasonable limitation of the freedom 
of expression. ${ }^{3}$ Furthermore, if the State of Israel indeed seeks to anchor its response in a legal framework which relies on a genuine notion of the rule of law, then, in addition to the annulment of the sedition offence, the Ordinance for the Prevention of Terrorism should also be limited. This should also apply to a variety of administrative regulations at the State's disposal which have always empowered it to deal with extremist manifestations while significantly circumventing the criminal court system.

However, as past events have shown, when there is any type of policy shift towards more liberal forms of response to violent and extremist phenomena, often a change in security conditions, together with political considerations, can ultimately lead to the suspension of the reformation process and may in fact culminate in a reversal in policy. An example is the bill attempting to outlaw support for terrorist organisations, which was raised for debate in June 2001 on the basis of the continuing Palestinian uprising in Judea, Samaria and Gaza. A bill designed to restrict the freedom of expression of Arab Members of Parliament who condone guerilla and terror forces operating in southern Lebanon and in the areas of the Palestinian Authority similarly embodies a genuine potential for restricting the freedom of expression of extremist Jews who support movements defined as terror organisations, such as Kach or Kahane Hai. Despite governmental reservations regarding this bill, if it nevertheless does pass into law, it could push back freedom of expression for many years. ${ }^{4}$

The bill was hastily pushed before the Knesset in direct response to many of the Jewish public's gut reaction to Arab Members of Parliament who expressed their identification with the Palestinians' struggle. It gives an indication of the main hindrance impeding the movement of the Israeli 'defending democracy' in a more immunised direction, a weakness that has received attention throughout this book. This weakness is located the political-cultural infrastructure in Israel, which is still very far from the liberal democratic vision. A central assumption outlined in the Introduction was that for the 'defending democracy' to make the transition from the 'militant' to the 'immunised' route, it would take more than just a reduction in the intensity of the State's response to extremism. In order to arrive at the goal of 'immunisation', the scope of the response must also be extended and the principal expression of this must be the strengthening and fortifying of the democratic infrastructure of Israeli society. Until liberal democratic ideas are internalised by the majority of the different walks of life in Israeli society, the State will be goaded by its citizens and their representatives to strike as forcefully as possible at those perceived to be its 'enemies', whatever might be the price in terms of democracy.

However, this is neither the only nor the outstanding problem stemming from the non-liberal socio-cultural infrastructure. This type of infrastructure provides fertile ground for the germination and flourishing of extremist phenomena and their consolidation into political alternatives liable to constitute a 
threat to the State. As noted above, when the State is subject to repeated threats by society, it is more liable to toughen its response policy and to reintroduce measures whose admissibility in democratically governed countries is in doubt. Only recently, we were witness to evidence of this phenomenon with the adoption of severe and undemocratic counteractive measures against representatives from the right-wing camp in the months following the assassination of Prime Minister Yitzhak Rabin.

The conclusion drawn from the analysis in chapters 3 and 4 submits that policy-makers in Israel, in the context of the struggle against extremism, seek to constrain the activities of state institutions and keep them within democratic boundaries which are as distinct as possible. They then attempt to refrain from using severe measures capable of undermining the polity's ethical foundations, but have not been successful so far in offering a preventative and 'immunised' treatment in terms of the social underpinnings of the phenomenon of extremism. In consequence, a situation fraught with paradox has evolved. In the past, the scope of the response was fairly circumspect, as state authorities concentrated their efforts on dealing only with the symptoms of the phenomenon while disregarding their perpetrators. More recently, there has indeed been significant moderation in the intensity of the response toward the symptoms, thus making it easier for the State to maintain its democratic character. However, at the same time, the State has not invested in the empowerment of the democratic foundations of its citizenry, so that there has not been an equally significant reduction in the intensity of the challenges faced by the State.

Research results displayed in previous chapters indicate that the adult Jewish population is far from presenting a sound democratic worldview. Still, the findings of the survey conducted among adolescent students from Israeli high schools show that among pupils who participated in civics lessons in their new format there are signs of a tendency towards democratic values, compared to their counterparts who did not take the course. This outcome implies that even the limited efforts invested by the State in the inculcation of democracy have yielded their first fruits. It can therefore be inferred that if the Kremnizer Report's recommendations are fully implemented, thus leading to the substantial reinforcement of democracy in the State of Israel, there will be an improvement in the prospects that the democratic foundations of the Israeli public will be significantly strengthened.

The fly in the ointment, however, concerns the non-liberal constraints on Israeli democracy involved in the processes of policy-making, which prevent movement in the 'immunised' direction. Evidence of this was apparent in early 2001 when Limor Livnat, a seasoned conservative politician, was appointed minister of education. One of Livnat's first formal statements on taking up her appointment was to the effect that she would permit independent religious 
education systems to retain their pedagogical autonomy, that is, continue to teach religious subject matter rooted in a nationalist orientation in the absence of democratic checks and balances. In addition, she intended to adopt the Shinhar Report and launch a revolution of values in the state-run schools with the purpose of bolstering Jewish national identity among pupils. And, indeed, in May 2001, a broad reform of high school study curricula was initiated. In the context of this reform, the nationwide study programme was supplemented with a new field called 'The Heritage of Israel' which included, inter alia, the teaching of texts from the Talmud and the Torah and the introduction of pupils to significant personages in the history of Zionism. Prima facie, there is nothing wrong with this: democratic polities all over the world strive to inculcate their national traditions among their pupils. Still and all, according to Minister Livnat, the main goal of reform was 'to build a common basis for all pupils of Israel which will be grounded in Jewish, Zionist and nationalist values'. ${ }^{5}$ But what about the other aspect of the Israeli union of Judaism and democracy, that is, the delivery of instruction in democratic values? The minister's decision on this issue was unequivocal. Livnat declared that the recommendations of the Kremnizer Report were not to be implemented at that stage other than in a trial format and then only at a number of designated schools. ${ }^{6}$ In this fashion, the Ministry of Education ended up with neither one thing nor the other. First, it rejected the implementation of the Kremnizer Report and frustrated the reformation of citizenship education. Second, the Shinhar Report, which was intended to build up the inculcation of Israeli heritage in schools yet proposed to do this in the context of a humanistic and pluralistic approach, was interpreted by the Ministry's directors in such a way as to stress its ethnonationalist particularistic aspects. ${ }^{7}$

The odds that this education policy - which once again weakens the prospects of instilling democratic values in Israeli society - will be significantly contested by organisations of the 'pro-democratic civil society' are not promising, despite the accelerated growth of these institutions in recent decades and the considerable efforts of their members to advance their goals. A number of obstacles remain in place, making it difficult to pursue these aims: the number of organisations nationwide engaged in the provision of instruction in democratic values is still limited, the resources at their disposal are in short supply and their access to the education system is restricted. Therefore, it seems that, at least for the near future, Israeli pupils and students are destined to undergo an exhaustive and persistent socialisation in ethno-nationalistic values and at the same time will receive only a partial and diluted socialisation in democratic and humanistic principles.

From the above, it may be deduced that the State of Israel today is at a crossroads. While its policy of response to symptoms of political extremism and violence has renounced the 'militant' pole of the continuum and instead is making 
its way towards the 'immunised' pole, as regards the social underpinnings of extremism the movement along the continuum is much slower, and at times may even seem to be in the opposite direction. This predicament has raised doubts over the continuation of the State's restrained response to the agents of extremism and, consequently, also over the system's stability and the extent to which it can nevertheless continue to exist as a democratic polity.

In this case, we find the Israeli 'defending democracy' faced with two principal options. The first will be to return to 'militant' types of response. This path will perhaps make it feasible for government elites to preserve governmental stability in a state of increasing social pressure, but it will also place the status of Israel as a democracy in serious doubt. The second option is to move in the direction of the 'immunised' route. However, that alternative will be able to hold its own only if the State and the 'pro-democratic civil society' are successful in establishing a democratic political culture and are able to reduce the extremist threats facing the State, thus minimising the incentives for exercising harsh measures against expressions of extremism and violence.

I have to confess that any attempt, no matter how cautious, to forecast the future of the 'defending democracy' in Israel leaves me in two minds. While my heart is with the second alternative, that is, the 'immunisation' of the Israeli democracy, a glance at social and political reality in the country reveals the not unlikely prospect of movement in the direction of the 'militant' pole.

This evaluation is based first and foremost on ill winds which have been blowing for many years now among different sectors of Israeli society. Some of its main manifestations are hostility towards various groups, disdain for liberal values and the rule of law, and a tendency to regard democracy as secondary to nationalist and occasionally religious convictions. Over the course of time, and in the absence of a proper substructure of checks and balances taught by the education system, there has been a diffusion of these attitudes and they have become a central aspect of Israeli political culture.

Assuming that things will not unexpectedly change, and taking account of the fact that the paradoxes inherent to the Jewish democratic State do not seem to be near solution, it is not easy to envisage the Israeli governmental system and its various affiliates reaching an all-embracing decision to upset the status quo and inculcate democratic values in the education system while paying tribute to liberal ideas. Support for this prognosis comes from the fact that, in spite of Israel's encounter with Rabbi Kahane and his ideology, and notwithstanding the assassination of Prime Minister Yitzhak Rabin, the Ministry of Education has still not undertaken any revolutionary policy changes towards the assimilation of democratic values.

A feasible, albeit partial, resolution of the tension between the State's aspiration to preserve its Jewish national foundations and the need to empower its democratic character is embedded in the ability of the State's leadership to shrug 
off, once and for all, the perception of these two elements as a zero-sum game. In other words, Jewish national and democratic values should not be viewed as clashing and competing principles inevitably leading to the complete subordination of the democratic quality to the Jewish element. The other side of the coin is that these principles may be treated as complementary and in fact presented side by side. Of course, this is not a flawless solution, for there are undoubtedly several substantial points of conflict in the juxtaposition of Jewish principles in their prevailing orthodox interpretation in Israel with the conventional tenets of democracy. Yet, instead of the ostrich-like policy adopted by the leaders of the education system over the years, which supports the view that pupils should not be presented with issues that are controversial or a threat to the national consensus, the future citizens of this country should in fact become acquainted with the entire complex of circumstances pertaining to the existence of the State of Israel as a Jewish and democratic state, including both complementary and conflicting topics in respect of the dissent among religious beliefs, ethno-nationalist ideas and the principles of democratic thought. The advantage of this proposed solution over the current state of affairs is that it opens up the possibility of Israeli pupils grasping the complicated reality in which they live and in fact of developing the discriminating tools needed to deal with this situation.

However, a change in the nature of the Israeli pupil's familiarity with political and social reality in the country is not the only aspect which may help steer the 'defending democracy' in the direction of the 'immunised' route. As noted in chapter 4, the 'pro-democratic civil society' is a non-state-affiliated actor with significant potential for strengthening the 'defending democracy': yet, in order to capitalise on this latent potential, the 'pro-democratic civil society' in Israel must be autonomous and free to act. At this point, we once again encounter the non-liberal character of the Israeli democracy; however, this time, the obstacles facing the centralist custodian State, which elsewhere was colourfully described as embracing society in a 'bear hug', are not so formidable. As demonstrated in many other spheres, and in particular the economic sphere, the State of Israel has gradually eased its iron grip on many economic sectors and allowed other forces to take its place. Therefore, with regard to the 'civil society', it seems that the State should continue the process of its liberation from the 'statehood' mentality and expand even further the range of social organisation activities. Although, at first, the chances are that a number of organisations closely affiliated to the State will undergo difficulties, especially of a financial kind, as the survey reported here shows, those not dependent on state economic support would be able to find other sources of finance. At the same time, the autonomy they enjoy enables them to fill an important role as a critic of the State, and that may be of some benefit in moving the 'defending democracy' in the direction of 'immunisation'. 
While such solutions are not perfect, it is my view that if and when the State elects to adopt them, its prospects of moving slowly but surely toward the goal of 'immunisation' will, in due course, improve instead of possibly drifting back to the 'militant' pole of the spectrum.

\section{The 'defending democracy' in comparative perspective}

One of the major difficulties facing the social scientist in his/her attempt to confirm an analytic model by means of a case study resides in the model's singularity and the complications which may ensue when trying to draw conclusions regarding the validity of certain assumptions without putting them to the test of additional cases. Therefore, in the following paragraphs, the same model of analysis of the 'defending democracy' will be used to compare the Israeli case to other democracies subject to internal threats, specifically, the American and German democracies. Of course, we are speaking of a very condensed attempt to conduct a comparison employing this analytic framework; however, the product of this effort may afford insight as to the model's inherent potential.

The choice of the United States and Germany democracies with which to compare the Israeli case study is not random. Although these are countries with profound historical, cultural and political distinctiveness, a comparison among them will serve the purpose because these countries have all experienced the varied phenomena of extremism and political violence in past decades and all were compelled to contend with the 'paradox of the defending democracy'. Nevertheless, it is important to be aware of an important structural difference whose impact is central in regard to the methods of operation utilised by 'defending democracies'. Unlike the United States and Germany, Israel has never adopted a constitution. The absence of constitutional specifications, as elaborated in chapters 1 and 2, has had a decisive impact as reflected in the many changes and improvisations in the Israeli policy of response toward both political parties and extra-parliamentary extremist organisations.

There are essential differences between the American and German conceptions of the polity's protection. While the American constitution puts forward the freedoms of the individual, the German constitution, while recognising the importance of such liberties, emphasises the importance of a stable democratic system of governance and thus provides authorities with more 'space' in their attempts to defend the state. In effect, German concern that history might repeat itself is so great that, according to clause 79 (3) of the constitution (the 'perpetuity clause'), clauses 1 (civil rights) and 20 (the democratic nature of the country) may not be amended under any circumstances. ${ }^{8}$ Furthermore, the German constitution refers to domestic emergency situations and grants authorities permission to deal with them in a more decisive manner than other constitutions allow. ${ }^{9}$ 
In order to make the most of the comparison between the three cases, I will examine them from the perspective of the same two levels of analysis on which this book is based. The first level is institutional, implying the respective countries' institutional responses to political parties, extremist organisations and incidents of violence and terror. The second level concerns the social sphere or, more explicitly, the State's attempt to establish democratic foundations in society and the status of the 'pro-democratic civil society'.

\section{Political parties}

From the institutional level of analysis, I look first at the paths chosen by the different states in response to extremist parties. However, before discussing the administrative and legal barriers imposed by democracies on extremist parties, another latent structural barrier, i.e. the electoral system - discussed in chapter 1 - should be clarified. The electoral system was not intended to block extremist parties from gaining representation. However, different electoral systems or the levels of their threshold of representation may become crucial variables in explaining the success or failure of these parties. ${ }^{10}$ Therefore, when considering electoral and party system variables, it should be noted that the United States, with its strong two-party system, and Germany, with its 5 per cent representation threshold, enjoy considerable structural protection from extremist elements in their parliaments. Israel, as mentioned earlier, with its low representation threshold (1.5 per cent), enjoys no such protection.

Despite the almost insuperable barriers facing small parties in the United States, a National Socialist Party (NSPA) was established and succeeded in reaching the forefront of public debate in April 1977 while attempting to stage a march in Skokie, Illinois. The Skokie affair has major importance in this discussion since it signified the United States' judiciary's attitude as to the type of restriction that should be imposed on extremist parties. Following extended judicial discussion, in January 1978 the Illinois Supreme Court, in a - decision, ruled in favour of the Nazi march:

The main argument was the content neutrality rule, according to which, political speech shall not be abridged because of its content, even if that content is verbally abusive. Speech can be restricted only when it interferes in a physical way with other legitimate activities; when it is thrust upon a captive audience, or when it directly incites to immediate harmful conduct. Otherwise, no matter what the content of the speech, the intention of the speaker, and the impact of the speech on non-captive listeners, the speech is protected under the First Amendment to the United States Constitution. ${ }^{11}$

With this ruling, the Court reinforced the United States' constitutional commitment to a most extended liberal approach. This ruling was extremely important 
in the light of the far less liberal approach of American authorities in the 1940s and 1950s, especially towards the Communist Party.

The liberal United States' approach toward the NSPA might be explained by two variables. The first, socio-historical explanation is the American tradition of sanctifying the freedom of the individual. The other variable is more practical the fact that, due to structural barriers, the NSPA stood no real chance of becoming an influential political actor. Yet other far-right organisations did in fact make their way into the legislature and gained access to policy-making procedures, mainly through the Republican Party. ${ }^{12}$ Despite the limited success of David Duke and other extremist leaders of the right, American authorities have never had to confront the dramatic emergence of such forces and hence has not adopted any special measures to deal with the phenomenon.

Though structural and social conditions in Israel and Germany themselves are hardly similar, the two countries differ dramatically from the United States in two major senses. First, both countries have variants of the multi-party system, and, second, both have adopted legislation aimed at preventing the representation of extreme parties in their parliaments.

As noted in Chapter 1, clause 21 of the German Basic Law, from 8 May 1949 , sets very strict standards as to the kinds of political parties that are entitled to take part in elections to the legislature. For example, the law demands that the internal organisation of parties conforms to democratic principles. Moreover, political parties which, by reason of their aims or the behaviour of their adherents, seek to malign or abolish free democratic basic order or endanger the existence of the Federal Republic of Germany, shall be declared unconstitutional by the Federal Constitutional Court. ${ }^{13}$ Israel's section 7A of Basic Law: The Knesset (1958), discussed elsewhere in length, sets similar barriers for extremist parties. ${ }^{14}$

The test of reality reveals that although German and, especially, Israeli law invests the State with the authority to disqualify parties, in recent decades they have nevertheless both chosen to do so on rare occasions. In post-war Germany, only two parties have been banned according to clause 21: the Communist Party (KDP) and the Nazi Party's successor, the Socialist Reich Party (SRP) (both were disqualified in the 1950s). According to the Constitutional Court's ruling, the SRP was considered an unconstitutional party. It did not exhibit a commitment to civil rights, the rule of law, pluralism, and equality of opportunity for all political actors. Consequently, the court ruled that such a party had no place in the political arena and ordered it to be dismantled and stripped of all of its assets. ${ }^{15}$

In Israel, similarly, only two extreme right-wing parties have been disqualified, Kahane's Kach Party and its splinter party, Kahane Hai. Both were banned on grounds of being anti-democratic and racist.

Despite these exceptional disqualification procedures carried out by 
Germany and Israel, the two countries have demonstrated a rather high commitment to liberal values. In the years following these disqualifications, extreme right-wing parties surfaced in both countries. In Germany there was the NPD (Nationaldemokratisch Partei Deutschland), established in 1964, the DVU (Dutsche Volksunion), established in 1971, and the REP (Die Republikaner), incepted in 1983. The authorities, on the one hand, and the political parties, on the other, committed themselves to several ground rules. While the State was not so quick in implementing disqualification, the parties were very careful with their language concerning issues such as liberal democracy and foreigners. ${ }^{16}$ It was only in the summer of 2000 that Germany finally decided to initiate a process of disqualification against the NPD in consequence to its plan to instigate a racist revolution. In contrast to Israel, the disqualification process for a political party in Germany takes a considerable time and involves executive, parliamentary and judicial authorities. This protracted process is more likely to guarantee that the constitutional rights of the party in question will not be undermined. ${ }^{17}$ However, although the formal procedure of disqualification in Israel takes less time, the Israeli Supreme Court, as mentioned earlier, has set highly detailed guidelines for the disqualification process, thus constituting a safeguard which helps ensure structural commitment to liberal values.

An interesting fact, one that puts the Israeli attitude towards extremist parties in a light perhaps even more liberal than that of Germany, involves the decision of the State of Israel to refrain from monitoring parties represented in the Knesset. In Germany, on the other hand, extremist parties, especially those of a far-right nature, although not disqualified, are not allowed to act freely. The Republikaner, for example, was defined by the BfVS (Federal Bureau for the Protection of the Constitution) as a radical party hostile to the constitution. In consequence, authorities limited the freedoms of the party and its members, although they were not de facto proscribed parties. ${ }^{18}$ The same thing happened in the case of the NPD, even prior to the initiation of the disqualification process. Announcement published on the NPD's website, the following complaint was issued:

Like his predecessor as NPD chairman, Gunter Deckert Voight is being hounded by the German government because of his political views. He is currently the subject of police investigation for alleged 'defamation of the state and its symbols', which is a criminal offence under the current German regime. Voight made a statement at the NPD party congress on May 1, 1996, where he compared German democracy with the Communist system in the former German Democratic Republic in its suppression of nationalist political activity across Germany: 'We live once again in a police state in which we have no right of freedom of speech... Those who criminalise people for voicing their opinions are themselves criminals. ${ }^{19}$

As mentioned earlier, Israel's policy is to concede the liberties of questionable parties as long as they are not disqualified from participating in elections or 
declared entirely illegal. However, once a party is banned or, as in the case of Kach and Kahane Hai, even declared a terrorist organisation, liberal considerations become almost irrelevant.

It may be concluded that United States' policy towards extremist parties also is almost irrelevant due to the structural barriers imposed upon small parties. Yet, even in cases where such parties were active, the authorities' attitude towards them tended to be very liberal and thus conformed to the 'immunised route'. In Germany and Israel, the need to defend the polity from subversive elements was considered urgent enough that in both countries extremist parties have been disqualified in accordance with constitutional and legal arrangements. ${ }^{20}$ Over the years, the disqualification measure has been employed only rarely. Therefore, Israeli as well as German policies on extremist parties may be characterised as approaching the 'immunised' route.

\section{Subversive organisations and violent movements}

As in Israel, in comparison to their efforts to deal with political parties, the United States and Germany found it more difficult to keep their struggle against extra-parliamentary movements - including violent ones - within democratic boundaries. This is due to the simple fact that not all social movements aspire to parliamentary representation and are therefore not bound by the rules of the electoral game. Moreover, social movements which enjoy a lax organisational structure do not have to be officially registered; at the same time they are free to act within the social sphere and may also have the capacity to impress themselves upon the political arena.

The activity of such movements is a pivotal element of United States' political culture and is widely protected by the First Amendment to the Constitution. As mentioned in chapter 4 , as early as the beginning of the nineteenth century, so prominent were these movements that Alexis de Tocqueville praised the high levels of decentralised communal organisation and freedom of association. ${ }^{21}$ From that time onwards, although such associations in their 'uncivil' form would present serious challenges to the authorities, their important role in American democracy made it almost impossible to restrict their actions.

These political and cultural contexts led American authorities to adhere to a narrow interpretation of 'the criminal justice model' in their response to violent political acts. ${ }^{22}$ Smith's description of the steps taken against several extremist movements in the 1980s confirms this view. These measures had proved effective in countering terrorism, ${ }^{23}$ and at the same time did not cross liberal boundaries. Even the anti-terrorist legislation passed in the wake of the Oklahoma City bombing did not seem to exceed the limitations of the liberal version of the 'criminal justice model', especially following the appraisal of its 
constitutionality by the Supreme Court. ${ }^{24}$ The notion that United States' policy complies with the narrow 'criminal justice model' was reinforced, once again, by the words of the director of the FBI himself in the summary report for the years 1993-98: 'In the past five years, I have established core values for all FBI employees: Obedience to the constitution, respect for the dignity of all protected by the FBI, compassion, fairness, and total integrity. ${ }^{25}$ Even the reform adopted in late 1999, aimed at according the FBI wider authority in its response to terrorism, did not seem to effect a radical change in agency activities. According to Deputy Director Robert M. Bryant, the new policy will not change the FBI's long tradition of respect for civil rights. ${ }^{26}$ The tragedy of the 11 September 2001 terrorist attacks on the World Trade Centre and the Pentagon may indeed lead to a change in United States' counter-terrorist policy. However, on the basis of President Bush's declaration as well as the reactions of the directors of the various security agencies, it seems that, despite their genuine intention to effectively eliminate terrorism, US policy-makers and security officials are generally reluctant to sacrifice basic democratic liberties in the course of this struggle, at least in the domestic arena.

Germany, like Israel, provides a very different example of counterextremist policies. Since the late 1960s Germany, like Israel, has presented its own version of the "extended criminal justice model' ${ }^{27}$ and, inevitably, has attracted much criticism as a result. Although, according to Finn, this model of response has always been constrained by the constitution and thus has been committed to civil rights, ${ }^{28}$ Loewenstein argues that this policy was "probably among the most repressive anti-terrorist legislation in existence in a liberal democracy' ${ }^{29}$ Such criticism was generated as a result of the emergency regulations of 1968 which gave the Federal Government extended authority to fight terrorism within the states of the German Republic. These regulations also gave extra powers to the Federal Criminal Police Office as well as the BfVS. Left-wing terrorist attacks, which beleaguered Germany in the years 1974-78, led to the adoption of even more rigid legislation against subversive and terrorist acts. These new regulations included the Penal Code $88 \mathrm{a}$, according to which a crime against the constitution may result in three years' imprisonment. This law was subject to severe criticism and was thus made void in 1981. Further expansion of the 'criminal justice model' may be found in amendments 129 and 129a to the Penal Code, the purpose of which was to impose stricter limitations on attempts to form terrorist organisations. Moreover, the German Government adopted the 'Radicals' Decree' policy, which sanctioned restrictions on radical political activists. This regulation excluded many Germans from employment in the public sector and many others had to face unpleasant interrogations. ${ }^{30}$ These policies, although legally better defined than those in Israel, reflect a similar tendency of the German State to give priority to security issues even at the price of undermining civil rights. 
Over time, the extended model of response in Germany has undergone several liberal reforms ${ }^{31}$ in a process similar to the Israeli attempts to effect a departure from its 'extended criminal justice model'. Events of the 1980s and 1990s demonstrated that although Germany still had at its disposal various means to cope with politically motivated violence, it tended to avoid extensive use of them. For example, during the 1990s, only fifteen radical organisations were declared illegal, while the actual number of far-right movements in 1999 stood at $134 .^{32}$ In recent years, German policy on violent right-wing bodies has become more resolute, yet, according to police officials as well as the BfVS, it is strictly bound by legal as well as liberal boundaries. ${ }^{33}$ Indeed, contrary to Israeli security forces and especially the Shabak, the modus operandi of the German BfVS as well as the special police forces is more in conformance with liberal values. These forces are subject to strict parliamentary, judicial and public review and therefore try to deal with the problems of extremism and violence by employing less severe tactics. For example, the BfVS, which is in charge of gathering intelligence on extremist movements, is prohibited from acting against these elements. For that reason, besides gathering information, the organisation issues reports on extreme right-wing activities. These reports are then distributed both to decision-makers and to the general public. The aim of publishing such intelligence information is to raise public awareness about the risks originating from the far right and the expansion of its movements. Furthermore, special police forces - established for the purpose of contending with the neo-Nazi scene - are trained to use non-violent measures with violent crowds. In fact, one of the most important tasks of these forces is to educate, i.e. to try, by means of persuasion, to prevent radical youths from committing violent crimes.

To conclude: in the past, both Germany and Israel tended to put security considerations at the forefront of their counter-violent activities, and as a result were subject to criticism for violations of liberal rights. While in recent years both countries have attempted to limit their response to extremism to more democratically acceptable policies, it seems that Germany is more in accord with the 'immunised route' than Israel. The United States, on the other hand, has for a long time been inclined towards the narrow interpretation of the "criminal justice model' and thus complies much more closely with the liberal conception.

\section{Civics education}

As for the social level of analysis, the role of civics education in these three democracies is compared, and then an attempt is made to assess the role of the 'pro-democratic civil society' in helping defend those democracies.

Most democracies acknowledge the need for socialising their future citizens in conformity with the rules of the democratic game. However, for many years, civics education in the United States and Germany has remained fairly 
comparable to the Israeli programme (i.e. an emphasis mainly on the structures and functions of governmental institutions). Yet, in the last few decades, the curricula of civics education in many liberal democracies, including the United States and Germany, have expanded the role of civic studies and shifted the emphasis from structures and procedures to democratic and liberal values. ${ }^{34}$ Moreover, ministries of education in many German states and especially in the former states of East Germany (GDR) are opening the doors of the education system to 'civil society' organisations which work to promote tolerance and democracy. ${ }^{35}$

One of the most active institutions of the civil society in providing education in tolerance, particularly in East Germany, is the RAA (regional centres for inter-cultural understanding, education and schools). This was established in 1992 primarily in the wake of an increase in xenophobic incidents and early indications of a wave of violence against foreigners in the ex-Communist parts of the country. Under the patronage of the Federal Government, the RAA opened ten offices in the state of Brandenburg and provided assistance for similar initiatives in other states formerly part of East Germany. ${ }^{36}$ Its principal goal is to promote inter-cultural understanding and to prevent, or at least reduce, xenophobia and violence aimed at foreigners. The main part of its operations focuses on designing study programmes on the subjects of democracy and tolerance and administering them in kindergartens, schools and youth clubs. Organisation members are also engaged in adult education and in fact have expanded their range of activities to providing assistance to refugees and immigrants. According to RAA representatives, the majority of schools in Brandenburg receive with open arms organisations of the "pro-democratic civil society' and governmental involvement on this issue, while the demand for extra-curricular programmes in this vein are on the increase. ${ }^{37}$

The rapid development of the field of civics education in the former East Germany corresponds with Frazer's assertion that in order to complete the democratisation of countries from the former Eastern Bloc, the new governments of these states have adopted study programmes designed to help young and senior citizens alike deal with a political system based on values previously unknown to them.

Yet, in order to better understand the growing emphasis on "civics education' in established liberal democracies, it should be stressed that political apathy, low electoral turnouts and declining levels of social and political participation in recent decades and, at the same time, an increase in manifestations of racist, sectarian, authoritarian and anti-humanitarian values, have alarmed many countries in Western Europe and North America, thus sparking a renewed interest in civics education. ${ }^{38}$

In the former East Germany, the liberal variant of civics education has become a central factor in processes of democratisation. The United States and 
Germany also have instituted comprehensive civics education programmes with an emphasis on liberal and humanistic values aimed at encouraging the public to be a part of the political procedure. However, in the attempt to contend with phenomena stemming from political extremism and xenophobia, Israel has yet to devise a clear-cut policy on this matter.

As explained in chapter 3, the reason why civics education policy in Israel remains ambiguous is not so much that its social structure is sufficiently 'immunised' as to render education of this genre unnecessary as that the State's political and ideological structures make it difficult for leaders to choose a specific policy and then to pursue it.

\section{Civil society}

Regarding the 'pro-democratic civil society's' role in assisting the State move towards the 'immunised' model, as already noted, many civil society organisations are engaged in promoting tolerance and consequently have assumed a role in the 'immunisation' process of the Israeli society. These activities make it far harder for extremist political leaders and activists to mobilise wide support from the population. Moreover, an active 'pro-democratic civil society' may also help limit the State's response to democratically acceptable boundaries. In both the German and the United States' experience, examples may be found of dynamic civil activity in reaction to challenges of an extremist nature. Following the success of the DVU in the Sachsen-Anhalt elections in April 1998, the German post office workers' union asked the Federal Government to find ways to prevent the delivery of racist mail by the German postal system. This step was taken prior to the national elections of September 1998 and reflected concern that the DVU would enter the national Parliament. Prior to the 1998 elections, many parliamentary members were approached by the organisation of Christian churches in Germany and were asked to refrain from using xenophobic rhetoric during their election campaigning. Moreover, both the employers' (DGB) and the employees' (UVB) unions in Berlin urged their members not to vote for extreme right-wing parties. They also asked them to act openly to stem the rising tide of violence against foreigners. ${ }^{39}$

Similarly, the American tradition of a strong civil society finds its expression in the struggle against racism and extremism. Such civil society activity comes in all shapes and sizes, beginning with grassroots activities in the local community and ending with the activities of established interest groups. For example, when in New Town, Pennsylvania, violent far-right activists broke a window only because a Hanukkah Menorah stood behind it, the local community stepped into action and a Menorah was placed in almost every house in the neighbourhood. A similar example may be found in the neo-Nazi graffiti attack in Washington, DC. When newspapers wrote that the city did not have enough 
resources to deal with these defacements, local communities decided to take on the task and wiped clean all the wall writings themselves. ${ }^{40}$ Similar events took place following the September 2001 terrorist attack. Due to the fear that American Muslims would be attacked by angry militants, local communities all over the country became engaged in projects aimed at promoting religious and ethnic tolerance.

Yet, in accordance with a longstanding tradition, the most active members in American civil society are the more institutionalised organisations, especially the interest groups. Among the most prominent groups acting against racism, xenophobia and hate crimes are the Anti-Defamation League, the American Jewish Committee, the Simon Wiesenthal Centre, and many others representing minorities. In such cases, the groups themselves attempt to strengthen the ties between society and the local state by initiating joint activities. In 1998, the ADL cooperated with the state of New Jersey in proposing prizes for those who exposed racist graffiti perpetrators. In 1999, the same organisation, this time in conjunction with the New York Police Department, published a handbook for designed to help members of the community respond to racist violence. ${ }^{41}$ These organisations do not restrict themselves to local activities, but also aim at the legislative level. The 'hate crimes' laws, adopted by many states in the US, are a direct consequence of the ADL's efforts to find a way to fight racist and xenophobic crimes within constitutional boundaries, followed by a concentrated effort of the organisation to establish lobbies to support such legislation. ${ }^{42}$

As described at length in chapter 4 , the 'pro-democratic civil society' in Israel is still in its developmental stage and its influence is significantly less pronounced as compared to organisations of the 'civil society' in the United States and Germany. Particularly in recent years, it seems that a political window of opportunity has gradually opened, enabling these associations to flourish and take their place as a significant factor in the protection of Israeli democracy. However, as noted before, the State must help create the conditions needed to facilitate their development; and, as Yishai states: 'Society itself needs to overcome its polarising trends as well as the tendencies of individuals to assemble together and work in small frameworks which serve individualistic interests instead of the interest of society as a whole. ${ }^{43}$

To conclude this comparative analysis: placing the three countries on the continuum leading from the 'militant' to the 'immunised route' will readily establish the United States as the country closest to the ideal type of the 'immunised defending democracy'. Although not a country entirely free of extremist phenomena and political violence, the political culture of the USA gives an impression of considerable commitment to liberal and democratic values. Furthermore, the 'pro-democratic civil society', which has proved to be a cornerstone of United States' political life, is largely successful in responding effectively to the challenges of extremism. A review of that country's response to 
these challenges, whether in the form of political parties or other types of organisation, shows evidence of great restraint and commitment to the "rule of the law' and liberal democratic values. Even after the events of September 2001, the odds are presumably low that American democracy will fall victim to the agents of political extremism or that its liberal democratic foundations will be undermined in the effort to defend itself in the face of those threats.

Germany also is positioned closer to the 'immunised' model than is Israel, although a distinction must be made between West Germany, where democracy has been able to take root in the decades following the Second World War, and its neighbouring countries, which were subject to Communist rule and are still engaged in the processes of democratisation. Quite unlike the American instance where democratic and liberal values have played a central part in the political culture, for many German citizens who had lived under Communist rule these are unfamiliar values. Therefore, both federal and local governments, together with the notable participation of 'civil society' organisations, are striving to fashion anew a democratic political culture by means of the processes of political socialisation. Furthermore, in the aftermath of the exceptional history of the German Republic, the Holocaust and related issues such as tolerance and pluralism have become central topics in its education system. From a young age, children in Germany learn the advantages of democracy, as well as the potentially disastrous consequences should the basis of democracy be challenged or ignored. In terms of Germany's institutional response to the challenges of extremism, there is now a marked inclination toward liberalisation in comparison to earlier decades. Despite the fact that today, especially in the eastern parts of the country, a significant threat consisting of right-wing extremism and skinhead street violence is making its presence felt, the security forces, which closely follow these events, still refrain, in most cases, from crossing conventional democratic boundaries in their response. In fact, the German constitution, which sanctifies the preservation of the polity's stability - even at the expense of the liberties of extremists - prevents the German State from a facile crossing of democratically accepted boundaries in its struggle against extremists. Proof of this is in the drawn out and obstacle-laden process through which state authorities have to go in order to disqualify a political party.

The Israeli case has already been discussed were in detail, and therefore only one conclusion, relevant to the present comparison with the other two cases, remains to be briefly outlined. In Israel, there is a disparity between its progress toward the 'immunised' pole in its response to extremist political parties (and also, to a certain degree, to violent movements), on the one hand, and the weakness of its democratic political culture, which includes the State's difficulty or perhaps reluctance to partake in the shaping of this political culture, on the other. In the first decades of its existence, Israel acted swiftly and decisively when faced with any factor perceived by its leadership as a threat to either the Jewish 
or the democratic nature of the State. After undergoing processes of institutionalisation, and having become an established fact in the Middle East, the intensity of its response to the challenge of extremist Jewish elements has gradually decreased. The credit for this turn of policy goes to the increasing commitment to democratic values of ruling elites and their fear of forfeiting public legitimacy by responding with too heavy a hand to the representatives of one of the groups constituting the polarised Israeli society. However, this novel approach will founder unless there is significant change in the empowerment of the democratic underpinnings of Israeli society. The various chapters of this book present evidence of the significant incongruity that exists between the Israeli policy of response to extremist manifestations, such as political parties or violent movements, and its long-term policy of attempting to inculcate democratic values. This gap between the State's response to extremists and its teleological struggle with the phenomenon of extremism has been attributed, in the main, to the non-liberal character of Israeli democracy and, more specifically, to the tension between Jewish-nationalist and democratic features included in the formula of the Jewish and democratic State which find expression in the political system and in policy-making processes. Furthermore, the fact that Israel can still be called a centralist state in relation to other democracies prevents it from providing a wider range of action for those bodies in the social sphere whose goal is to strike at the sources of extremism. Therefore, in comparison to the United States - and to Germany - Israel is to be found more distanced from the 'immunised' point of the continuum, and perhaps it is possible to see the Israeli democracy as having the greatest potential to be affected by the phenomenon of political extremism or by its response to it.

\section{Conclusions}

What, therefore, are the theoretical conclusions to be drawn from this study? And which questions are still left unanswered?

At the beginning of the book, I discussed the terms, 'militant democracy' and 'defending democracy' as defined and used by both scholars and policymakers. The upshot of this discussion was that these are terms of considerable ambiguity and ambivalence which ultimately rely on one basic assumption: to wit, a democracy has the right to defend itself from its adversaries. And, in the light of the events of the twentieth century, 'militant democracy' and 'defending democracy' are terms that apply, generally speaking in the context of antidemocratic political parties. Yet a closer look at the challenges facing democratic systems of governance at the beginning of the third millennium reveals a more intricate picture. This is primarily due to the fact that not only do certain political parties pose a danger to the stability of these systems but, today, radical or revolutionary extra-parliamentary movements and terrorist organisations con- 
stitute a threat. Furthermore, the formal nature of the definitions of 'militant democracy' and 'defending democracy' principally stresses the judicial means at the disposal of state institutions in their struggle with anti-democratic challenges. This limits discourse to the paradoxes generated by the need of democratic polities to defend themselves and which, in their very efforts to do so, are liable to undermine the ethical foundations on which they are structured.

Accordingly, and in the attempt to address the complex of challenges facing the self-defending democratic polity, I proposed to expand the notion of the 'defending democracy' beyond the conventional definitions of the construct, mainly by supplementing the formal-institutional perspective with a social perspective. The rationale for this expansion was that simply investigating the measures employed by states in their efforts to deal with defiant elements seemed inadequate when those elements were already immanent. Alternatively, the 'defending democracy' should be perceived as a more comprehensive term which involves the complex of actions effected in the political and social spheres designed to reinforce the democratic bases of society and to reduce the mobilising potential of extremist parties and movements. Furthermore, including the social perspective in this analysis introduces the potential for a more penetrating scrutiny of the 'defending democracy paradox' and possible means for its resolution. For, as noted above, one of our fundamental assumptions is that as society enjoys a more stable democratic social sub-structure, the intensity of the extremist threat aimed at the state is reduced and, as a result, the inclination of state authorities to cross democratically acceptable boundaries in the context of their struggle against provocative elements is also weakened. In order to facilitate the use of the concept of the 'defending democracy' for analytical purposes, two ideal types were proposed - the 'militant' and the 'immunised' route. These concepts are structured on both institutional and social components and in effect form a continuum. Presenting these types imparts to the notion of the 'defending democracy' a dynamic aspect and enables the examination of the change in the nature of a certain country's confrontation with extremist phenomena over a period of time, and in fact provides the means for comparison among several countries.

In conclusion, the two principal goals achieved in this book are the expansion and elucidation of the characteristics of the 'defending democracy', and the devising of an analytic continuum which provides for the positioning of different countries' responses somewhere between the two ideal types. Yet, in order to pursue and develop the above model into a comprehensive theoretical framework, both research questions and fields of research should be developed further. In this fashion, for example, the study of the Israeli case has shown that the intensity of extremist threats is not the only determinant which shapes the nature of the state's response, but that other factors, including those related to its political culture, institutional structure, social issues and various political 
considerations, have parts to play. A comprehensive comparative study can provide a more detailed answer and perhaps an interesting explanatory model for the various factors impacting on the features of the state's response and can additionally put to the test the assumption that the overriding factor in a state's counteractive policy is the extent and degree of the hostile threats it faces.

\section{NOTES}

1 Shahar Ilan, 'Supreme Court of Justice Tends Not to Intervene in Decisions Made by the Elections Committee', Ha'aretz, 7 May 2001.

2 Gideon Alon, 'The Law Does Not Include the Question of GSS Interrogations', Ha'aretz, 7 June 2001.

3 Gideon Alon, 'The New Incitement Law Will Be Submitted for Approval by the End of July', Ha'aretz, 3 June 2001.

4 Gideon Alon, 'Preliminary Law Passed Against Support for Terrorist Organisations', Ha'aretz, 7 June 2001.

5 Re'eli Sa'ar, 'General Education in the Haredi Sector: Heritage in the State-Run School System', Ha'aretz, 14 May 2001.

6 Re'eli Sa'ar, 'A New Subject in High School - the Heritage of Israel', Ha'aretz, 14 May 2001.

7 Re'eli Sa'ar, 'A New Subject in High School - the Heritage of Israel'.

8 Samuel E. Finer, Vernon Bogdanor and Bernard Rudden, Comparing Constitutions (Oxford: Clarendon Press, 1996), p. 17.

9 Finer, Bogdanor and Rudden, Comparing Constitutions, p. 33; Kurt Groenewold, 'The German Republic's Response and Civil Liberties', Terrorism and Political Violence, 4:4 (1992), p. 144.

10 See: Giovani Sartotri, Comparative Constitutional Engineering: An Inquiry into Structures, Incentives and Outcomes (New York: New York University Press, 1997).

11 Raphael Cohen-Almagor, The Boundaries of Liberty and Tolerance: The Struggle Against Kahanism in Israel (Gainesville: University of Florida Press, 1994), pp. 132-3.

12 Michael Minkenberg, "The New Right in Comparative Perspective: The United States and Germany', Cornell Western Societies Paper, no. 32 (1993), pp. 40-6.

13 Finer, Bogdanor, Rudden, Comparing Constitutions, pp. 137-8.

14 John Finn, 'Electoral Regimes and the Poscription of Anti-Democratic Parties', in David C. Rapaport and Leonard Weinberg (eds), The Democratic Experience and Political Violence (London: Frank Cass, 2001), p. 61.

15 Booklet by Talia Einhorn, Statutory Proscription of Political Parties that Have Racist Platforms: Article 7a of the Basic Law: Ha-Knesset (Jerusalem: Israeli Association for Parliamentary Issues, 1993), p. 16 (Hebrew).

16 Minkenberg, 'The New Right in Comparative Perspective', p. 53.

17 Anon., 'First Vote in Germany: To Ban an Extreme Right-Wing Party', Ha'aretz, 27 October 2000.

18 Gillian More, 'Undercover Surveillance of the [German] Republikaner Party: Protecting a Militant Democracy or Discrediting a Political Rival?', German Politics, 3:2 (1994), pp. 284-92.

19 NPD website: http://npd.net/npd-pv/sprachen/englisch/eng2.htm

20 It should be mentioned that in Israel, the Socialist Party, an Arab left-wing party, was banned in 1965 without specific legal authorisations. 
21 Alexis de Tocqueville, De La Democratie en Amerique (Jerusalem: Bialik Institute, 1979), p. 213.

22 Peter Chalk, West European Terrorism and Counter-Terrorism: The Evolving Dynamic (Basingstoke, Hampshire: Macmillan Press, 1996), p. 97.

23 Brent L. Smith, Terrorism in America: Pipe Bombs and Pipe Dreams (Albany: State University of New York Press, 1994), p. 89.

24 Tricia Andryszewski, The Militia Movement in America (Brookfield, CT: Milbrook Press, 1997), pp. 101-2.

25 Federal Bureau of Investigation booklet, Ensuring Public Safety and National Security Under the Rule of the Law. A Report to the American People on the Work of the FBI 1993-1998 (1999), p. 4.

26 David Vice A. and Lorraine Adams, 'FBI to Restructure, Adding Emphasis on Crime Prevention', Washington Post, 11 November 1999, p. A02.

27 Ariel Merrari, quoted in Ronald D. Crelinsten and Alex P. Schmid, 'Western Responses to Terrorism: A Twenty-Five-Year Balance Sheet', Terrorism and Political Violence, 4:4 (1992), p. 334.

28 John E. Finn, Constitutions in Crisis: Political Violence and the Rule of Law (New York: Oxford University Press, 1991), p. 206.

29 Quoted in Finn, Constitutions in Crisis, p. 206.

30 Finn, Constitutions in Crisis, pp. 207-12.

31 Michael Getler, 'Hamburg Mayor Fights Job Restrictions Against Radicals', Washington Post, 10 March 1979, p. A20.

32 Data from the Stephen Roth Institute for the Study of Contemporary Anti-Semitism and Racism, Tel Aviv University, available online: www.tau.ac.il/Anti-Semitism/asw99-2000/germany.htm

33 Personal interview with Officer Zimmerman, Mega Task Force, Franufurt-Oder, (23.10.2000); personal interview with Dr Annegret Ortling and Mr Jorg Milbradt, BfV, Ministerium des Innern, Land Brandenburg (24.10.2000).

34 Elisabeth Frazer, 'Introduction: The Idea of Political Education', Oxford Review of Education, 25:1-2 (1999) pp. 5-22.

35 From an interview with Mr Karsten Friedel, coordinator, Tolerantes Benadenburg (23.10.2000).

36 RAA Brandenburg brochure - Regional Centres for Inter-Cultural Understanding, Education and Schools in Brandenburg.

37 From an interview with Ms Annegret Ehmann, head, RAA Brandenburg (25.10.2000).

38 Frazer, 'Introduction: The Idea of Political Education', pp. 5-6.

39 Stephen Roth Institute: www.tau.ac.il/Anti-Semitism/asw98-9/germany.htm

40 Dina Porat, Raphael Vago and Roni Shtauber (eds), Anti-Semitism and Radical Movements in the World: Data, Characteristics and Estimations (Tel Aviv: Ramot-Tel-Aviv University, 1998), p. 179 (Hebrew).

41 Anti-Defamation League, Security for Community Institutions A Handbook (1999).

42 Anti-Defamation League, Hate Crimes Laws (1997), p. 2.

43 Yishai, Civilian Society in Israel towards the Year 2000, p. 87. 


\section{INDEX}

Adam Institute for Democracy and Peace 147-8

administrative detention $74,75,77,80$, 82, 83, 93

Agranat, Justice Shimon 33

Al-Ard 38

Altalena 17, 21-2, 71-2

Amir, Yigal 19, 21, 92, 94, 117

Amnesty International 153

Anti-Defamation League (ADL) (US) 188

Arabs

attitudes toward 99-100, 124, 127, $128,129,131$

in civics education $109,111-12$, 117

human rights organisations 153

intifada 56, 86, 174

Kach and Kahane 34, 35, 36-7, 41, 43-4, 46, 50, 51

Moledet 54

political parties 61

regulatory measures 13

Ashkenazi, Hillel 54-5

Association for Civil Rights in Israel

(ACRI) 152-3, 154-5, 164

Avnon, Dan 58

Bach, Justice Gabriel 40, 41-2, 45

Bagrut certificate 111-12, 114, 133

Balad 53

Barak, Justice Aharon 42, 44-5, 59

Barzilai, Gad 49, 58, 72, 78, 88

Basic Law - The Knesset 47-50, 52-3, 60, 181

Be'er, Yizhar 151

Begin, Menahem 72, 89

Belhasan, David 93

Ben-Eliezer, Uri 144-5, 148, 149, 156

Ben-Gurion, David 70, 78

Altalena 17, 72

education 109 guided democracy 143

political parties 32

Ben-Horin, Michael 94

Benvenisti, Professor Eyal 95

Bernadotte, Count Folke 77

Bernstein, Tzvi 39

Board for the Education of Values (BEV) 118-19, 120

Brit Hakanaim 17, 79

B'Tselem 153

Central Elections Committee (CEC) 49, 61,172

Kach 37-9, 40-2, 51-3, 56, 57

Kahane Hai $56-7$

Moledet 54-5, 57, 58

Socialist List 33, 60

Yemin Israel 59

Chalk, Peter 68

civics education 130-4, 175-6, 177-8, 106-8

and civil society 167

comparative perspective $185-7$

nationalist ideas 108-15

organisations 147-8

quantitative assessment of reform 122-30

reform efforts 115-22

civil society $8,12,14-15,23,139-43$

comparative perspective 187-90

in Israel 143-6

see also pro-democracy civil society

Cohen-Almagor, Raphael 49, 58, 61-2, $75,84,85$

conservative radicalism 15

constitution 73, 75, 179

Crelinsten, Ronald D. 69, 76, 78

criminal justice model 68-70, 75, 97, 100

contraction 82-96

legislation $80-2$

United States 183-4, 185 
see also extended criminal justice model

data sources 24-6

Defence (Emergency) Regulations (1945) $73-5,80,81$

defending democracy viii, 1, 190-2

comparative perspective 179-90

definition 3-5

developments and challenges 171-9

militant and immunised routes $8-11$

paradox 2, 68, 140, 191

political context 12-21

and pro-democracy civil society 139 , $141,143,145-6,156,165-7$

theoretical framework $5-8$

democratic orientation $124-5,126$, 128,129

Derech Hanitzotz 87

de Tocqueville, Alexis 141, 183

devotee parties 30

Division for Democracy and Coexistence (DDC) 118-19, 120, 147

education 7-8, 14, 22-3, 106, 109 see also civics education

Elba, Rabbi Ido 94

Elinson, Yehuda 41

elite party model 30

Eskin, Avigdor 94

ethnic democracy 13, 14, 15

ethnocentrism 115, 124, 127, 128, 129,131

ethnocracy 13

ethno-nationalism 108-15, 131

Etzel 17, 22, 71-3, 77, 78

Etzioni, Justice Dr Moshe 37-8, 39

extended criminal justice model 70,73 , 97, 99

constitutional and legislative

foundations 73-5

General Security Service 75-7

Germany 184-5

Jewish Underground 89

operational aspects 77-9

extra-parliamentary movements see

subversive organisations and violent movements far right
political parties 34-59

see also Kach; Kahane Hai; Moledet

Feiglin, Moshe 94

Foundations Institute 148

freedom of assembly 81

freedom of association 74

freedom of expression 2, 95

ACRI 153

Kahane 44-7

restrictions $74,80-1$

freedom of movement 74

Freidman, Aryeh 93

Gaza 18, 88, 153

General Security Service (GSS) see Shabak

Germany 179

civics education $185-7$

civil society $187,189,190$

political parties 30-1, 180, 181-2

subversive organisations and violent movements $184-5$

Gillon, Carmi 76, 78, 87, 88-9, 90

Ginsburg, Rabbi Yitzhak 93

Goldberg, Justice Eliezer 51, 57

golden path 24

Goldstein, Baruch 83, 84, 93, 94

grass-roots groups 140

Greater Land of Israel 17, 18, 88

Gur-Aryeh, Professor Miri 87

Gush Emunim 18, 20-1, 88

Gutmann, Professor Emanuel 114

Guttman, Professor Shaul 58-9

Habad 20

Halakhic law 19-20, 38, 56, 117

Halima, Justice 57

Hamachaneh 79

Hammer, Zevulun 118, 120

Hanitzotz 87

Hardal 20

Haredim 19-20, 79

Harel, Isser 78, 79

Hefetz, Assaf 90

Herut 34

Heshin, Justice Michael 172

Horowitz, Dan 5 
ideological cleavage 16,17-19, 71

see also left; right

immunised route $6,10-11,22,23,24$, $171,174,177-9,191$

ACRI 153

civics education $25,115,120,132$, 133-4

civil society 187, 156, 163, 164, 165

political parties $57-9,60-1,63$

radical and violent movements 68,70 , 86, 96-7

Institute for Democratic Education 148

Integrated Law Enforcement Task Force against Incitement and Sedition Offenders 93

interest groups 140

intifada 56, 86, 174

Irgun 17, 22, 71-3, 77, 78

Israeli Broadcasting Authority (IBA) 44-5, 60

Israeli Defence Forces (IDF) 99

Jabarin, Mohammed 86, 93

Jewish Underground 18, 21, 88-90, 97 Judea $18,88,153$

Kach 21, 34, 59, 90

tenth Knesset elections 36-9

eleventh Knesset elections 40-3

twelfth Knesset elections 51-3

thirteenth Knesset elections 55-6, 57

and civics education 116

and criminal justice model $82-7$

disqualification 50, 61, 181-2, 183

early years $34-5$

Kahane, Binyamin 56, 84-5, 86

Kahane, Rabbi Meir 20-1, 34, 60, 82-3, 84,177

tenth Knesset elections $36-7,39$

eleventh Knesset elections 40, 41, 42-3

amendment to Basic Law 47-50

and civics education 115,116

early years $34-5$

in Knesset 43-7

Kahane Hai 55

and criminal justice model $83-7$

disqualification 56-7, 61, 181-2, 183
Käsztner, Dr Rudolph 17

Keshev 150-1

Knesset 32

Basic Law 47-50, 52-3, 60, 181

Kahane 43-7, 60

Knesset elections

eighth (1972) 35

ninth (1977) 35

tenth (1981) 36-9

eleventh (1984) 40-3

twelfth (1988) 50-5

thirteenth (1992) 55-7

Kremnizer, Mordechai 119, 173-4

Kremnizer Committee 119-20, 122, 176

Labour Movement 17, 18, 54, 71

Labour Party 32

Law and Administration Ordinance (1948) 74

Law of Associations (1980) 81

left

and criminal justice model $87-8$

extremism and violence 22

underground movements 17

legal 96

legal-judicial analysis 3-4, 6-7, 172

legitimate 96

Lehi 17, 19, 22, 71, 77-8, 79

Levinson, Meira 106, 107, 108, 121

Levy, Itzhak 118

liberty 80

Likud 34, 88

Lissak, Moshe 5

Livnat, Limor 175-6

Mapai 31-2

mass party model 30

Meshulam, Rabbi Uzi 21, 90-2, 97

militant democracy 3, 190-1

militant route $6,9-11,22,24,171$,

$174,177,191$

and civil society 139-40

Kahane 43-7

political parties 49

radical and violent movements 68 , 70-3, 77, 78, 97, 99-100

Socialist List $33-4$ 
military-operative analysis 3

Mill, John Stuart 2

Ministry of Education 116, 132-3, 176, 177

civics education status $114-15$

policy implementation 120-1, 122

policy-making 119-20

and society-oriented organisations $147,148-9$

structural reform $117,118-19$

Moledet 53-5, 57, 58-9

Morasha 20

Mossad 99

Movement for Quality Government in Israel 152

Nationaldemokratisch Partei Deutschland (NPD) 182

nationalism 22-3, 108-15

national religious 19

National Socialist Party (NSPA) (US) 180-1

national ultra-orthodox 20

Natorei Karta 19

Netanyahu, Benyamin 118

New Israel Fund 154-6, 157

Nissim, Moshe 48

non-liberal democracy $12-15$

civics education 107-8, 109-10

occupied territories $18,54,75,88,153$

opinion polls 97-9, 112-13, 167

Or, Justice Theodore 86, 87, 93

Ordinance for the Prevention of Terrorism

$75,81,93-4,95,173,174$

Kach and Kahane Hai $83-4,85$

radical left $87-8$

Zrifin 79

Oslo Agreements 85, 88, 92

and civics education $115,116-17$

Palestine Liberation Organisation (PLO) $88,92,116-17$

Palestinians see Arabs

Panim L'khan U'l'khan 148

paradox of tolerance 2, 68, 140, 191

Parties Law (1992) 58-9, 60 party state 31

Peled, Yoav 49

Penal Code 80, 81, 86, 94, 95

political cynicism $124,125,126-7$, 128,129

political efficacy $124,125,127,128,129$

political-institutional analysis 2-3

political knowledge 124, 128, 129, 130

political parties 30-4, 60-3, 144

comparative perspective $180-3$

disqualification 172

far right 34-59

and pro-democracy civil society 161

political socialisation 106

Popper, Karl 2

pro-democracy civil society $23,139-40$, $141,143,165-7,176,177$

and defending democracy 145-6, 178

organisations' evolution 25, 157-64

targets and prominent organisations

146-56

pulsa denura 94

Putnam, Robert 141, 158, 159, 166

qualitative sources $24-5$

quantitative sources 25-6

Rabin, Yitzhak

assassination 1, 92-6, 115, 117, 175, 177

Jewish Underground 88

radical and violent movements see subversive organisations and violent movements

Rawls, John 2

relgious extremism 19-21

religious messianism 16

Republikaner, Die (Germany) 182

research methodology 24-6, 123-4,

$$
\text { 145-6 }
$$

right

radical and violent movements $18-19$

underground movements 17, 22

see also far right

Rubinstein, Professor Amnon 119

rule of law 69-70, 73, 75, 97, 100, 117 
Samaria 18, 88, 153

Sarid, Yossi 118-19

Schmid, Carlo 4

Seamen's Revolt 16

secularity 19-21

sedition 80-1, 86-7, 94, 173-4

self-help groups 140

September 11, 184, 188, 189

Sezon affair 17

Shabak 22, 25, 78, 79, 97, 185

Jewish Underground 89

Kach 83

public opinion 82,99

radical left 87

status $75-7,173$

Shamgar, Justice Meir 52-3, 57

Shamir, Yitzhak 90

Shatil 154

Shinhar Committee 120, 176

Sitrin, Shmuel 93

Six-Day War 17-18, 21, 34

Skokie affair 180-1

Smooha, Sammy 13

Socialist List 33-4, 60

social movements 140

society-oriented organisations 146-9

special courts 75

Sprinzak, Ehud 16, 17, 87

state of emergency 22, 73-4

statehood 14-15

state-oriented organisations $146,151-4$

statutory-judicial analysis 3-4, 6-7, 172

Stern Gang 17, 19, 22, 71, 77-8, 79

subversive organisations and violent movements 68-70, 96-100, 183-5

comparative perspective $183-5$

criminal justice model $80-2$

criminal justice model contraction 82-96

extended criminal justice model $73-$ 9

militant route $70-3$
Supreme Court of Justice 61, 63, 172

Belhasan 93

Etzel 77

Kach and Kahane 38-9, 42, 44-5, $46-7,52,57,60$

Kahane Hai 57

public opinion 99

radical left 88

Socialist List 60 , 33-4

Yemin Israel 59

territories $18,54,75,88,153$

theoretical-normative analysis 2, 3

ultra-orthodox 19-20, 79

uncivil society 141, 146, 149-51, 167

underground movements 17

United States 179

civics education $185-7$

civil society $187-9,190$

political parties 180-1

subversive organisations and violent movements $183-4,185$

volunteer associations 140

Wadi Salib 16

war model $68-73$

wehr-hafte Demokratie 3-5

xenophobia $124,127,128,129,131$

Yehud affair 90-2

Yemenite children 90, 91

Yemin Israel 58-9

Yishai, Yael 140, 143, 144, 145, 148, 149, 156, 159, 188

Yom Kippur War 34

Ze'evi, Rechavam 53-4, 58-9

Zrifin 17, 79

Zusman, Justice 4-5, 33-4 